\title{
AT03-76SF 70051
}

\author{
Analytical Study \\ EFFECT OF CONTROL RODS ON \\ SEISMIC RESPONSE OF THE CORE \\ Of

\section{A LARGE HIGH TEMPERATURE GAS COOLED REACTOR}

June 1975

Prepared for

GENERAL ATOMIC COMPANY

San Diego, California 92138

HOLMES \& NARVER, INC.

ENGINEERS-CONSTRUCTORS

A Resource Sciences company

400 EAST ORANGETHORPE AVENUE - ANAHEIM. CALIFORNIA 92801 


\section{DISCLAIMER}

This report was prepared as an account of work sponsored by an agency of the United States Government. Neither the United States Government nor any agency Thereof, nor any of their employees, makes any warranty, express or implied, or assumes any legal liability or responsibility for the accuracy, completeness, or usefulness of any information, apparatus, product, or process disclosed, or represents that its use would not infringe privately owned rights. Reference herein to any specific commercial product, process, or service by trade name, trademark, manufacturer, or otherwise does not necessarily constitute or imply its endorsement, recommendation, or favoring by the United States Government or any agency thereof. The views and opinions of authors expressed herein do not necessarily state or reflect those of the United States Government or any agency thereof. 


\section{DISCLAIMER}

Portions of this document may be illegible in electronic image products. Images are produced from the best available original document. 
HN 8217.2

\section{Analytical Study \\ EFFECT OF CONTROL RODS ON SEISMIC RESPONSE OF THE CORE \\ Of \\ A LARGE HIGH TEMPERATURE GAS COOLED REACTOR}

by

R. E. Bachman

R. P. Kennedy

S. A. Short

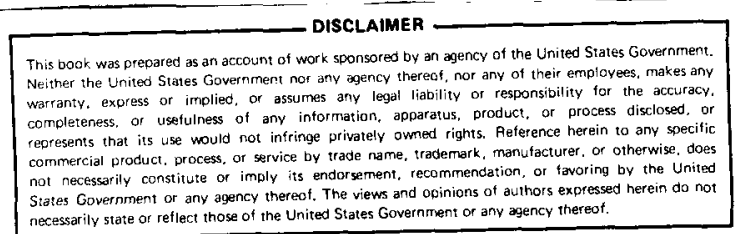

June 1975

Prepared for

GENERAL ATOMIC COMPANY

San Diego, California 92138

HOLMES \& NARVER. INC.

ENGINEERS-CONSTRUCTORS

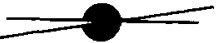

A Resource Sciences company

400 EAST ORANGETHORPE AVENUE - ANAHEIM. CALIFORNIA 92801 


\section{ERDA Review Notice}

This report was prepared as an account of work sponsored by the United States Government. Neither the United States nor the United States Energy Research \& Development Administration, nor any of their employees, nor any of their contractors, subcontractors, or their employees, makes any warranty, express or implied, or assumes any legal liability or responsibility for the accuracy, completeness or usefulness of any information, apparatus, product or process disclosed, or represents that its use would not infringe privately owned rights. 
TABLE OF CONTENTS

$\underline{\text { Section }}$

Page

1

INTRODUCTION

$1-1$

1.1 Purpose and Scope

1.2 Description of HTGR Core

1. 3 Description of Control Rod System

1.4 HTGR Core Operating Environment

1.5 Analyses Performed in this Study

1. 6 Conservatism in Analytical Model

$1-1$

$1-4$

$1-6$

$1-8$

$1-11$

$1-13$

2

CONCLUSIONS AND RECOMMENDATIONS

$2-1$

2. 1 General

$2-1$

2. 2 Conclusions

2.3 Recommendations

$2-1$

$2-4$

3

IDEALIZED MODEL OF CORE COLUMN AND

$3-1$

CONTROL ROD

3.1 General

3. 2 Description of Column Model

$3-1$

3. 3 Properties of Idealized Column Elements

$3-1$

$3-4$

3. 4 Properties of Control Rods

$3-9$

3. 5 Boundary Input Excitation

$3-14$

4

METHOD OF ANALYSIS

$4-1$

4. 1 General

4. 2 Theoretical Basis of Drain-2D

4-1

4-2

4. 3 Mathematical Model

$4-3$

4. 4 Damping

4-5

4.5 Time Step Size.

$4-7$

RESULTS OF PRINCIPAL ANALYSES

$5-1$

5.1 General

$5-1$

5. 2 Results of the Analysis

$5-2$

5. 3 Effect on the Lateral Response of the Column

$5-3$

5.4 Effect on Relative Angle Between Elocks

$5-6$

5. 5 Effect on the Horizontal Shear Between Blocks

$5-7$

5. 6 Control Rod Response

5-9

5. 7 Summary of Results

5-10 


\section{TABLE OF CONTENTS (Continued)}

Section

Page

6

RESULTS OF SUPPLEMENTAL ANALYSES

$6-1$

6.1 General

6. 2 Results of the Supplemental Analyses

$6-1$

6. 3 Effects of Gap Distribution on Column Response

$6-3$

6.4 Effect of Modified Control Rod on Column Response

$6-3$

6.5 Control Rod Response

$6-5$

6.6 Summary of Results of Supplemental Analyses

$6-7$

$6-8$

7

REFERENCES

$7-1$

Appendix

A

THE EFFECT OF THE INTEGRATION TIME INTERVAL A-1 SIZE ON STRUCTURAL RESPONSE 


\section{LIST OF TABLES AND FIGURES}

Tables

Page

1.1

Heights and Weights of Hexagonal Elements in a

$1-16$

Typical Control Column

1.2 Maximum Accumulated Gaps for a Fuel Element

Column for Various Operating Condition

3.1 Properties of Idealized Guide Tube Assembly

$3-18$

Properties of Idealized Control Column Blocks

$3-19$

Mass Properties of Idealized Control Rods

$3-20$

3.3

Equivalent Pendulum Stiffness Properties of Idealized

$3-21$ Control Rods

5.1

Comparison of Peak Responses at Various Control Rod

$5-12$ Insertion Depths

$\underline{\text { Figures }}$

1.1

General View of an HTGR

$1-18$

1.2

Plan View of Core and Permanent Side Reflector

$1-19$

1.3

Fuel Element

$1-20$

Control Element

$1-21$

1.5

Cross Sectional Elevation View of Hexagonal Core

$1-22$

Columns - $3000 \mathrm{Mw}(\mathrm{t})$ HTGR

1.6

1.7

HTGR Reactor Core and Support Arrangement

$1-23$

Control Rod Details

$1-24$

Control Rod Guide Tube Assembly

$1-25$

1.9

Schematic Model for Stacked Column Analysis

$1-26$

The Stacked Column with Doweled Elements Under

$3-22$

Boundary Excitation

3.2

Idealized Model of Control Element Column and Guide

$3-23$

Tube Assembly.

3.3

Discrete Model of Column Block Interface

$3-24$

3.4

Coefficient of Restitution Versus Impact Velocity for

$3-25$

Full Size Large HTGR Fuel Elements

3. 5 Simple One-Dimensional Spring Dashpot Collision Model

3.6

Coefficient of Restitution versus Fraction of Critical

Damping

3.7 Vertical Corner Impact Force vs Initial Rocking Angle 3-28

Full Size Fuel Element

3.8 Reduction in Impact Force versus Fraction of Critical

Damping

3. 9 Single Cannister Binding

$3-26$

$3-27$

$3-29$

$3-30$

Control Rod Fully Withdrawn Model

$3-31$

Control Rod Halfway Inserted Model

$3-32$

3.11

Control Rod Fully Inserted Model

3-33 


\section{LIST OF TAB LES AND FIGURES (Continued)}

Figures

$\underline{\text { Page }}$

3.13 Discrete Model of Control Rod and Channel

$3-34$

3.14

3.15

Single Mass Perdulum and Equivalent Mass Spring System

$\mathrm{N}$ Mass Pendulum System and Equivalent Mass-Spring

$3-35$

System

3.16 Plan View of Control Rod in Channel Illustrating Installed Gaps

3.17 GA Design Response Spectra Horizontal Response at 3-38 Selected Points in PCRV for $1.0 \mathrm{~g}$ Safe Shutdown Earthquake

3.18 GA Design Response Spectra Vertical Response of PCRV Core Cavity Floor for $1.0 \mathrm{~g}$ Safe Shutdown Earthquake 3.19 Artificial Horizontal Response of PCRV at Core
Support Elevation, $0.5 \mathrm{~g} \mathrm{SSE}$

3.20 Artificial Vertical Response of PCRV at Core Support Elevation, $0.5 \mathrm{~g}$ SSE

3.21 Comparison of Response Spectra from Artificial

Excitation with Design Response Spectra; Horizontal

Component, $0.5 \mathrm{~g} \mathrm{SSE}, 5 \%$ Critical Damping

3.22 Comparison of Response Spectra from:Artificial

Excitation with Design Response Spectra; Vertical

Component 0.5g SSE, 5\% Critical Damping.

4. 1

DRAIN Model of a Column Block

4.2

DRAIN Model of Control Rod

4- 10

Variation of Mass and Stiffness Proportional Damping

$4-11$

with Natural Period

5.1 Comparison of Peak Column Response for Three Control

Rod Insertion Depths - Horizontal Shears Between Blocks

5.2 Comparison of Peak Column Response for Three Control 5-14

Rod Insertion Depths - Horizontal Relative Velocity

Between Block and Boundary

5. 3 Comparison of Peak Column Response for Three Control

Rod Insertion Depth's - Relative Angles Between Blocks

5.4 Comparison of Peak Control Rod Response for Three

Control Rod Insertion Depths - Horizontal Relative

Velocity Between Control Rod and Control Rod Channel

5.5

Illustration of Vertical Separation and Relative Angle

$5-17$

Comparison of Column Responsefor Three Control Rod

$5-18$

Insertion Depths - Relative Horizontal Displacements

Between Top of Block 2 and Boundary.

5.7 Comparison of Column Response for Three Control Rod

Insertion Depths - Relative Horizontal Displacements

Between Top of Block 6 and Boundary 


\section{LIST OF TABLES AND FIGURES (Continued)}

Figures

$\underline{\text { Page }}$

5.8

Comparison of Column Response for Three Control Rod

$5-20$ Insertion Depths - Relative Horizontal Displacements Between Top of Block 11 and Boundary

5.9

Comparison of Column Response for Three Control Rod Insertion Depths - Relative Horizontal Velocity Between Top of Block 2 and Boundary

5.10 Comparison of Column Response for Three Control Rod Insertion Depths - Relative Horizontal Velocity Between Top of Block 6 and Boundary

5.11. Comparison of Column Response for Three Control Rod Insertion Depths - Relative Horizontal Velocity Between Top of Block 11 and Boundary

5.12 Comparison of Column Response for Three Control Rod Insertion Depths - Relative Angle Between Blocks 2 and 3

5.13 Comparison of Column Response for Three Control Rod Insertion Depths - Relative Angle Between Blocks 6 and 7

5.14 Comparison of Column Response for Three Control Rod Insertion Depths - Relative Angle Between Blocks 11 and 12

5.15 Horizontal Shear Force Time History Between Blocks

6 and 7 - Control Rod Withdrawn

5.16 Vertical Separation Between Blocks 2 and 3 - Control 5-28 Rod Withdrawn

5.17 Vertical Separation Between Blocks 6 and 7 - Control 5-29 Rod Withdrawn

5.18 Vertical Separation Between Blocks 11 and 12 - Control 5-30 Rod Withdrawn

5.19 Horizontal Relative Velocity Between Control Rod and 5-31

Guide Tube at CR Node 1-Control Rod Fully Withdrawn Analysis

5.20 Horizontal Relative Velocity Between Control Rod and

Channel at Node 11 - Control Rod 1/2 Inserted Analysis

5. 21 Horizontal Relative Velocity Between Control Rod and

$5-33$

Channel at Node 12 - Control Rod Inserted Analysis

6.1

Comparison of Peak Column Response for Control Rod Withdrawn and Inserted Principal and Supplemental Analyses - Horizontal Shears Between Blocks 


\section{LIST OF TABLES AND FIGURES (Continued)}

Figures

Page

6.2 Comparison of Peak Column Response for Control Rod

$6-11$ Withdrawn and Inserted Principal and Supplemental Analyses Horizontal Relative Velocity Between Column and Boundary

6.3 Comparison of Peak Column Response for Control Rod Withdrawn and Inserted.- Principal and Supplemental Analyses Relative Angle Between Blocks

6.4

Comparison of Peak Control Rod Response for Control

$6-13$

Rod Withdrawn and Inserted - Principal and Supplemental Analyses - Horizontal Relative Velocity Between Control Rod and Control Rod Channel 6.5 Comparison of Column Response for Control Rods Withdrawn and Inserted Supplemental Analyses with Modified Gap and Control Rod Stiffness Relative Horizontal Displacement Between Top of Block 2 and Boundary 6.6 Comparison of Column Response for Control Rods Withdrawn and Inserted Supplemental Analyses with Modified Gap and Control Rod Stiffness Relative Horizontal Displacement Between Top of Block 6 and Boundary

6.7 Comparison of Column Response for Control Rods Withdrawn and Inserted Supplemental Analyses with Modified Gap and Control Rod Stiffness Relative Horizontal Displacement Between Top of Block 9 and Boundary

6.8 Comparison of Column Response for Control Rods Withdrawn and Inserted Supplemental Analyses with Modified Gap and Control Rod Stiffness Relative Horizontal Velocity Between Top of Block 2 and Boundary

6.9 Comparison of Column Response for Control Rods Withdrawn and Inserted Supplemental Analyses with Modified Gap and Control Rod Stiffness Relative Horizontal Velocity Between Top of Block 6 and Boundary

6.10

Comparison of Column Response for Control Rods Withdrawn and Inserted Supplemental Analyses with Modified Gap and Control Rod Stiffness Relative Horizontal Velocity Between Top of Block 9 and Boundary

6.11 Comparison of Column Response for Control Rods 6-20 Withdrawn and Inserted Supplemental Analyses with Modified Gap and Control Rod Stiffness Relative Angle Between Blocks 2 and 3 
LIST OF TABLES AND FIGURES (Continued)

Figures

Page

6.12 Comparison of Column Response for Control Rods

$6-21$

Withdrawn and Inserted for Supplemental Analyses with Modified Gap and Control Rod Stiffness Relative Angle Between Blocks 6 and 7

6.13. Comparison of Column Response for Control Rods

$6-22$

Withdrawn and Inserted Supplemental Analyses with

Modified Gap and Control Rod Stiffness Relative

Angle Between Blocks 9 and 10

6.14 Horizontal Shear Force Time History Between Blocks

6 and 7 Control Rod Withdrawn Supplemental Analyses with Modified Gap.

6.15 Horizontal Shear Force Time History Between Blocks

6 and 7 Control Rod Inserted Supplemental Analyses

with Modified Gap and Control Rod Stiffness

6.16 Horizontal Relative Velocity Between Control Rod and

Guide Tube at Node 1 - Control Rod Withdrawn

Supplemental Analyses with Modified Gap

Horizontal Relative Velocity Between Control Rod and
Channel at Node 10 - Control Rod Inserted Supplemental

$6-23$

$6-24$

Analyses with Modified Gap and Control Rod Stiffness

A-1 Comparison of Response for Rod Withdrawn Analyses in

A -3

which Different Integration Time Steps are Used

Column Shears

A-2 Comparison of Response for Rod Withdrawn Analyses

A -4

in which Different Integration Time Steps are Used

Column Lateral Velocity Relative to Boundary

A-3 Comparison of Column Response for Modified Rod

A -5

Withdrawn Analyses in which Different Integration

Time Steps are Used - Horizontal Relative Displace-

ment Between Top of Block 2 and Boundary

A-4 Comparison of Column Response for Modified Rod

A -6

Withdrawn Analyses in which Different Integration

Time Steps are Used - Horizontal Relative Displace-

ment Between Top of Block 6 and Boundary

A-5 Comparison of Column Response for Modified Rod

A - 7

Withdrawn Analyses in which Different Integration

Time Steps are Used - Horizontal Relative Displace-

ment Between Top of Block 9 and Boundary

A-6 Comparison of Column Response for Modified Rod

A - 8

Withdrawn Analyses in which Different Integration

Time Steps are Used - Horizontal Relative Velocity

Between Top of Block 2 and Boundary 


\section{LIST OF TAB LES AND FIGURES (Continued)}

Figures

Page

A-7 Comparison of Column Response for Modified Rod

A -9

Withdrawn Analyses in which. Different Integration Time Steps are Used - Horizontal Velocity Between Top of Block 6 and Boundary

A-8 Comparison of Column Response for Modified Rod A -10 Withdrawn Analyses in which Different Integration Time Steps are Used - Horizontal Relative.Velocity Between Top of Block 9 and Boundary. A-9 Comparison of Column Response for Modified Rod Withdrawn Analyses in which Different Integration Time Steps are Used - Relative Angle Between Blocks 2 and 3

A-10 Comparison of Column Response for Modified Rod Withdrawn Analyses in which Different Integration Time Steps are Used,- Relative Angle Between Blocks 6 and and 7

A-11 Comparison of Column Response for Modified Rod A -13 Withdrawn Analyses in which Integration Time Steps are Used - Relative Angle Between Blocks 9 and 10 


\subsection{INTRODUCTION}

\subsection{PURPOSE AND SCOPE}

An analytical study to assess the influence of control rods on the seismic response of the core of large High Temperature Gas Cooled Reactors (HTGR) is reported upon in this document. The study is part of an extensive experimental and analytical program concerned with demonstrating the safety and functionability of the control rods and reserve shutdown systems during and after seismic events. This program which is being conducted by General Atomic Company (GAC) under the sponsorship of the Energy Research \& Development Administration (ERDA), includes seismic testing of a one-fifth scale full array model of the core including both the control rods and the reserve shutdown systems.

The purpose of this analytical study is to determine the relative influence that inserted control rods have on the dynamic response characteristics of the core during seismic disturbances. To meet this objective, a parametric set of analyses was performed in which control rods were assumed inserted at varying depths. The study was performed on the $3000 \mathrm{Mw}(\mathrm{t}) *$ HTGR core design. This design is GAC's standard HTGR reference design and is the design upon which the one-fifth scale model of the core is based. It should be noted that the core design of all large size HTGR's is very similar and that, therefore, results of this study are presumed applicable to other core sizes as well.

An HTGR core consists of closely spaced columns of stacked graphite blocks. In this study, a single core column with control rods has been modeled mathematically. The model includes the nonlinear

\footnotetext{
"Rated full power thermal output in mega-watts.
} 
effects of gaps opening and closing between the blocks and considers boundary conditions which account for impact between adjacent columns of blocks and overall core boundary constraints. Utilizing this model, the structural time history response of the column subjected to simultaneous horizontal and vertical seismic boundary motions was computed for the following three control rod insertion depths.

- Rod fully withdrawn

- Rod approximately halfway inserted

- Rod fully inserted

By comparing the results of these analyses, an assessment of the relative influence of control rods on the core seismic response has been made.

In the remainder of this chapter, the HTGR core and control rod system are described. The operational environment in which the core functions is also discussed along with factors which can effect core seismic response. Finally, the various analyses performed as part of this study are described and conservatisms in the analytical model are discussed.

In Chapter 2, the conclusions for this study are presented. The major conclusions of this study are drawn from comparisons of like column response quantities with varying insertion depths. Important response quantities include peak shear between blocks, peak relative velocities, and peak relative block rotations throughout the column. Also compared are time histories of these response quantities at selected column locations. Significant parameters which effect structural response are discussed and recommendations regarding factors and measurements to be considered in the one-fifth scale model testing based on the findings of this study are presented. 
In Chapter 3, the idealized model of the core and control rod system usedin the analyses and its relationship to the actual reactor core are described. Properties of the graphite fuel element blocks a re discussed including their behavior during impact. Also presented are properties of the idealized control rod including a discussion of the method used to compute the shear stiffnesses of idealized beam members which represent the pendulum system. Finally, the boundary excitations used in the analyses are described along with their response spectra.

In Chapter 4, the method of analysis used in this study is summarized. The complexities of the nonlinearities of the system are reviewed and the computer code utilized in the analysis is discussed. The method of performing the dynamic time history analyses to obtain structural response is described. Also the determination of time step size and treatment of damping in the analysis is discussed.

In Chapter 5, the results of the principal analyses performed of the core model with control rods inserted at varying depths are presented and compared. The significant results of each analys is include envelopes of the peak shears between adjacent blocks, the peak block and control rod impact velocities and peak block rotations. Also presented are comparisons of the time histories of these response quantities at selected column locations.

In Chapter 6, the results of the analyses performed of a modified core column model are presented. In this model, larger gaps and a stiffer control rod were considered. The properties of this model are described and significant results are presented and compared for two control rod insertion depths (fully withdrawn and fully inserted). 


\subsection{DESCRIPTION OF HTGR CORE}

The core of a 3,000 Mw(t) HTGR consists of columns of loosely stacked graphite elements arranged to approximate a right circular cylinder 34-1/2 feet in diameter and 33 feet in height, as shown in Figure 1.1. The core is located and supported within the core cavity of the Prestressed Concrete Reactor Vessel (PCRV). Vertically, the core is supported above the core cavity floor on 323 graphite posts which are approximately 6 feet in height. Lateral support of the core is provided by 252 radially oriented metal spring assemblies which are spaced uniformly between the core and the sidewall of the PCRV cavity.

During operation of the reactor, heat from the core is transferred to steam generators using pressurized helium gas. Helium coolant enters through penetrations in the open region above the core (called the upper plenum) and then flows downward through holes in the core elements. The heated gas then flows outward through the space between the bottom of the core and the core cavity floor (called the lower plenum). To maintain operation or to safely shutdown an HTGR after a seismic event, it is essential that the holes in the core elements remain in alignment and the graphite elements remain structurally intact.

The core consists of over 600 columns of stacked hexagonally shaped graphite fuel control and reflector elements. The columns of hexagonal elements are surrounded by columns of larger graphite blocks (called permanent side reflector blocks) which are designed to make the transition from the irregular boundary of the hexagonal core elements to an approximately circular boundary concentric with the PCRV side walls. A plan view of the core showing the arrangement of the various core columns is presented in Figure 1.2. As shown in the figure, the core is made up of 420 fuel element columns, 73 control element columns, 114 reflector element columns, and 36 permanent side reflector columns. 
The hexagonal core columns are assemblèd into groups of seven columns in which a central column is surrounded by six adjoining columns. Each group of columns is called a refueling region. In the innermost 73 refueling regions, the central column is a control column into which the control rods and reserve shutdown system pellets are inserted. Surrounding each control column are positioned six fuel element columns. In the peripheral regions of the core, one or more fuel or control columns are replaced by reflector columns. The fuel, and reflector columns are formed by stacking thirteen individual fuel, reflector and plenum elements, while the control columns consist of twelve stacked elements. The top block of each column is a plenum element. Details of the fuel and control elements are shown in Figures 1.3 and 1.4. With the exception of height, the reflecto $\ddot{r}$ and plenum elements have the same hexagonal dimensions as the fuel elements. The reflector elements have three basic heights; full, three-quarters or half the height of a standard fuel element. The reflector elements are also made of graphite. The plenum elements have two heights, half and three-quarters of the standard fuel element and are made of steel. The nominal heights and weights of the hexagonal elements comprising the control element column are tabulated in Table 1.1. These values were taken from Reference 1. Cross sectional and cutaway views which show the general arrangement of the core elements are shown in Figures 1.5 and 1.6 The plenum elements of each region are loosely keyed together to insure stability of a region when adjoining regions are removed during refueling.

The elements in each column rest on the flat face of the element below. The alignment of elements within a column is maintained by the three graphite dowels located on the top face of an element that fit into three mating holes in the bottom face of the element above. The dowels transfer horizontal shear forces but offer no resistance to vertical motion. It should be noted that elements in the central control column in 
each region are axially displaced downward relative to the elements in the surrounding six columns, the reby eliminating the possibility of a continuous shear plane at element interfaces across the core (see Figure 1.5).

The columns of core elements rest on large graphite core support floor blocks which are in turn supported by the graphite posts. The lower ends of each post is hemis pherically shaped and fits into a matching dished seat on the bottom head of the PCRV core cavity. The posts and seats allow relatively unrestrained horizontal differential movements between the bottom of the core and the PCRV.

To accommodate thermal expansion and to facilitate installation and refueling, the adjacent core columns, core support blocks, and permanent side reflector blocks are installed with small gaps between them. The gaps will vary with temperature, irradiation dose and other factors. During normal full power operation, gaps between the permanent side reflector and core support floor blocks are nominally closed by thermal expansion. Gaps between core column elements are discussed in further detail in Subsection 1.4.

\subsection{DESCRIPTION OF CONTROL ROD SYSTEM}

Reactor control is provided by 146 control rods operated in pairs by 73 control rod drives. Each pair of control rods are inserted vertically downward through two 4.00-inch diameter holes in the control columns (see Figure 1.4). The control rod drives are electrically powered winches that raise and lower each pair of control rods by means of flexible steel cables. The drives are located within the refueling penetrations which are located in the top head of the PCRV directly above each control column (see Figure 1.1). 
Each control rod consists of a series of 15 metal tubular cannisters containing graphite compacts of neutron absorbing material. Details of the current large HTGR control rod and cannister design are presented in Figure 1.7. Each canniste $r$ is 16.50 inches long, 3.5 inches in diameter, and weights approximately 11 pounds. The tubular cannister wall is made of nickel alloy Inconel 800 and is nominally 0.05 inch thick. The cannisters are spaced 0.28 inch apart and are connected by articulating ball joints . Four stand off fins each 0.15 inch high protrude from the bottom end of each cannister. These fins insure that the cannisters slide freely within the control rod channel past the element interfaces.

A crushable tube type shock absorber is located in the replaceable reflector element at the bottom of each control rod channel. The absorber is designed to absorb the energy resulting from the unlikely occurrence of the entire control rod being dropped from its fully withdrawn position. A metal fixture attached to the bottom end of each control rod is designed to serve as the impact point under such accident conditions.

Each control rod is a total of 253.2 inches long and weighs 170 pounds. When fully inserted, the bottom tip of the control rod is even with the bottom of the lowest block in the active core. When fully withdrawn, the bottom of the control rods is 60 inches above the active core and thus is slightly above the top of the control plenum elements.

In the fully withdrawn position, each pair of control rods are fully contained within two sets of telescoping steel guide tubes. The guide tubes provide a continuous control rod channel between the control column and drive mechanism located in the top end of each refueling penetration. Details of the control rod guide tube are shown in Figure 1.8. The upper section of the guide tubes are located with the refueling penetration and form an integral part of the radiation shield. The lower sections of the control rod guide tubes are joined to the upper sections at a point which 
is approximately even with the top of the core cavity. This joint is 96 inches above the top of the plenum element. The lower end of the guide tube assembly rests on a pivot located at the center of the control plenum element. Telescopic, articulating couplings at the ends of the upper section of the guide tube allow both lateral and vertical displacement of the reactor while at the same time permitting the guide tubes to maintain engagement with the plenum elements in the reactor core.

Fixed to the lower end of the guide tube assembly is an orifice valve assembly which controls the helium entering the fuel region. The valve assembly weighs approximately 100 pounds and is located as shown in Figure 1.8.

Each guide tube is made of .25 inches thick steel with an inner diameter of four inches. The total weight of the lower guide tube and valve assembly resting on the plenum element is estimated to be 391 pounds while the total weight of the portion of the guide tube assembly suspended from upper section is estimated at 100 pounds (Reference 2 ).

\subsection{HTGR CORE OPERATING ENVIRONMENT}

The operating life of an HTGR is 40 years. During this period, the reactor is designed to function through a variety of operating and accident conditions. The fuel elements and some of the reflector elements are designed to be replaced every four years. Refueling will take approximately one month every year, therefore, a portion of the operating life of the core is spent in the shutdown condition.

The core functions in an environment of hot flowing gases and radiation field. As noted earlier, during power conditions helium gas coolant enters the plenum area above the core under pressure. The helium next flows downward through the core where it is heated by the fuel elements and exits through the cavity below the core. During full power operation, the gas pressure and temperature entering the core is approximately 
725 psia and $600^{\circ} \mathrm{F}$ respectively, while the pressure and temperature of the gas exiting the core are 713.5 psia and $1430^{\circ} \mathrm{F}$ respectively. The temperature of the elements comprising the core vary with elevation and radial position with the hotest elements located near the center of the core. At full power, the temperature of the elements range from $600^{\circ} \mathrm{F}$ to $2500^{\circ} \mathrm{F}$. During shutdown conditions, the helium flow through the core is minimal and temperatures of the core elements range from 200 to $500^{\circ} \mathrm{F}$.

Differences in the gas pressure in the upper and lower plenum areas result in pressure loads acting on the core. During full power operation, this pressure drop results in a maximum pressure of 11.5 psi acting vertical downward and 10.0 psi acting radially inward on the core. The radial pressure drop is carried by the permanent side reflector elements in hoop compression and tends to cause the permanent side reflector to act as a continuous ring. The vertical pressure drop is resisted by the individual core columns and acts as an additional static force applied vertically downward on the top plenum elements.

Temperature has two significant effects on the core properties. First, thermal expansion increases the size of the elements which in turn decreases the horizontal gaps between core columns. Secondly, mechanical properties of the fuel element graphite are effected. At core normal operating temperatures, the modulus of elasticity and ultimate strength will increase over room temperature values by between 10 and 50 percent (Reference 3).

Neutron radiation has three significant effects on the properties of the core elements. First irradiation will induce shrinkage in the fuel elements which will increase the size of gaps between adjacent fuel elements. Secondly, the gradient of neutron flux will cause shrinkage to be greater on one side of an element than the other which in turn causes the element to bow slightly. This bowing is more pronounced in the peripheral regions 
of the core where the neutron flux gradient is higher. Lastly, the mechanical properties of fuel element graphite are affected as irradiation causes both the modulus of elasticity and ultimate strength of graphite to increase (Reference 4).

Experimental and analytical studies performed as part of the core seismic safety program indicate that one of the important variables which affects the core system response during seismic disturbances is the gap size between columns. During seismic disturbances, adjacent columns respond laterally by displacing through the gaps and impacting adjacent columns. It has been observed in tests that as the columns move laterally they tend to group together. The maximum that any point on the column can displace relative to the core support floor and permanent side reflector during such excitations is the accumulated across-the-core gap between elements in the direction of motion. In a centrally located column, the accumulated core gap is equal in both directions while in peripheral regions the accumulated gap is much greater in the across-the-core direction then in the direction of the permanent side reflector blocks.

In this study, analyses were performed assuming the gap conditions which exist on a peripherally positioned column. As noted earlier, gaps between elements vary because of thermal expansion and irradiation shrinkage of the core elements. Gaps are also affected to a lesser extent by PCRV creep and shrinkage and thermal expansion of spring packs. Since core temperature, radiation levels, and creep vary throughout the height of the core, the gaps for various conditions vary with height and position. The total accumulated in-core gaps predicted to occur at various heights in a column for a variety of ope rating conditions are presented in Table 1.2. These gap conditions are taken from Reference 5 . Note that initially the blocks are all the same size so the gaps are identical. The extremes in gap sizes occur near the core midheight where temperatures and radiation levels are the greatest. The smallest gaps occur for a full 
power initial startup condition while the largest gaps occur for a fully irradiated core during shutdown conditions. Gaps between core support floor blocks are also presented. It should be noted that since the core support blocks are much larger and there are fewer blocks, the accumulated gàp between blocks is much smaller.

Increases in the modulus of elasticity caused by temperature and irradition will effect the fuel element stiffness. However, such changes are anticipated to have only a localized effect on response (fuel impact force) and a relatively insignificant effect on the overall system response.

The properties of the control rods are only slightly affected by temperature and irradiation. At full power operating temperatures the modulus of elasticity of Inconel 800 from which the control rod cannisters are made is reduced from $29 \times 10^{6}$ psi to $26 \times 10^{6} \mathrm{psi}$.

\subsection{ANALYSES PERFORMED IN THIS STUDY}

To assess the relative influence of control rods on the core seismic response, dynamic analyses were performed of a control element column with a control rod inserted at the following depths.

- Fully withdrawn

- Halfway inserted

- Fully inserted

In these analyses, a control element column was idealized as twelve blocks which are doweled together in shear but which are free to "rock" or lift off each other vertically. The column is idealized as contained within a rigid box with the initial gaps between the column and boundary walls simulating the accumulated gap distance between core elements (see Figure 1.9). Horizontal collisions with the boundary as well as the vertical collisions which take place when the elements rock on top of each other are described by gap springs and dampers. The two control rods 
which are inserted into the column are idealized as a single series of lumped masses connected together by shear springs which represent the pendulum stiffness of the two segmented rods.

The column boundary is driven by simultaneously applied horizontal and vertical excitations. The horizontal boundary excitation is imposed on the column through the dowels which connect the lower most column element to the floor, and through collisions with the boundary wall. Vertical excitation is transmitted through the bottom column block. The boundary excitations used in the analyses performed in this study conservatively represent the response of the $P C R V$ at the core support points caused by a $0.5 \mathrm{~g}$ safe shutdown earthquake. To insure that the peak responses would occur..during the excitation, the boundary excitations were artifically derived such that their response spectra would equal or exceed the design response spectra of the core support points in the anticipated frequency range of the core. Because of the high computational costs of the column analysis; the duration of the excitation was specified as 2.5 seconds. This duration is great enough to insure the obtaining of the peak column response while limiting computational costs to acceptable levels.

As noted earlier, gaps between core columns vary with operating condition and core position. In the analyses performed, the gap conditions corresponding to a peripherally positioned control column were used. The response of a peripheral column was considered to be more sensitive to control rod insertion because the accumulated across-gaps distance is much greater in one direction than the other. The gaps simulate those found in a fully irradiated core during full power conditions. The same gap condition was used for all analyses although larger gaps exist during shutdown conditions.

In the analysis performed, static loads corresponding to the dead loads of the blocks and orifice valve assembly were applied to the column. During full power conditions, a vertical load caused by gas pressure also 
acts on the column. During shutdown conditions this gas pressure load is zero. Since the pressure load would tend to lessen the response, particularly separation and rocking between blocks, it was neglected in the analyses performed.

In addition to the analyses described above, an additional set of analyses were performed on the control element column. The model used in these analyses is identical to the one described earlier, except that a larger accumulated gap condition and stiffer control rod is assumed. These analyses permit an additional assessment of column response under other conditions which may have a greater effect. Additional analyses were also performed of this model to establish the accuracy of the analysis by varying the time step size.

\subsection{CONSERVATISM IN ANALYTICAL MODEL}

The analytical model used in this study is highly idealized and thus several assumptions about core behavior were necessary. Since the purpose of this study is to determine whether control rods could possibly effect the core seismic response, assumptions which emphasize possible difference in response have been considered desirable. For this reason, any necessary assumptions tend to maximize and accentuate the effect of control rods on the response of the core. The following assumptions, in particular, insure conservative estimates of the influence of control rods on core column response.

1. The core is represented by a single column constrained within rigid boundaries. Actually each column is bounded by adjacent columns which also displace laterally and the refore lateral impacts are not nearly as abrupt as those predicted by analysis. 
2. The full weight and stiffness of a pair of control rods and guide tube as semblies are used in the analysis. In effect, it is being assumed that control rods and guide tubes are associated with every core column. Actually, a pair of control rods are inserted in only one column in every seven and thus, control rod and guide tube mass and stiffness effects on overall core column response are overemphasized.

3. The size of the lateral gaps between the column and the rigid boundary were selected to simulate the largest gaps associated with a full power condition. Large gaps will maximize relative rotations between elements and therefore should be the condition most greatly influenced by the control rods.

4. The lateral gap distribution between the column and boundary was idealized to simulate a peripherally located column with gaps much larger on one side of the column than on the other. Also a smaller gap was used for the top element thus constraining the column to respond as a simply supported beam. Such a gap distribution tends to maximize relative rotations and simple beam response which should accentuate any influence of control rods.

5. Extreme horizontal and vertical boundary excitations have been used in the analysis. These excitations conservatively envelope the responses of the PCRV at the core support points caused by an earthquake with $0.5 \mathrm{~g}$ peak ground acceleration for a wide variety of different soil conditions. It should be noted that the ground motion time history from which the PCRV motions are calculated 
conservatively envelopes the design response spectra from NRC Regulatory Guide 1.60 for a peak ground acceleration of $0.5 \mathrm{~g}$.

6. To lower computational costs, boundary excitations used in the analysis were artifically generated with a short duration of 2.5 seconds. In order to obtain excitations which match the $P C R V$ response in the frequency range of interest ( 0.7 to 15 hertz) with such a short duration, the response of the excitation in the frequency range above 20 hertz has been greatly over estimated. This has greatly accentuated the vertical separation between adjoining blocks which in turn minimizes relative rocking stiffness between blocks thus maximizing any stiffening effects the control rods have on the column.

7. Any pressure drop loads acting on the column have been ignored. Vertical pressure drop loads would tend to lessen response, particularly separation and rocking between blocks and therefore decrease the influence of control rods.

Because of the above assumptions, the effects of control rods are over estimated. 


\section{TABLE 1.1}

HEIGHTS AND WEIGHTS OF HEXAGONAL ELEMENTS

IN A TYPICAL CONTROL COLUMN

\begin{tabular}{|l|l|r|}
\hline \multicolumn{1}{|c|}{ Element Type } & $\begin{array}{l}\text { Height } \\
\text { (Inches) }\end{array}$ & $\begin{array}{c}\text { Weight } \\
\text { (Lbs) }\end{array}$ \\
\hline Plenum Element & 23.415 & 240.0 \\
Top Replaceable Reflector Element & 31.22 & 216.0 \\
Control Fuel Element & 31.22 & 224.5 \\
Bottom Replaceable Reflector Element & 15.61 & 128.2 \\
Bottom Permanent Reflector Element & 23.415 & 196.0 \\
\hline
\end{tabular}


TABLE 1.2

MAXIMUM ACCUMULATED GAPS FOR A FUEL ELEMENT COLUMN FOR VARIOUS OPERATING CONDITIONS

All Gap Dimensions Are in Inches

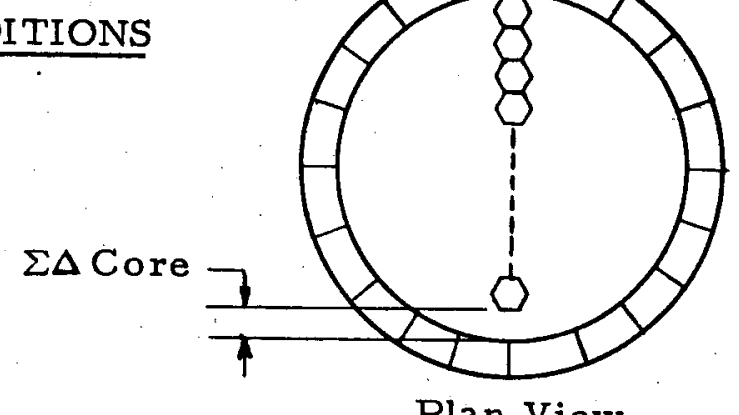

\begin{tabular}{|c|c|c|c|c|}
\hline Position & $\begin{array}{l}\text { Installed } \\
\text { Room Temperature }\end{array}$ & $\begin{array}{l}\text { Initial Startup } \\
\text { Full Power }\end{array}$ & $\begin{array}{l}\text { Fully Irradiated } \\
\text { Full Power }\end{array}$ & $\begin{array}{l}\text { Fully Ir radiated: } \\
\text { Shutdown }\end{array}$ \\
\hline Near Top of Column & 2.30 & 1.30 & 1.20 & 1.70 \\
\hline Center of Column & 2.30 & .80 & 2.60 & 3.40 \\
\hline Near Bottom of Column & 2.30 &. .80 & 1.80 & 2.80 \\
\hline Core Support Floor & 1.10 & .20 & .20 & .30 \\
\hline
\end{tabular}




\section{$3000 \mathrm{MW}(\mathrm{t})$ GENERAL ARRANGEMENT}

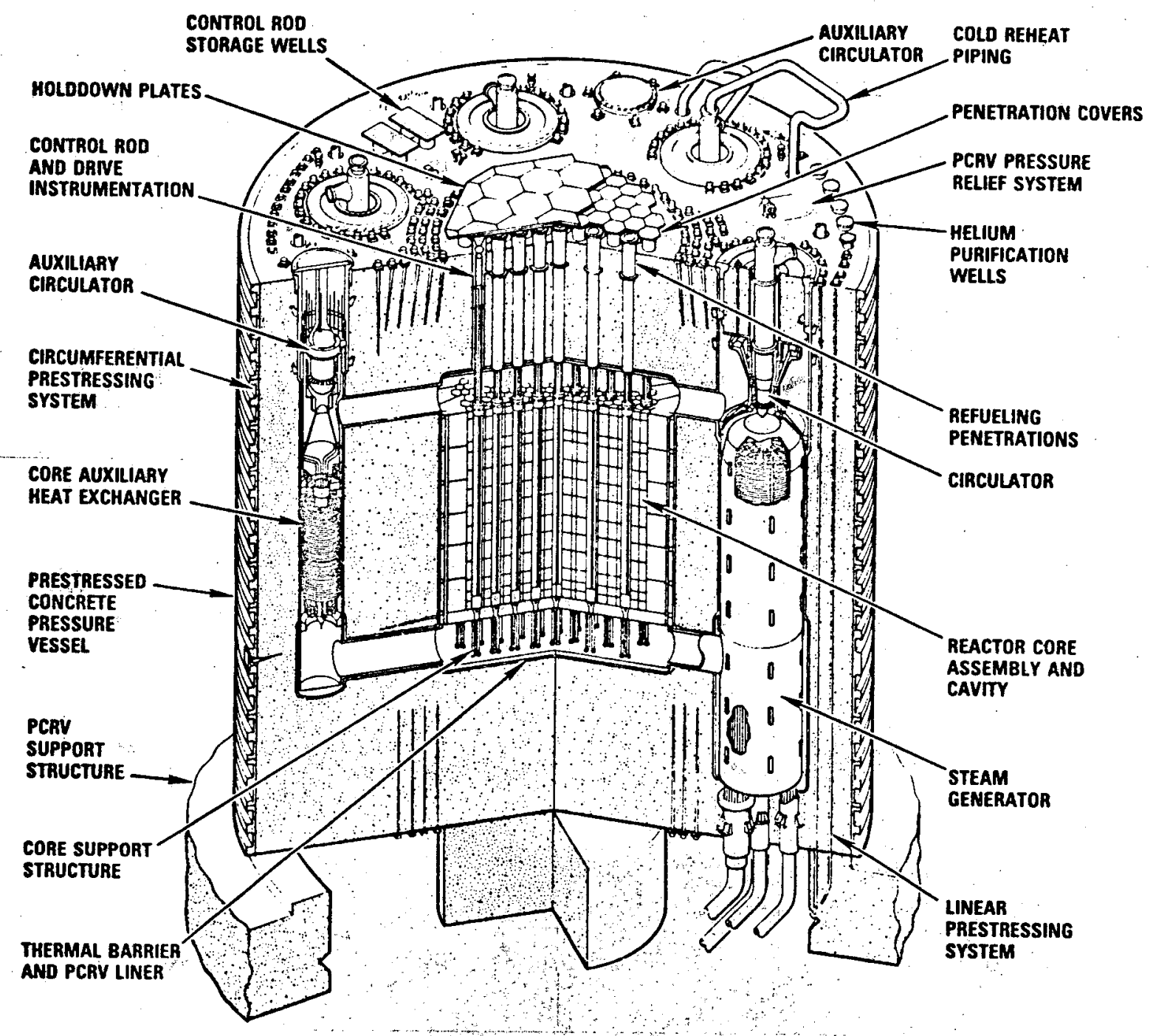

FIGURE 1.1 GENERAL VIEW OF AN HTGR 


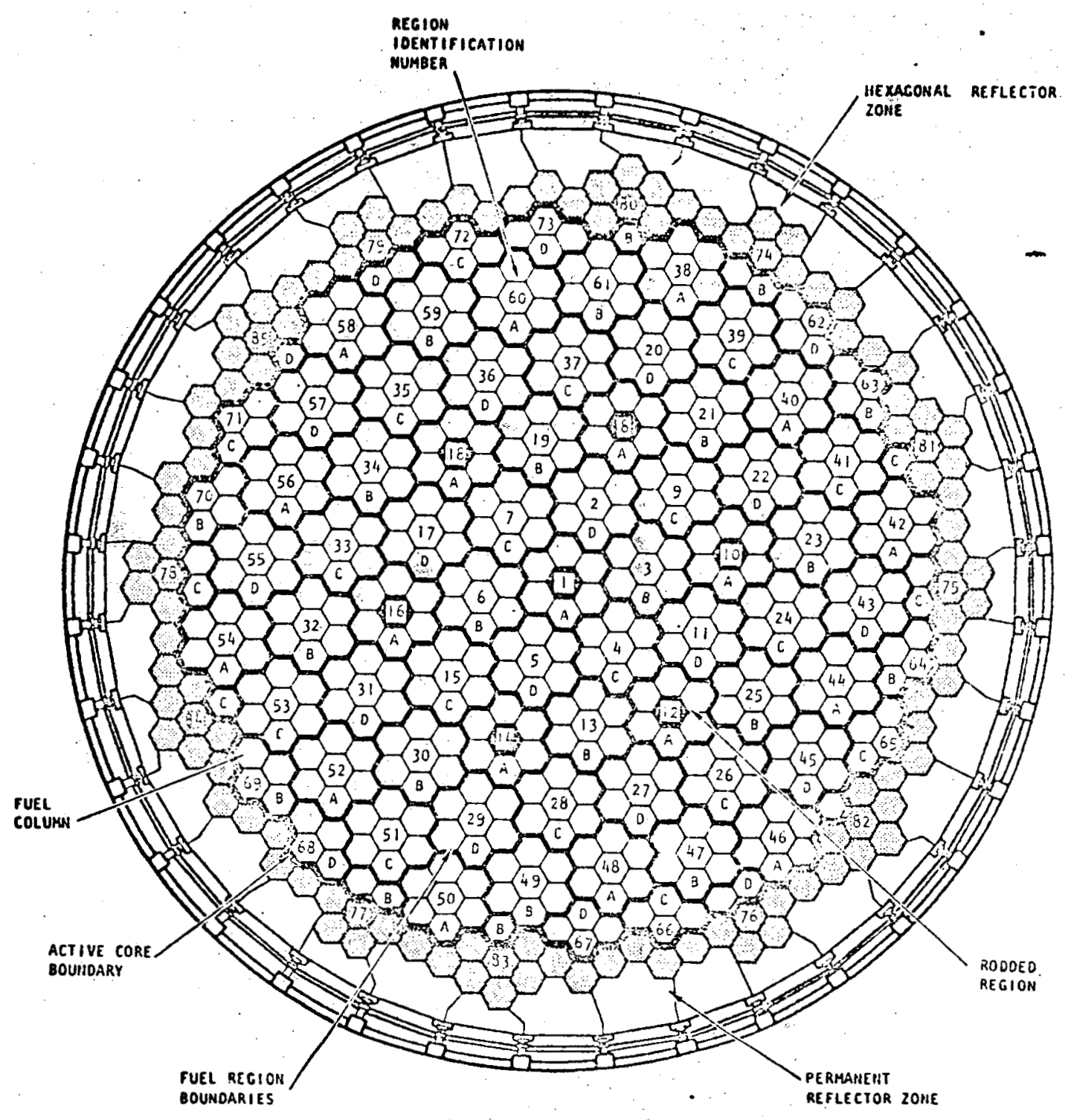

pemetration

NUABERS

\begin{tabular}{|c|c|c|}
\hline $1-73$ & SENTPOL ROOS 6 ORLFICE VALVES & FJEL TULUAN \\
\hline $74-85$ & SHIE IS FLUCS & REFEECSOP COLLAM \\
\hline $65,69,73$ & SOURCE RANES UETECTOPS & CONTROL COLUUNA \\
\hline
\end{tabular}

FIGURE 1.2 PLAN VIEW OF CORE AND

PERMANENT SIDE REFLECTOR 


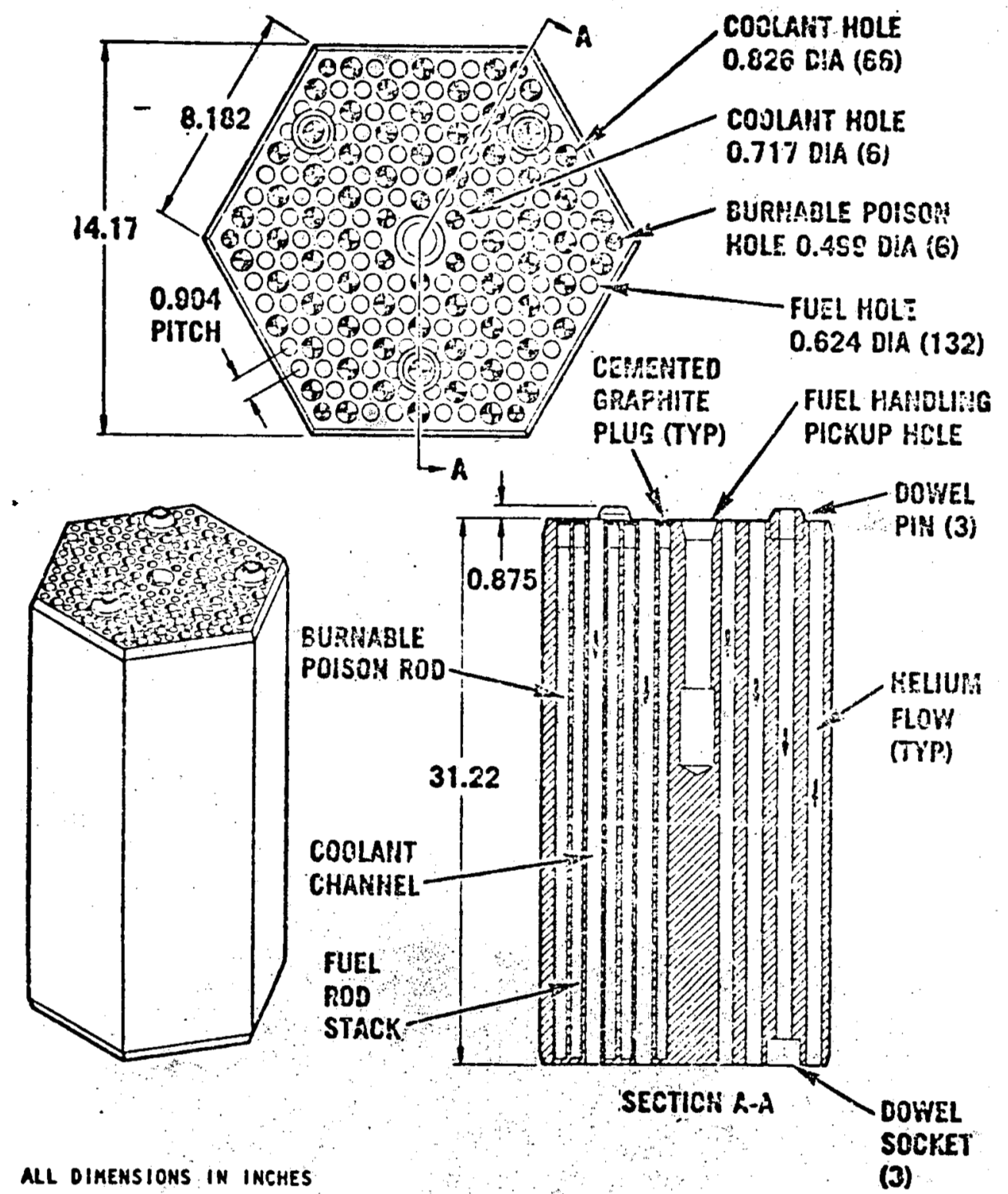

FIGURE 1.3 FUEL ELEMENT 


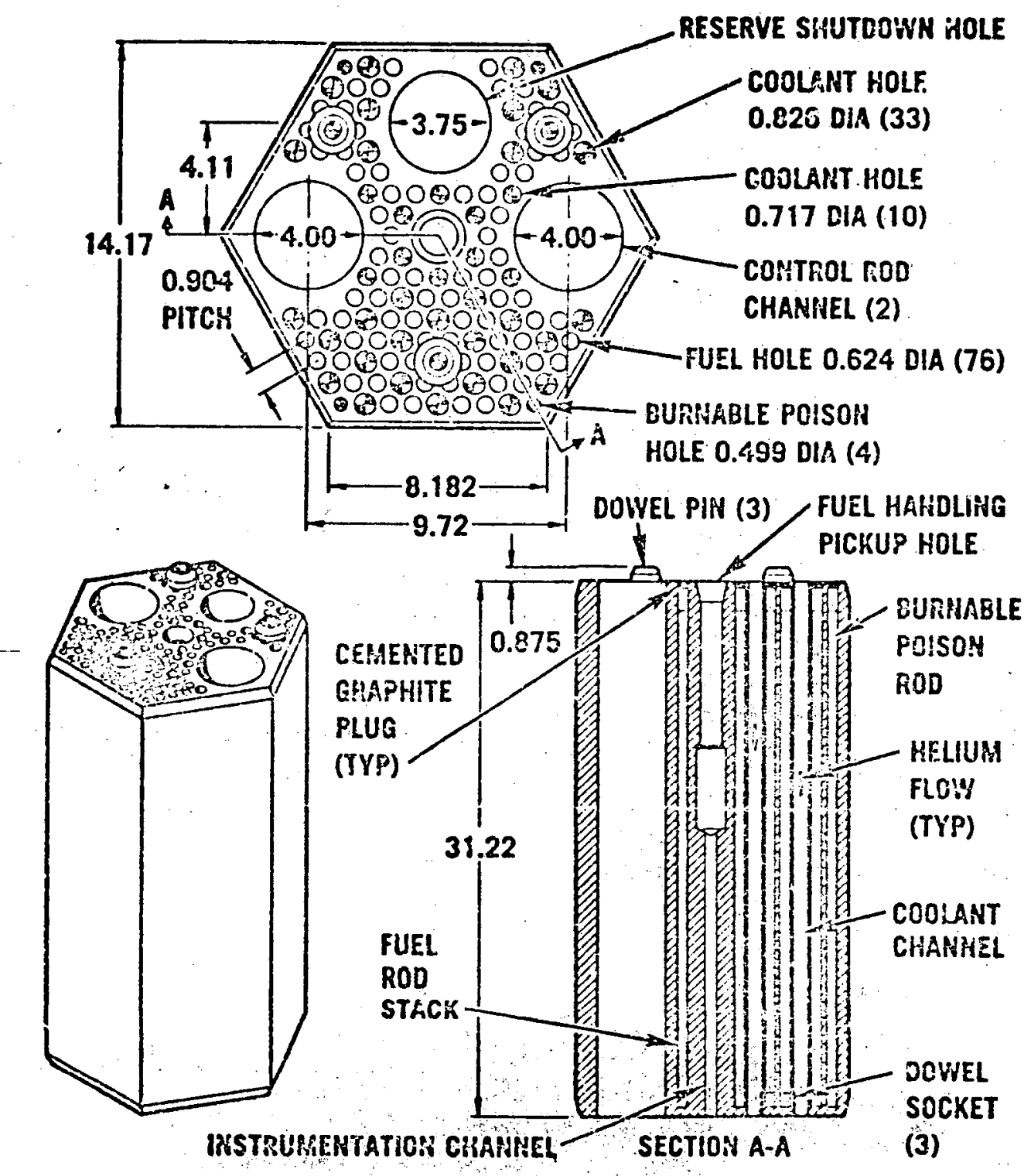

AL DIMENSIONS IN INCHES

AS-72100 B /3

$11 / 73$

FIGURE 1.4 CONTROL ELEMENT 


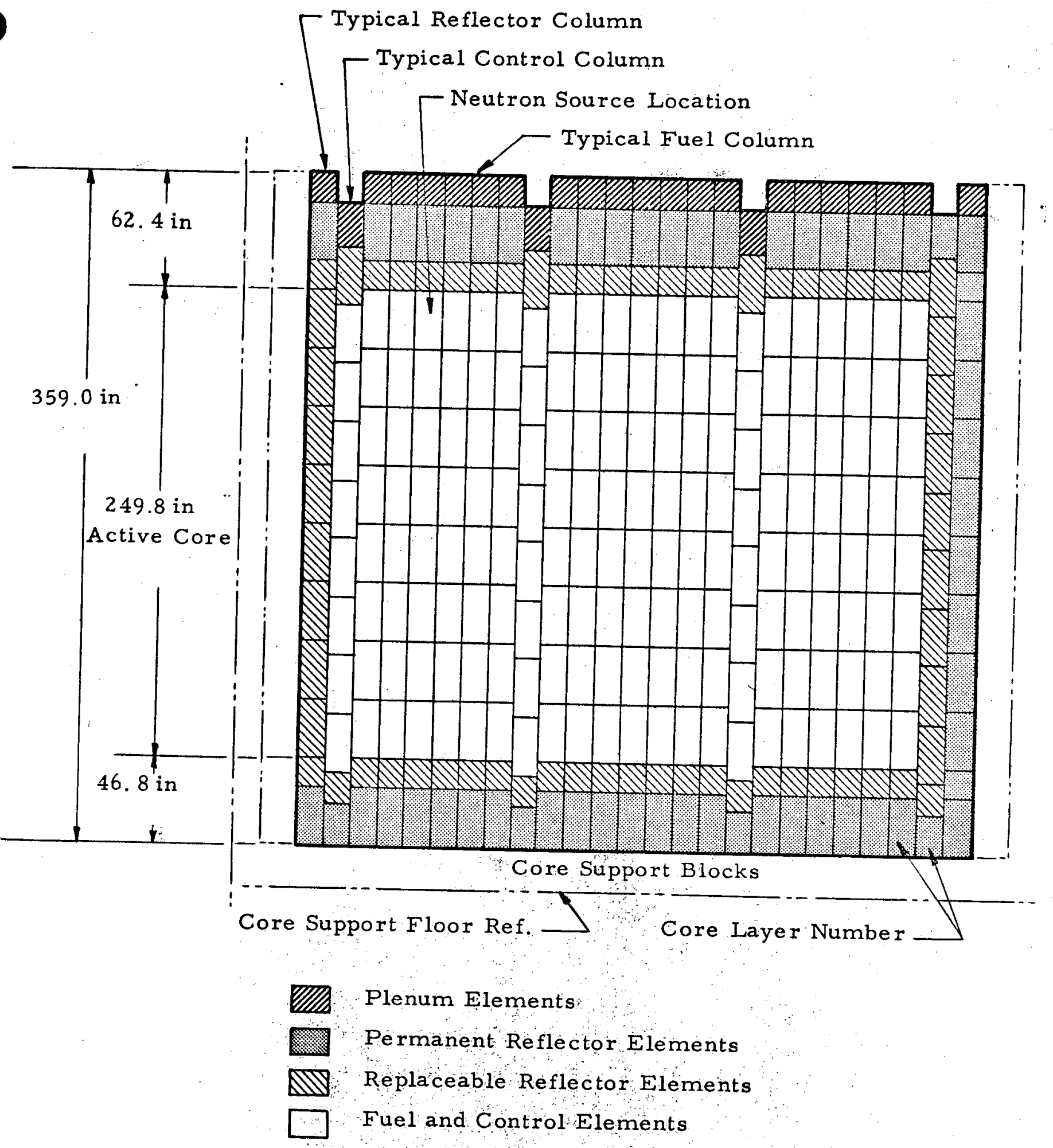

FIGURE 1.5 CROSS-SECTIONAL ELEVATION VIEW OF HEXAGONAL CORE COLUMNS - $3000 \mathrm{Mw}(\mathrm{t})$ HTGR 


\section{HTGR REACTOR CORE AND SUPPORT ARRANGEMENT}

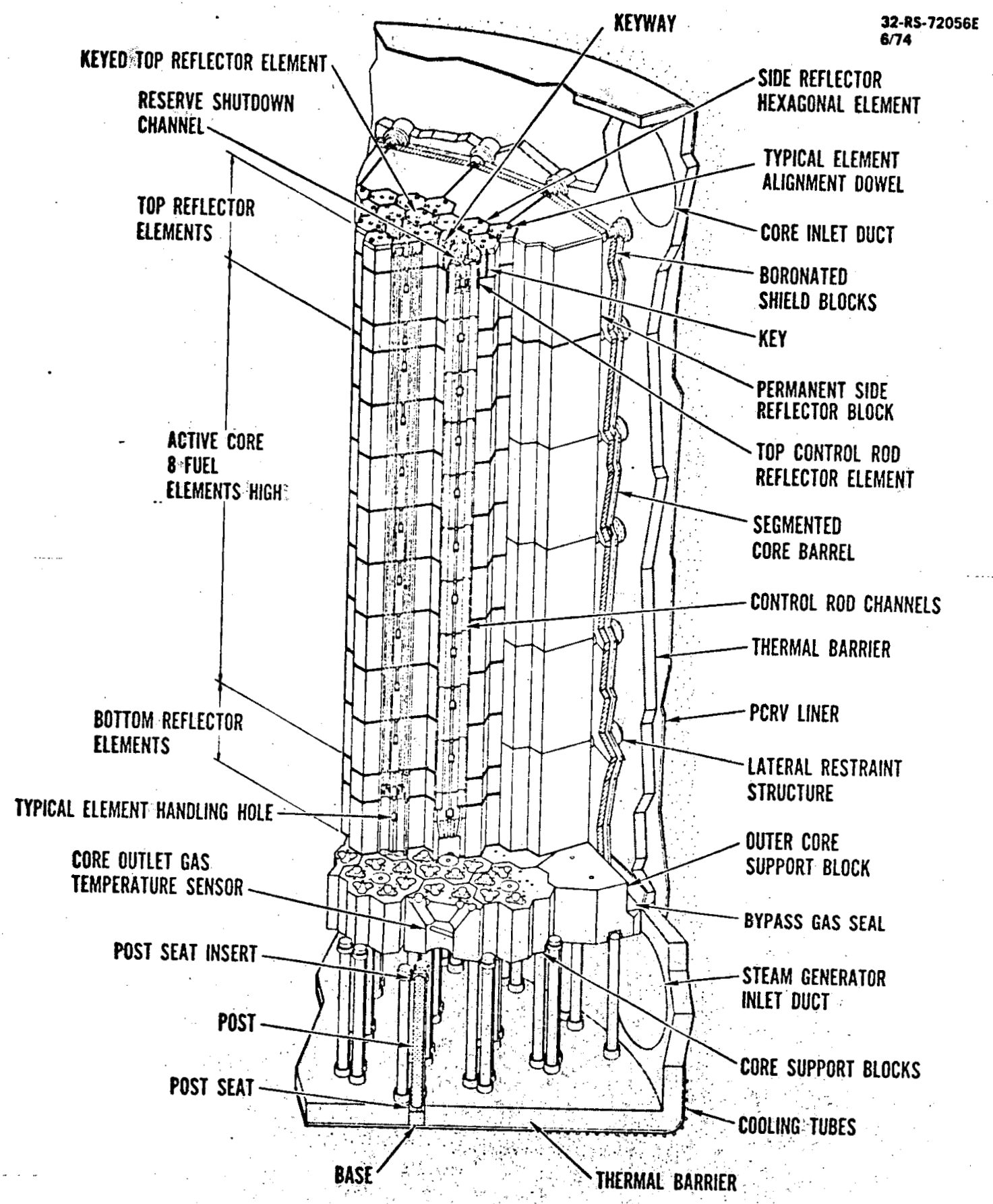

FIGURE 1.6 HTGR REACTOR CORE AND SUPPORT ARRANGEMENT 


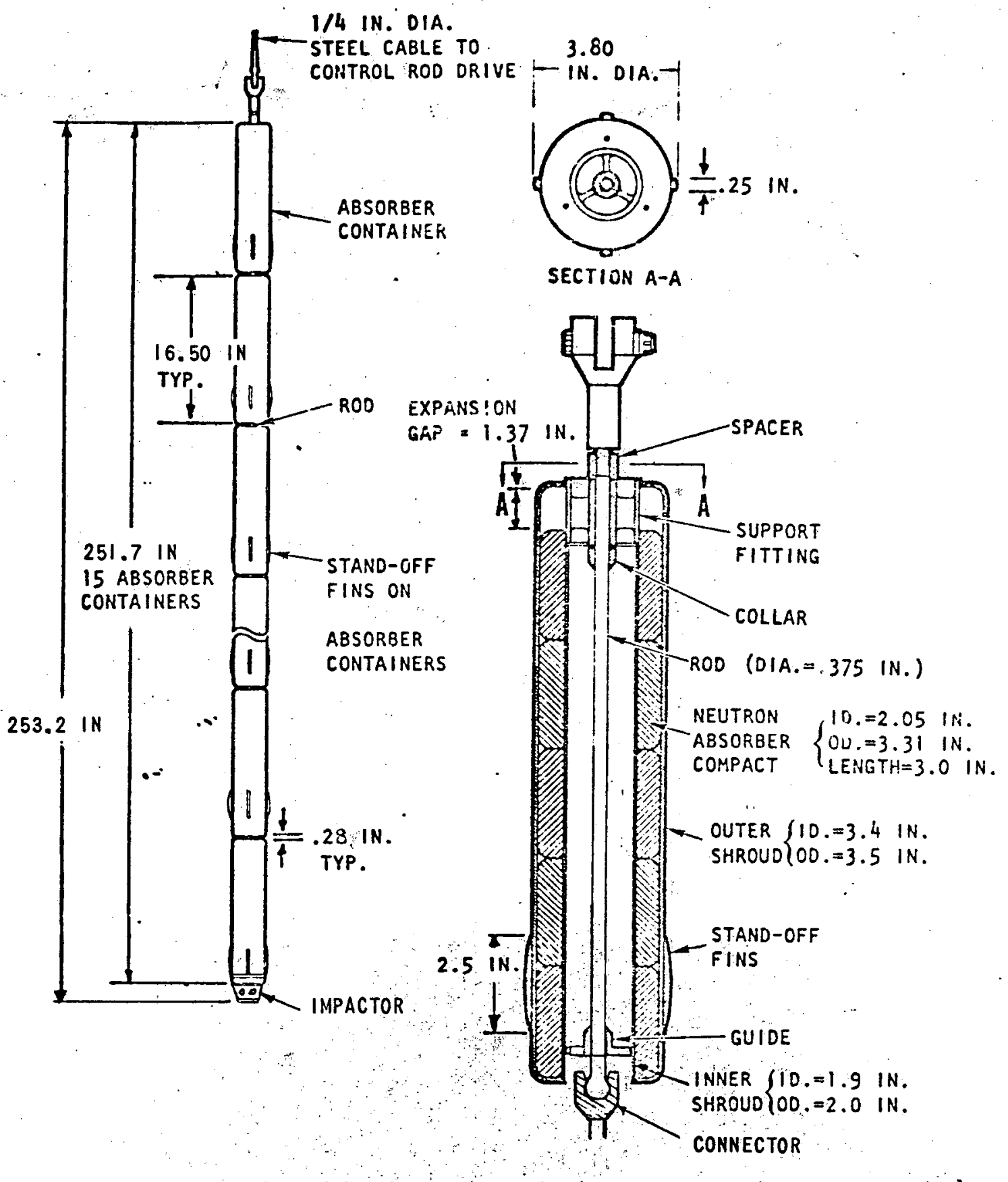

FIGURE 1.7 CONTROL ROD DETAILS 


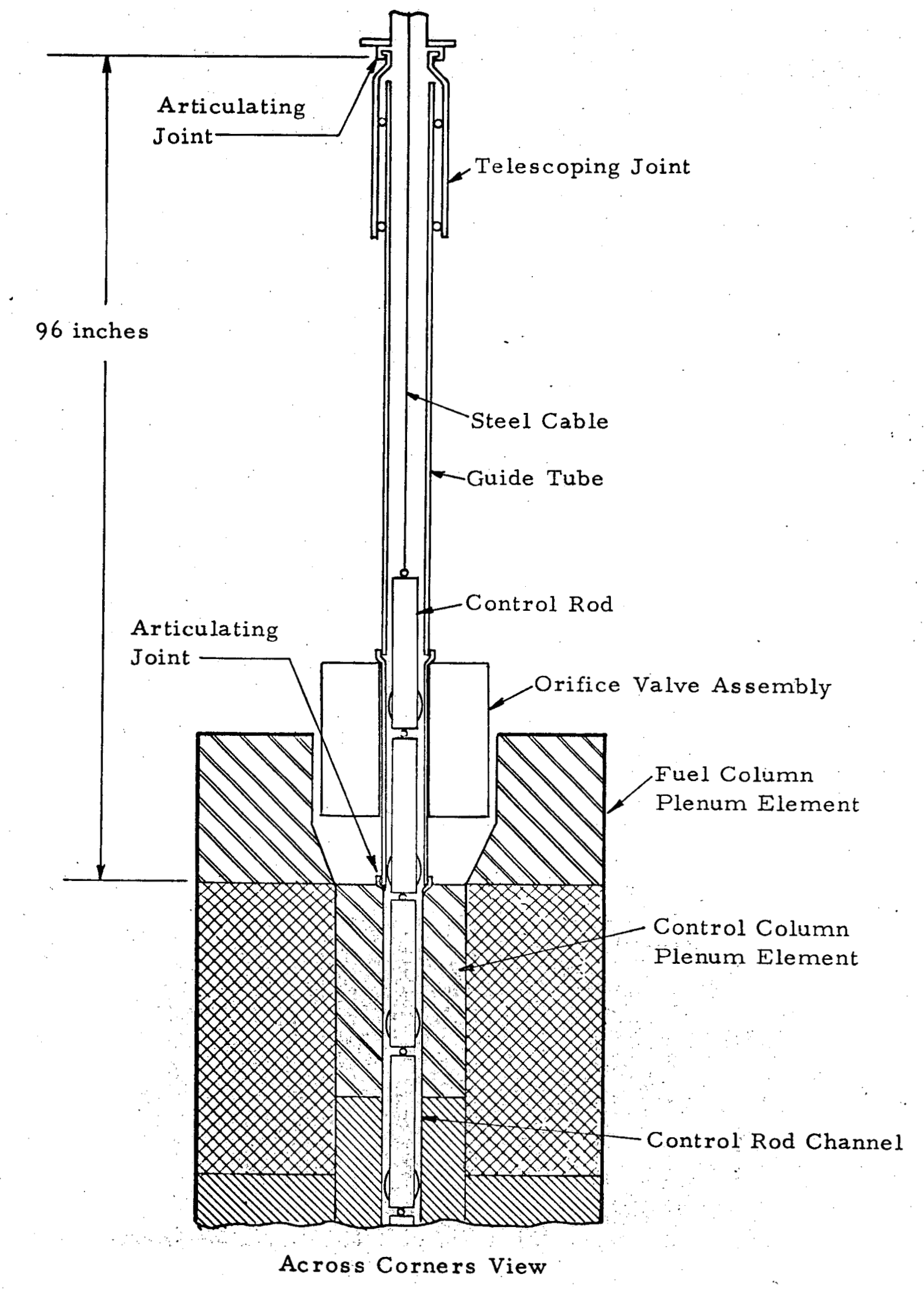

FIGURE 1.8 CONTROL ROD GUIDE TUBE ASSEMBLY 

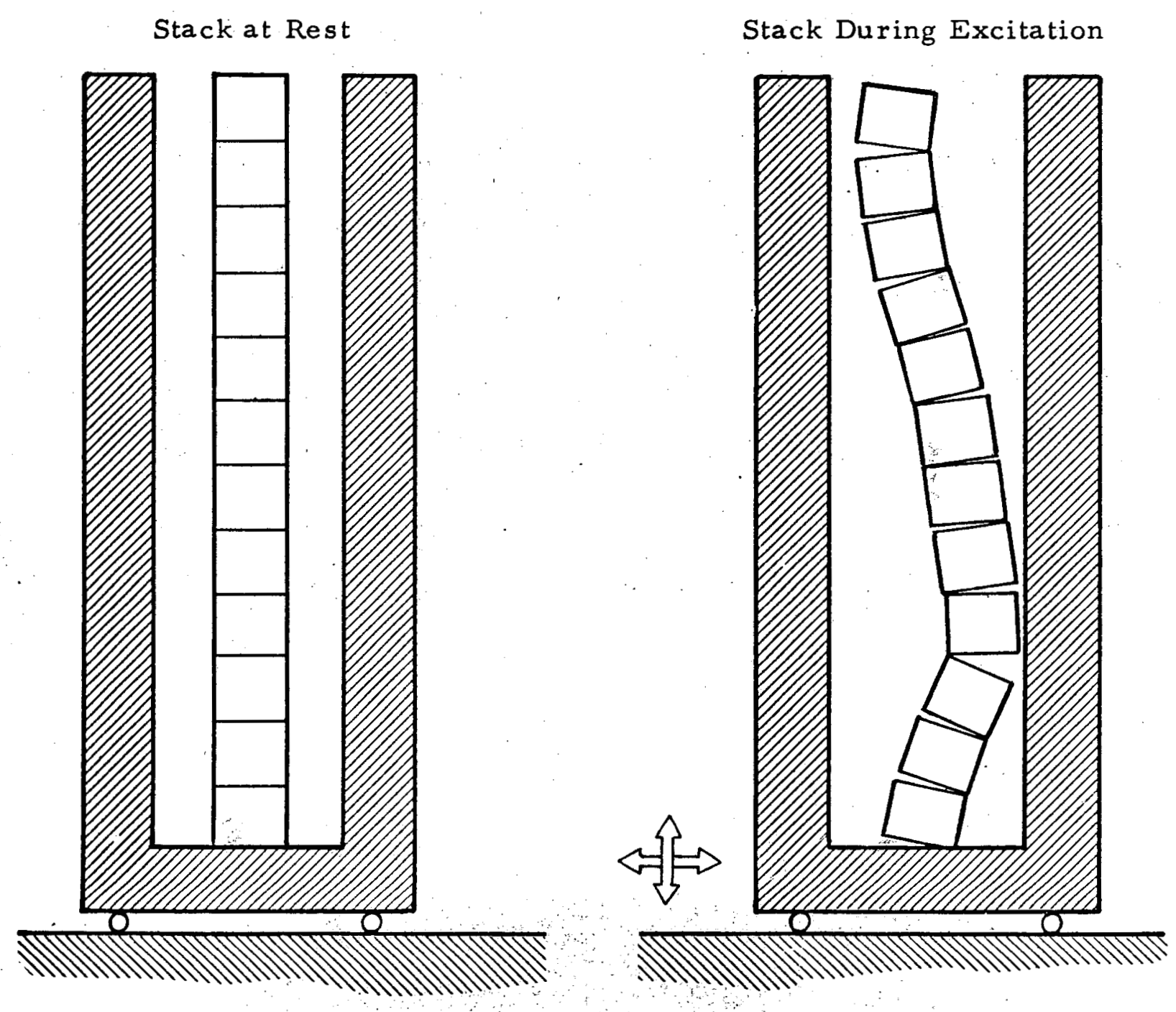

FIGURE 1.9 SCHEMATIC MODEL FOR STACKED COLUMN ANALYSIS 


\subsection{CONCLUSIONS AND RECOMMENDATIONS}

\subsection{GENERAL}

The main objective of this study was to assess the relative influence of inserted control rods on the seismic response of an HTGR. To make this assessment, the responses of a control column and a control rod assumed inserted to three different depths were computed analytically and compared. Additional analyses were also performed to investigate the influence of gap distribution and cannister bindup on column response. Many conservatisms were assumed in developing the analytical model so that any possible control rod effects would be maximized. Therefore, the resulting response of the column are presumed to be significantly. overestimated. Conclusions based on the results of these analyses are reported upon in this chapter.

\subsection{CONCLUSIONS}

It was concluded in this study that inserted control rods have no influence on the seismic response of a core column unless column blocks significantly separate vertically from one another during the excitation. In the analyses performed, the vertical input excitation utilized was conservatively overestimated and thus large enough to cause significant separations to occur between the blocks, during one period of the response. This permitted significant differences in the column responses to be detected.

The response most greatly affected by inserted control rods was the relative angle between blocks. Peak rotational angles between blocks for different insertion depths are compared in Figure 5.3. During periods of separation, the control rods we re found to significantly reduce rotations in the portion of the column in which they are located while increasing rotations at the interface level just below the bottom tip of the rod. The 
maximum relative angle occurred at the bottom tip of the rod when the rod was fully inserted. When the blocks separate vertically, there is a loss in rotational stiffness between vertically adjacent blocks. Therefore during separation, the block response, especially rotations, are much more sensitive to the stiffness of the control rods since they provide the only rotational connectivity between blocks. Once the blocks fall back onto one another, the rotational stiffness is again provided by direct contact of adjacent blocks. Time history plots of the relative angles (Figure 5.12 through 5.14) show that large angles occur only one time during the record and at this time there is separation between adjacent blocks. During all other periods in which column elements are in contact, the largest angles predicted to occur are less than 3.5 degrees.

The lateral velocity response between the column and adjacent boundary was found not to be greatly affected by control rod insertion even during periods of separation. The peak column velocities for different rod insertion depths did not vary by more than 10 percent at essentially all points on the column. The peak impact velocities occur in the center of the column and decrease near the top and bottom of the column indicating that the column is responding somewhat like a simple vibrating beam with the ends restrained. Peak velocities range between 127 and 138 inches/sec. Since fuel element impact forces are directly related to impact velocities, it can be concluded that impact forces are also essentially unaffected by control rod insertion. Time history plots of column displacements and velocities (see Figures 5.6 through 5.11 ) show that except during one period of separation $(0.7-1.3$ seconds), the responses for different control rod depths match very closely and that even during the se periods the responses are in reasonably close agreement.

The horizontal shears forces between vertically adjacent column blocks were also found not to be greatly affected by control rod insertion. As shown in Figure 5-1, the maximum shear forces occur at the top, 
midheight, and bottom of the column. Shear forces at the top and bottom of the column are associated with simple beam behavior while shear forces in the center of the column are associated with impacts of the column with the boundary. At most locations in the column; peak shear forces did not vary by more than 15 percent for differing control rod insertion depths. In general, it appears that shears throughout the column are reduced slightly (less than 10 percent) by insertion of control rods. However, no significant trends or changes in the shear force distribution associated with different control rod insertion depths were apparent.

The relative impact velocity between the control rod and the control column was found to be directly related to the impact velocity of the column with the boundary. As seen in Figure 5.4, the peak control rod impact velocity occurs near the column midheight at the same point as the peak column velocity. The magnitude of the peak control rod impact velocity was found to be slightly greater (less than 25 percent greater) than the peak column velocity with the maximum velocity occurring with the rod fully inserted. The lateral boundary gap distribution was found to be a significant factor in core column response. A highly skewed gap distribution like that found in peripheral column results in large shears at the top, middle, and bottom of the column while a larger more evenly distributed gap distribution such as those found in a more centrally positioned column was found to increase shears at the top of the column while decreasing shears at the center of the column. Larger midheight gaps were also found to result in slight increases in the column lateral velocity and significant increases in the peak rotations between blocks. Thus, in general, larger gaps result in greater responses of the column.

In an additional analysis described in Chapter 6; it was found that even if the relative angles between blocks were great enough to cause individual control rod cannisters to bind up within the column, the additional rotational stiffness between blocks caused by bindup would not be great 
enough to influence column response except during periods of separation. Bindup of the column during such periods was found to reduce response, particularly relative rotations in the region of the column in which the rods are inserted. Column lateral velocities, horizontal shears, and control rod impact velocities were also found to be reduced slightly (between. 15 and 25 percent) in the region of the column in which the rod is inserted. However, other than a slight reduction in response, no other trends related to control rod insertion were apparent. At levels below the bottom tip of the control rod, peak responses were found to be essentially unaffected by rod insertion. Thus, it can be concluded that even if the control rods were to bindup in the column during seismic disturbances, the only response effects expected to occur are slight reductions in the responses of the core columns.

\subsection{RECOMMENDATIONS}

To perform the analyses in this study, it was necessary to make several assumptions. These assumptions include idealizing core behavior by a single column excited by the motion of the PCRV. It was also assumed that the most critical response would occur in a peripherally positioned column.

The results of the study indicated that the control rod significantly affects response of the core only during periods of vertical separation of the core elements. During those periods, the greatest effects occur when the rod is fully inserted. Therefore it is recommended, that for the rod inserted tests, the rods be fully inserted. To demonstrate and confirm that effects resulting from control rod insertion will not cause detrimental effects on overall core response or safety of the negative reactivity systems, a one-fifth scale full array test with simultaneous horizontal and vertical excitations will be performed. To verify the assumptions and results of this study, the following measurements should be considered in these tests: 
1. Measurements should be made in both a central and peripherally positioned control column.

2. Relative angles and separations should be measured in several positions throughout the column. For rod inserted tests, one location at which relative angles should be measured is at a level even with the bottom tip of the inserted rods.

3. The impact velocities of the control column with adjoining columns should be measured at three points along the column in the direction of horizontal excitation. One of the points should be near the column midheight. This test should demonstrate that inserted control rods have little effect on impact forces.

4. The horizontal dowel shear forces between blocks should be measured at three locations. One location should be level with the bottom tip of the control rod to demonstrate that a shear plane is not created by the presence of control rods. Other measurements should include a location near the midheight and between the top two elements of the column.

5. To insure that adjacent columns are not significantly affected, similar instrumentation should be placed on the two columns adjacent to the instrumented control column. 


\subsection{IDE ALIZED MODEL OF CORE COLUMN AND CONTROL ROD}

\subsection{GENERAL}

The idealized model of the core column and control rod used in the analysis is described in this chapter. The impact properties of the fuel elements are discussed along with the methods used to obtain equivalent stiffness and damping elements used to simulate impact behavior. Properties of the control rods and guide tubes are presented and methods used to obtain an equivalent pendulum stiffness are described. The development of the input excitations used in the analysis is also presented and the response spectra of the excitations are compared with design spectra.

\subsection{DESCRIPTION OF COLUMN MODEL}

The reactor core of large HTGR's consists of thousands of individual graphite blocks which are stacked to form hundreds of fuel columns separated from one another by gaps. Each column of blocks is essentially free standing and constrained only by dowels which restrict relative horizontal movement but permit vertical lift-off and rocking motions between elements. During an earthquake which has a peak ground acceleration above a small threshold level of approximately $0.05 \mathrm{~g}$, the columns of core elements respond by displacing through the gaps and colliding with each other. To move through the gaps, the elements form a "linked mechanism" where the elements rock on top of each other as they undergo translational as well as rotational motion (see Figure 3.1). In effect, the blocks behave as rigid bodies. Such behavior results in horizontal and vertical impact forces on the fuel elements and shear forces in the dowels. The response of rocking impacting blocks is highly nonlinear. A complete characterization of the seismic response of an HTGR core would require modeling every column of the core as a set of stacked blocks which are permitted to rock and impact adjacent blocks. Since the 
computational costs associated with such a generalized model would be very great, the scope of this investigation has been limited to studying the response of a single column subjected to a prescribed boundary motion which conservatively simulates the dynamic environment of the core. The objective of this study is to assess the influence of inserted control rods on the seismic response of the core. Therefore a typical control element column into which control rods are inserted was selected as the subject of the analysis.

The idealized model of the control element column is shown in Figure 3.2. The column is treated as a stack of two dimensional blocks. The reduction of the three dimensional system to a two dimensional planar model is based on the observation that experimental tests show that the core columns respond primarily in the direction of excitation with little or no coupling in the perpendicular direction.

In the column model, each element is idealized as a rectangular rigid block with contact springs and dampers located at the corners of the blocks to account for surface deformations resulting from collisions. The stiffness of the dowels is represented by a shear spring and damper. A discrete model of the interfaces of the elements is shown in Figure 3. 3 . Properties of contact and dowel springs and dampers are discussed in the next section. The column displacements are completely defined by a set of rigid body coordinates at the c.g. of the elements. Each element has three degrees of freedom; horizontal and vertical translation and rotation.

The idealized column model is contained within a rigid box which represents the boundary of the column with adjacent columns and the core support floor. The lateral gaps between the column and the boundary have been selected to conservatively simulate those which occur for a fully irradiated 3,000 $\mathrm{Mw}(\mathrm{t})$ core during full power conditions. Under these conditions, the maximum accumulatedacross-the-core gap is estimated to be 2.6 inches (see Table 1.2). The full power condition was selected because the effect of control rods on response is of prime importance when core is 
in an operating condition. The full irradiated condition was selected because the largest in core gaps occur for this condition. Large gaps result in large relative angles between blocks and are therefore believed to accentuate any effect of control rods on column response.

The gap distribution has been selected to conservatively represent a peripherally positional column. A peripheral column was selected because experimental and analytical studies currently in progress by GAC show that the largest response (impact forces, shear forces, and angular motions) occur in the peripheral columns and therefore would most be the columns most greatly affected by control rods. For such a peripheral column, it is estimated that 2.3 inches of the total gap is towards the center of the core while the remaining. 3 inch is away from the core center. Near the top of the core, the gap is 1.2 inches in the direction in the core center. During full power conditions, the core support floor blocks and the ring of permanent side reflector blocks are essentially tight. In the idealized model, the gap between the column and boundary was set equal to the midheight gap for all but the top element. For the top plenum element, the boundary gap was set to the smaller 1.2 -inch gap size. A smaller plenum element gap partially restrains the upper portion of the column and results in the column responding simarily to a simple beam. It is anticipated that such beam behavior will accentuate any control rod effects.

The dimensions and mass properties of the idealized column elements were chosen to correspond directly to the properties of an actual HTGR control column element. The masses and inertias for each block are presented in the next section.

As shown in Figure 3.2, the guide tube assembly which consists of two guide tubes and the orifice valve assembly is idealized as a single tubular beam element extending from the center of the plenum element 
vertically upward to an elevation corresponding to the top joint of the guide tube assembly. The ends of the tube are treated as pinned ended joints. It is assumed that the top end of the guide tube moves laterally the same as the rigid core boundary containing the column. The lower end of the guide tube is connected to the plenum element by a contact element which permits the assembly to transmit only compressional loads and to vertically lift off in tension. The stiffness of the tube represents the stiffness of two guide tubes acting in parallel. Masses are lumped along the tube to represent the mass of the two guide tubes and the orifice valve assembly. The mass and stiffness properties of the guide tube and orifice valve assembly used in the analyses are given in Table 3.1.

The control rod is idealized as series of lumped masses interconntected by equivalent shear springs representing the pendulum stiffness of the cannister. The rod is assumed to be suspended from the upper end joint of the idealized guide tube assembly. In its fully withdrawn position, the control rod is totally located within the idealized guide tube while in its fully inserted position, the control rod is totally contained within the control element column. Details of the control rod model are discussed in Subsection 3.4.

\section{3 PROPERTIES OF IDEALIZED COLUMN ELEMENTS}

The elements comprising the column model represent the hexagonal fuel and reflector elements of a typical control element column. Each element is idealized as a rectangular planar rigid block. The blocks are assumed oriented such that in an elevation view, the control rod channels coincide in the center of the column.

The width and height of the blocks of the model correspond directly to the dimensions of the actual elements. The control element column consists of eight full height fuel elements, three reflector elements of varying height and one three-quarter height steel plenum element. The blocks are identified by numbers 1 through 12 . 
The mass properties of the idealized elements were also taken to correspond to properties of actual elements. In the model, it is assumed that the mass of the element is uniformly distributed throughout the element. Thus the center of gravity of each element coincides with its geometric center. In addition to the mass and c.g. location, the mass moment of inertia of each block is also required. For a hexagonal element with uniformly distributed mass, the mass moment of inertia, I, about a central axis is given by

$$
I=\frac{M}{72}\left(6 h^{2}+5 b^{2}\right)
$$

where $M=$ mass of the element, $h=$ height of the element and $b=$ across the flats width. Using the mass and geometry of each element, mass moments of inertia were calculated. The dimensions and mass properties of the idealized elements are presented in Table 3.2 .

As discussed earlier, each element is idealized as a rigid planar block with contact springs and dampers located at the corners of the blocks to account for surface deformations resulting from collisions (see Figure 3.3). The springs and dampers act only in compression when the gaps close and do not offer any tensile load resistance. Two vertically oriented contact springs are located at the corners of the interface between blocks and two horizontally oriented contact springs are located at the upper and lower corners of each block. The relative horizontal dowel shear stiffness between vertically adjacent elements is represented by a single centrally positioned shear spring. In the model, effects caused by small gaps between the dowel and socket and friction caused by sliding between interface surfaces have not been considered except in damping as sociated with the dowel shear spring.

It should be noted that rotational stiffness between column blocks is provided by the vertical contact springs. Therefore, during periods of separation when none of the vertical contact springs are acting, the 
rotational stiffness connectivity between adjacent blocks is zero. It is assumed that the dowel pins will be sufficiently. long to accommodate any predicted separation between elements and therefore the horizontal dowel shear stiffness is maintained in the model irregardless of the separation distance. It should be noted that because of conservatisms in the analytical model, separations predicted in this study are over estimated and other studies currently being conducted by GA indicate that the dowels are sufficiently long to prevent dowel disengagement.

The shear stiffness of an individual dowel and socket is based on experimental tests performed on a full scale dowel socket system. In these tests described in Reference 6, a lateral shear stiffness of approximately 40,000 lb/in was measured for a dowel socket unit. For the present three dowel design, two of three dowels are positioned in oval sockets in such a manner that only two dowels are expected to be acting at any one time. Thus a combined dowel shear stiffness of $80,000 \mathrm{lb} / \mathrm{in}$ representing the stiffness of two dowels was used in the analyses performed. The same dowel stiffness was used between all blocks. It should be noted that recently conducted experimental and analytical studies performed of the dowel socket system suggest a somewhat higher stiffness varying between 120,000 and $200,000 \mathrm{lb} /$ in may be appropriate. Since the dowels are already very stiff when compared to the lateral stiffness of the overall system, an increased dowel shear stiffness is not expected to significantly effect overall column response but might possibly cause increases in the dowel shear forces between elements.

Properties of the fuel element contact springs and dampers are based on data measured during single and multiblock collison tests and on basic element rocking tests performed by GAC (Reference 7). In these tests, it was observed that the impact between fuel elements was highly inelastic. In the single and multiblock collision tests, flat faces of full size fuel elements impacted one another at varying impact velocities. 
The momentum of the blocks before and after impact was compared and the coefficient of restitution computed. The coefficient of restitution $\mathrm{C}_{\mathbf{e}}$ between two colliding bodies is defined as the ratio of the relative velocity of the bodies after collision to the relative velocity before collision. Thus

$$
c_{e}=\frac{v_{2}-v_{2}^{\prime}}{v_{1}-v_{1}^{\prime}}
$$

where $\mathrm{V}_{2}$ and $\mathrm{V}_{2}$ ' are the velocities of the two bodies after the collision and $\mathrm{V}_{1}$ and $\mathrm{V}_{1}{ }^{\prime}$ are the velocities of the bodies just prior to the collisions (impact velocity). It was determined from tests conducted on the graphite fuel elements found that the coefficient of restitution varied between 0.2 and 0.5 depending on impact velocity. The measured coefficient of restitution versus impact velocity are plotted in Figure 3.4 (Reference 8). It is anticipated that the impact velocity between fuel elements will range between 30 and 60 inches/sec. As shown in Figure 3.4, in this impact velocity range, the coefficient of restitution is approximately 0.40 .

Inelastic impact is accounted for in the control element model by. contact dampers. The contact dampers act in parallel with the contact springs and act only when the gaps are closed during collisions. It can be shown that for the single degree of freedom mass-contact spring system illustrated in Figure 3.5, the coefficient of restitution (defined as the ratio of approach velocity to separation velocity) can be expressed as a function of the damping of the system by:

$$
C_{e}=e^{\frac{-\pi \lambda}{\sqrt{1-\lambda^{2}}}}
$$

where $\lambda$ is the fraction of critical damping of the mass-contact spring system. The coefficient of restitution is plotted versus the fraction of critical damping in Figure 3.6. The fraction of critical damping corresponding to coefficient of restitution of 0.40 is 0.27 . This fraction of critical damping was used in establishing all damping constants associated with the contact dampers. It should be noted that the same coefficient of 
restitution and associated damping was also assumed for the steel plenum elements. The steel plenum elements vertically and laterally impacts graphite elements and therefore graphite element coefficients of restitution may be appropriate. Also, in the one-fifth scale control rod tests, the steel plenum elements are represented by graphite elements. Therefore, to permit direct comparison, the steel plenum elements were modeled as if they were graphite elements.

As noted earlier, the contact springs represent the stiffness of local surface deformations and not the overall axial stiffness of the block. As long as the stiffness of the springs are relatively high, variations in the contact spring stiffnesses are not expected to cause significant differences in the overall system behavior and will effect only the local impact forces. Stiffness values of the contact springs were developed such that predicted impact forces would correspond to those measured during the basic rocking tests (Reference 7). In these tests, a single standard fuel element was initially tipped to various specified initial angles and then released and the corner impact forces measured. In Figure 3.7, the range of measured impact forces are plotted versus initial tip angle. Preliminary analyses were performed of a single block rocking model in which the stiffness of the gap spring was varied. Based on the results of these analyses a gap spring stiffness of 74,000 $\mathrm{lb} /$ in was selected and used for all fuel element gap spring stiffnesses. For an initial tip angle of 0.10 radian ( 5.73 degrees), the analyses predicted a peak vertical impact force 3,680 pounds which is within the range of the measured forces. It should be noted that both the measured and predicted impact forces are for local corner impacts.

As noted earlier, changes in the contact stiffness would not be expected to significantly effect overall response but would likely increase local impact forces. For a given impact velocity $V_{0}$, it can be shown that for the idealized system shown in Figure $3-5$, the total peak impact force, $F_{1}$, on a block is given by the following expression. 


$$
F_{\mathrm{I}}=R V_{\circ} \sqrt{\mathrm{KM}}
$$

$$
\begin{aligned}
& \text { where } R=\frac{e^{\frac{\lambda}{\sqrt{1-\lambda^{2}}}} \operatorname{Sin} \theta}{\sqrt{1-\lambda^{2}}} \\
& \theta=\tan ^{-1} \frac{\lambda}{\sqrt{1-\lambda^{2}}}
\end{aligned}
$$

and $\lambda$ is the fraction of critical damping.

The quantity $R$ is plotted versus the fraction of damping in Figure 3.8 and provides an easy means of determining the impact force. For any given impact velocity, stiffness, mass and fraction of critical damping, the impact force can be computed directly.

\subsection{PROPERTIES OF CONTROL RODS}

The control rods consist of a series of fifteen metal cannisters which are suspended by a steel cable from the control rod drive mechanism. Individual cannisters are connected to one another by ball joints. Details of the control rod design were discussed earlier in Subsection 1.4. There are two control rods for each control column. When fully withdrawn, each control rod pair is located entirely within the guide tubes while when fully inserted the control rods are located entirely within the control element column.

During an earthquake, the control rods could possibly effect the core response by altering the mass, damping, or stiffness characteristics of the core. It is expected that the control rods will act essentially as "chain dampers" during seismic events and thus are expected to dampen response to some extent. The rods may also effect the core response by providing additional bending stiffness to the control columns. By far the largest 
increase in stiffness would occur if during a seismic event, two stacked blocks rock relative to one another causing one of the control rod cannisters located within the blocks to contact with the sidewalls of the control rod channel. This behavior would cause the cannister to bind up within the channel resulting in a substantial increase in the rotational stiffness between the two stacked blocks. Such a condition is illustrated in Figure 3.9. Geometric analysis (see Reference 9) performed of the cannister control rod channel system indicate that such binding would begin to occur when the relative angle betweer the blocks was between 4.5 and 7.0 degrees. In this analysis the effect of irradiation induced bowing of individual blocks was not considered. Since relative angles between blocks greater than 4 degrees are currently not predicted to occur, such binding is not anticipated.

The control rods are idealized as a series of lumped masses connected to one another by shear springs. Lateral contact springs and dampers are used to represent impact of the control rods with the walls of the channels and guide tubes. Three separate control rod models were developed, one corresponding to each of the depths of insertion considered. The models for the fully withdrawn, partially inserted and fully inserted cases are shown in Figure 3.10 through 3.12 respectively. In each case, the idealized masses and stiffnesses represent the combined masses and stiffness of two control rods. The discrete model of the control rod at a typical location is shown in Figure 3.13.

When fully withdrawn, the lower tip of the control rod is 60 inches above the active core and located entirely within the guide tube with the lower tip approximately even with the top of the column. The upper end of the control rod is located in the refueling penetration within the PCRV. Since the guide tube acts essentially as a rigid beam, it is reasonable to assume that the control rod cannister responds in phase in this region. 
For this reason, the portion of the control rod located within the guide tube was modeled by only two lumped masses, one even with the top of the column and one at the midheight of the guide tube.

When fully inserted the lower tip of the control rod is about even with the bottom face of the lowest active fuel element (Block 3) while upper end of the top cannister is a few inches above the highest active fuel element (Block 10). For this case, the control rod has been modeled by a total of 18 lumped masses which are at the same elevation as the bottom face and c.g. of each block. Thus the masses are spaced 15.6 inches apart vertically. Each mass represents approximately one cannister.

A partially inserted control rod case was also considered. In this case, the lower tip of the control rod was assumed to be even with the bottom of block 8 while the top end was approximately even with the top of the guide tube (see Figure 3.11). Consistent with the other models, that portion of the control rod located within the column was modeled with masses at the bottom face and c.g. of each element while that portion of the control rod located within the guide tube was modeled with two masses located at the top of the column and the midheight of the guide tube. Thus a total of 12 lumped masses are required to model the rod.

In all cases, values for the masses were lumped based on a tributary mass approach assuming that the mass of the control rod was uniformly distributed along its length. As noted earlier, the idealized control rod actually represents a pair of control rods, therefore, the combined mass of two control rods was used in determining the mass values. The masses of the idealized control rod for the three models considered are tabulated in Table 3.3 . 
During seismic excitations, a control rod acts essentially as multimass pendulums which impact the inner walls of the control rod and guide tube channel. To model the pendulum behavior, the lumped masses are connected by shear springs which provide the equivalent lateral stiffness of the pendulum system.

For the simple pendulum system shown in Figure 3.14, the dynamic equation of equilibrium for small angles can be written as

$$
M \ell^{2} \ddot{\theta}+W \ell \theta=0
$$

Noting that $W=M g, x=\ell \theta$, equation (3.8) can be expressed as

$$
m \ddot{x}+\frac{W}{\ell} x=0
$$

This equation is identical to that for a single.degree of freedom system in which the effective stiffness of the spring $m$ equals $\frac{W}{\ell}$.

Using this approach, it can be shown that for the $\mathrm{n}$ mass pendulum system shown in Figure 3.15, an equivalent $n$ degree of freedom mass shear spring model can be developed in which the equivalent shear stiffness of spring $k_{j}$ is given by

$$
k_{j}=\frac{\sum_{i=j}^{i=n} w_{i}}{\ell_{j}}
$$

where

$$
\begin{aligned}
& k_{j} \text { is the equivalent stiffness between nodes } j \text { and } j-1 \\
& w_{i} \text { is the weight of node } i \\
& \ell_{j} \text { is the distance between nodes } j-1 \text { and } j .
\end{aligned}
$$


Using equation (3.10), equivalent shear springs were developed for the three control rod models. These stiffnesses are tabulated in Table 3. 4.

Since, vertically, the response of the control rod has no effect on the core response, the vertical response of the control rod was uncoupled from the response of the rest of the system. The control rod model, therefore, consists only of horizontal translation degrees of freedom.

The impact behavior between the control rod cannisters and control rod channel is modeled with gap element springs and dampers. The gap spring and damper are only active during collisions when the gaps between the control rod and channel are closed.

The properties of the control rod gap elements are based on the stiffness of the cannister tubes since the stiffness of the tubes is much less than the graphite fuel elements. Each cannister tube, which is 16. 5 inches long, 3.50 inches in diameter, with a wall thickness of 0.05 inches, contains boron $r$ ings. It is assumed that impact between the cannisters and the channel always occurs at one of the stand-off fins which protrude from each cannister and that this impact is resisted by uniformly distributed inertial forces. Based upon these assumptions, an approximate analys is was performed and the effective cannister impact stiffness was estimated to be 10,000 pounds per inch. Since the idealized control rod represents a pair of control rods, the stiffness of the impact spring used in the model was the combined stiffness of two cannisters or $20,000 \mathrm{lb} /$ in. This impact stiffness was utilized at all control rod cannister impact points.

In the absence of test data, it is difficult to estimate the amount of damping that is associated with control rodimpact. Therefore, for convenience, the damping has been arbitrarily taken to be the same as between impacting fuel elements. This value is $27 \%$ of critical and corresponds to a coefficient of restitution of 0.40 . 
It should be noted that the impact forces predicted by the analysis are a function of the impact velocity and gap element spring stiffness and damping. Since impact stiffnesses are not well known, the impact forces resulting from the analyses should be treated carefully. In evaluating the adequacy of the cannister to resist impact, a preferred parameter would be impact velocity which is not significantly affected by the gap element stiffness.

The gap between the control rod cannister and the control rod channel varies with orientation and condition. As seen in Figure 3.16, there is an initial cold gap of 0.10 inch between standoff fins and the column channel. For lateral movement which occurs at an angle of 45 degrees with the axes of the fins, the gap is 0.14 inch. During normal operating conditions, the cannister thermally expands relative to the graphite channel, decreasing the gap. During full power conditions, the gap between the fins and the channel wall decreases to 0.075 inch, while at orientation of 45 degrees the gap decreases to $0.11 \mathrm{inch}$. Since the gap varies between 0.075 inch and $0.14 \mathrm{inch}$, a gap of 0.10 inch was selected and used at all control rod node points located within the core column for all analyses.

The gap between the control rod cannister and the inner wall of the guide tube was taken as 0.1875 inch. This gap was used because a guide tube inner diameter of 4.125 inches was assumed. This diameter results in gap between the standoff fins and guide tube inner wall varying between .16 and .23 inch. Small changes in the gap sizes in the guide tube area are not expected to significantly effect the column response.

\subsection{BOUNDARY INPUT EXCITATION}

The control element column has been analyzed for simultaneous horizontal and vertical boundary excitation which conservatively bounds the motion to those predicted to occur at a PCRV core support point during a safe shutdown earthquake which has a maximum ground acceleration of $0.5 \mathrm{~g}$. 
To obtain seismic design excitations for the HTGR equipment and components, time dependent analyses were performed on the reactor containment building and PCRV by the GAC Structural Mechanics Branch using the GA artificial earthquake as the input ground motion. The GA artificial earthquake has a response spectrum which envelopes the Newmark-type design response spectra as given in the U. S. AEC Regulatory Guide 1.60 (Reference 10). The duration of the artificial earthquake is 12 seconds. Analyses were performed for a variety of soil conditions ranging from rock with a shear modulus of $10 \times 10^{6}$ psi to a soft soil with a shear modulus of $3.6 \times 10^{3}$ psi. Using the response excitations, in-structure response spectra were generated in the PCRV at the floor of the core cavity and top head of the PCRV. At each location the response spectra for all of the various soil conditions were enveloped to create a single design response spectrum which lies above the response spectrum for any individual soil condition. The design response spectra at the PCRV support points for both the horizontal and vertical components of motion are shown in Figures 3.17 and 3.18 respectively. These spectra have been taken from Reference 11 and result from an earthquake ground motions with a peak acceleration of $1.0 \mathrm{~g}$. The spectra are for 5 percent critically damped systems.

The horizontal seismic excitations are transferred from the PCRV directly into the core by the lateral restraint structure while the vertical excitations are transferred directly by the posts. Therefore, it is believed that a reasonable estimate of core response can be obtained by using the PCRV motion as input. For the idealized core column model, the boundary excitations are assumed to have the same response spectra as the PCRV core support points.

The nonlinearities of gaps opening and closing require that extremely small integration time steps be used to perform the time history analysis of the core column. Because of the small time step requirements, it was 
determined that performing the analyses for any single full 12 -second record corresponding to the motion at the PCRV core support for one site soil condition would require a great number of time steps and would be unnecessarily expensive. Furthermore, since the PCRV design response spectrum is the envelope of response for several soil conditions, the PCRV response spectrum for any single record is well below the PCRV design response spectrum over portions of the frequency range. As an alte rnative, artificial excitations were developed for the PCRV core support location whose response spectra match the design response in the frequency range of interest $(0.7$ to $10 \mathrm{~Hz}$ for horizontal motions and 0.7 to $15 \mathrm{~Hz}$ for vertical motion). The estimated lateral fundamental frequency of the column system is $2 \mathrm{~Hz}$. To insure a maximum response of the column, it was estimated that a minimum of 5 complete oscillations of the column would be required. Thus the duration of the artificial excitation was set at 2.5 seconds.

Using Holmes \& Narver's in-house computer code STUF (Reference 12), artificial excitations which have response spectra matching those given in Figures 3.17 and 3.18 over the frequency range of interest were generated. Note that the horizontal excitation was generated to match the response spectra at point midway between the top and bottom of the core cavity (at approximately the core center of gravity) while the vertical excitation was generated to match the response spectra of the core cavity floor. The resulting excitations were scaled by 0.5 to correspond to an earthquake with a peak ground acceleration of $0.5 \mathrm{~g}$.

Plots of the acceleration, velocity, and displacement time histories of the artificial horizontal and vertical excitations are presented in Figures 3.19 and 3.20 respectively. Response spectra generated from the excitations are plotted along with design spectra which they match in Figures 3.21 and 3.22 . 
Since the artifical excitations have such a short duration (2.5 seconds) they must have very high acceleration in order to generate response spectra which agree with the design response spectra in the frequency range of interest $(0.7$ to $15 \mathrm{~Hz})$. For instance the 2.5 second vertical artificial excitation has a peak acceleration of $2.6 \mathrm{~g}$ 's compared to $1.2 \mathrm{~g}$ 's for the actual vertical design response spectra envelope. This overestimation of peak acceleration results in greatly increased response for frequencies above $20 \mathrm{~Hz}$. This overestimation of high frequency response will cause greater vertical separation between blocks and thus will permit greater freedom for relative block rotation.

Because of the overestimation of high frequency response and because the artifical excitations envelope the response for a wide range of soil conditions for very strong ground motion of $0.5 \mathrm{~g}$ 's, the core responses predicted from this artificial excitation will be considerably greate $r$ then that obtained for any actual earthquake time history associated with a particular soil condition. This conservative overprediction of response was used because it was expected to cause greater block separation, and greater relative rotation between blocks and thus result in maximizing any possible differences in response for the three different control rod insertion depths. Since the purpose of this study was to determine whether differences in response could occur, this maximization of possible differences was considered to be desirable. 
TABLE 3.1

PROPERTIES OF IDEALIZED GUIDE TUBE ASSEMBLY

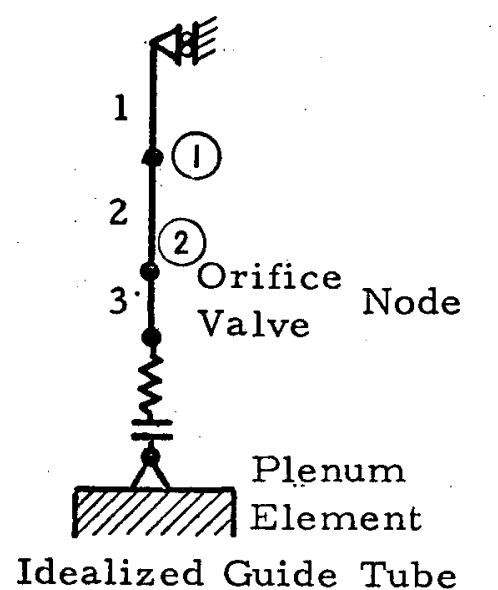

\begin{tabular}{|c|c|c|}
\hline \multirow{2}{*}{$\begin{array}{c}\text { Node } \\
\text { Number }\end{array}$} & \multicolumn{2}{|l|}{ Mass Properties } \\
\cline { 2 - 3 } & $\begin{array}{c}\text { Translational } \\
\text { DOF }\end{array}$ & $\begin{array}{c}\text { Vertical } \\
\text { DOF }\end{array}$ \\
\hline 1 & .1295 & 0.0 \\
2 & 1.03 & 1.03 \\
\hline
\end{tabular}

Beam Properties $(1-3)$

Cross Section Area $A=6.60 \mathrm{In}^{2}$

Moment of Inertia I $=14.80 \mathrm{In}^{4}$

Modulus of Elasticity $E=29 \times 10^{6}$ psi

Poissons Ratio

$v=.30$

Vertical Contact Spring

$k_{v}=74,000 \mathrm{lb} / \mathrm{in}$ 
TABLE 3.2

PROPERTIES OF IDEALIZED CONTROL COLUMN BLOCKS

\begin{tabular}{|c|c|c|c|c|c|c|}
\hline $\begin{array}{l}\text { Block } \\
\text { Number }\end{array}$ & Element Type & $\begin{array}{l}\text { Height } \\
\text { (In) }\end{array}$ & $\begin{array}{c}\text { Width } \\
\text { (In) } \\
\end{array}$ & $\begin{array}{c}\text { Weight } \\
\text { (Lbs) }\end{array}$ & $\begin{array}{c}\text { Mass } \\
\left(1 \mathrm{~b}-\sec ^{2} / \text { in }\right) \\
\end{array}$ & $\begin{array}{l}\text { Mass Moment } \\
\text { of Ine rtia } \\
\left(1 \mathrm{~b}-\mathrm{sec}^{2} / \mathrm{in}\right)\end{array}$ \\
\hline 1 & Bottom Permanent Reflector & 23.415 & 14.17 & 196.0 & .5078 & 30.28 \\
\hline 2 & Bottom Replaceable Reflector & 15.61 & 14.17 & 128.2 & .3321 & 11.37 \\
\hline $3-10$ & Control Fuel Element & 31.22 & 14.17 & 224.5 & .5816 & 55.35 \\
\hline 11 & Top Replaceable Reflector & 31.22 & 14.17 & 216.3 & .5604 & 55.33 \\
\hline 12 & Plenum Element & 23.415 & 14.17 & 240.0 & .6218 & 37.08 \\
\hline
\end{tabular}


TAB LE 3. 3

MASS PROPER TIES OF IDEALIZED CONTROL RODS

\begin{tabular}{|c|c|c|c|}
\hline \multirow[b]{2}{*}{$\begin{array}{l}\text { Control Rod } \\
\text { Node }\end{array}$} & \multicolumn{3}{|c|}{ Mass (lb/in/sec ${ }^{2}$} \\
\hline & $\begin{array}{c}\text { Rod } \\
\text { Withdrawn }\end{array}$ & $\begin{array}{l}\text { Rod } \\
1 / 2 \text { Inserted }\end{array}$ & $\begin{array}{l}\text { Rod } \\
\text { Fully Inserted }\end{array}$ \\
\hline 1 & .1641 & .1641 & .02669 \\
\hline 2 & .0866 & .1067 & .05337 \\
\hline 3 & - & .0400 & .05337 \\
\hline 4 & - & .0467 & .05337 \\
\hline $5-11$ & - & .05337 & .05337 \\
\hline 12 & - & .02669 & .05337 \\
\hline $13-17$ & - & - & .05337 \\
\hline 18 & - & - & .02669 \\
\hline
\end{tabular}


TAB LE 3.4

EQUIVALENT PENDULUM

STIFFNESS PROPERTIES OF IDEALIZED CONTROL RODS

\begin{tabular}{|c|c|c|c|}
\hline \multirow[b]{2}{*}{$\begin{array}{l}\text { Control Rod } \\
\text { Element }\end{array}$} & \multicolumn{3}{|c|}{ Shear Stiffness (lb/in) } \\
\hline & Rod Withdrawn & $\begin{array}{c}\text { Rod } \\
1 / 2 \text { Inserted }\end{array}$ & $\begin{array}{c}\text { Rod } \\
\text { Fully Inserted }\end{array}$ \\
\hline 1 & 2.14 & 6.45 & 2.59 \\
\hline 2 & .66 & 4.52 & 21.78 \\
\hline 3 & - & 16.06 & 20.46 \\
\hline 4 & - & 14.74 & 19.14 \\
\hline 5 & - & 9.90 & 17.82 \\
\hline 6 & - & 8.58 & 16.50 \\
\hline 7 & - & 7.26 & 15.18 \\
\hline 8 & - & 5.94 & 13.86 \\
\hline 9 & - & 4.62 & 12.54 \\
\hline 10 & - & 3.30 & 11.22 \\
\hline 11 & - & 1.98 & 9.90 \\
\hline 12 & - & 0.66 & 8.58 \\
\hline 13 & - & - & 7.26 \\
\hline 14 & - & - & 5.94 \\
\hline 15 & - & - & 4.62 \\
\hline 16 & - & - & 3.30 \\
\hline 17 & - & - & 1.98 \\
\hline 18 & - & - & .66 \\
\hline
\end{tabular}




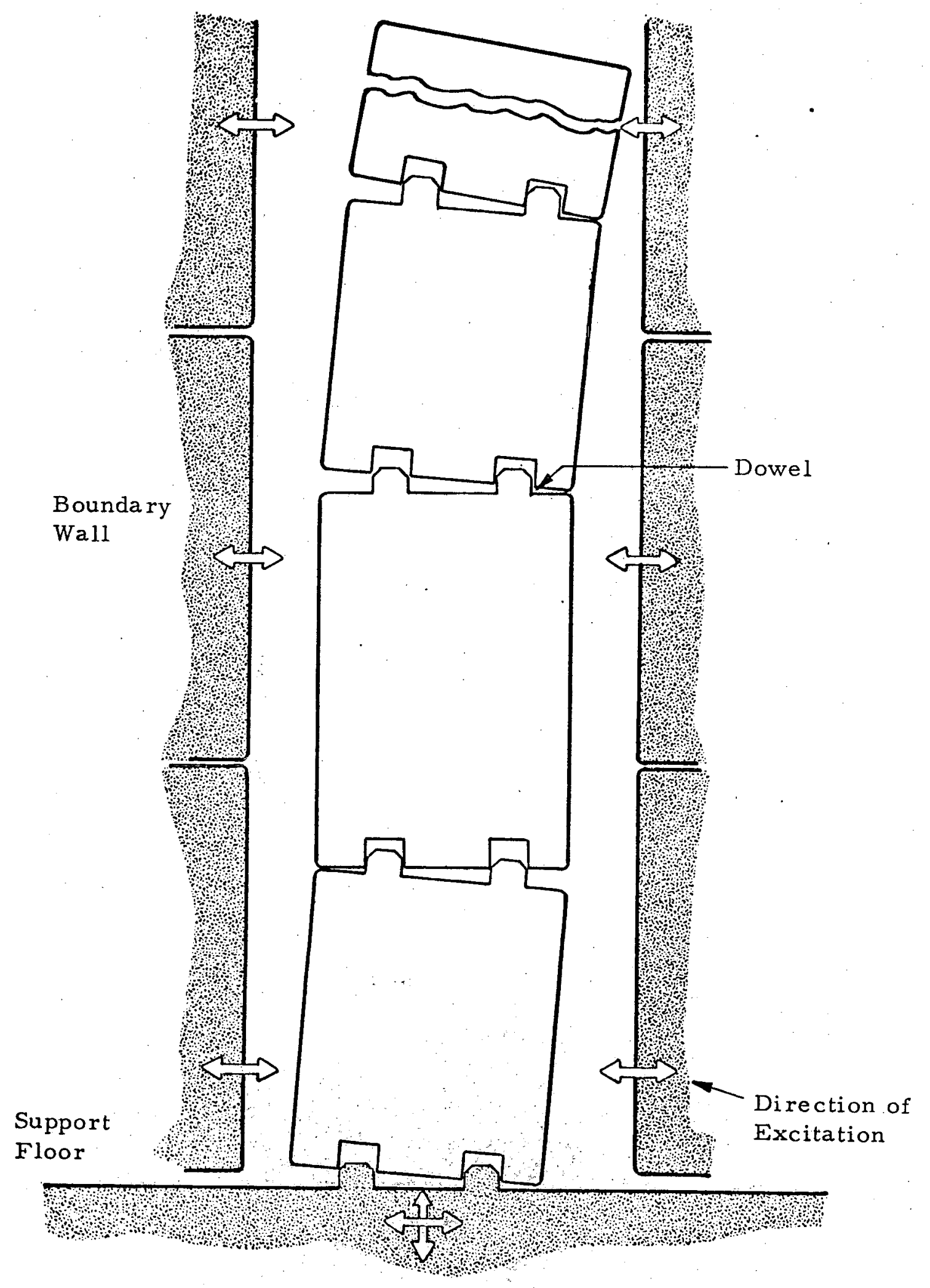

FIGURE 3.1 THE STACKED COLUMN WITH DOWELED ELEMENTS UNDER BOUNDARY EXCITATION 


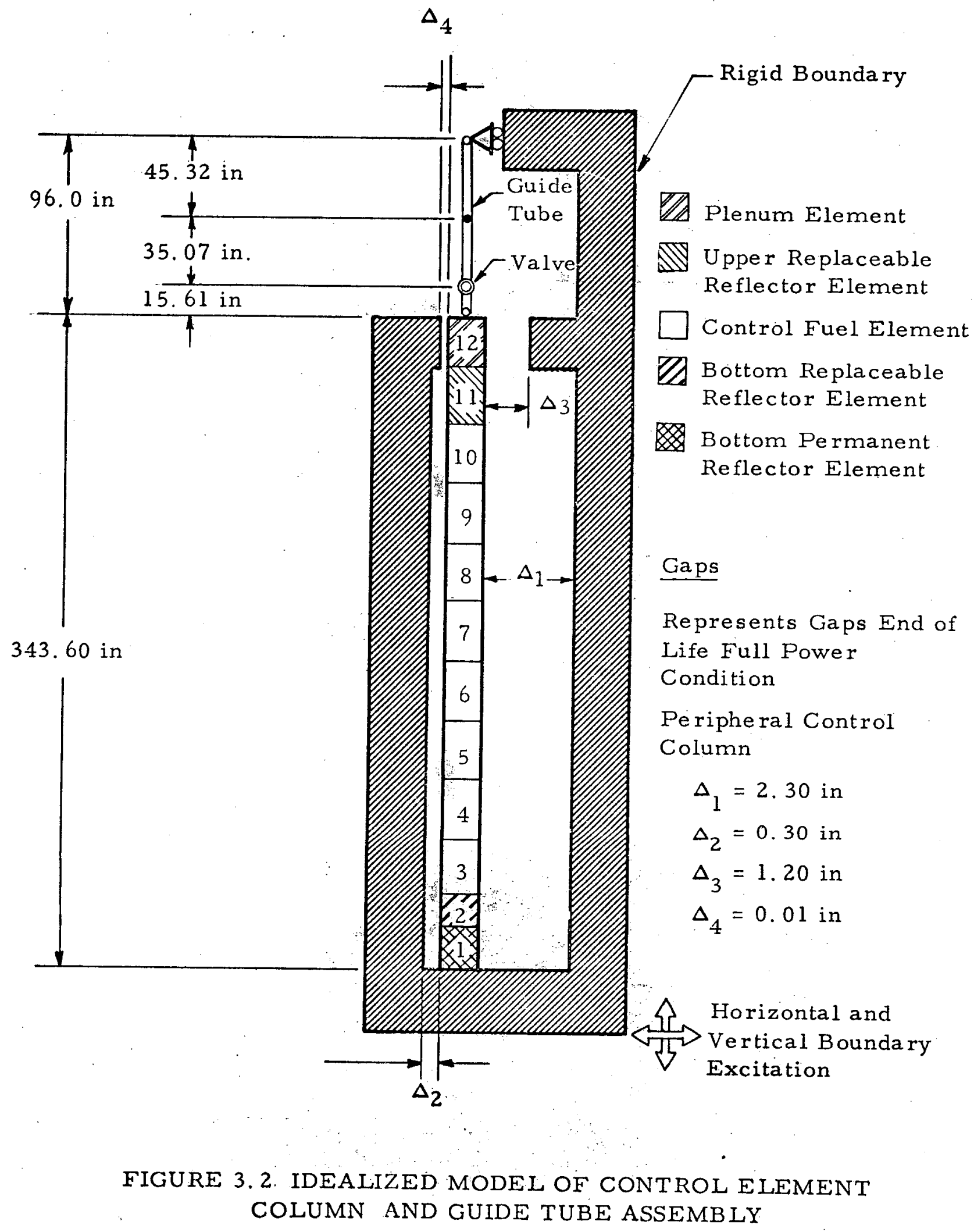


Spring Dashpot Gap Elements Representing Contact Surface Deformations

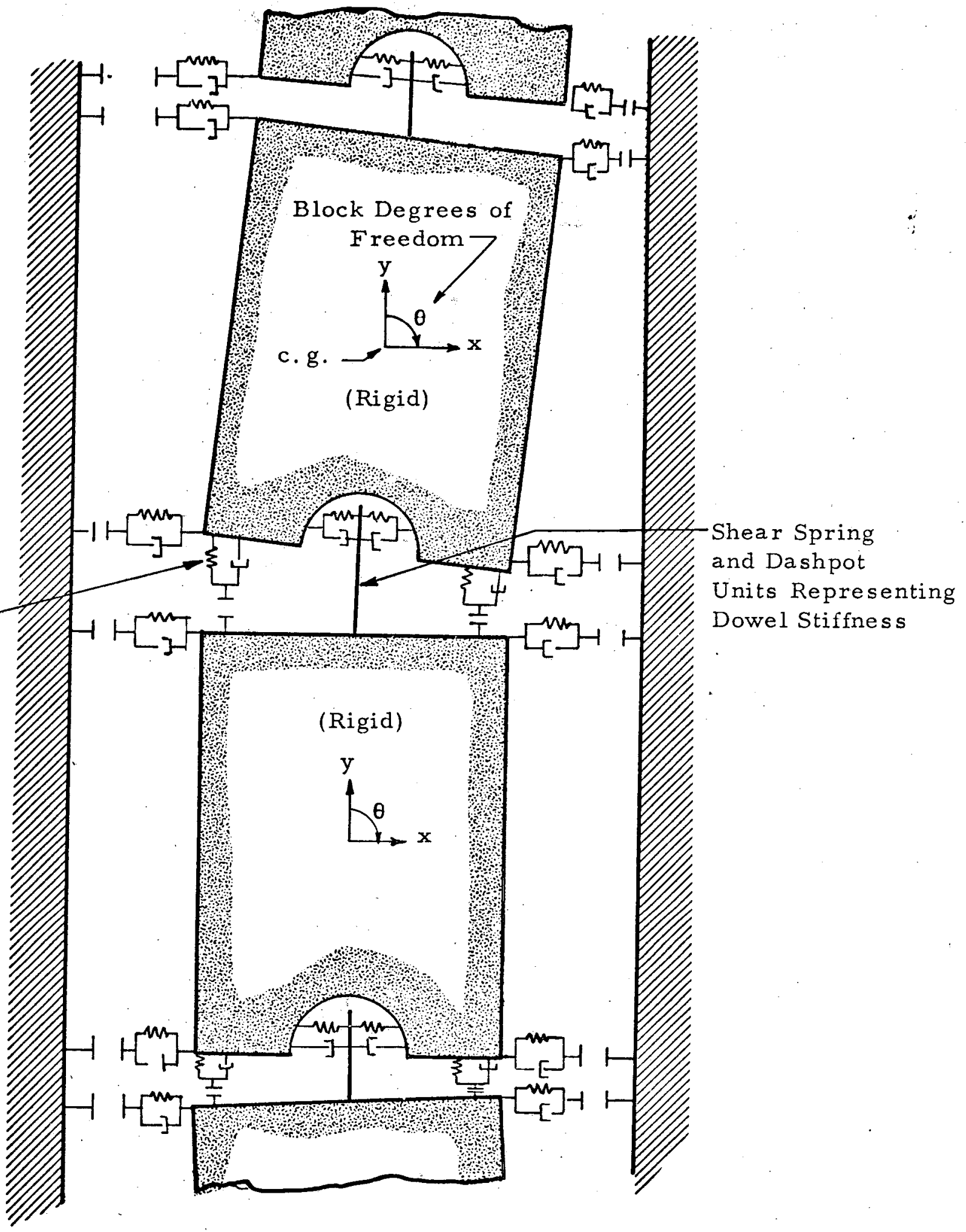

FIGURE. 3. 3 DISCRETE MODEL OF COLUMN BLOCK INTERFACE 


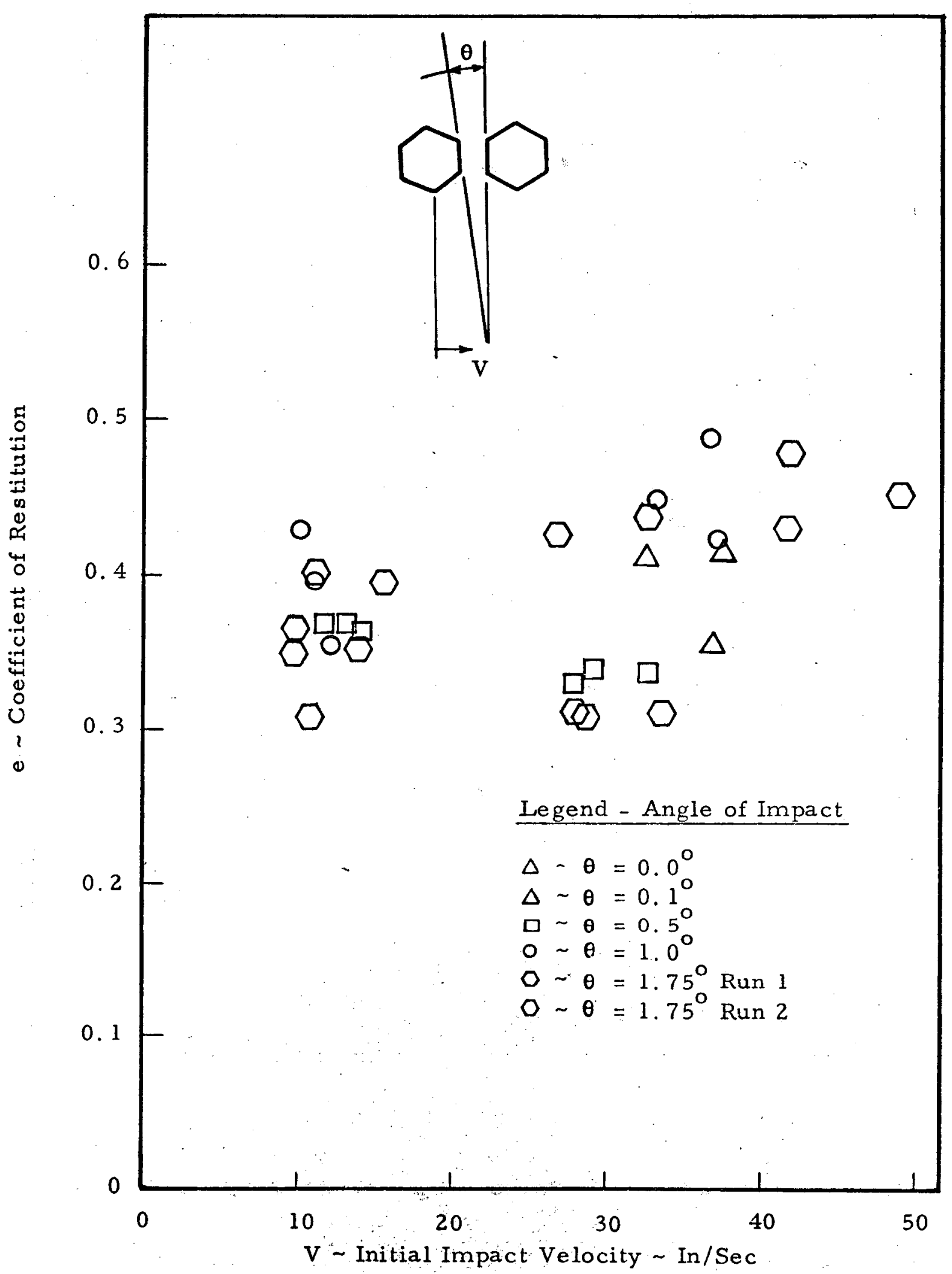

FIGURE 3. 4 COEFEICIENT OF RESTITUTION VERSUS IMPACT VELOCITY FOR FULL SIZE LARGE HTGR FUEL ELEMENTS 


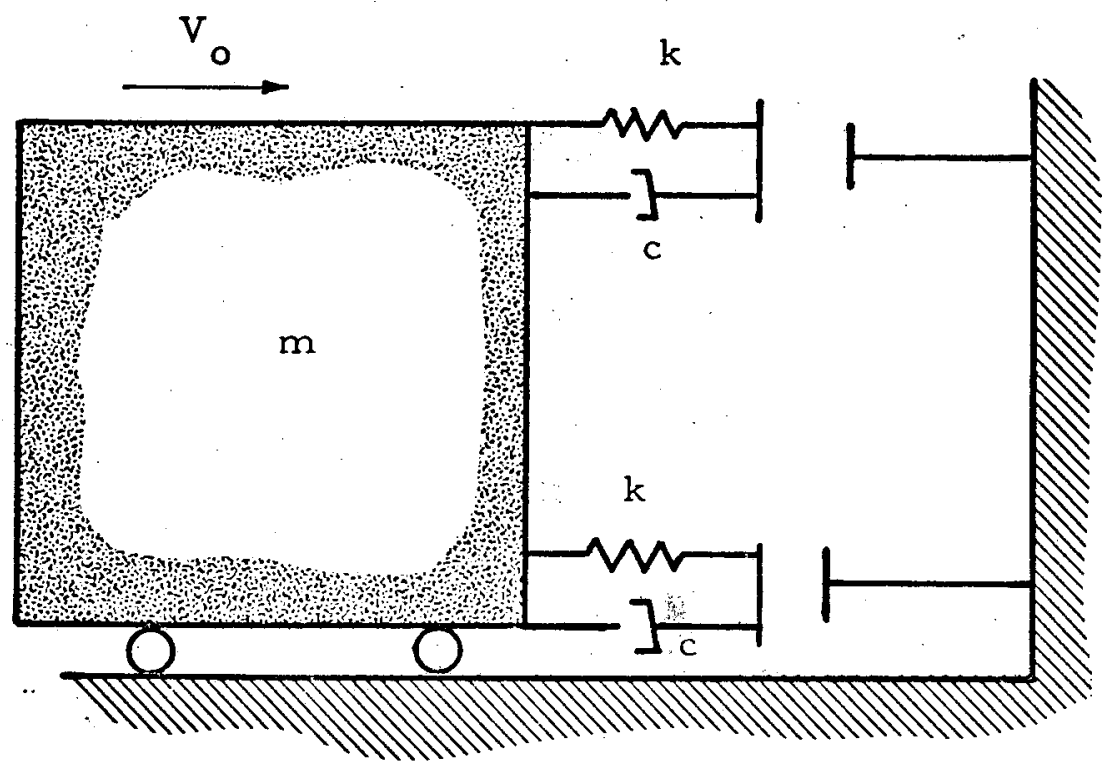

Parameter Definitions

Mass $\quad M=m$

Stiffness $\quad K=2 k$

Damping $\quad \mathrm{C}=2 \mathrm{c}$

Undamped Natural

Frequency $\quad \omega=\sqrt{\mathrm{k} / \mathrm{m}}$

Critical Damping $\mathrm{C}_{\mathrm{C}}=2 \mathrm{M \omega}$

Fraction of Critical Damping $\lambda=\frac{C}{C_{c}}=\frac{2 c}{2 M \omega}=\frac{C}{M \omega}$

FIGURE 3. 5 SIMPLE ONE-DIMENSIONAL SPRING DASHPOT COLLISION MODEL, 


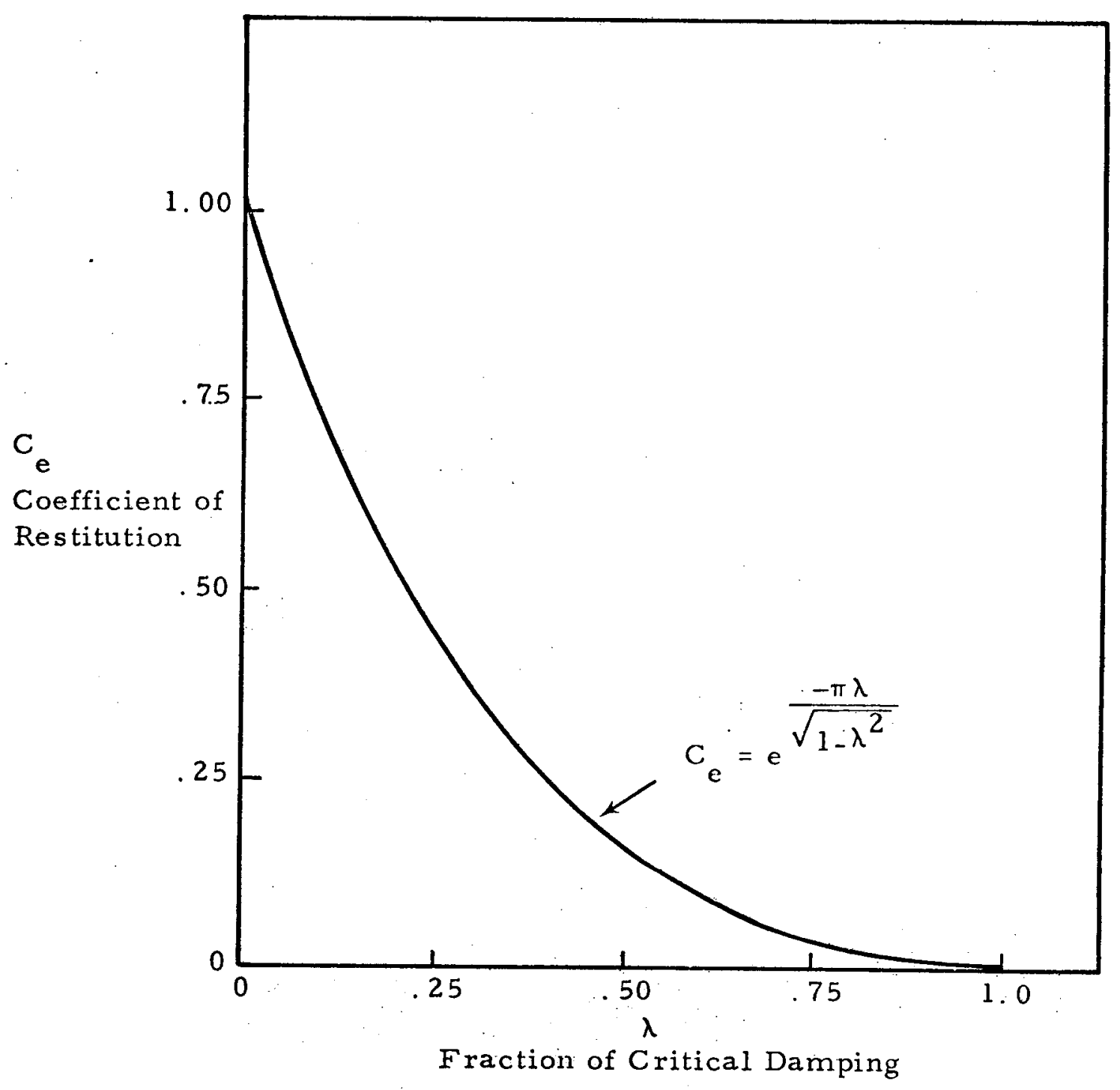

FIGURE 3.6 COEFFICIENT OF RESTITUTION VERSUS FRACTION OF CRITICAL DAMPING 


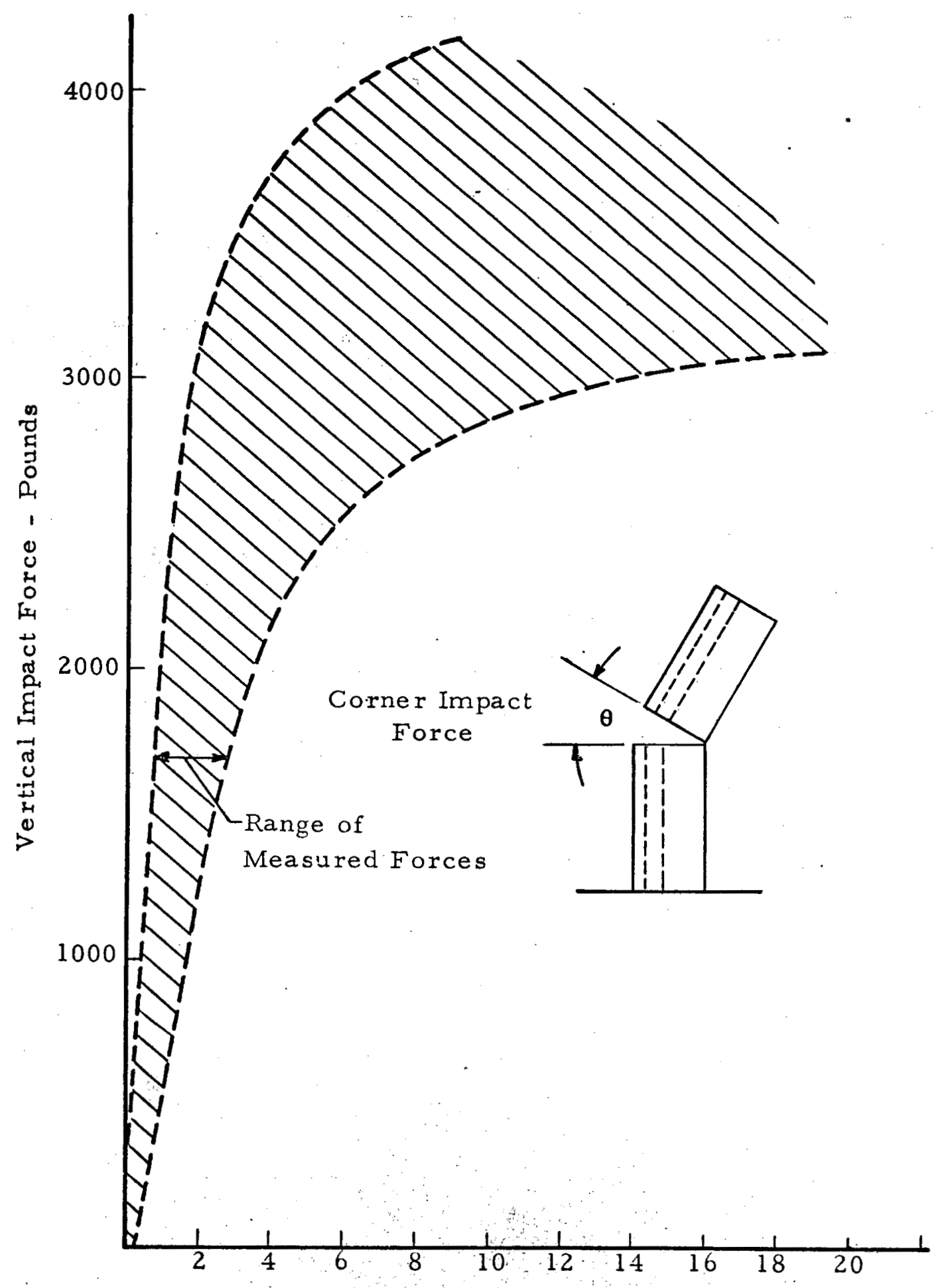

(日) Rocking Angle - Degrees

FIGURE 3.7 VERTICAL CORNER IMPACT FORCE

VERSUS INITIAL ROCKING ANGLE - FULL SIZE FUEL ELEMENT 


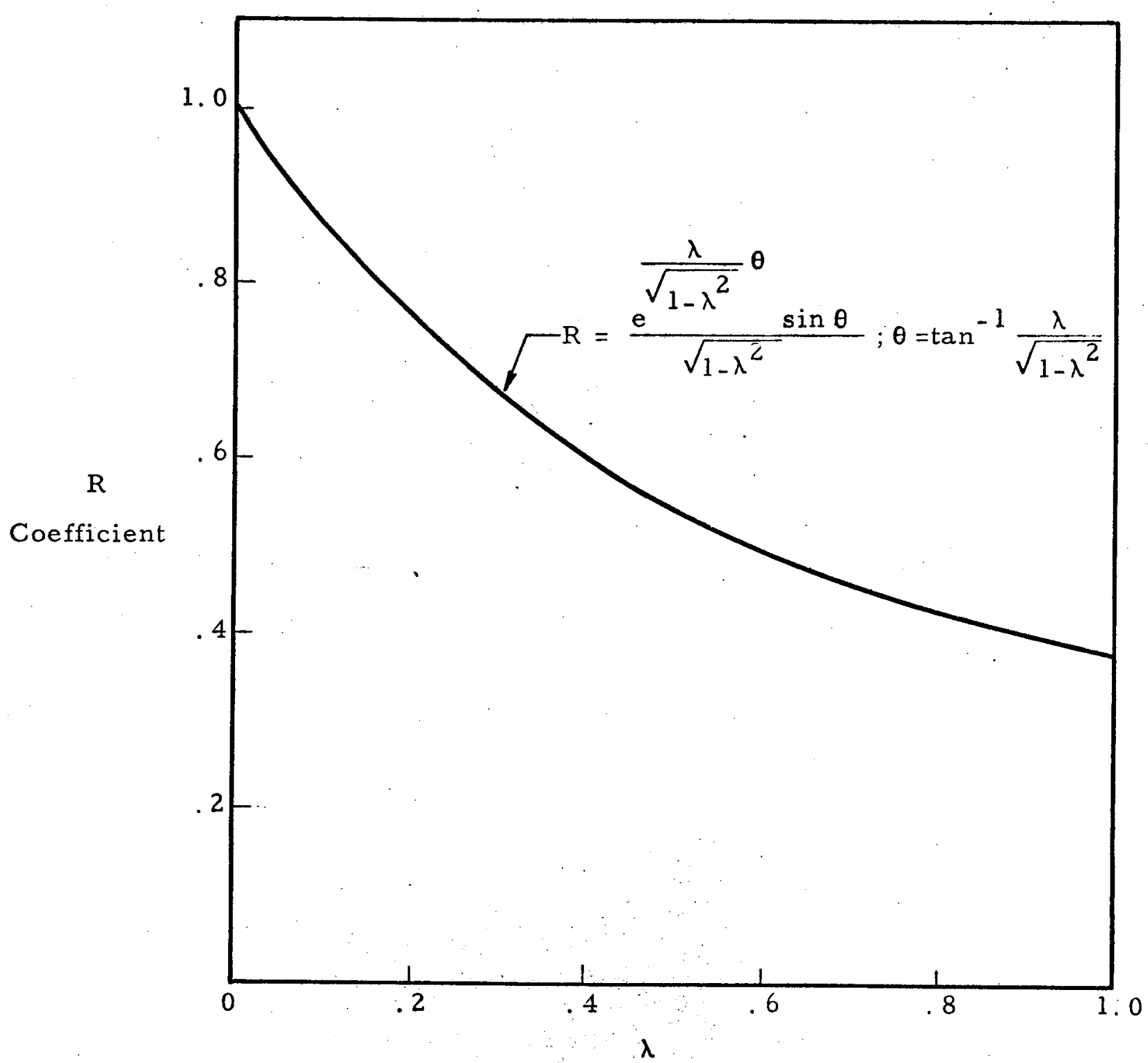

Fraction of Critical Damping

FIGURE 3.8 REDUCTION IN IMPACT FORCE VERSUS FRACTION OF CRITICAL DAMPING 


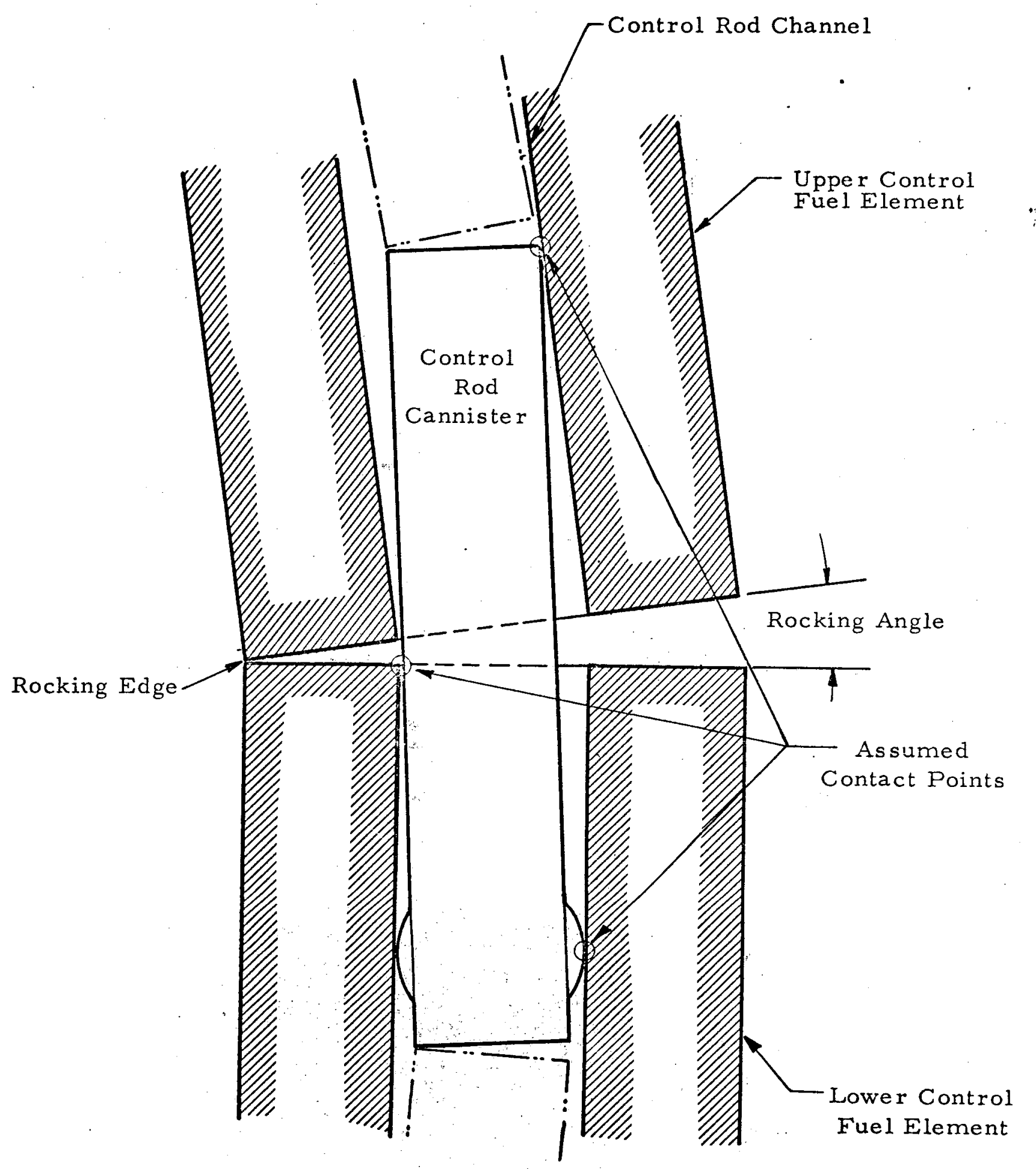

FIGURE 3.9 SINGLE CANNISTER BINDING 


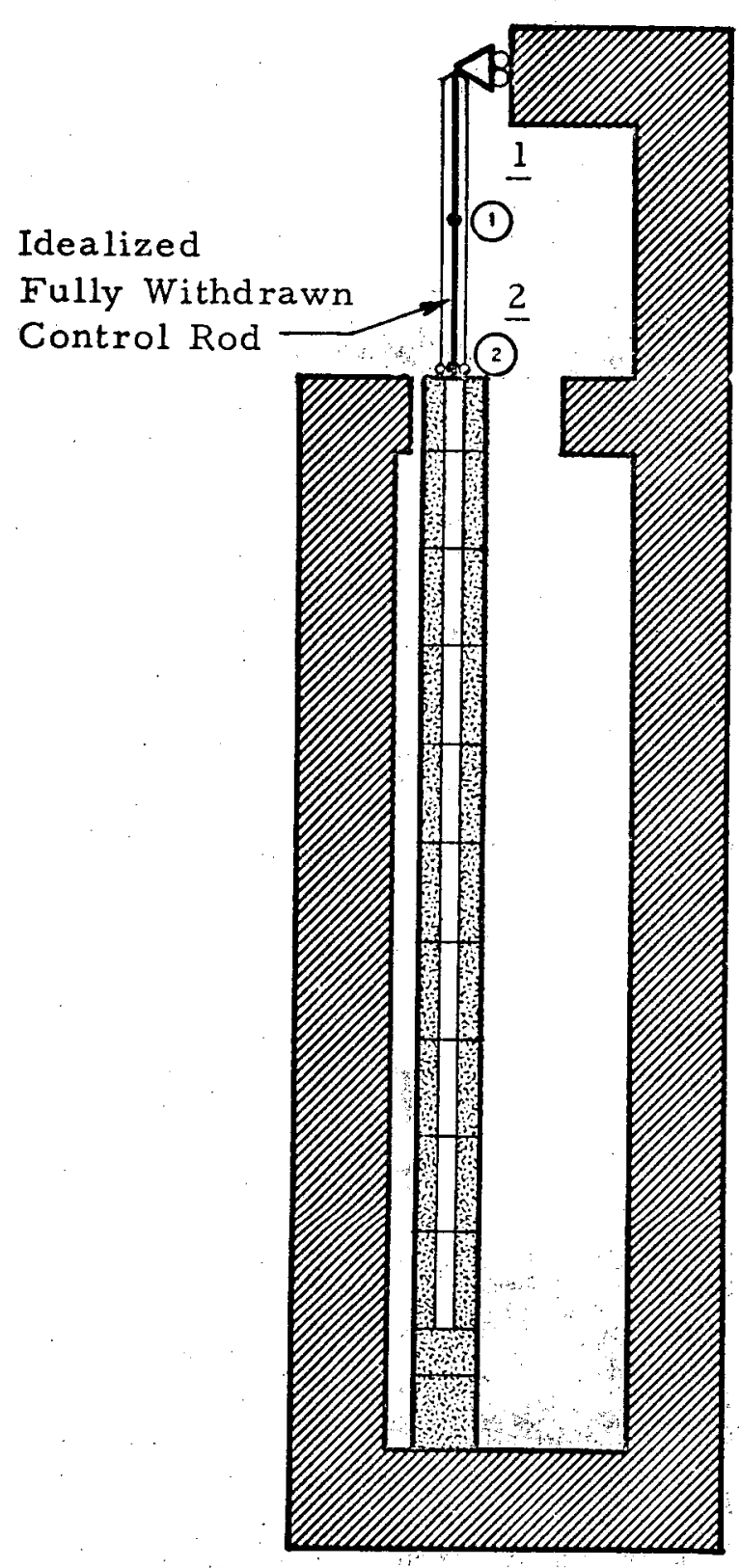

Control Rod Model

O CR Node Number

- CR Element Number

FIGURE 3. 10 CONTROL ROD FULLY WITHDRAWN MODEL 


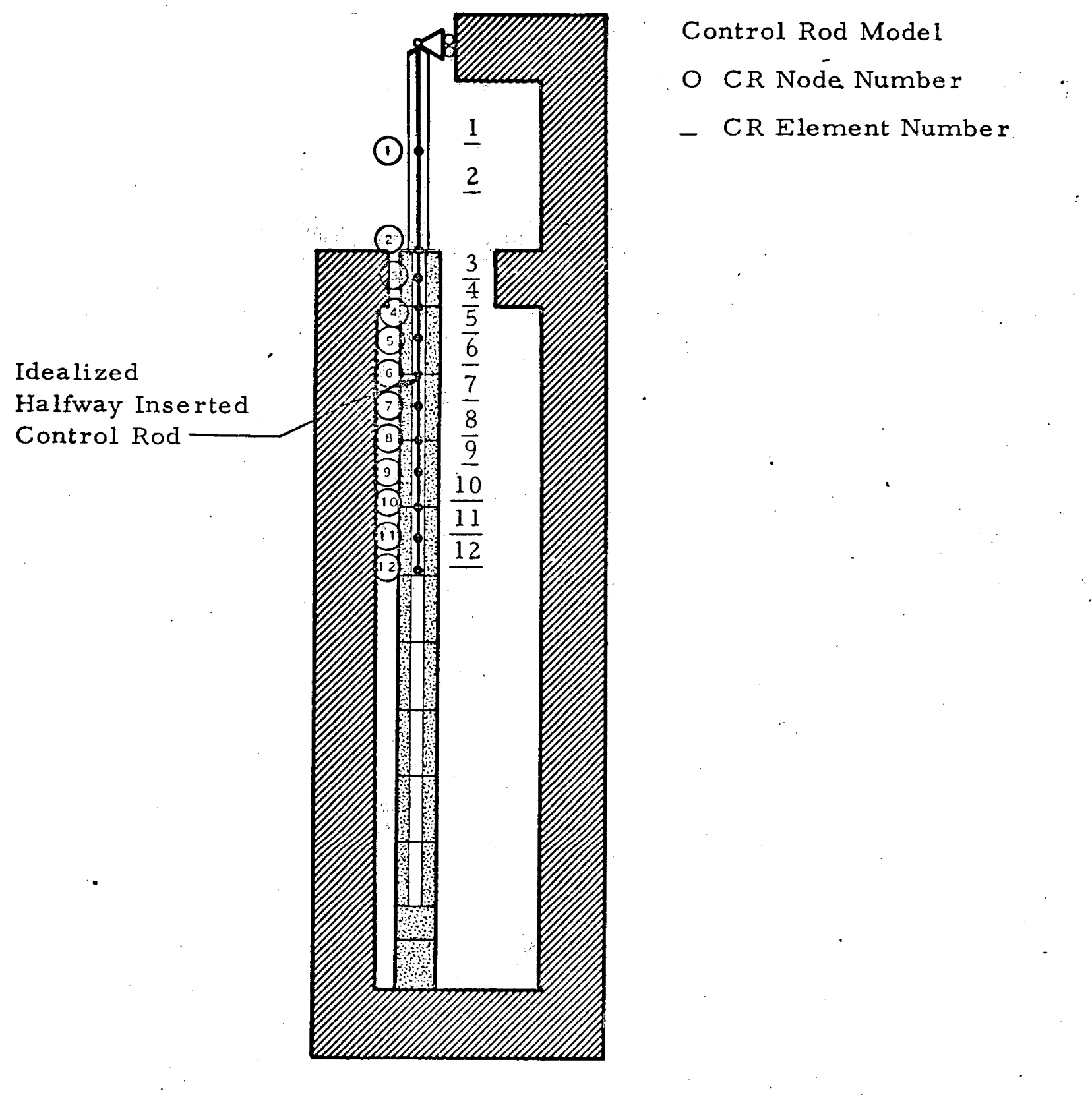

FIGURE 3.11 CONTROL ROD HALFWAY INSERTED MODEL 


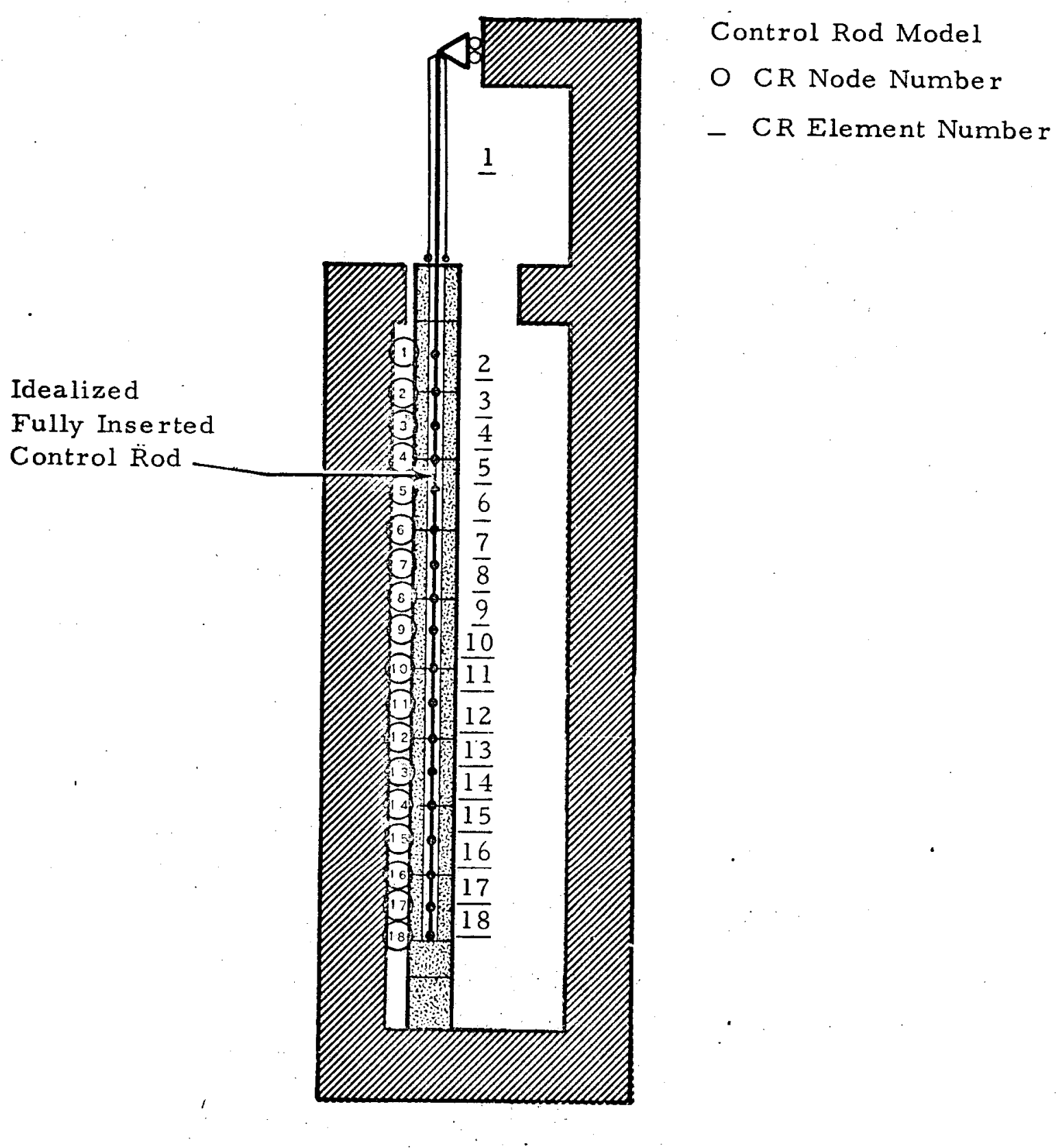

FIGURE 3.12 CONTROL ROD FULLY INSERTED MODE'L 
- Mass of Control Rod Concentrated at Nodes - Lateral Degree

of Freedom Only

Shear Spring Providing

Equivalent Stiffness of Pendulum System】

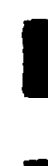

Mass of Cannister Concentrated at Node Control Fuel Element

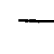

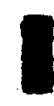

-
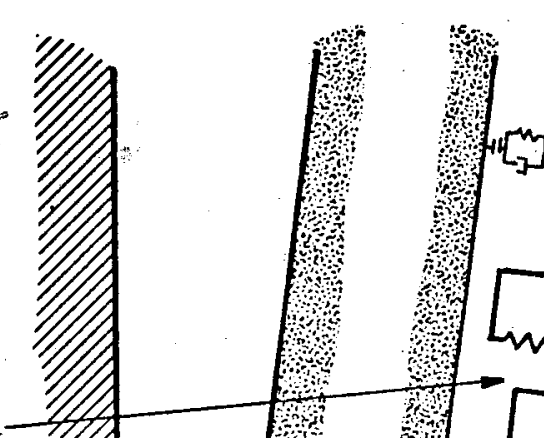

1
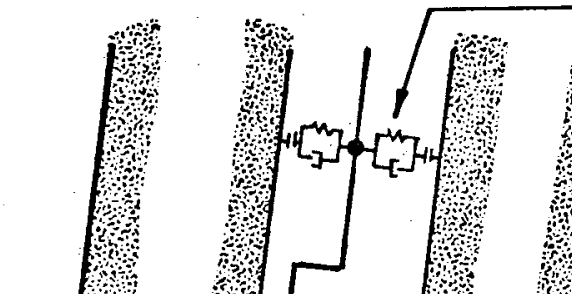
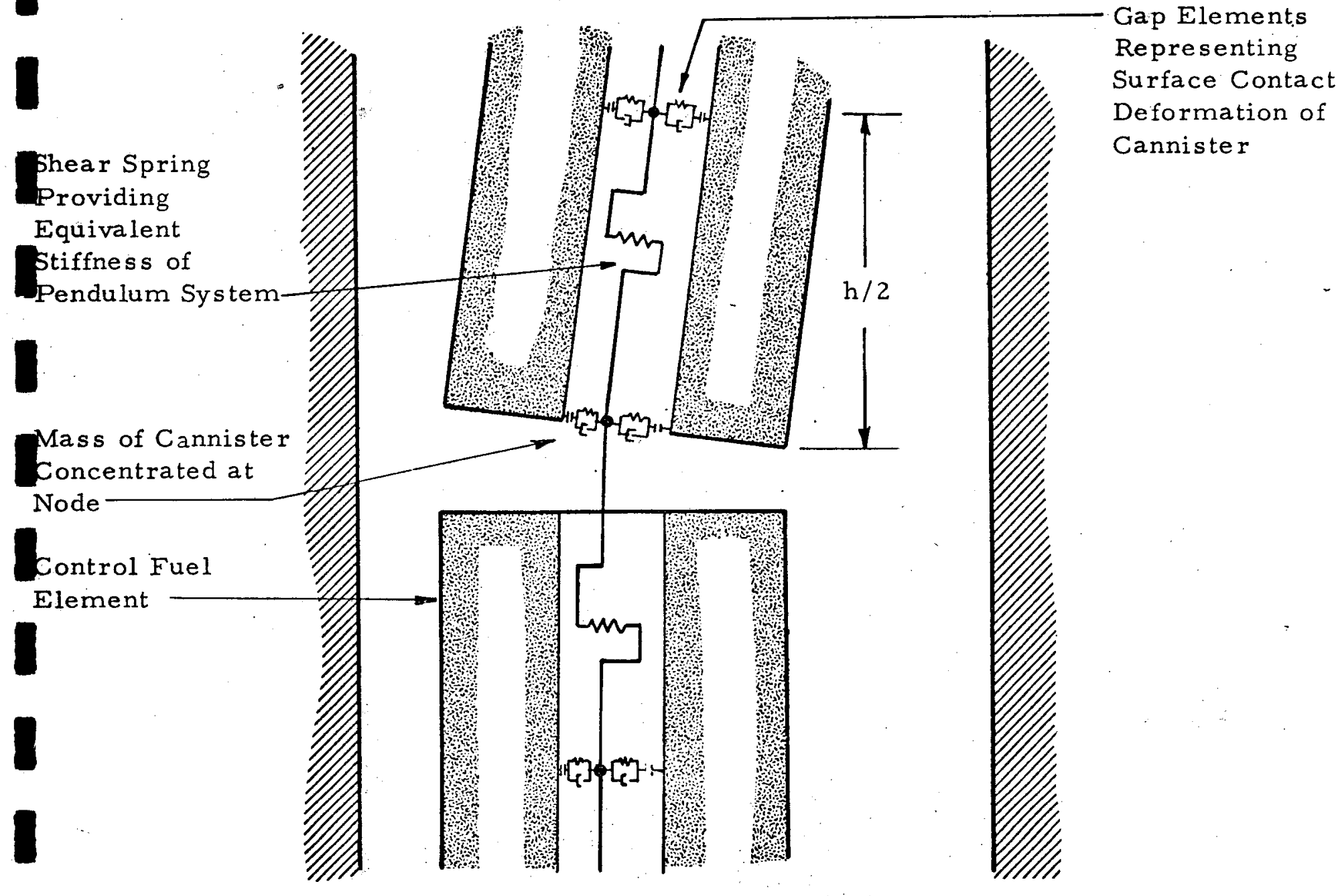

Gap Elements Representing Deformation of Cannister 


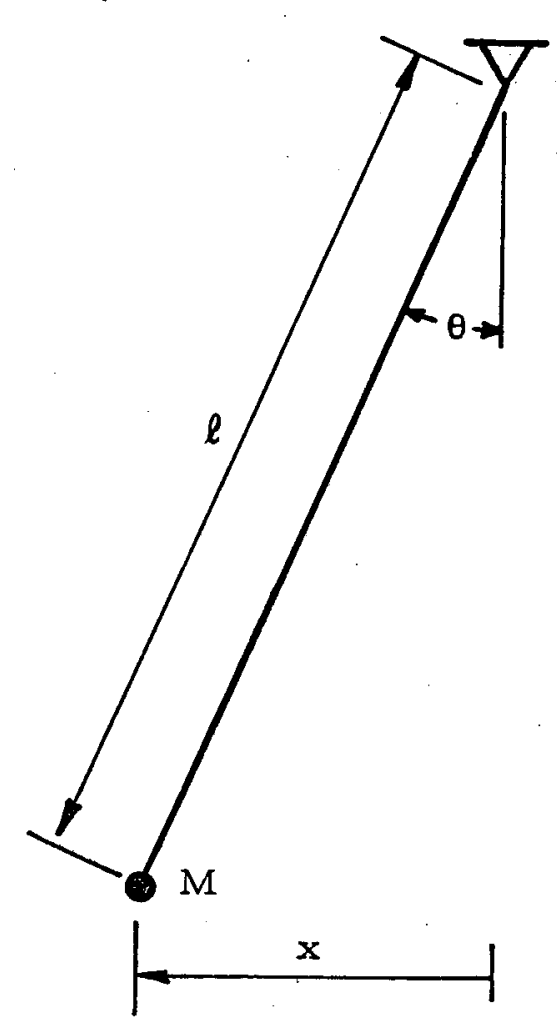

Single Mass Pendulum

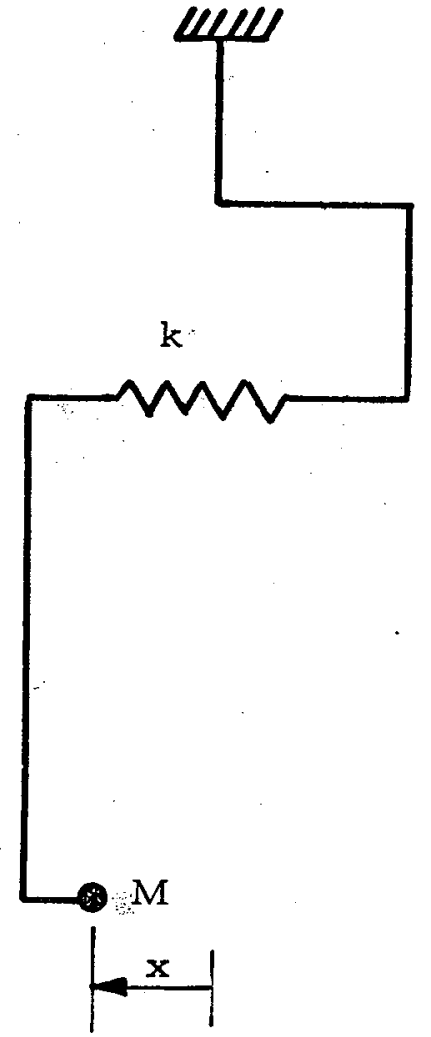

Equivalent Mass Spring System 


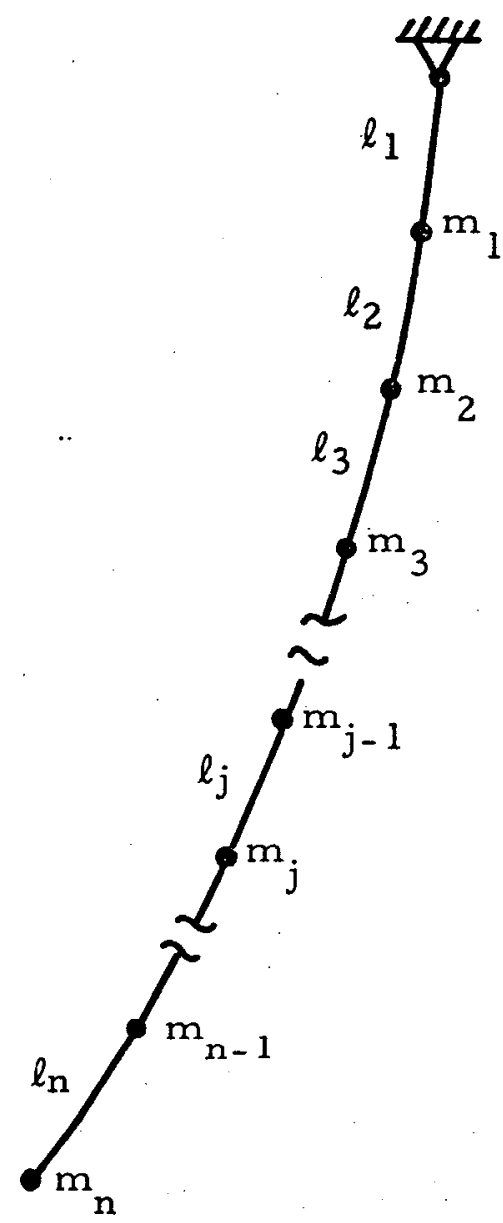

n - Mass Pendulum

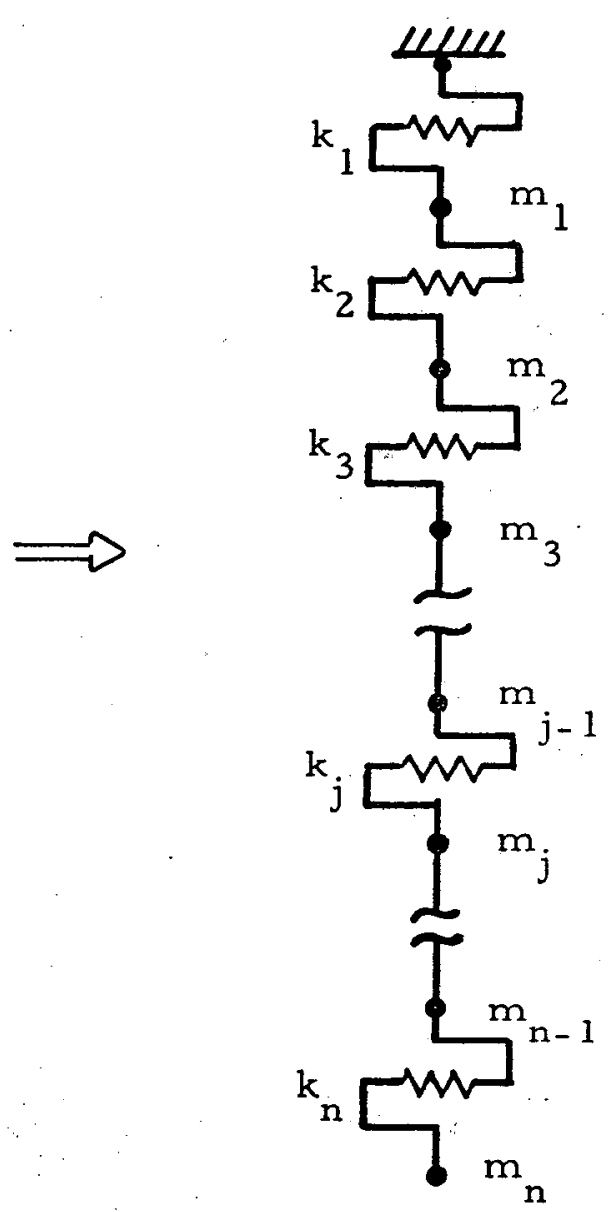

Equivalent Mass - Spring System 


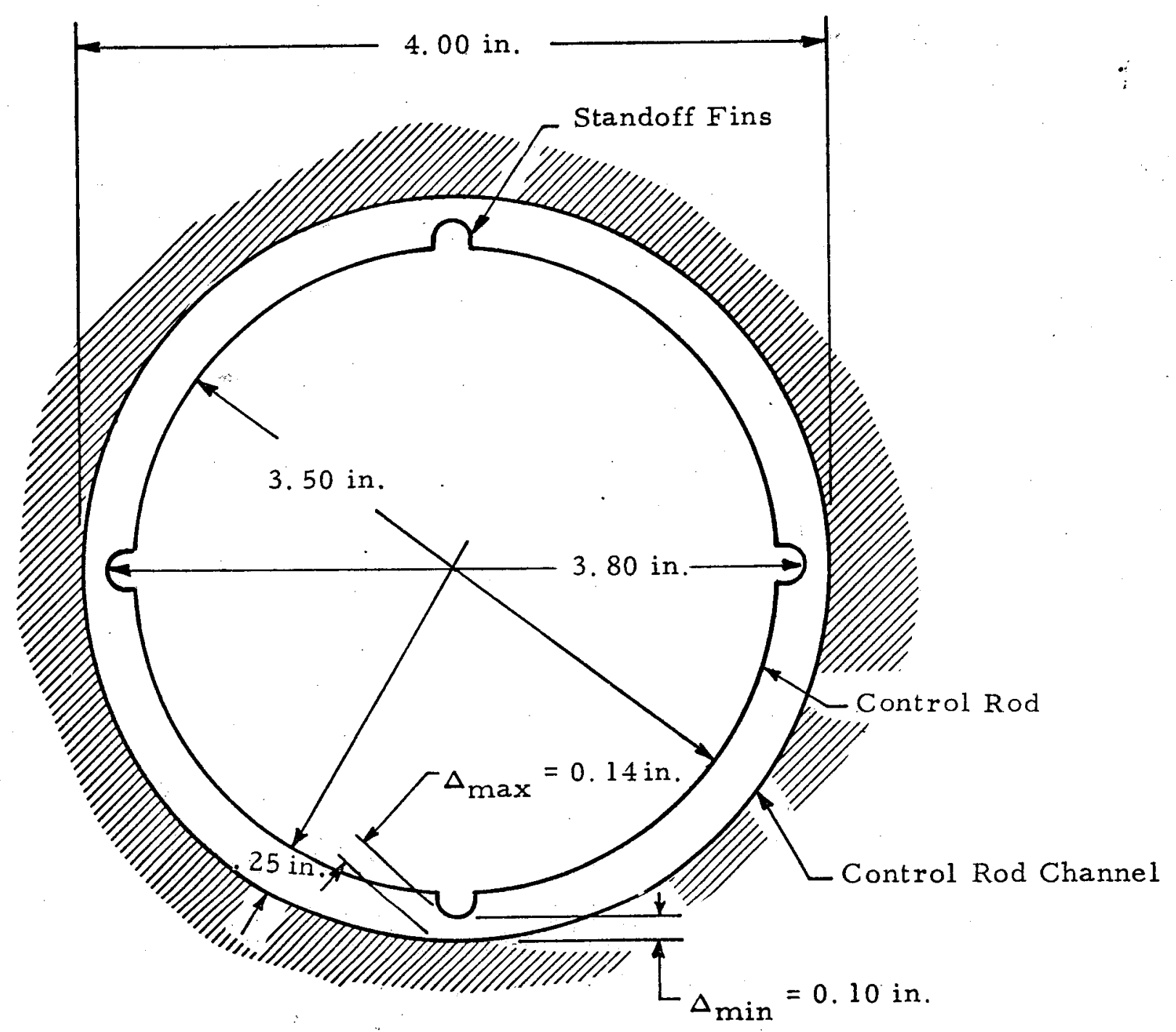

FIGURE 3.16 PLAN VIEW OF CONTROL ROD IN CHANNEL ILLUSTRATING INSTALLED GAPS 


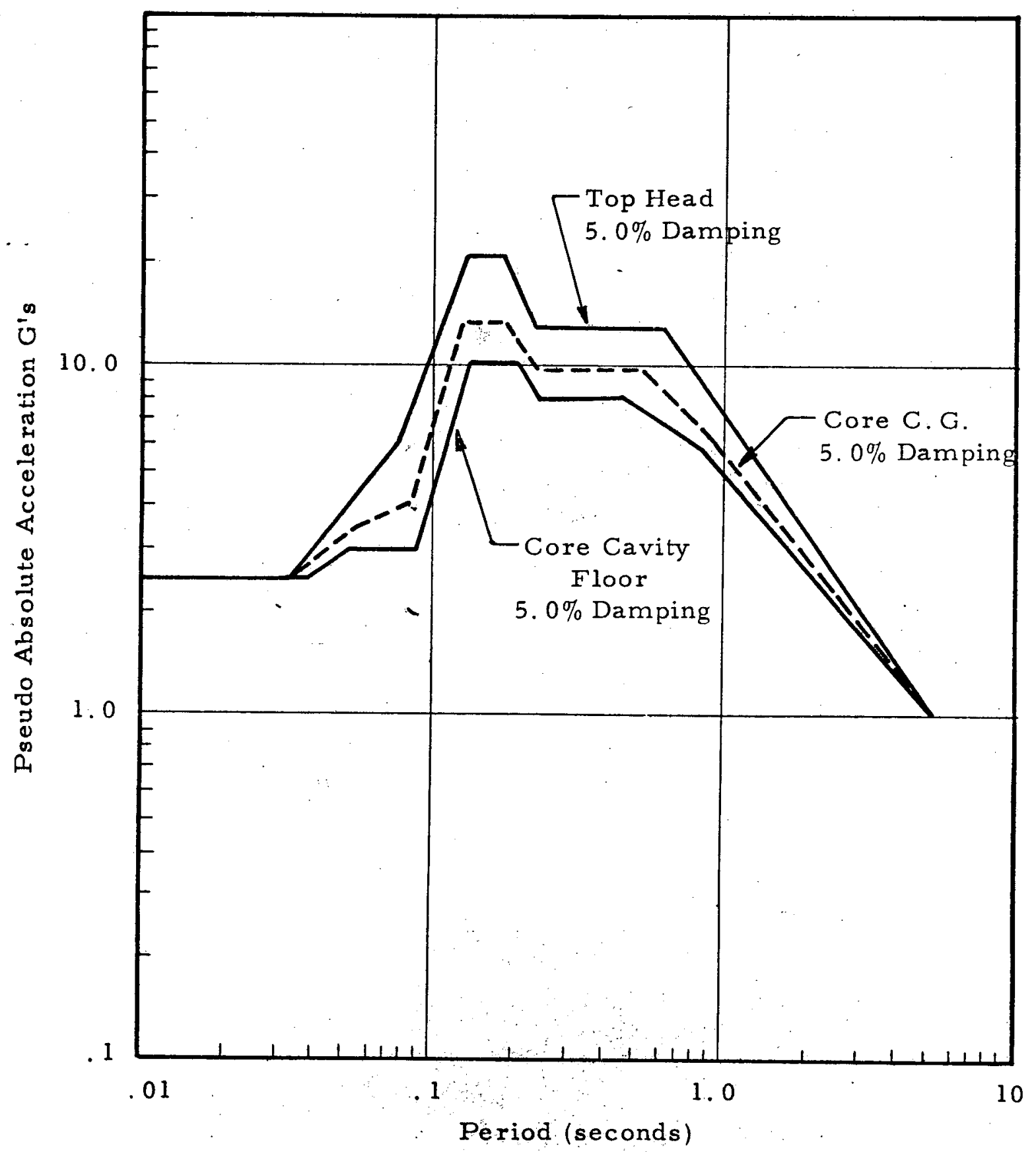

FIGURE 3.17 GA DESIGN RES PONSE SPECTRA HORIZONTAL RESPONSE AT SELECTED POINTS IN PCRV FOR $1.0 \mathrm{~g}$ SAFE SHUTDOWN EARTHQUAKE 


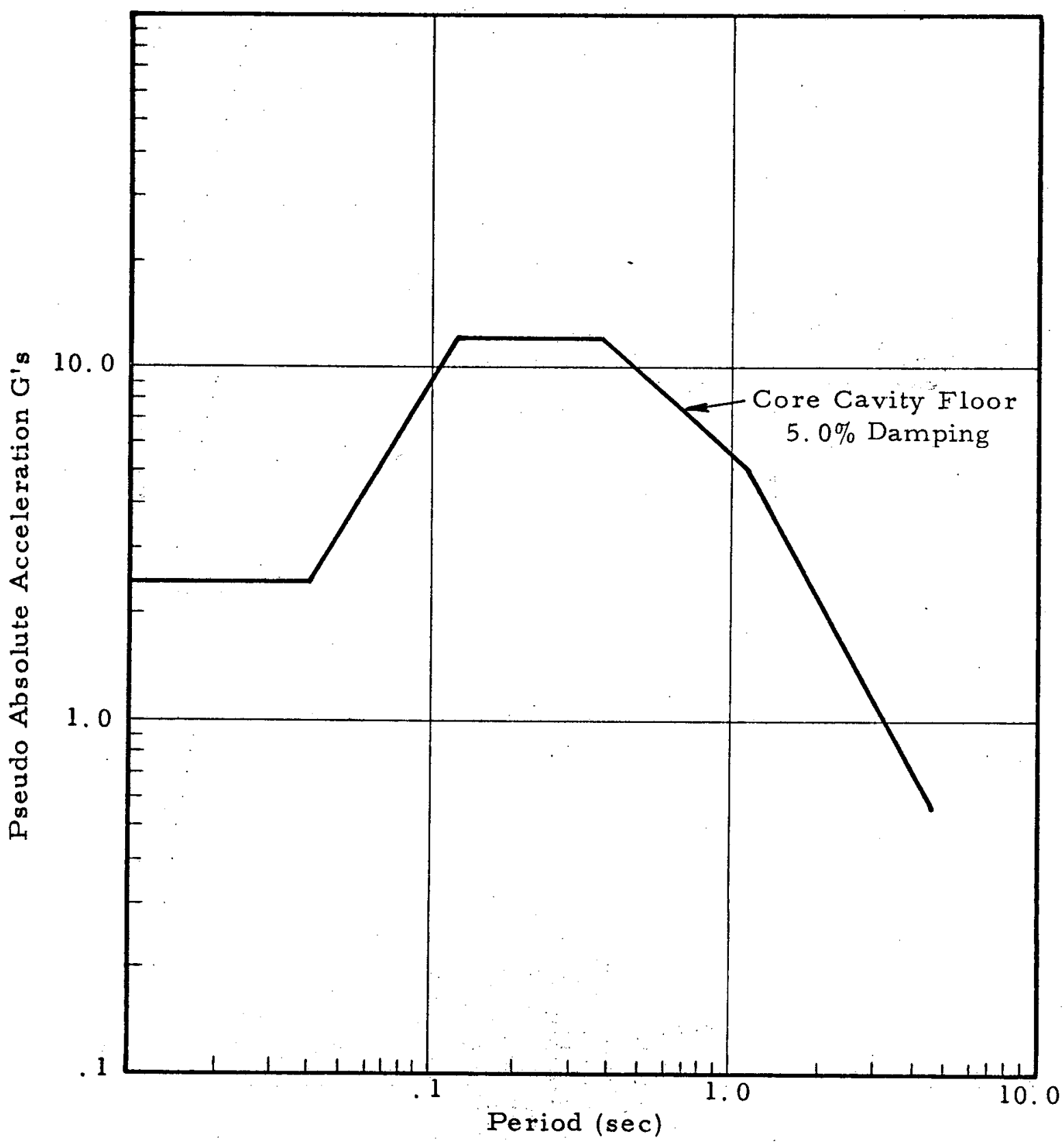

FIGURE 3.18 GA DESIGN RESPONSE SPECTRA VERTICAL RESPONSE OF PCRV CORE CAVITY FLOOR FOR 1.0g SAFE SHUTDOWN EARTHQUAKE 


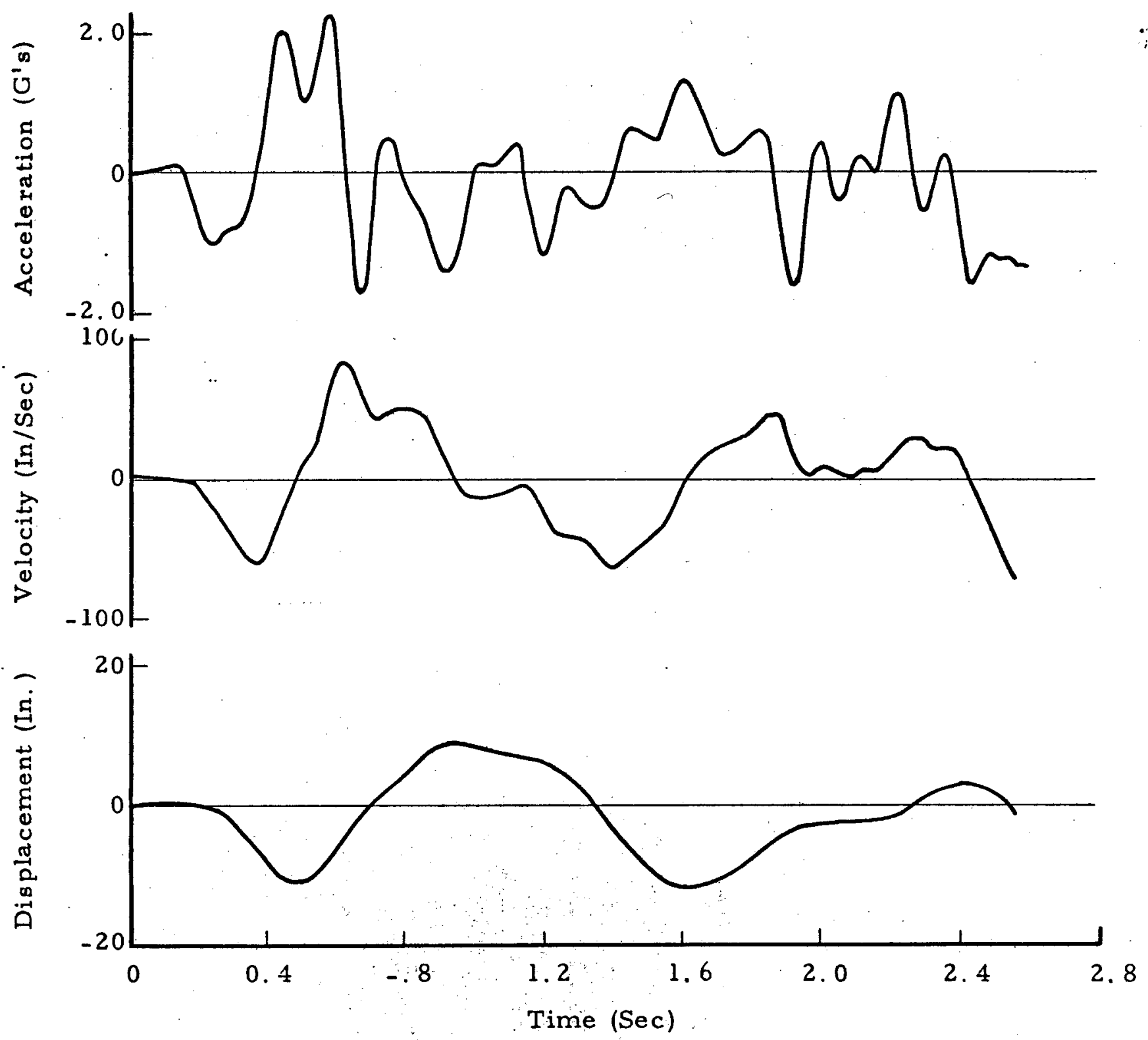

FIGURE 3.19 ARTIFICIAL HORIZONTAL RESPONSE OF PCRV AT CORE SUPPORT ELEVATION, $0.5 \mathrm{~g} \mathrm{SSE}$ 


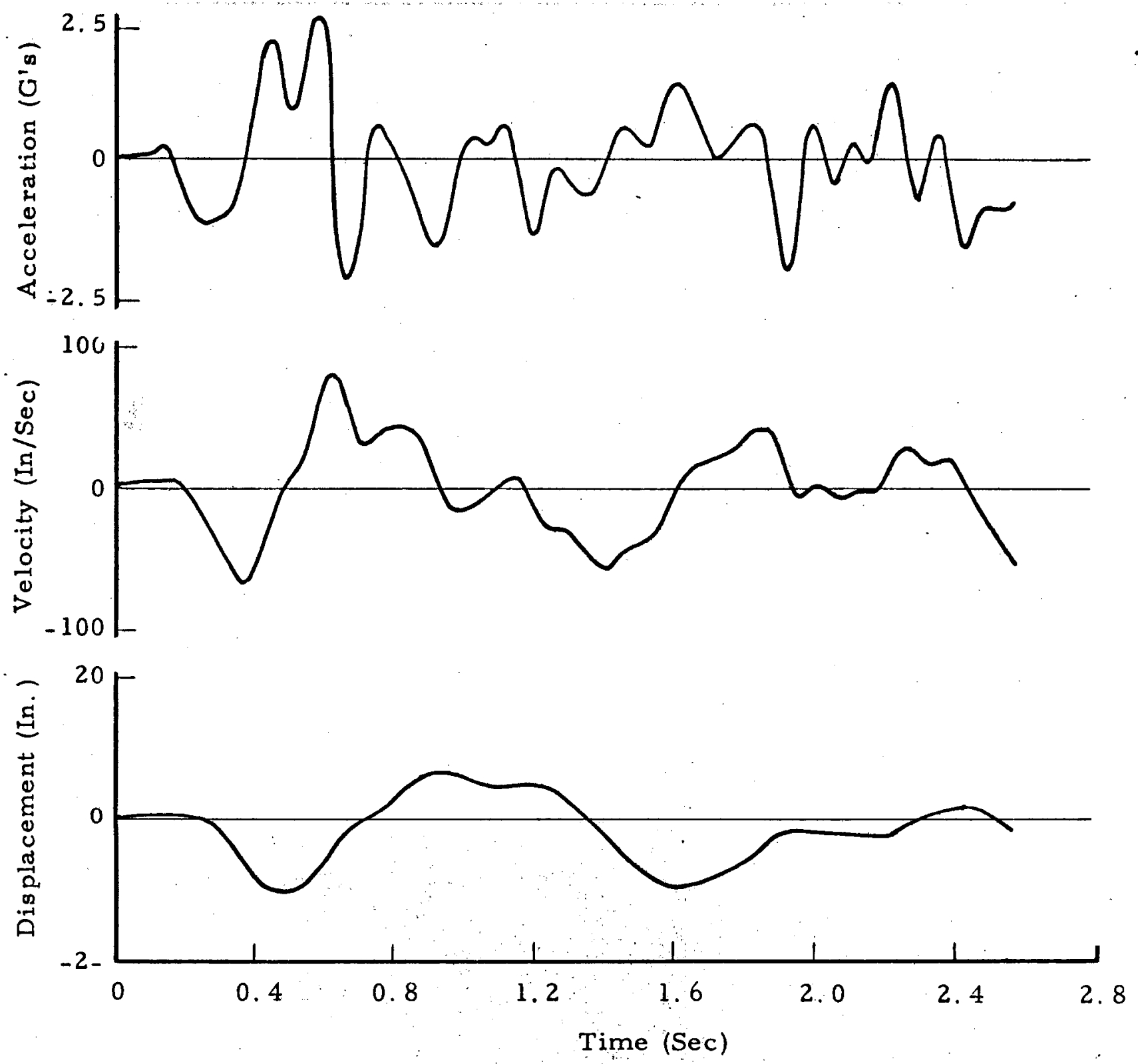

FIGURE 3.20 ARTIFICIAL VERTICAL RESPONSE OF PCRV AT CORE SUPPORT ELEVATION, $0.5 \mathrm{~g}$ SSE 


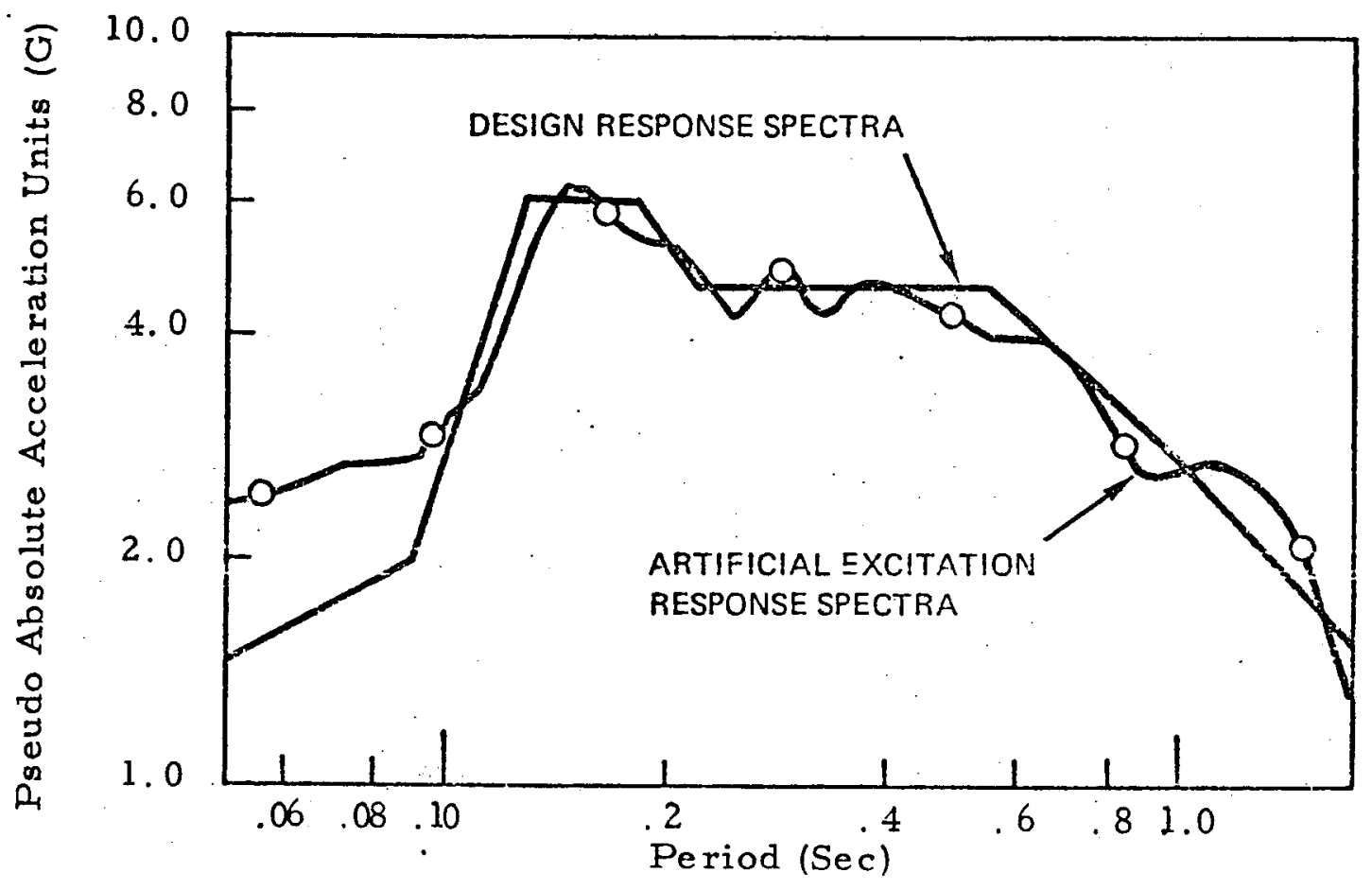

FIGURE 3.21 COMPARISON OF RESPONSE SPECTRA FROM ARTIFICIAL EXCITATION WITH DESIGN RESPONSE SPECTRA;

HORIZONTAL COMPONENT, $0.5 \mathrm{~g}$ SSE, 5\% CRITICAL DAMPING 


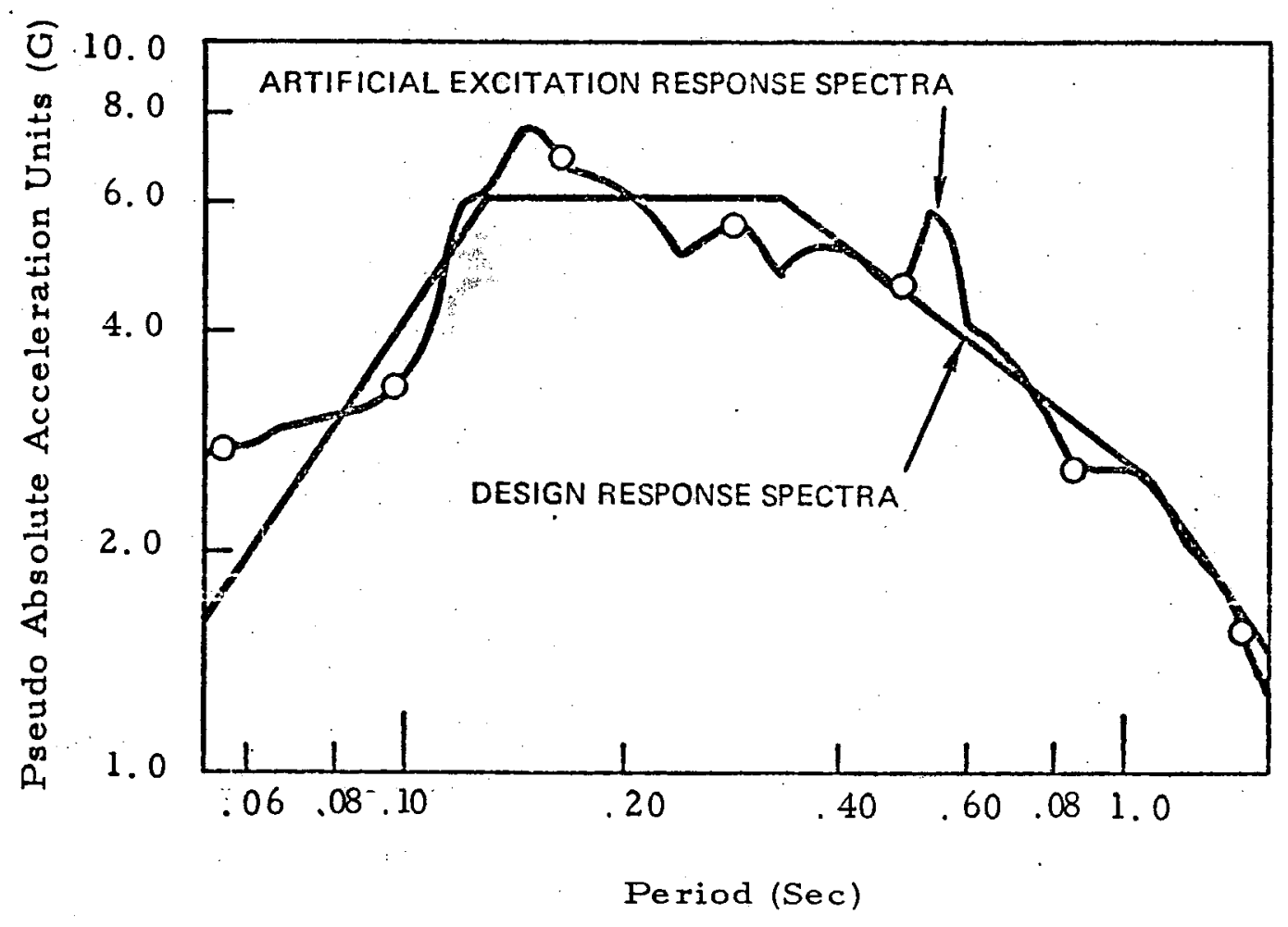

FIGURE 3.22 COMPARISON OF RESPONSE SPECTRA FROM ARTIFICIAL EXCITATION WITH DESIGN RESPONSE SPECTRA;

VERTICAL COMPONENT, 0.5g SSE, 5\% CRITICAL DAMPING 


\subsection{METHOD OF ANALYSIS}

\subsection{GENERAL}

The basic structural models used in the analyses performed in this report have been defined in Chapter 3 and are shown in Figures 3.10 through 3.12. The models each consist of a column of stacked rigid blocks and a control rod which is inserted to different positions within the column. Each block has three dynamic degrees of freedom ( $x$ and $y$ axis translation and in-plane rotation) while each control rod node has one degree of freedom ( $\mathrm{x}$-axis translation). Gap elements vertically connect adjacent blocks with one another and also laterally connect the column blocks with the rigid boundary in which the column is contained. The mass and stiffness properties of the idealized column and control rod models are presented in Tables 3.1 through 3.4.

The gap elements have nonlinear stiffness and damping behavior. When the gaps are open the stiffness and damping connecting the nodes across the gap are zero. When closed, the gap elements have the stiffness and damping properties described in Section 3.3. Because of the nonlinear behavior, it is necessary that a time history dynamic analysis be performed in order to determine the column response. Since the gap elements occur throughout the structure, the time history analysis must be performed using a numerical step-by-step integration method in which the stiffness and damping terms may vary from one time step to the next.

The analyses in this study were performed with computer code DRAIN-2D on the CDC6600 computer located in Inglewood, California. Computer code DRAIN-2D is a nonlinear time history two dimensional frame analysis code developed at the University of California at Berkeley (Reference 13). Early in this study, computer code ANSYS (Reference 14) was also considered for use. Since a comparison of computational costs 
indicated that DRAIN-2D was considerably more efficient (factor of four or greater) than ANSYS in solving the same nonlinear problem, DRAIN-2D was selected for use in this study.

In this chapter, the theoretical basis for DRAIN-2D is briefly discussed and the DRAIN-2D mathematical model is described. The treatment of damping in the analyses is also described along with the determination of time step size.

\subsection{THEORETICAL BASIS OF DRAIN-2D}

- Computer code DRAIN-2D is designed to analyze structures which are idealized as a planar assemblage of nodes connected by discrete beam type elements. Analysis is by the Direct Stiffness Method, with the nodal displacements as unknowns. Each node may possess up to three displacement degrees of freedom. However, provision is made for degrees of freedom to be deleted or combined, so that the total number of unknowns may be much less than three times the number of nodes.

The structure mass is assumed to be lumped at the nodes so that the mass matrix is diagonal. The earthquake excitation is defined by time histories of boundary support acceleration which may be different in the horizontal and vertical directions. All support points are assumed to move in phase. Static loads may be applied prior to the dynamic loading.

The structural elements are of the following two basic types which may be oriented in any direction in the two dimensional plane.

1. Truss bar, which may yield in tension or compression, buckle in compression or separate in tension.

2. Beam column element which may be of variable crosssection and strength and which may yield through the formation of plastic hinges at its ends. 
The dynamic response is determined by a step-by-step integration in which constant acceleration of response is assumed within any step. The tangent stiffness of the structure is used for each step; and linear structural behavior is assumed during the step. The equations of equilibrium are solved by a Gauss elimination procedure. If, within a time step, a gap opens or closes causing a change in an element stiffness, the tangent stiffness matrix is modified and the triangularization operation of Gauss elimination is repeated. Any unbalanced loads resulting from errors in the assumed linear behavior are applied as corrective loads in the subsequent time step. Viscous damping of mass-dependent and/or stiffness dependent-type may be specified. The stiffness dependent damping may be proportional to either the initial or instantaneous tangent stiffness. The reader is referred to Reference 13 for a more thorough treatment of the theoretical basis of the code.

\subsection{MATHEMATICAL MODEL}

To utilize DRAIN-2D in the solution, it was necessary to represent the idealized structural model presented in Chapter 3 by a planar assemblage of nodes and beam type elements.

The DRAIN model representation of a typical column element is shown in Figure 4.1. The model consists of one node located at the c.g. of the element and four nodes located at positions corresponding to corners of the element. The mass and mass moment of inertia of the element is concentrated at the center node which has three dynamic degrees of freedom. The other four nodes are connected to the central node by stiff beam elements but no mass is associated with them. Since the block is assumed to be rigid, the rotations of the nodes are specified as coupled and the refore treated as a single degree of freedom. Thus each block has a total of 11 degrees of freedom ( 10 translational and 1 rotational). Vertically adjacent blocks are connected between nodes by truss elements which transmit compression but separate in tension. An additional very 
soft vertical truss element with a stiffness equal to approximately one millionth the gap closure stiffness is provided between adjacent block nodes to provide numerical stability to the system when the gaps are open. The outer nodes of each block are connected to the lateral boundary wall by horizontal truss elements which transmit compression once the lateral relative displacement exceeds the initial gap displacement between the wall and element node. As long as the relative displacement does not exceed the initial gap displacement, no load is transmitted through these lateral elements. The dowel stiffness is represented by crossing truss elements which act as elastic members in both tension and compression. It should be noted that in the analysis, small deformation theory is assumed and therfore member forces always act in the direction of the initial orientation of the members.

The DRAIN model representation of the idealized control rod and guide tube is shown in Figure 4.2. The control rod model directly corresponds to the idealized model. Each node has only a horizontal translational degree of freedom and is connected to vertically adjoining nodes by beam elements which provide the equivalent stiffness of the shear springs of the idealized model. The top end of the top beam element is connected to a boundary node. The idealized gap elements are represented by horizontally oriented truss elements which transmit compressional loads once the lateral relative displacement between the rod and channel exceeds the initial gap.

The guide tube is modeled as a beam element. The upper end is pinconnected to a boundary node while the lower end is pin-connected to the central node of the top column element. $A$ vertical truss element located between the top plenum element and the guide tube beam element permits the beam element to vertically separate from the plenum element central node. 
The fully withdrawn control rod column DRAIN model has 118 nodes and 144 degrees of freedom. The half inserted control rod column model has 138 nodes and 154 degrees of freedom while the fully inserted control rod model has 158 nodes and 168 degrees of freedom.

\subsection{DAMPING}

Damping associated with the column model is nonlinear. During impacts when gap elements come into contact, there is high damping which is associated with the inelastic impact of the fuel $\in$ lements. During other periods when elements are not impacting, damping is low and associated with the fundamental lateral response mode of the column.

In DRAIN, damping may be specified as mass and/or stiffness dependent. It may be proportional to either the initial or tangent stiffness of the system. In order to achieve damping which is high during impacts and low when gap elements are not impacting, damping has been specified to be a function of the instantaneous tangent stiffness of the system. During impacts, the stiffness of the system is increased by the gap elements coming into effect. Therefore during impacts, damping of the system also increases. At other times when gap elements are open and the tangent stiffness of the system is low, damping is low as well.

If the dynamic system were uncoupled into normal nodes, the relationship among the generalized damping, mass, and tangent stiffness for the nth mode would be

$$
\mathrm{C}_{\mathrm{n}}^{*^{*}}=\alpha \mathrm{M}_{\mathrm{n}}^{*}+\beta \mathrm{K}_{\mathrm{n}}^{*}
$$

where $C_{n}^{*}=$ Generalized damping coefficient for $n$th mode

$\mathrm{M}_{\mathrm{n}}^{*}=$ Generalized mass for nth mode

$\mathrm{K}_{\mathrm{n}}^{*}=$ Genearlized instanteous tangent stiffness for $\mathrm{nth}$ mode 
Hence from the relationships

$$
\mathrm{C}_{\mathrm{n}}^{*}=2 \lambda_{\mathrm{n}} \mathrm{w}_{\mathrm{n}} \mathrm{M}_{\mathrm{n}}^{*}
$$

and

$$
\mathrm{K}_{\mathrm{n}}^{*}=\mathrm{w}_{\mathrm{n}}^{2} \mathrm{M}_{\mathrm{n}}^{*}
$$

in which $\lambda_{n}=$ proportion of critical damping in the nth mode; and $w_{n}=$ circular frequency of the nth mode. It follows that any specified values of $\alpha$ and $\beta$ imply damping in the inth mode equal to

$$
\lambda_{n}=\frac{\alpha}{2 w_{n}}+\frac{\beta w_{n}}{2}
$$

In order to achieve the desired fuel element inelastic impact properties, it was shown in Section 3.3 that the impact dampers should be specified as 27 percent of critical during impacts when the gaps are closed. The undamped natural frequency of a fuel element - gap spring system during impact is approximately $80 \mathrm{~Hz}$. Therefore the damping coefficients selected (i.e. $\alpha$ and $\beta$ ) should result in 27 percent critical damping for a modal frequency of $80 \mathrm{~Hz}$. When the column blocks are not impacting one another or the boundary, the damping associated with the motions are believed to be relatively low (conservatively assessed herein to be 0.5 and 1.0 percent). The fundamental lateral response mode for the column is about $2 \mathrm{~Hz}$. Therefore, the damping coefficient selected should also result in about 0.5 to 1.0 percent of critical damping for a natural frequency of $2 \mathrm{~Hz}$.

The desired damping of the column system can be achieved using mass and tangent stiffness dependent dampings where $\alpha=0.0$ and $\beta=0.0011$. These values of $\alpha$ and $\beta$ result in 27 percent critical damping at $80 \mathrm{~Hz}$ and - 7 percent critical damping at $2 \mathrm{~Hz}$. In all analyses performed, these values of $\alpha$ and $\beta$ were used. 


\subsection{TIME STEP SIZE}

For the step-by-step nonlinear analysis, modal accelerations, velocities, and displacements are generated at each time step from which individual member forces are generated. In the analyses, constant acceleration of response of each mode is assumed within each time step. Because the acceleration response is in general not constant, error may occur in tracing the actual system response. For the constant acceleration method, the magnitude of this error decreases as the time step size is shortened. To insure that the time step size is sufficiently short to compute an accurate system response, the time step size has been verified by comparing responses for various time step sizes.

As a rule of thumb, the time step should be at least fifteen times smaller than the estimated duration of impact of the gap element block system with the highest frequency. The duration of impact, ${ }^{t}$, of a gap element block system is given by

$$
t_{d}=\pi \sqrt{\frac{M}{k\left(1-\lambda^{2}\right)}}
$$

where $M=$ mass of system

$$
\mathrm{K}=\text { stiffness of system }
$$

$\lambda=$ fraction of critical damping

In the column model, the highest frequency column block is block 2 (the block with the lowest mass). For block 2

$$
\begin{aligned}
& M=.3321 \mathrm{lb} / \mathrm{in} / \mathrm{sec}^{2} \\
& K=2 \mathrm{k}=2(74,000)=148,000 \mathrm{lb} / \mathrm{in} \\
& \lambda=.27
\end{aligned}
$$


Substituting these values into equation 4.5 , results in an impact duration of .0049 seconds. All analyses in this study were performed using a time step of 0.0003 seconds which is less than one-fifteenth of the calculated impact duration.

To investigate the magnitude of error in tracing the system response associated with a time size of 0.0003 seconds, nonlinear analyses of a column model were run at time step sizes of $0.0004,0.0003$, and 0.0002 seconds. The comparison of results for these analyses is presented in Appendix A. It is shown that in general the response at time step of 0.0003 and 0.0002 seconds match closely (within 5 percent in most cases). Since the difference is small, it can be concluded that the time step size of 0.0003 seconds is short enough to provide a sufficiently accurate estimate of response. 


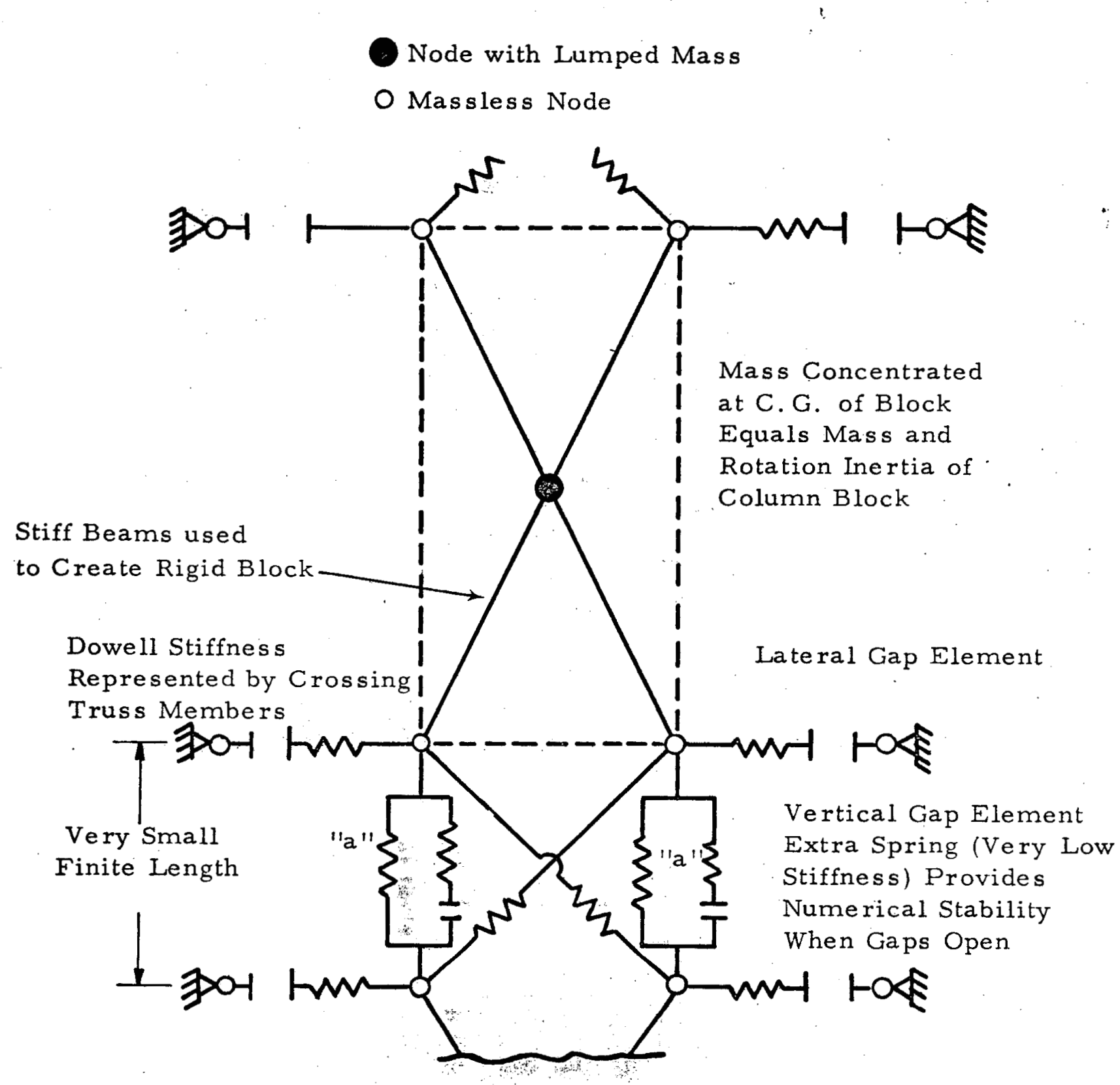

FIGURE 4.1 DRAIN MODEL OF A COLUMN BLOCK 


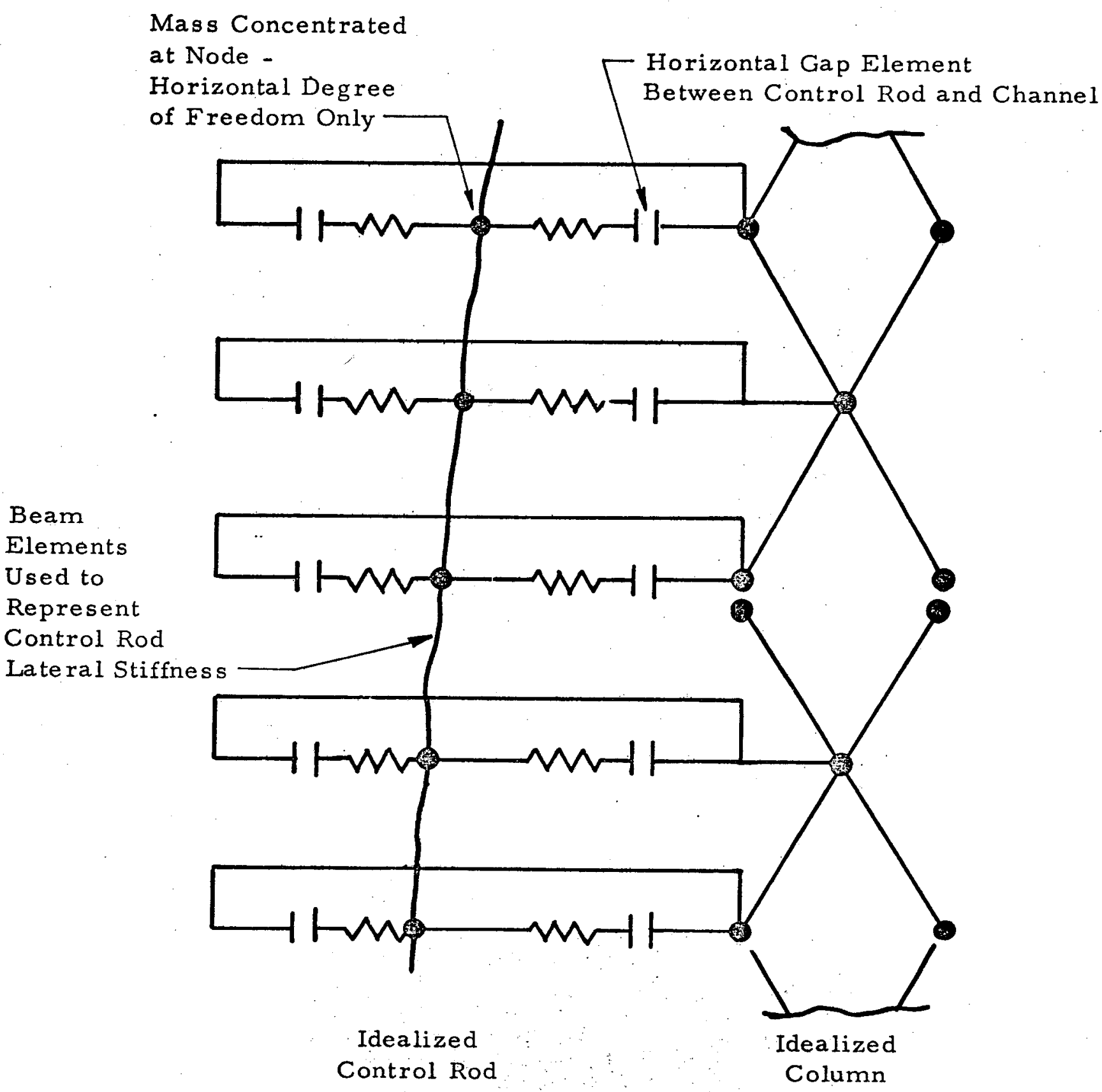

FIGURE 4.2 DRAIN MODEL OF CONTROL ROD 


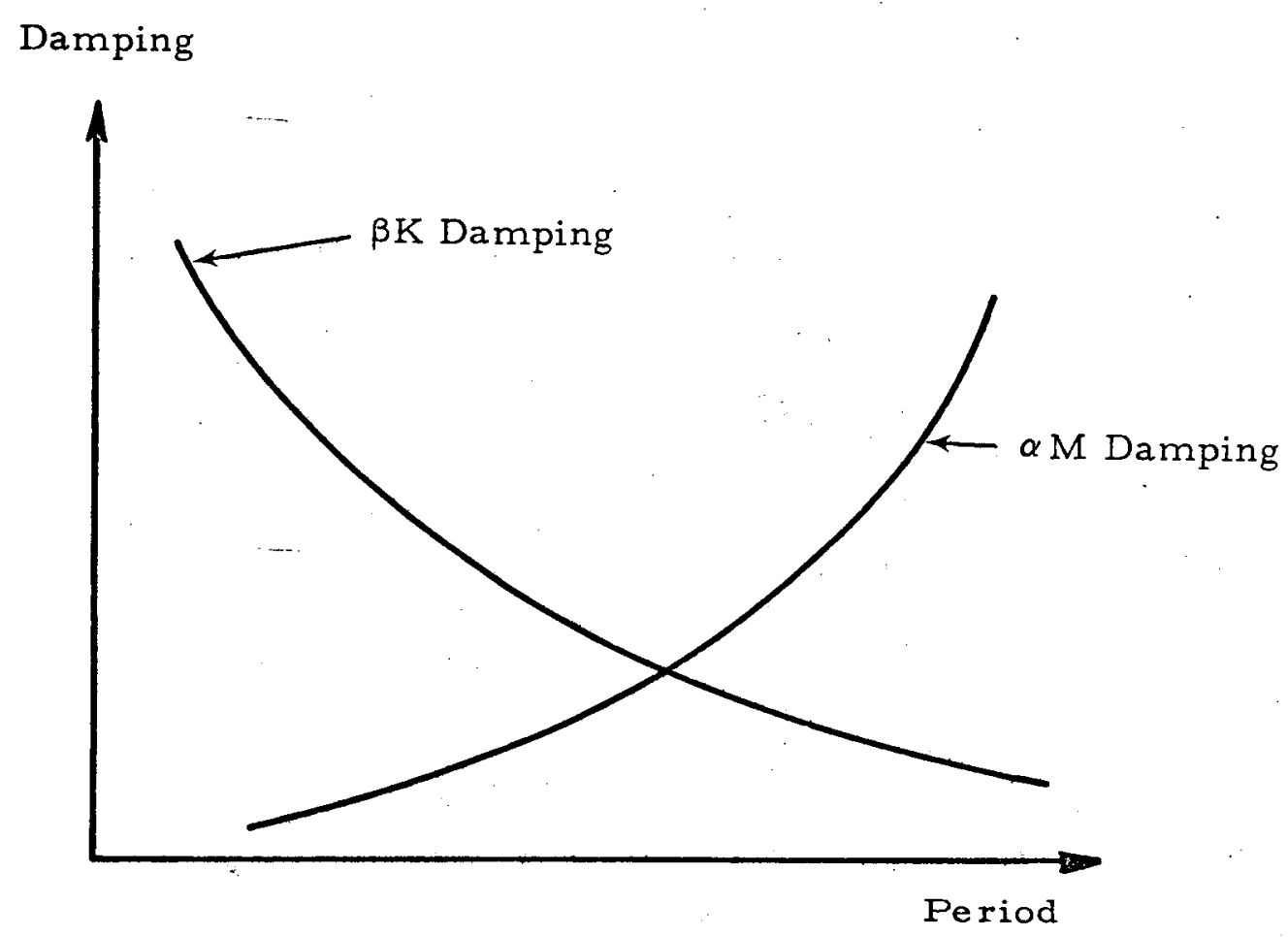

FIGURE 4. 3 VARIATION OF MASS AND STIFFNESS PROPORTIONAL DAMPING WITH NATURAL PERIOD

4-11 


\subsection{RESULTS OF PRINCIPAL ANALYSES}

\subsection{GENERAL}

The analyses described in this section are intended to fulfill the main objectives of this study; that is, to assess the relative influence of control rods on the seismic response of the core of a large HTGR. The analyses were performed on the structural models described in Chapter 3 using the analysis techniques described in Chapter 4. Three cases were considered corresponding to the following insertion depths:

- Control rod fully withdrawn

- Control rod halfway inserted

- Control rod fully inserted

In each case, a nonlinear time history analysis was performed of a typical control element column and a control rod subjected to simultaneous horizontal and vertical seismic excitations. The excitations are described in Section 3.5 and have been artificially generated to conservatively overestimate the maximum excitations that are possible at the core support points resulting from an earthquake with a peak ground acceleration of $0.5 \mathrm{~g}$. The duration of the artificial excitations is 2.5 seconds.

The lateral column gaps as sumed in the analysis correspond to those existing in a peripherally positioned fully irradiated control element column during full power conditions. The only static loads assumed acting on the column result from dead load. Pressure drop loads were assumed to be zero.

All analyses in this chapter were performed using a time step size of 0.0003 seconds. Damping was dependent on the tangent stiffness of the system and was selected to model impact behavior assuming a coefficient of restitution of 0.40 . 
In this chapter, the results from the three analyses are presented and discussed. In particular, the lateral displacement response, peak shear between blocks, the peak impact velocities, and the peak relative angle between blocks are compared. Also presented and discussed is the peak control rod impact velocity. In addition, time histories of these responses are compared at selected locations.

\subsection{RESULTS OF THE ANALYSIS}

A comparison of the peak responses of the control column for the three control rod positions are illustrated in Figures 5.1 through 5. 3. Compared responses are the horizontal shears between vertically adjacent blocks, impact velocities of the column with the boundary, and relative angles between blocks.

The peak velocities of the control rods relative to the column channel are illustrated in Figure 5.4. Note that because the control rods are inserted to different positions the velocities at similar points on the control rod are not directly comparable.

A summary of the peak column and control rod responses are tabulated in Table 5.1. Included in this table are the peak shear forces, impact velocities, relative rotational angles, and vertical separation between blocks. Vertical separation is defined as the minimum gap between two vertically adjacent blocks as illustrated in Figure 5.5. As long as blocks are in contact at some point along their interface, the vertical separation displacement is zero. Also presented are the peak impact forces at the block corners and peak control rod impact velocities and forces. Peak impact forces have not been emphasized in this report since they are highly dependent on the stiffness of the gap element which is a somewhat subjective quantity. A method for obtaining the impact force for any given element mass, contact stiffness, and impact velocity is described in Subsection 3. 3 . 
A comparison of time history responses at selected points in the column are presented in Figures 5.6 through 5.14. The responses and locations have been selected to provide a representative comparison of column behavior. Compared time history responses are relative lateral displacements and velocities between the column and boundary and the relative angles between blocks.

A time history plot of the horizontal shear between blocks at the center of the column for the rod withdrawn case is shown in Figure 5.15 . This shear time history is typical of those computed. Comparison plots of shears for different insertion depths are not presented because shear is a high frequency response, and it is very difficult to distinguish different time histories on the same plot.

Time history plots of the vertical separation at three typical points along the column for the rod withdrawn case are presented in Figures 5.16 through 5.18. Plots of the relative lateral velocity between a typicar point on the control rod and the column channel or guide tube for each case are presented in Figures 5.19 through 5.21 .

These responses are compared and discussed in the remainder of this chapter. In general, the column responses were found to be unaffected by control rod insertion except during periods of vertical separation between blocks. As noted earlier, the artificial excitations used in the analyses conservatively overestimates the PCRV response. These excitations result in vertical separation between blocks much larger than those expected to occur during actual earthquakes. This permits any effect control rods might have on column response during periods of separation to be accentuated.

\subsection{EFFECT ON THE LATERAL RESPONSE OF THE COLUMN}

During seismic excitations, the column blocks displace laterally between the boundary walls. The initial lateral gaps between the column 
and boundary for the bottom eleven blocks were specified as 2.3 inches on one side of the column and 0.3 inches on the opposite side. For the top block, the initial gap was specified as 1.2 inches and 0.01 inch. Corners of most blocks were found to impact the boundary at some time during the excitation.

To compare the effect control rods have on the lateral response of the column, displacement time histories for the three cases have been plotted together for three representative points on the column (see Figures 5. 6 through 5.8). Velocity time histories for the same points are compared in Figures 5.9 through 5.11 .

An examination of the displacement plots reveals that the column impacts the right boundary six times and the left boundary five times indicating that the column boundary system has a lateral fundamental frequency of approximately $2 \mathrm{~Hz}$ (as had been estimated). Note that for blocks 2 and 6 , a positive displacement of 2.3 inches incidates impact with the right boundary while a negative displacement of 0.3 inches indicates impact with the left boundary. The top of block 11 displaces essentially the same as the bottom of block 12 . Therefore, in Figure 5.8, a positive displacement of 1.2 inches indicates impact with the right boundary while a negative displacement of 0.01 inches indicates impact with the left boundary.

An examination of the velocity plots reveals that the peaks of the velocity pulses coincide with the time of impacts of the column elements with the boundary. Thus, the peak column velocities are the impact velocities of the column with the boundary. For each case, the peak column velocity is found to occur at 0.48 seconds just prior to the first impact of the column with the left boundary. An examination of boundary input velocity (Figure 3.19) finds that the maximum impact velocity coincides with the time of occurrence of the first large negative velocity pulse. A plot of the peak velocities along the column is shown in Figure 
5.2. It is interesting to note that the peak velocities occur near the midheight and decrease near the top and bottom of the column. - This behavior indicates that the column is behaving somewhat like a simple vibrating beam. The peak velocities for the rod inserted and rod withdrawn cases match within 10 percent of each other at essentially all points along the column. At the center of the column, the peak velocities for the three cases range between 127 and 138 inches/second. No dis cernible trends of peak velocity related to control rod depth of insertion are apparent. Since fuel element impact forces are directly proportional to impact velocities, it can also be concluded that impact forces are also essentially unaffected by control rod insertion. Both the displacement and velocity time history responses for different control rod insertion depths coincide during the first 0.70 seconds.indicating that the inserted control rods have essentially no effect on the response during this period. However between 0.70 and 1.50 seconds, deviations in response are found to occur. The reason for these deviations is found in an examination of the vertical separation time histories of the column (see Figures 5.16 through 5.18). In these figures, it is shown that large vertical separations between column blocks occur between 0.70 and 1.20 seconds. When vertical separation occurs, there is a loss in rotational stiffness between vertically adjacent blocks. During such periods, the block response is much more sensitive to the stiffness of the control rods since they provide the only rotational connectivity between adjacent blocks. After 1.5 seconds, the blocks have fallen back onto one another, and the rotational stiffness is again provided by direct contact of the adjacent blocks. As can be seen in the figures, after 1.5 seconds, the lateral responses for the control rod inserted cases are found to again match closely with the rod withdrawn cases. It is interesting to note that during periods of separation the largest difference in the displacement response occurs when the rod is fully inserted. 
The peak separations range between 1.0 and 3.0 inches with the smallest separations occurring at the bottom of the column and the largest occurring near the top. Smaller separations occur at the bottom of the column and are reasonable since the bottom blocks are more heavily preloaded by dead load of the blocks stacked above. It should be noted that the addition of gas pressure preload would tend to significantly reduce or prevent such separations. An examination of the vertical in put excitations (see Figure 3.20) finds that the period of separation coincides with the occurrence of the peak upward acceleration pulse followed by the peak downward acceleration pulse and thus is directly related to the input excitations.

In general, the velocity response is much less affected by the control rod insertion than are displacement responses even during periods of separation. Velocities are less sensitive because the lateral shear stiffness between blocks is maintained even during periods of separation and therefore lateral continuity of the column is preserved throughout the analysis.

\subsection{EFFECT ON RELATIVE ANGLE BETWEEN BLOCKS}

The effect of control rod insertion on the relative angles between blocks is reported on in this section. It should be pointed out that in Appendix A, relative angles are shown to be less accurately predicted than other response parameters. However trends in the response are believed to be accurate.

As shown in Figure 5.3, the peak relative angles between blocks vary greatly throughout the column for different rod insertion depths. The peak angle for the rod withdrawn case occurs at the midheight of the column and is 5.9 degrees. For the rod half inserted, the peak angle is 5.7 degrees and occurs between the bottom block and the floor. For the fully inserted case, the peak angle occurs between blocks 2 and 3 and 
is 7.8 degrees. For both the rod half and fully inserted cases, peak relative angles in which the rod is located are limited to less than 3.7 degrees. It is interesting to note that increased rotational angles occur at the block interfaces just below the bottom tip of the control rod with the largest increase occurring when the control rod is fully inserted.

Time history plots of relative angles for three points on the column are presented in Figures 5.12 through 5.14. Similar to the column displacement and velocity responses, the relative angles between blocks are essentially identical for all depths of control rod insertion through the first 0.7 seconds. However, between 0.7 and 1.5 seconds, large variations in relative angle responses between rod inserted and rod withdrawn cases occur. As noted earlier, during this period, significant vertical separation occurs between the blocks. During periods of vertical separation, the rotational stiffness between blocks is negligible except for that provided by the control rods. Therefore the rotations of blocks during these periods are very sensitive to lateral impacts and the rotational stiffness provided by the control rods. It can be seen in the plots that the relative angles which occur during this one period of separation are much greater than those predicted to occur in the remaining portions of the record. In all cases, the relative angles predicted to occur during periods of no separation are less than 3.5 degrees. It can also be seen in the plots, that in portions of the column where the control rods are inserted, the relative rotations between blocks is significantly reduced (see Figure 5.13).

\section{5 EFFECT ON THE HORIZONTAL SHEAR BETWEEN BLOCKS}

The horizontal shear between column elements is not significantly affected by variances in the control rod insertion depth. As seen in Figure 5.1, the distribution of shear forces is somewhat irregular with the largest shear forces occurring at the top, center, and bottom of the column. Large shear forces at the top and bottom of the column indicate 
that the column is responding like a simple vibrating beam supported at its ends. Like a beam, the lateral shear load is being essentially sucked to the top and bottom column support points. Maximum shear loads at the center of the column result from impact of the column with the boundary.

The peak shear loads for the three cases range between 4500 and 4800 pounds. It should be noted that the shear forces calculated are the total shear forces between blocks and that actual dowel shear forces between blocks are expected to be less because a portion of the shear force is resisted by friction between the blocks.

The peak horizontal shear forces in the center of the column are generally associated with a single impact occurrence and that for the remaining portion of the response, the shear forces are significantly less. The shear force time history presented in Figure 5-15 is typical of those calculated. In this case the peak shear force occurs at approximately .48 seconds and is associated with impact of the column with the left hand boundary. Large shear forces occur when the corner of one of the blocks of an interface impacts the boundary and starts rebounding prior to the impact of the corner of the vertically adjoining block. Such behavior is sensitive to the phasing of blocks and therefore conditions which induce large shear forces generally occur just a few times during the record.

At most block interfaces, the peak shear forces for the rod inserted cases are within 15 percent of the rod withdrawn case. The largest differences occurat the interface between blocks 7 and 8 where the shears vary by about 35 percent. These differences are attributed primarily to the sensitivity of shear forces to phasing of the blocks. No discernable trends or patterns of shear forces associated with different control rod depths is apparent. 
Shear forces were found not to be nearly as sensitive to separation as were other responses. This behavior is reasonable since the shear stiffness between blocks is maintained at all times in the analysis even during periods of separation. Thus, the additional lateral stiffness provided by the control rods was insignificant when combined with the dowel stiffness.

\subsection{CONTROL, ROD RESPONSE}

The control rod response was found to closely follow the response of the column. As shown in Figure 5.4, the peak relative velocity between a control rod and the channel for both fully and partially inserted control rods occurs at the midheight of the column at the same point as the peak column impact velocity. The peak control rod impact velocity is 160 inches/sec as compared to a peak column impact velocity of 138 inches/ sec. Both column and control rod peak velocities occur at essentially the same time. Thus, the impact velocities of the control rods with column channel wall can be directly related to the impact velocities of the basic column. A conservative estimate of the peak control rod impact velocity could be obtained by scaling the peak column velocity by a factor of 1.25. It should be noted that the greatest velocities tended to occur with the rod fully inserted.

Time histories of the control rod relative impact velocities are plotted for each case in Figures 5.19 through 5.21. As seen in the plots, impacts tend to occur at about a frequency of four per second with the peak impact velocity coinciding with time of occurrence of the peak column velocity.

The guide tube assembly was found to laterally respond essentially as a rigid beam with the bottom end moving with the plenum element and the top moving with the boundary. Vertically, the guide tube assembly was found to separate from the plenum element by a maximum of 2.74 
inches. As noted earlier, such large separations result from a conservative estimate of the PCRV excitations and that much smaller separations are expected to actually occur during actual earthquakes.

\subsection{SUMMARY OF RESULTS}

The following highlights briefly summarize the results of the analyses presented in this chapter.

1. Inserted control rods have no influence on the response of a core column unless blocks separate vertically such that no relative rotational restraint exists between the blocks.

2. When separation occurs, the control rods primarily effect the relative rotation response of the column. The control rods tend to reduce relative rotations between blocks in the portion of the column in which they are located and increase rotations at the interface level just below the bottom tip of the rods.

3. The lateral column impact velocity and horizontal shear force are not greatly affected by control rod insertion even during periods of separation. This is because the shear stiffness is maintained between blocks during periods of separation while rotational stiffness is not maintained.

4. The column was found to respond similarly to a vibrating simple beam. Maximum shear loads occur at the top and bottom, and the peak column velocity occurs near the midheight of the column. Impacts with the boundary also resulted in large shear forces in the center of the column.

5. The impact velocity of the control rods within the channel can be directly related to the impact velocities of the basic column with the boundary with peak velocities occuring near the column midheight. The velocities tend to be greatest when the control rods are fully inserted. 
6. The influence of control rods on response tend to be maximized with full control rod insertion. 


\section{TABLE 5.1 \\ COMPARISON OF PEAK RESPONSES AT VARIOUS CONTROL ROD INSERTION DEPTHS}

\begin{tabular}{|c|c|c|c|}
\hline Description & $\begin{array}{l}\text { Rod Fully } \\
\text { Withdrawn }\end{array}$ & $\begin{array}{l}\text { Rod } 1 / 2 \\
\text { Inserted }\end{array}$ & $\begin{array}{l}\text { Rod Fully } \\
\text { Inserted }\end{array}$ \\
\hline $\begin{array}{l}\text { Horizontal shear force between } \\
\text { blocks }\end{array}$ & $4,830 \mathrm{lbs}$ & $4,450 \mathrm{lbs}$ & $4,740 \mathrm{lbs}$ \\
\hline $\begin{array}{l}\text { Horizontal impact velocity between } \\
\text { column \& boundary }\end{array}$ & $127 \mathrm{in} / \mathrm{sec}$ & $136 \mathrm{in} / \mathrm{sec}$ & $138 \mathrm{in} / \mathrm{sec}$ \\
\hline Relative angle between blocks (1) & $5.9^{\circ}$ & $5.7^{\circ}$ & $7.8^{\circ}$ \\
\hline $\begin{array}{l}\text { Relative angle within zone of } \\
\text { control rods }\end{array}$ & -- & $3.7^{\circ}$ & $3.6^{\circ}$ \\
\hline $\begin{array}{l}\text { Vertical separation between } \\
\text { blocks }(2)\end{array}$ & $2.27 \mathrm{in}$. & $2.60 \mathrm{in}$ & 3.08 in \\
\hline $\begin{array}{l}\text { Lateral corner impact force } \\
\text { between column and boundary }\end{array}$ & $11,200 \mathrm{lbs}$ & $12,100 \mathrm{lbs}$ & $11,000 \mathrm{lbs}$ \\
\hline $\begin{array}{l}\text { Vertical corner impact force } \\
\text { between adjacent blocks }\end{array}$ & $12,900 \mathrm{lbs}$ & $13,100 \mathrm{lbs}$ & $13,300 \mathrm{lbs}$ \\
\hline Control rod impact velocity & $54 \mathrm{in} / \mathrm{sec}$ & $145 \mathrm{in} / \mathrm{sec}$ & $163 \mathrm{in} / \mathrm{sec}$ \\
\hline $\begin{array}{l}\text { Maximum vertical separation } \\
\text { between guide tube and plenum } \\
\text { element }\end{array}$ & 1. 95 in & $2.7 .4 \mathrm{in}$ & $1.29 \mathrm{in}$ \\
\hline
\end{tabular}

(1) Occurs below bottom of control rod.

${ }^{(2)}$ See Figure 5.5 for definition of vertical separation. 


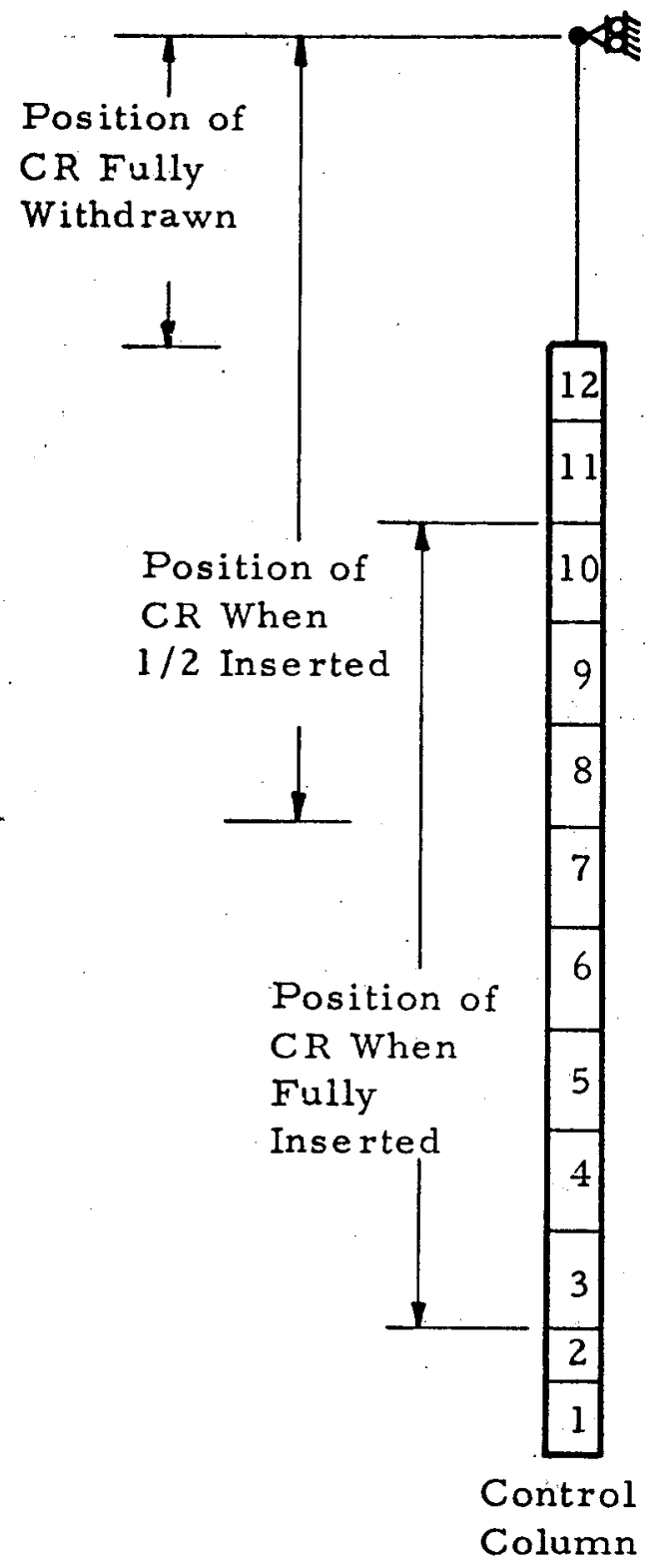

\section{Column Shears}

CR Fully Withdrawn

- C R Hal f Inserted

- - CR Fully Inserted

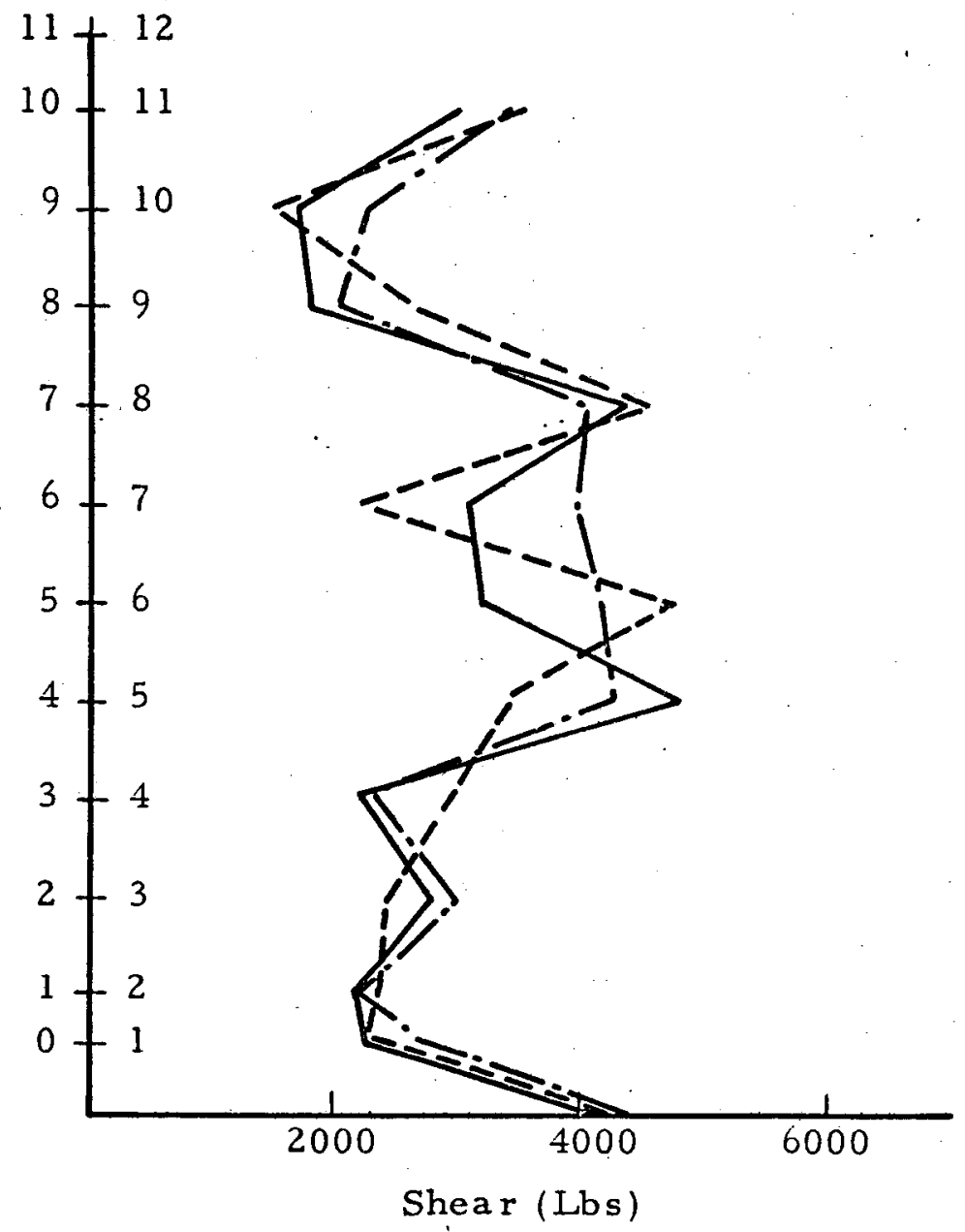

FIGURE 5-1 COMPARISON OF PEAK COLUMN RESPONSE FOR THREE CONTROL ROD INSERTION DEPTHS HORIZONTAL SHEARS BETWEEN BLOCKS 

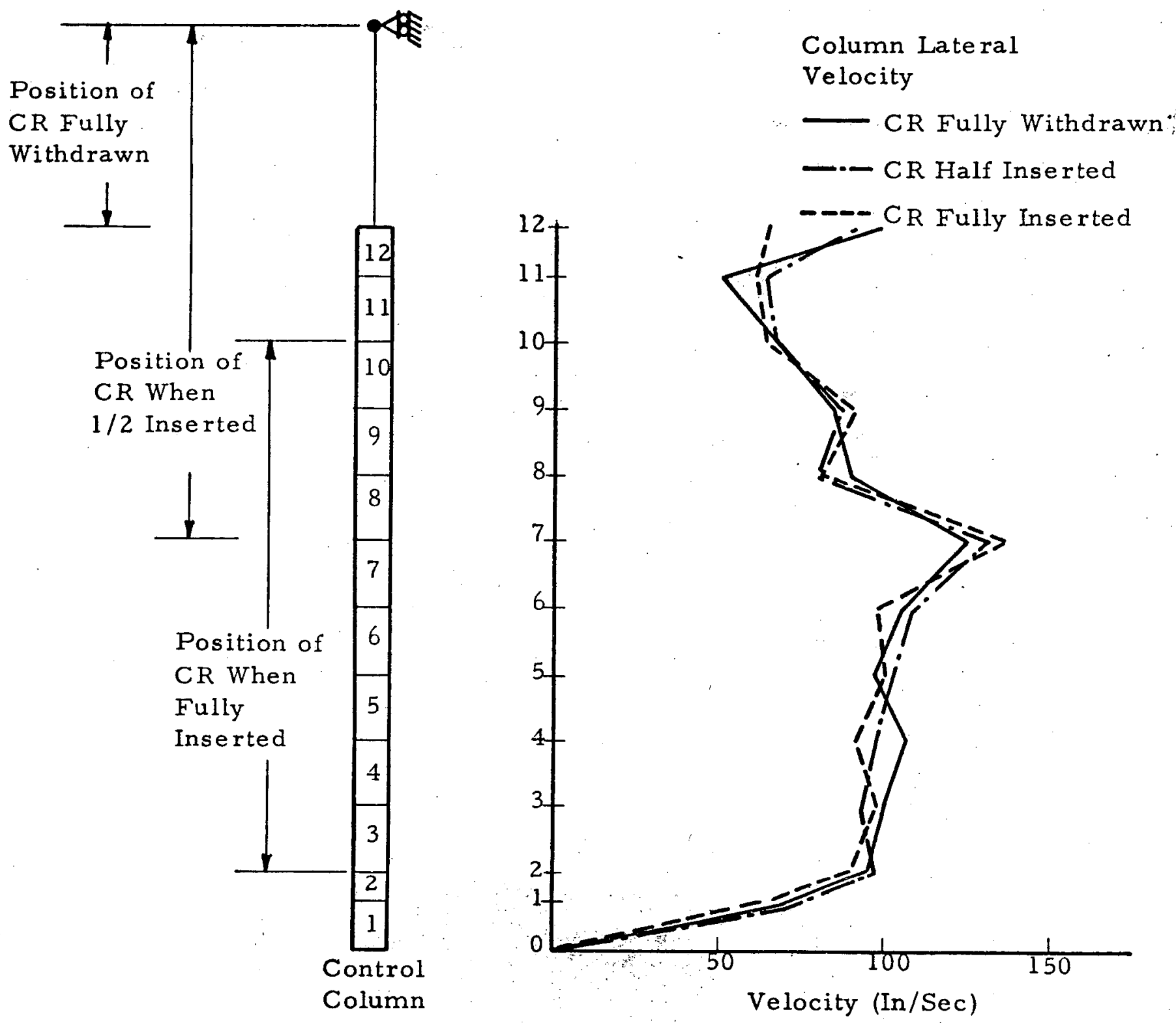

FIGURE 5.2 COMPARISON OF PEAK COLUMN RESPONSE FOR THREE CONTROL ROD INSERTION DEPTHS HORIZONTAL RELATIVE VELOCITY BETWEEN BLOCKS AND BOUNDARY 

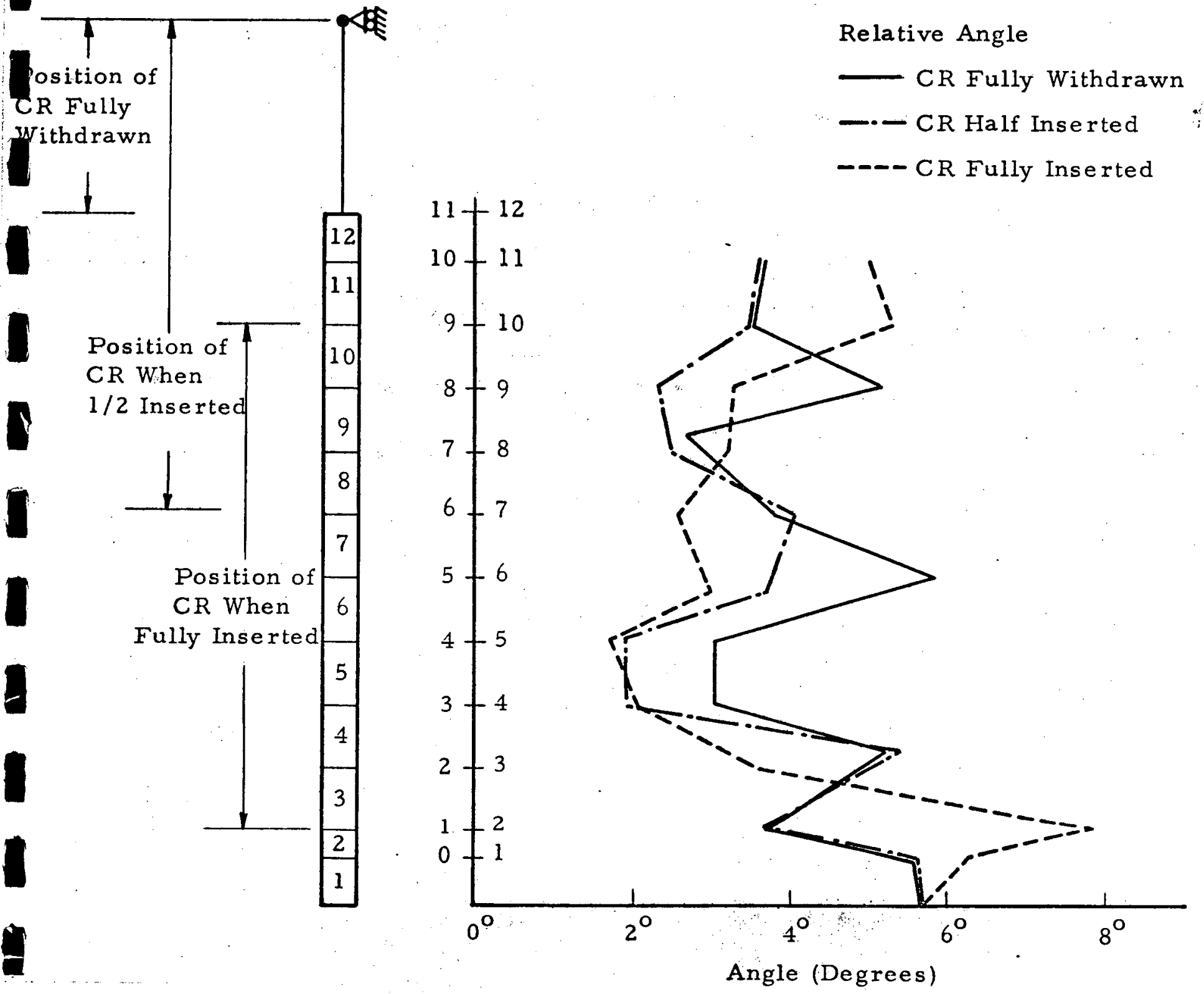

FIGURE 5. 3 COMPARISON OF PEAK COLUMN RESPONSE

FOR THREE CONTROL ROD INSERTION DEPTHS

RELATIVE ANGLES BETWEEN BLOCKS 

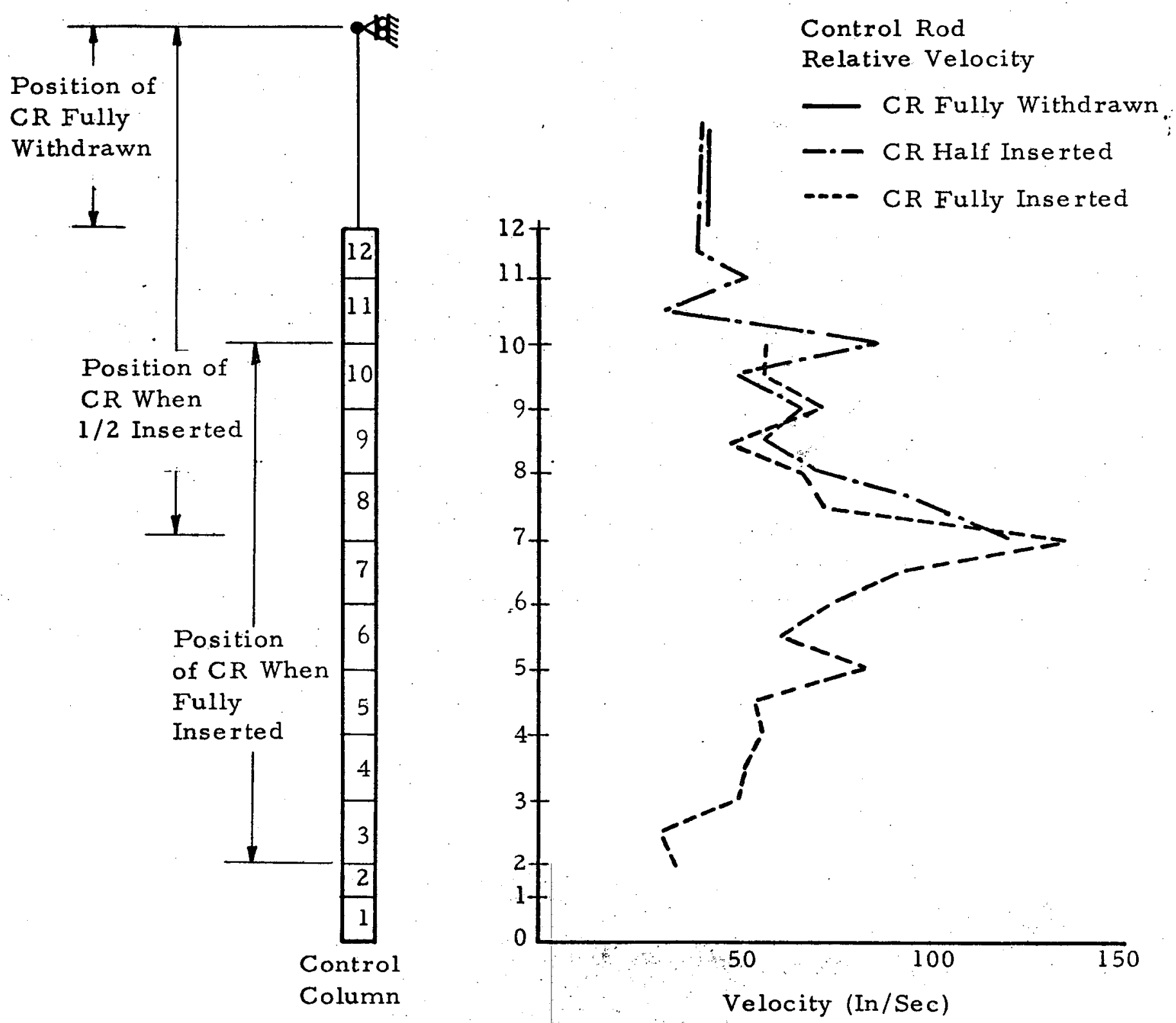

FIGURE 5. 4 COMPARISON OF PEAK CONTROL ROD RESPONSE FOR THREE CONTROL ROD INSERTION DEPTHS HORIZONTAL RELATIVE VELOCITY BETWEEN CONTROL ROD AND CONTROL ROD CHANNEL 


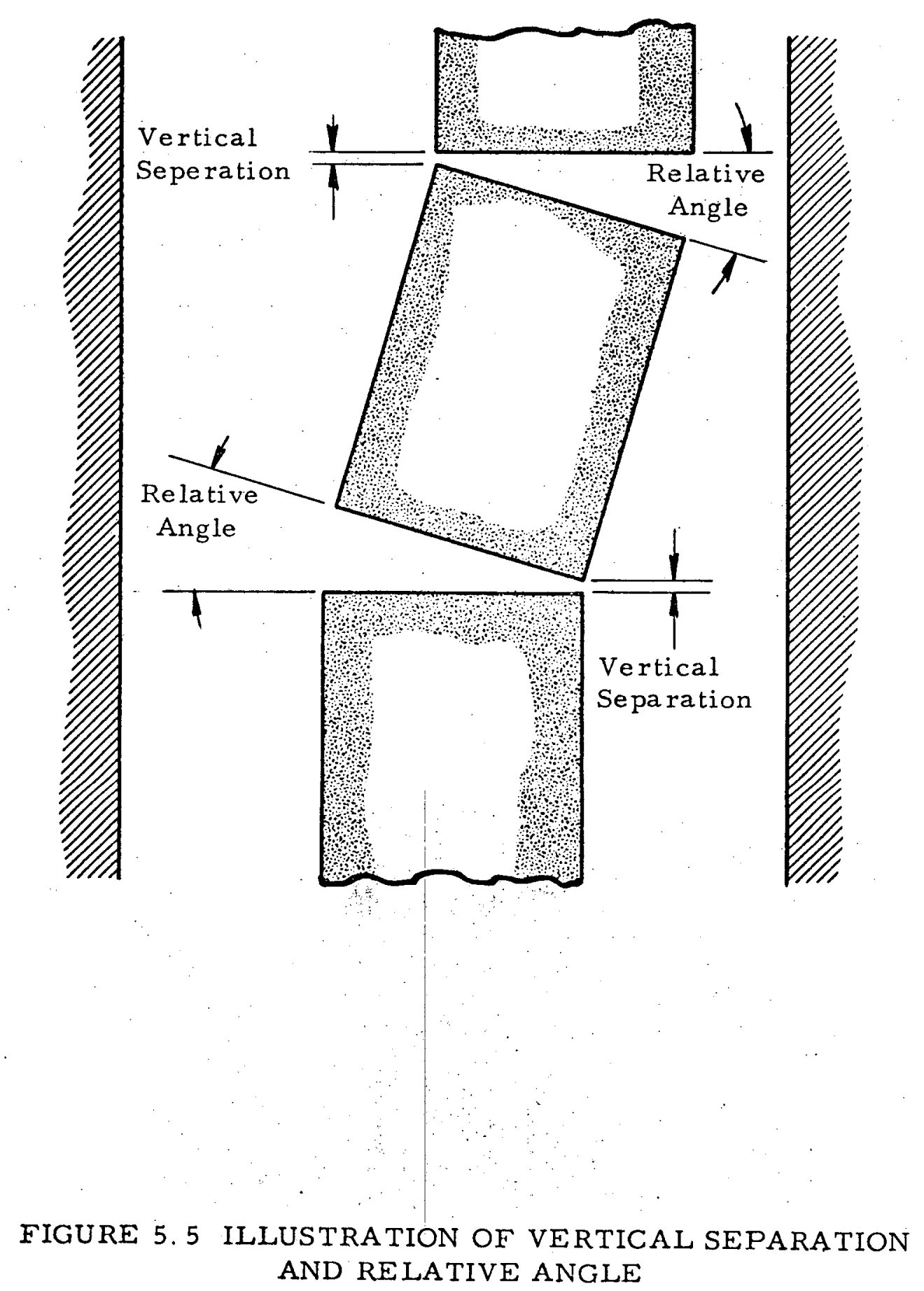




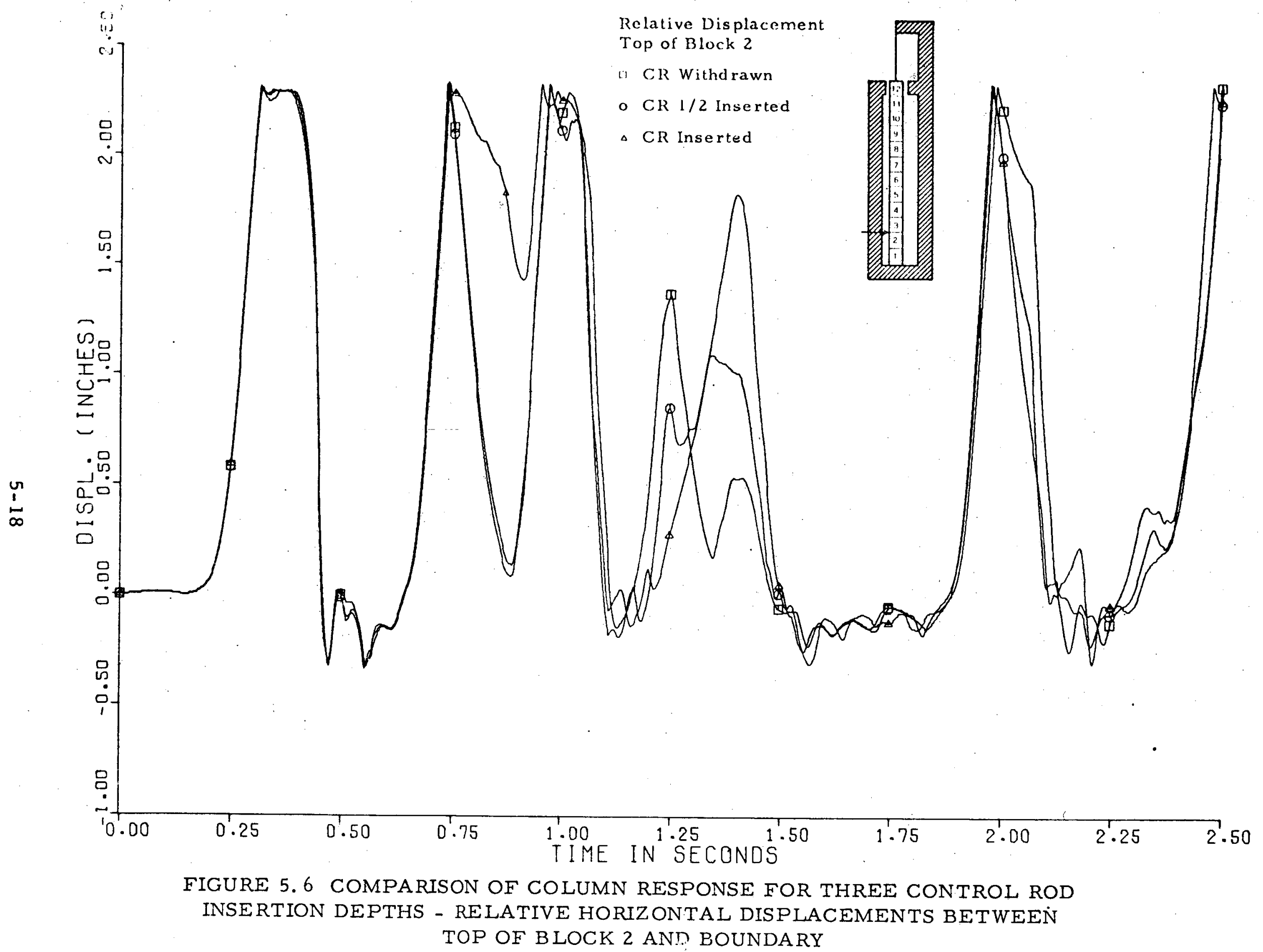




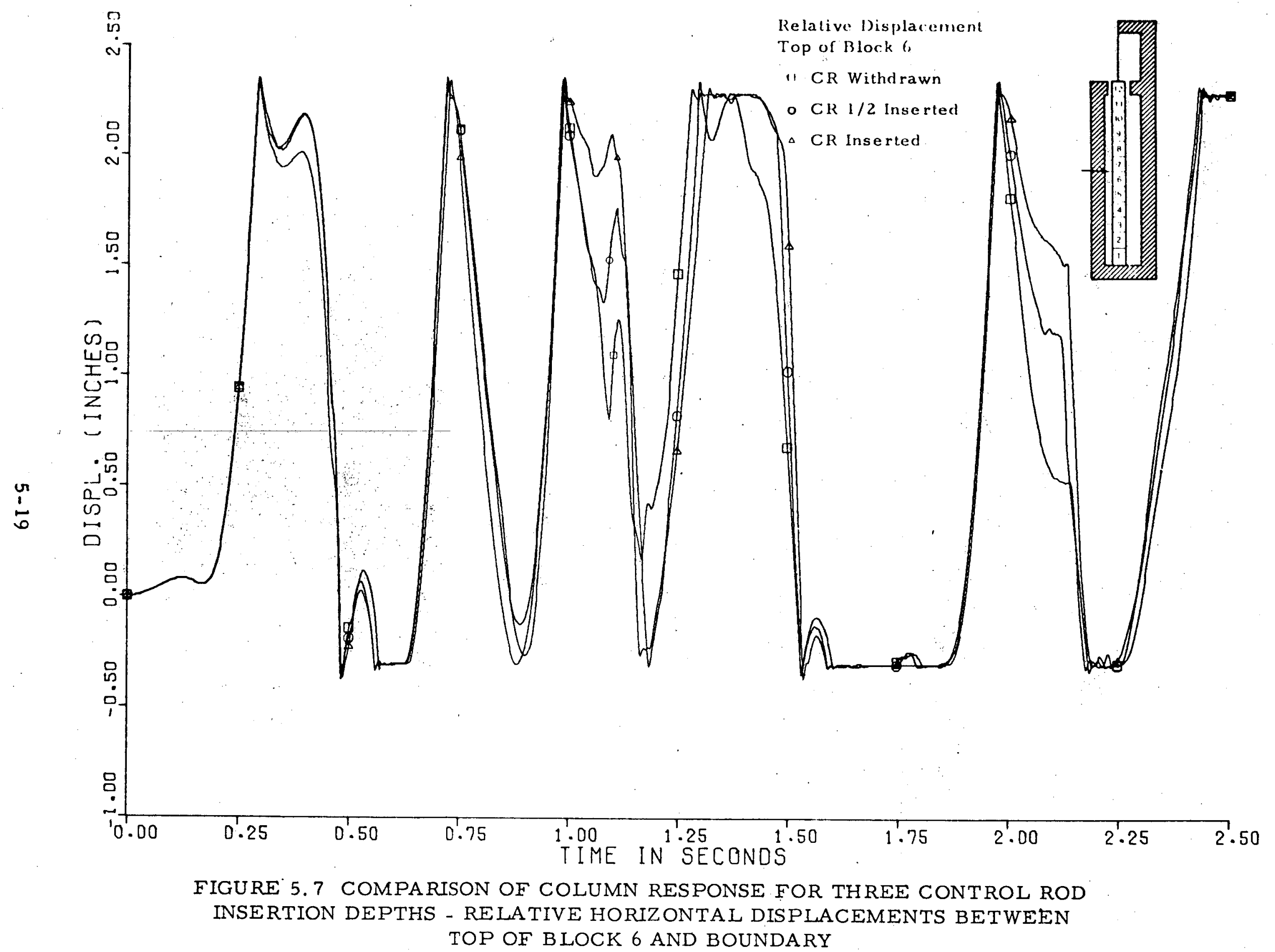




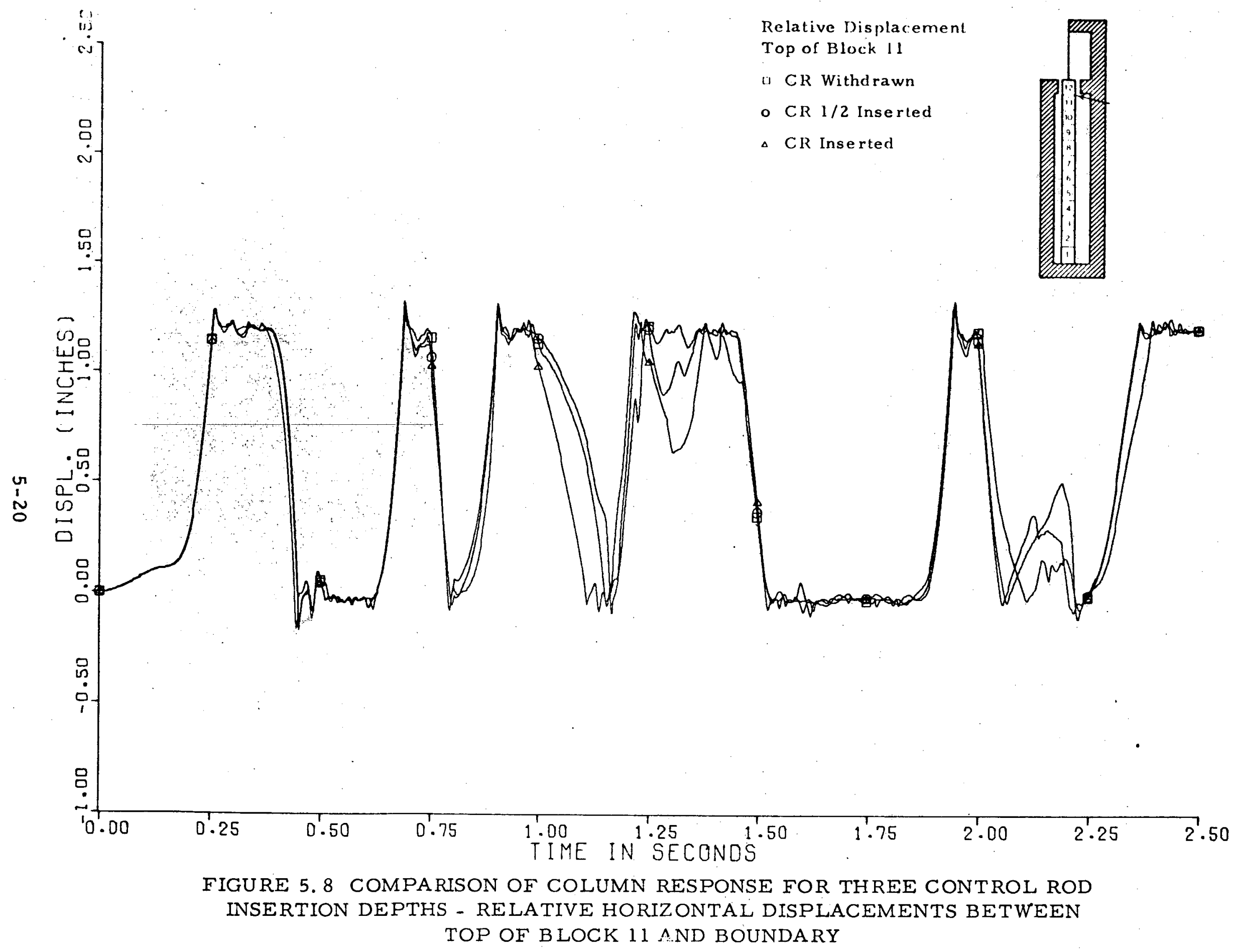




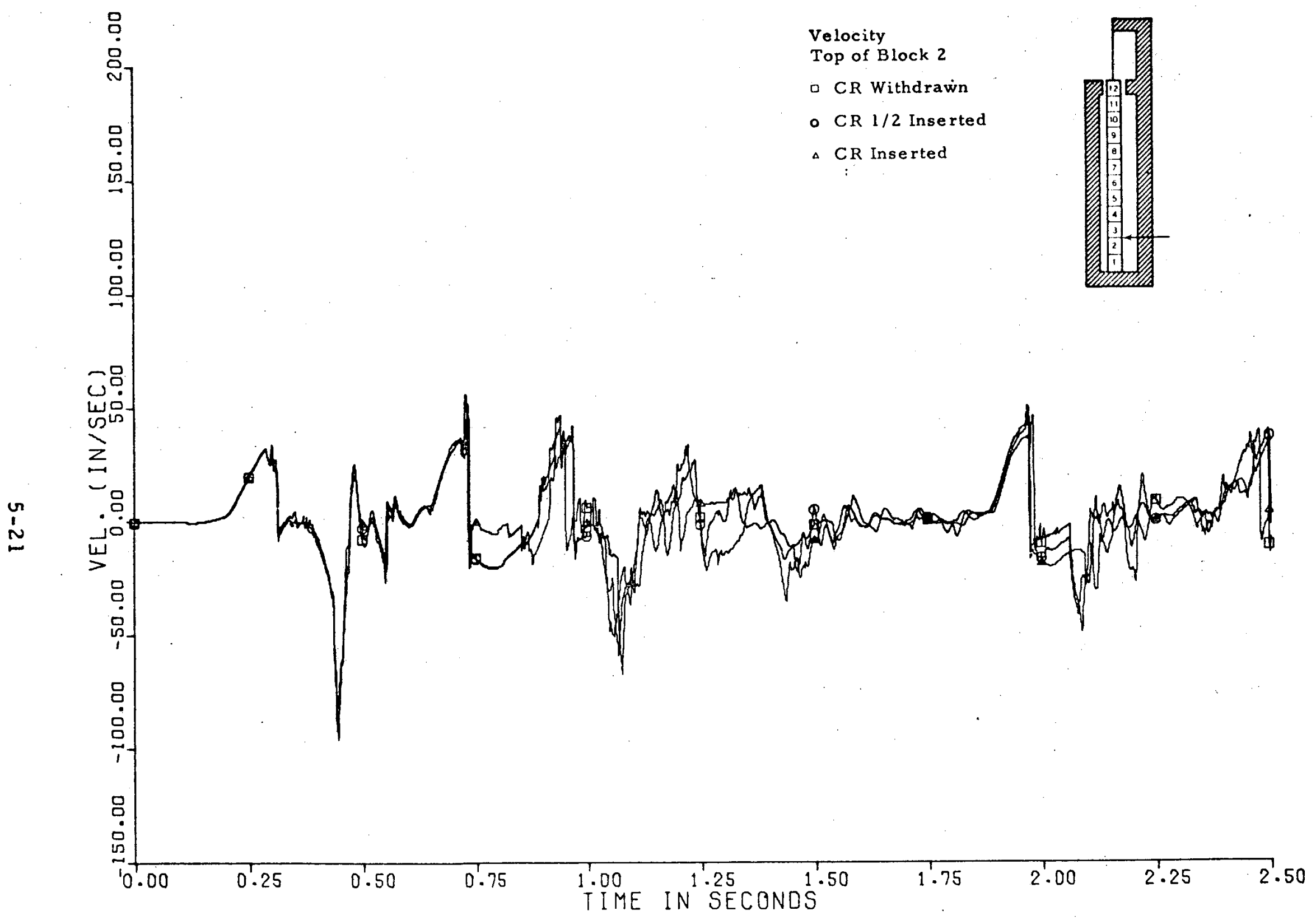

FIGURE 5. 9 COMPARISON OF COLUMN RESPONSE FOR THREE CONTROL ROD INSERTION DEPTHS - RELATIVE HORIZONTAL VELOCITY BETWEEN TOP OF BLOCK 2 AND BOUNDARY 


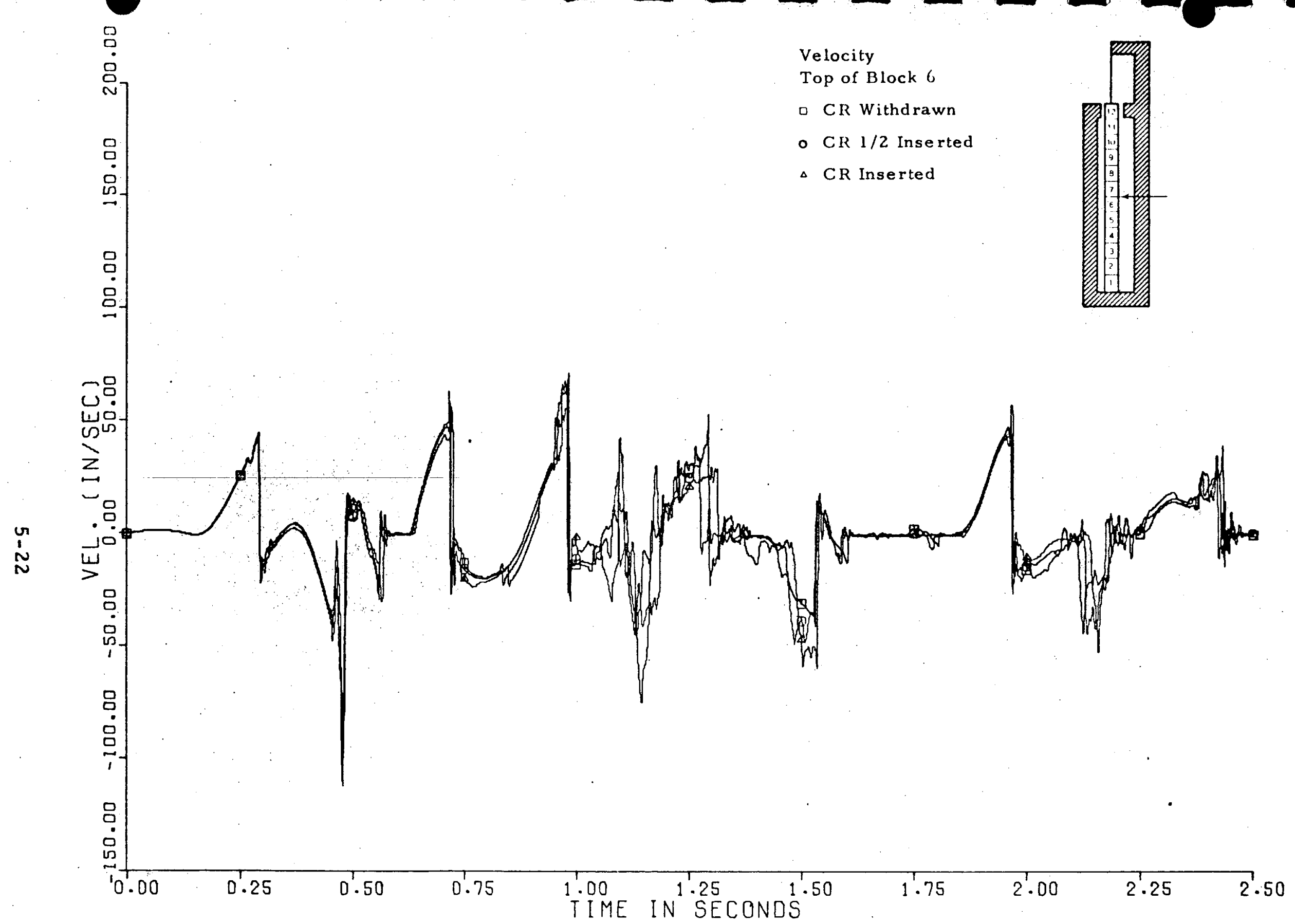

FIGURE 5.10 COMPARISON OF COLUMN RESPONSE FOR THREE CONTROL ROD INSERTION DEPTHS - RELATIVE HORIZONTAL VELOCITY BETWEEN •

TOP OF BLOCK 6 ATID BOUNDARY 


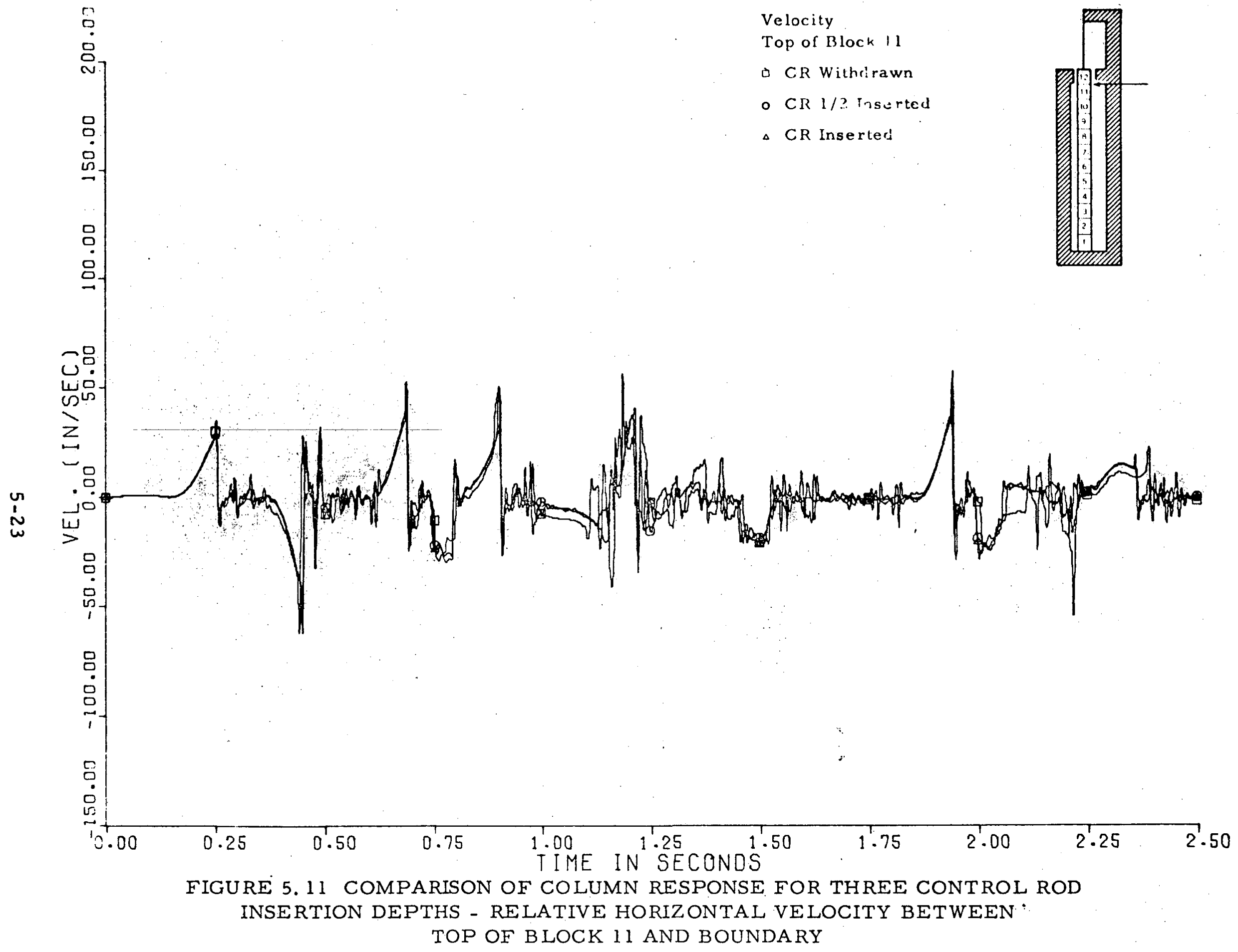




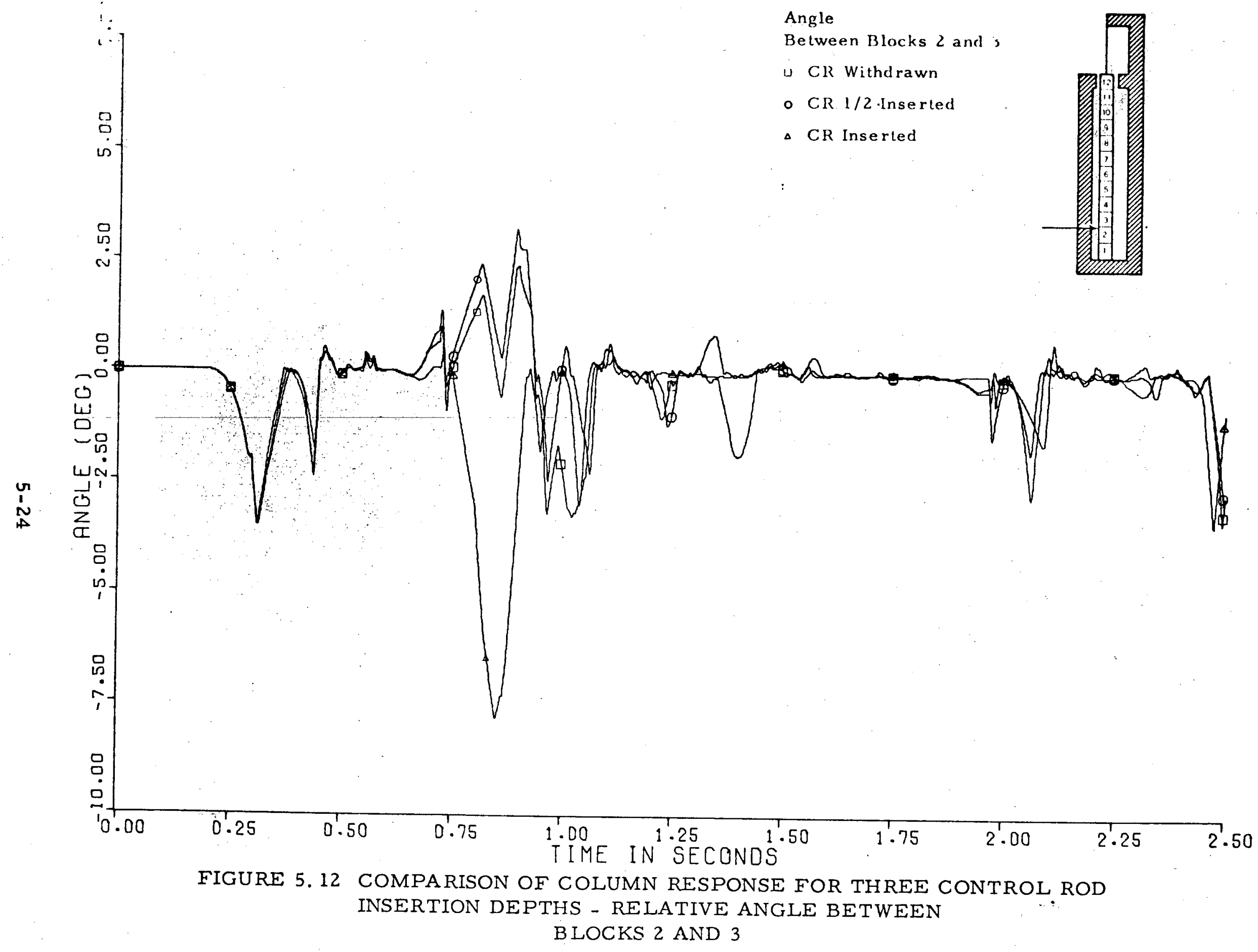




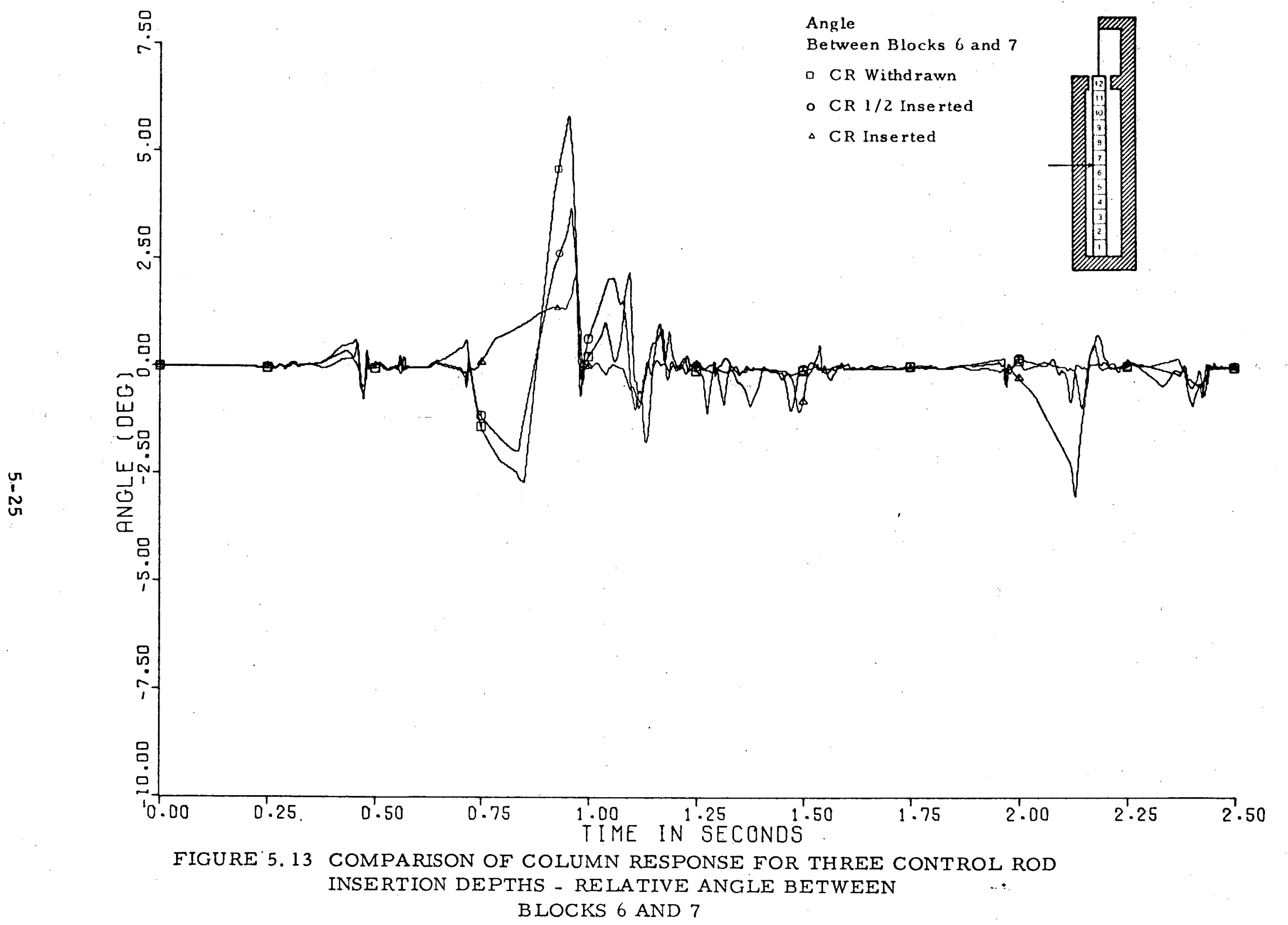




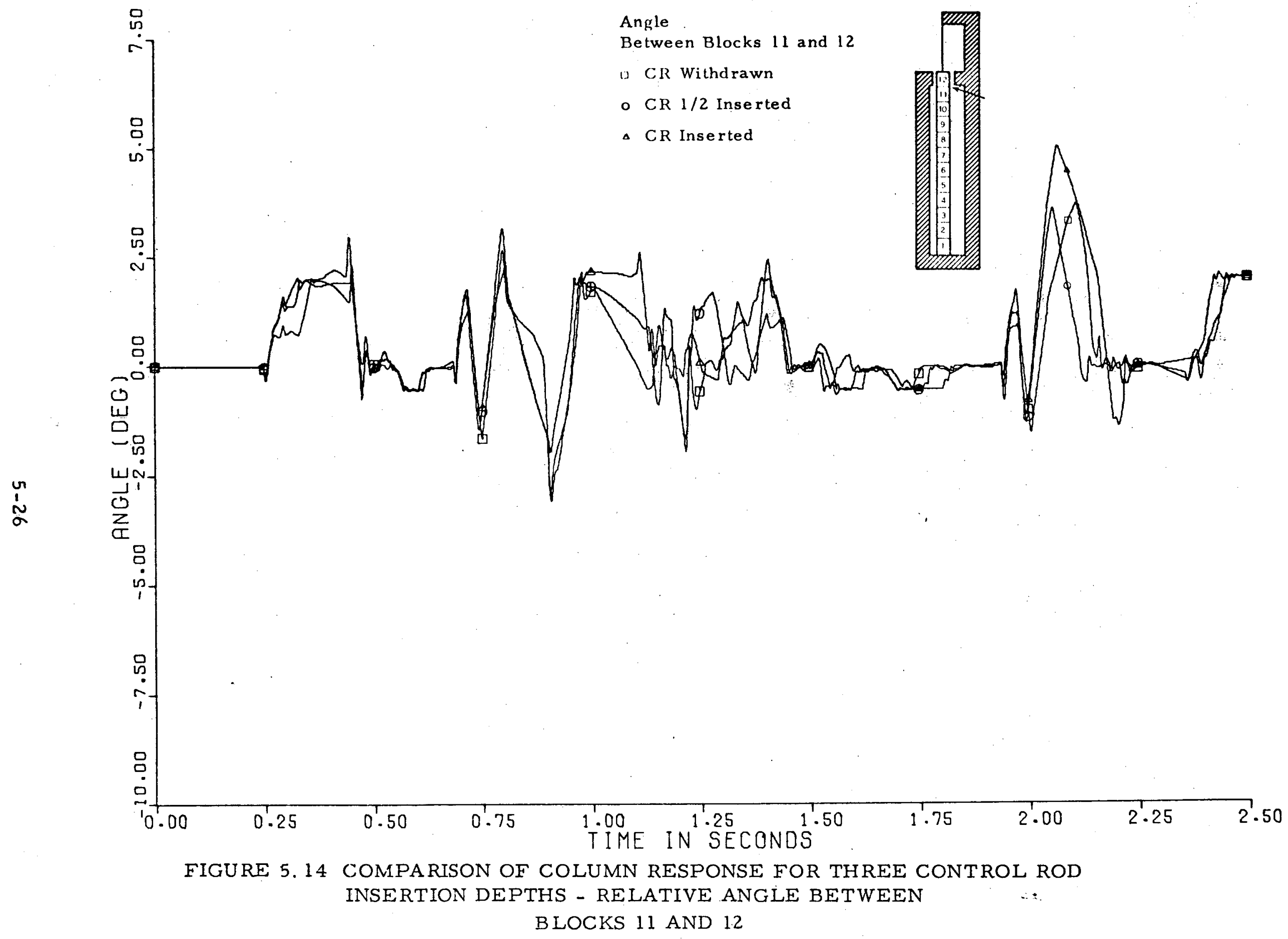




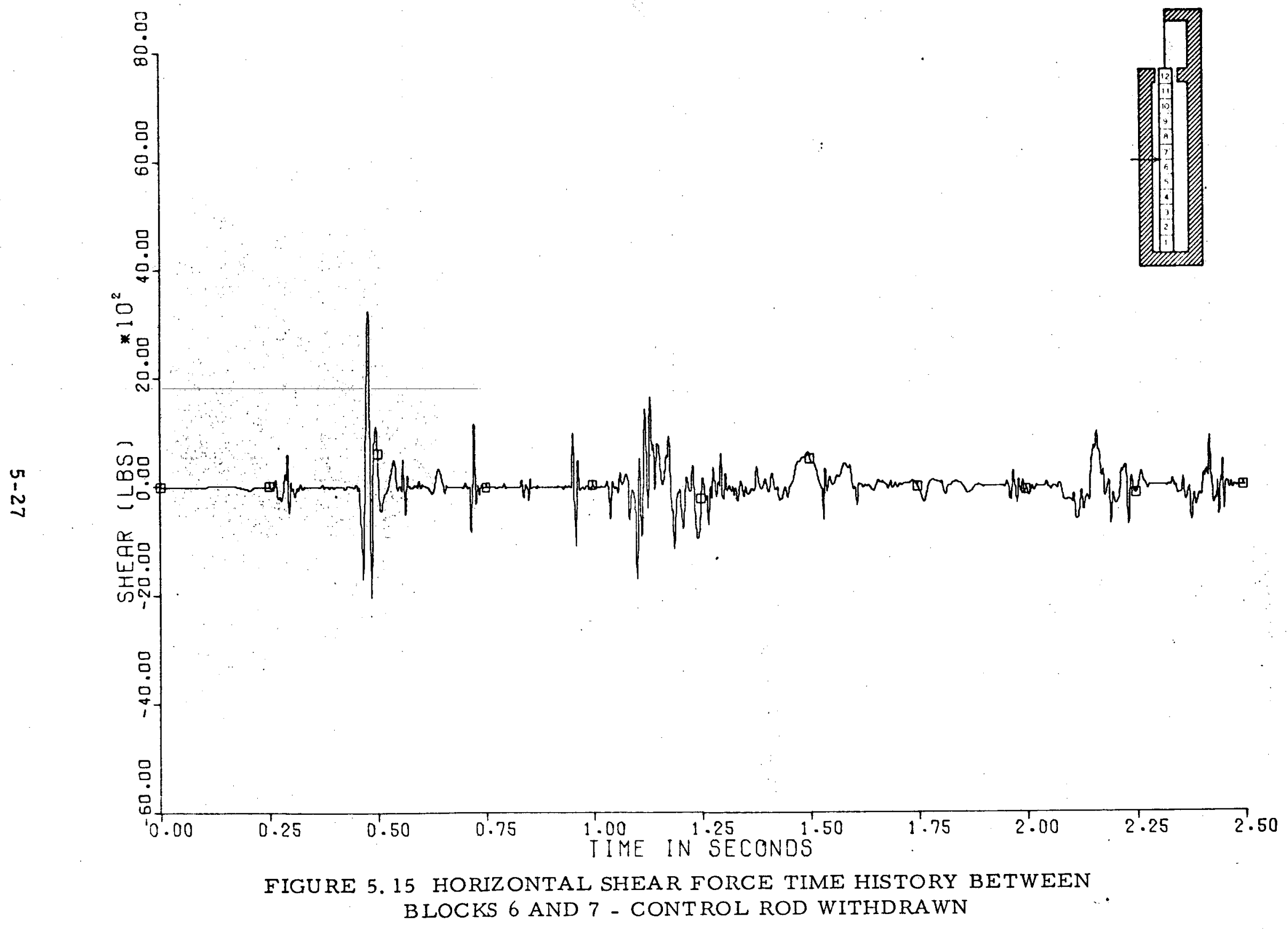




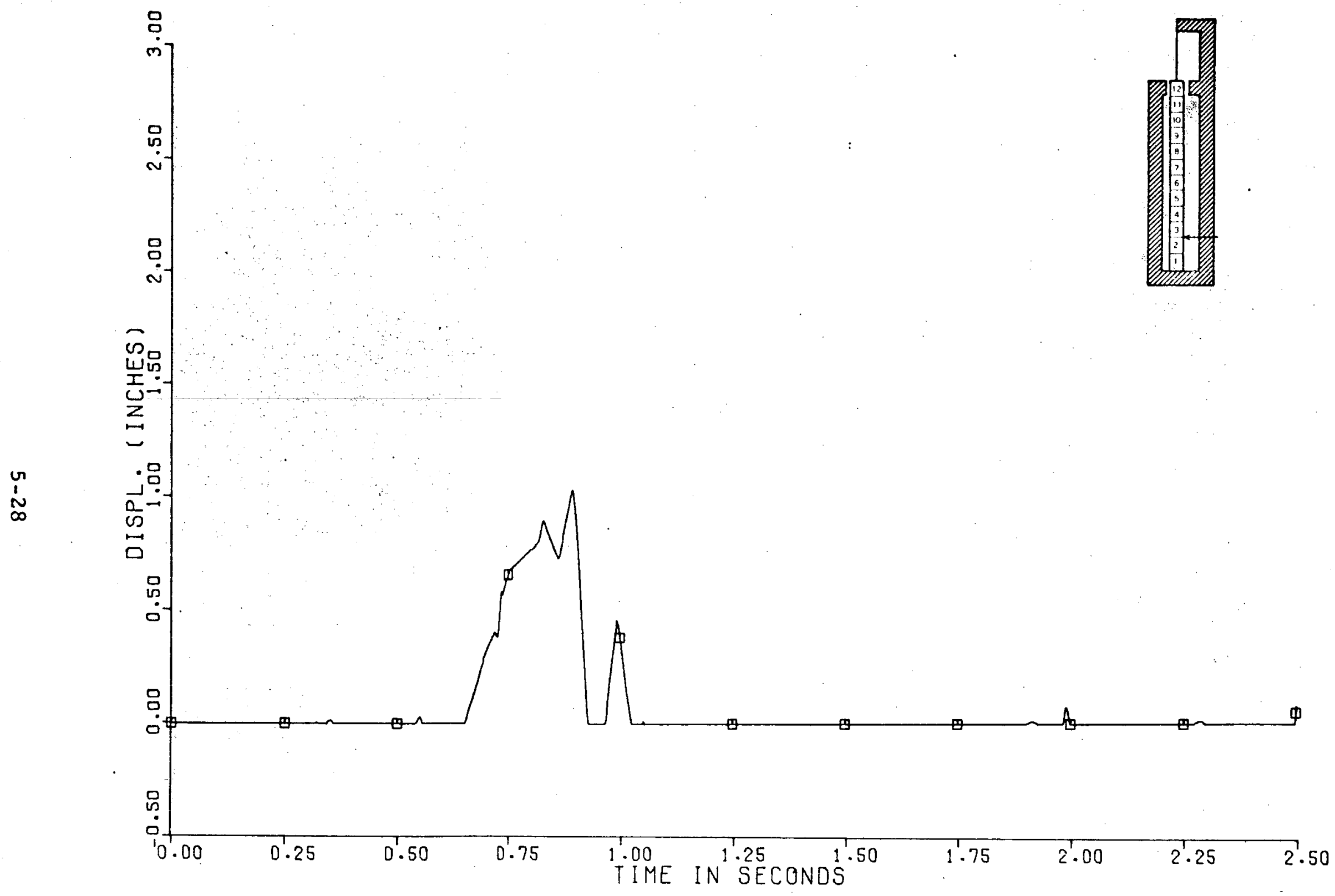

FIGURE 5.16 VERTICAL SEPARATION BETWEEN BLOCKS 2 AND 3 CONTROL ROD WITHDRAWN 


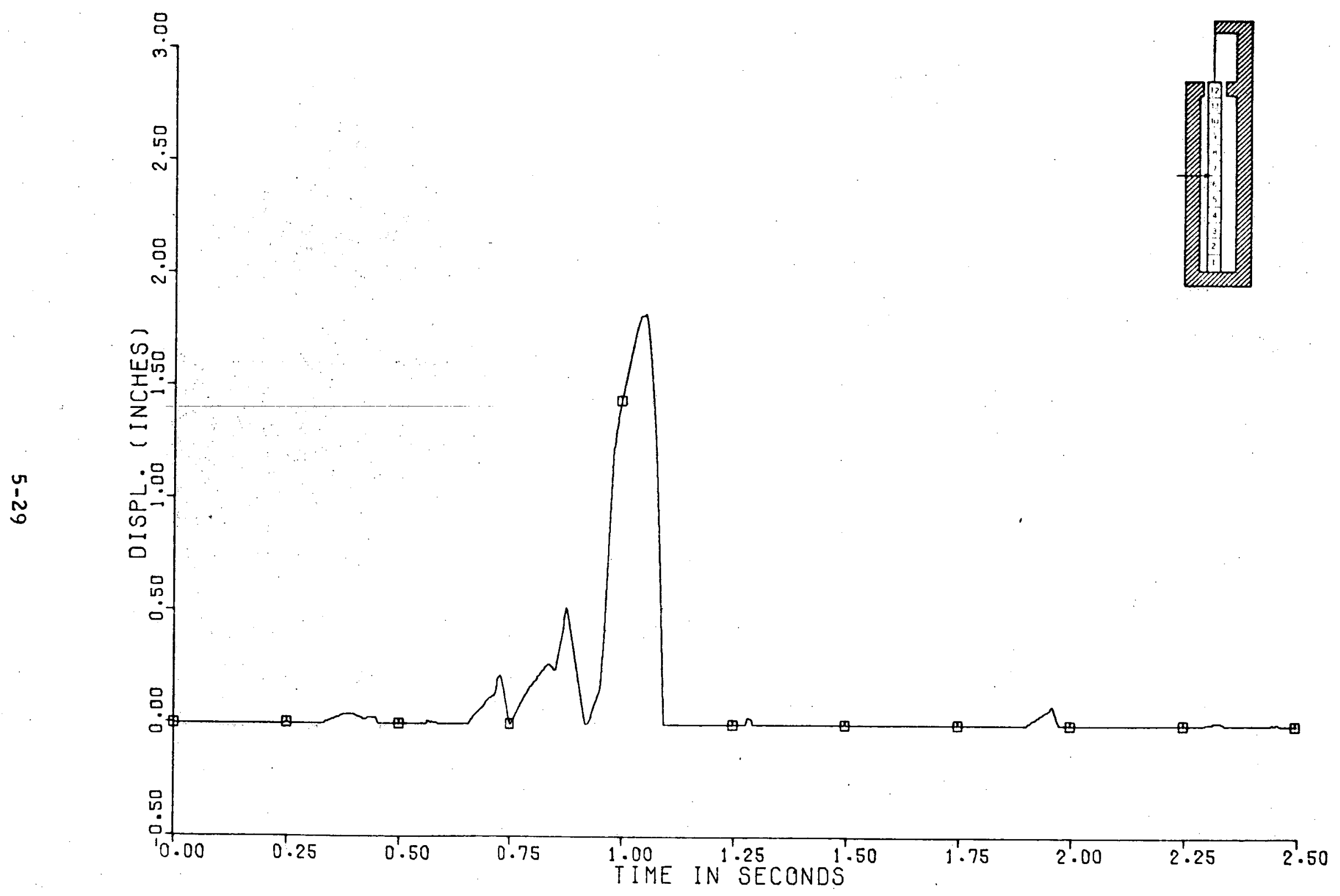

FIGURE 5.17 VERTICAL SEPARATION BETWEEN BLOCKS 6 AND 7 -
CONTROL ROD WITHDRAWN 


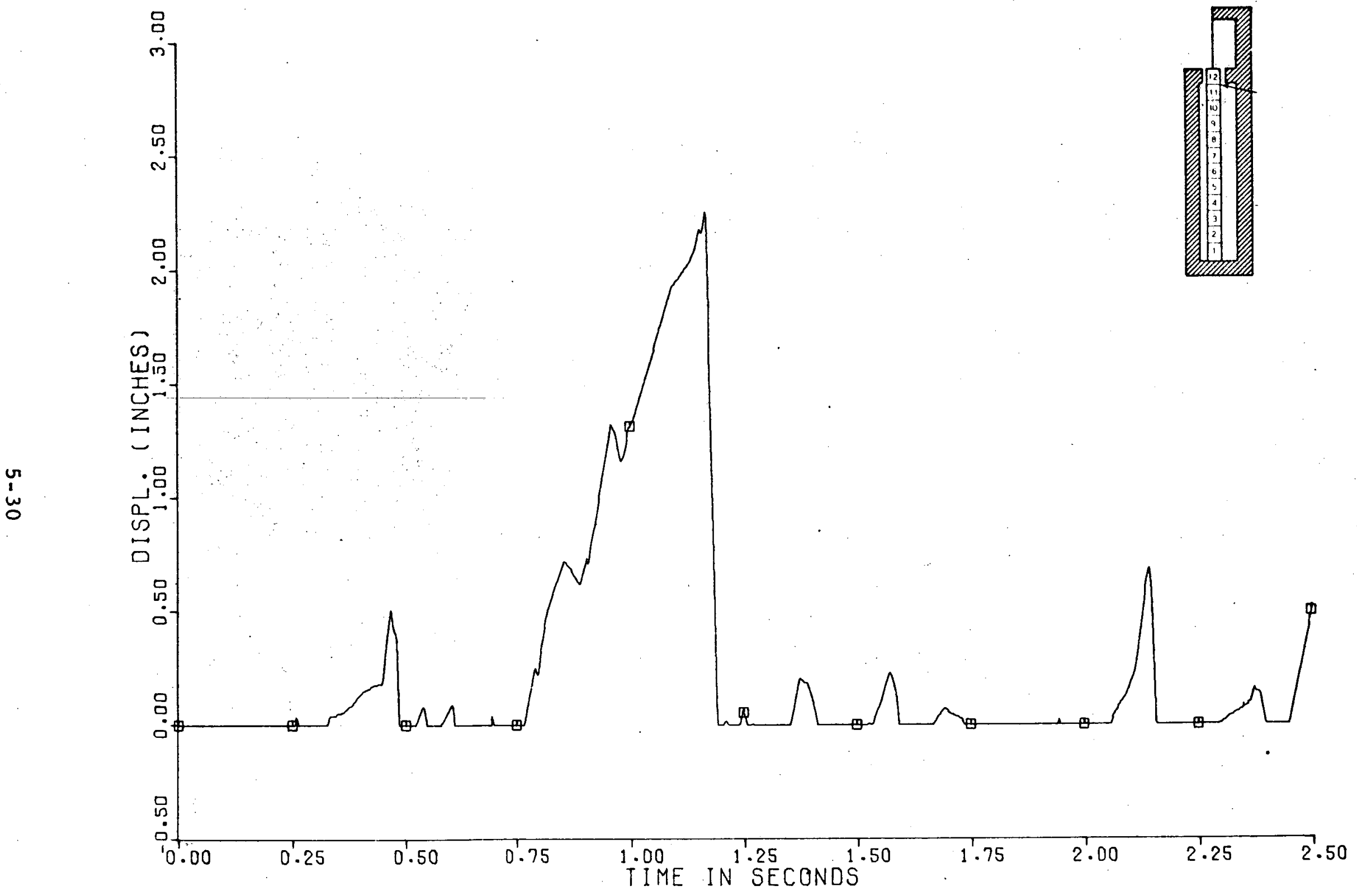

FIGURE 5. 18 VERTICAL SEPARATION BETWEEN BLOCKS 11 AND 12 CONTROL ROD WITHDRAWN 


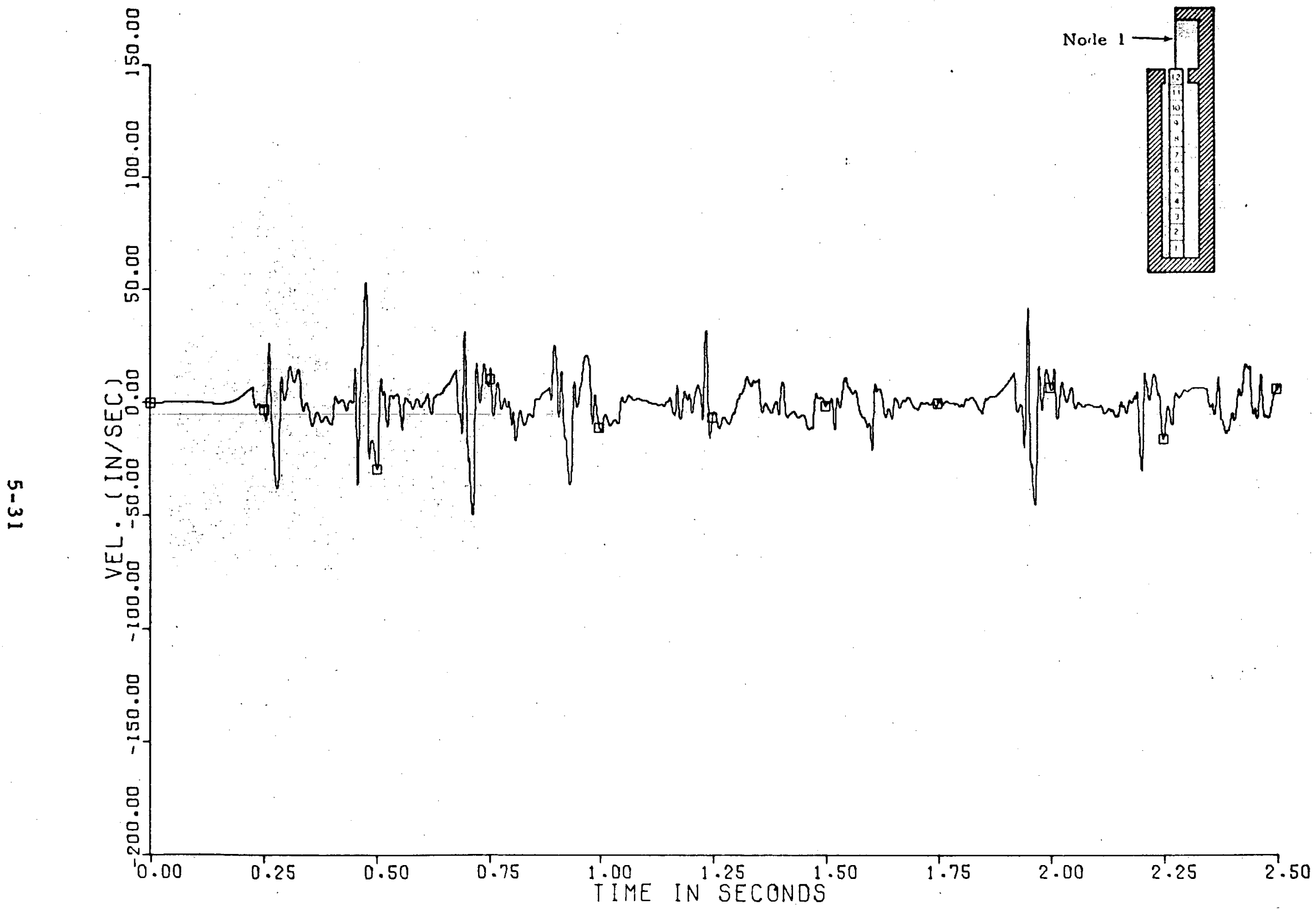

FIGURE 5. 19 HORIZONTAL RELATIVE VELOCITY BETWEEN CONTROL RỌD AND GUIDE TUBE AT CR NODE 1 - CONTROL ROD

FULLY WITHDRAWN ANALYSIS 


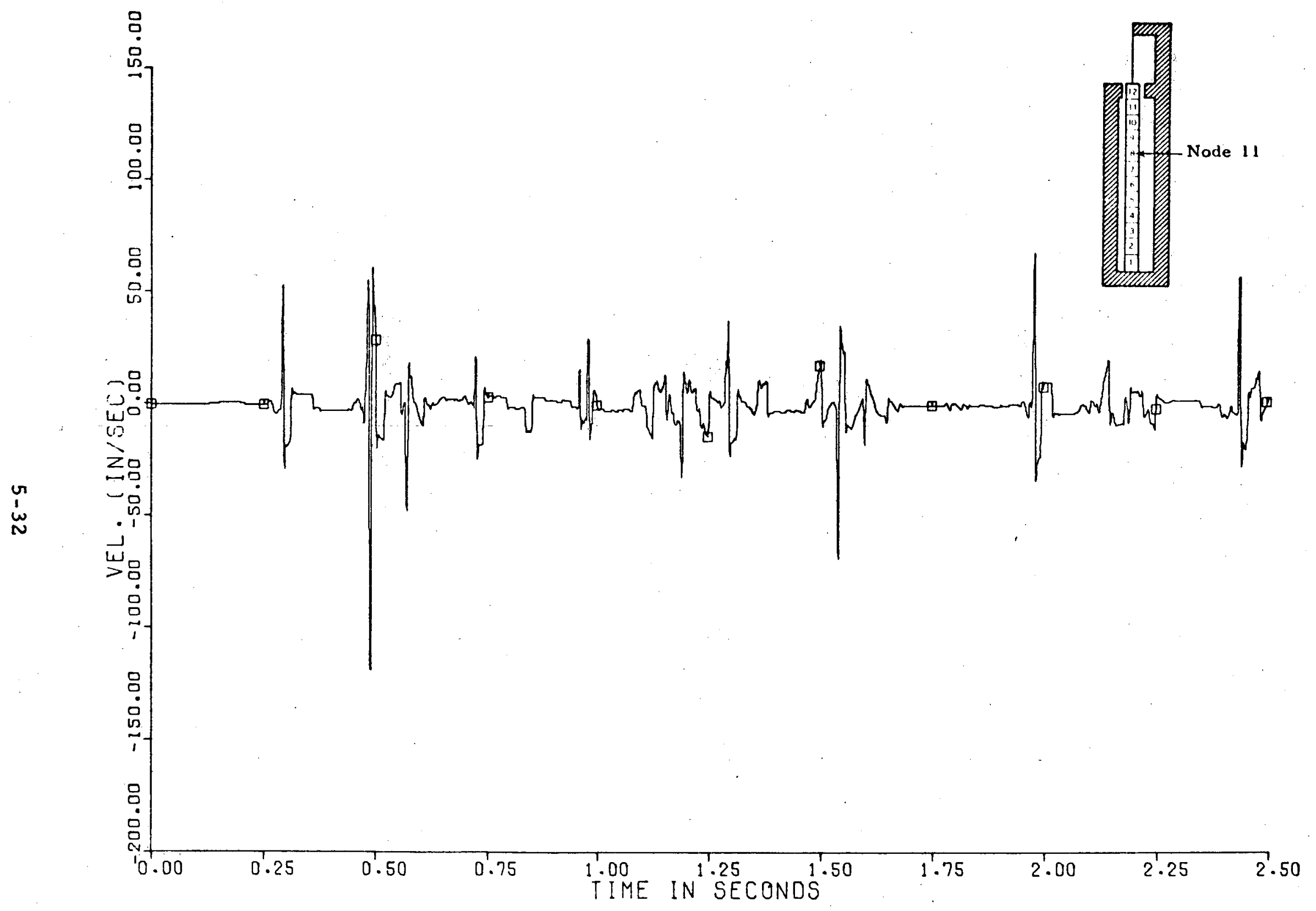

FIGURE 5.20 HORIZONTAL RELATIVE VELOCITY BETWEEN CONTROL ROD

AND CHANNEL AT NODE 11 - CONTROL ROD 1/2 INSERTED ANALYSIS 


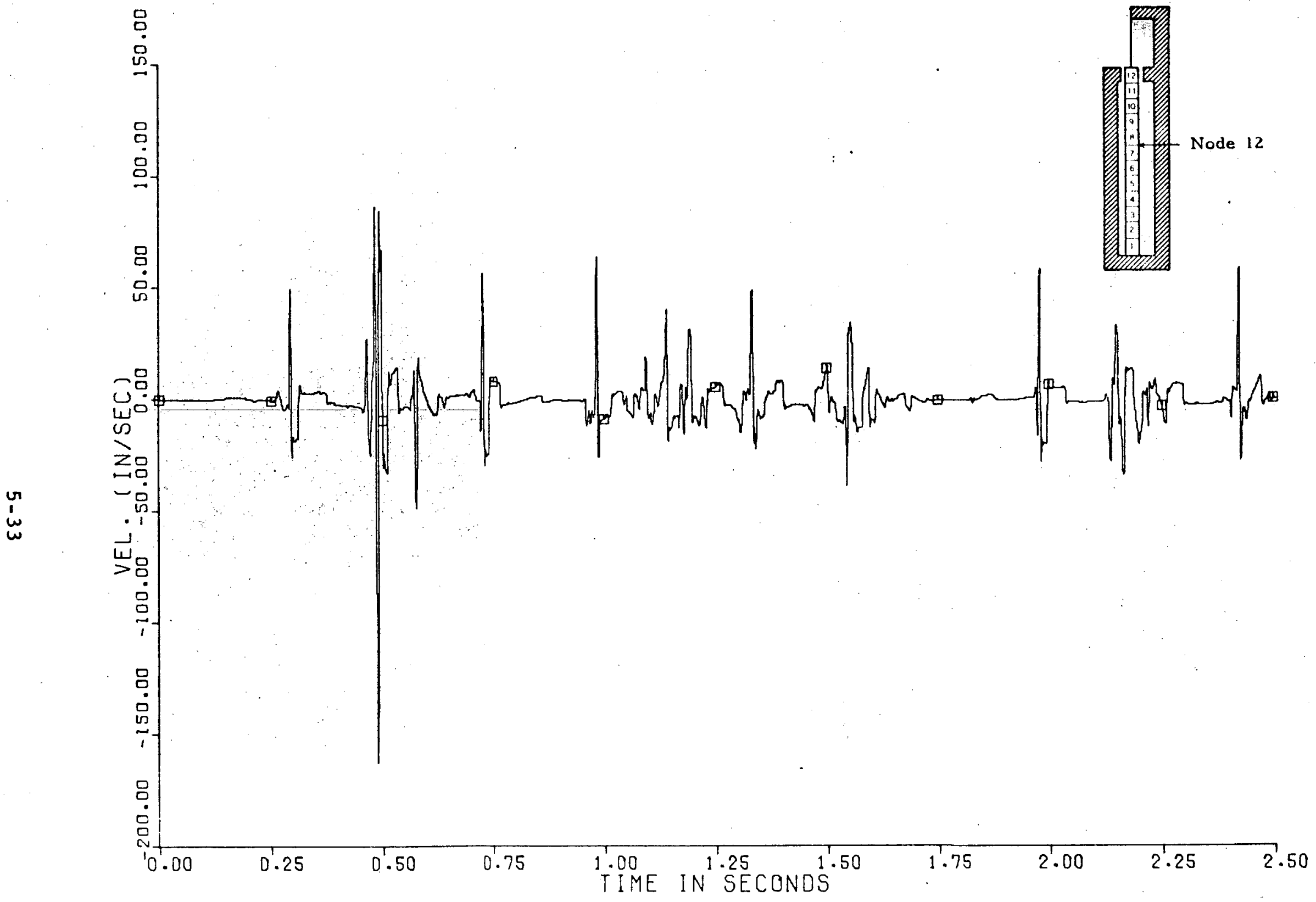

FIGURE 5.21 HORIZONTAL RELATIVE VELOCITY BETWEEN CONTROL ROD AND CHANNEL AT NODE 12 - CONTROL ROD INSERTED ANALYSIS 


\section{RESULTS OF SUPPLEMENTAL ANALYSES}

\subsection{GENERAL}

Additional parametric studies have been performed for the purposes of identifying other possible control rod effects on column response and insuring conservative results. The results and conclusions of these studies are presented in this chapter.

To investigate the influence of lateral gaps on column response, an additional analysis of the rod withdrawn model was performed in which a different gap distribution was used. With the exception of the lateral boundary gaps, the model was identical to the one described in Chapter 3. In this modified model, the gaps for the lower eleven blocks were specified as 2.3 inches for the right boundary and 1.2 inches for the left boundary while plenum element gaps were specified as $0.3 \mathrm{inch}$ and 0.01 inch. Thus the total midheight gap has been increased from 2.6 to 3.5 inches (approximately equal to that expected in a fully ix radiated core under shutdown. conditions) while the total gap for the plenum element has been reduced from 1.2 inches to 0.3 inch. This modified gap distribution was selected because it was believed that it would result in increased block rotation by increasing the simple beam bending mode of response.

A second investigation was performed in which the effects of control rod bindup were considered. As noted earlier, the most significant effect of the control rods on column response would be expected to occur if the relative angle between adjacent column blocks was great enough to cause an individual control rod cannister to bindup within a column. Such an occurrence would greatly increase the rotational stiffness between blocks. Analyses performed in Chapter 5 indicate that during periods of separation, relative angles between blocks may be great enough to cause bindup. Therefore, to assess this effect, an analysis of the rod fully inserted model 
was performed in which the control rods were modeled as continuous tubes along their full length. It was believed that by idealizing the control rod as continuous tubes an upper bound estimate of the increase in rotational stiffness resulting from control rod bindup would be obtained.

The model used in the control rod bindup analysis is identical to the rod fully inserted model described in Chapter 5 with three exceptions. First, the idealized control rod has been treated as a cantilever beam rather than as a shear beam with both rotational and translational beam stiffnesses and nodal degrees of freedom. Second, the stiffness of the beam has been significantly increased and represents approximately the effect of continuous cannisters rather than segmented cannisters. Lastly to provide a further comparison of the response, the modified gap distribution used in the first investigation described in this chapter was also used in this analysis.

The bending stiffness, EI, of the idealized rod was assumed to be $24.5 \times 10^{6} \mathrm{lb} / \mathrm{in}^{2}$ which is approximately 60 percent of the stiffnes of two continuous tubes acting in parallel with dimensions and properties of the control rod cannisters. This stiffness has been assumed to account for the fact that the rods are not actually fully continuous even during bindup.

Both rod fully withdrawn and rod fully inserted modified models were subjected to the horizontal and vertical boundary excitations described in Section 3.5. The analyses were performed using a time step size of 0.0003 seconds and the same impact stiffness damping values were used as in previous analyses.

In the remaining portion of this chapter, the results of the analyses are compared and discussed. 


\subsection{RESULTS OF THE SUPPLEMENTAL ANALYSES}

A comparison of the maximum horizontal column shears between blocks is illustrated in Figure 6.1, a comparison of the maximum column impact velocities in Figure 6.2, and a comparison of the maximum relative angles between column blocks in Figure 6.3. Peak relative velocities of the control rods relative to the channel are illustrated in Figure 6.4. The results of both rod withdrawn and rod inserted cases of both the principal analyses (reported in Chapter 5) and the supplemental analyses are compared in each figure.

Comparative relative displacement time histories between the column and boundary for the supplemental analyses are presented for three column locations in Figures 6.5 through 6.7. Similarly, relative velocity time histories between the column and boundary for the same locations in Figures 6.8 through 6.10. Relative angle time histories at three representative block interfaces are presented in Figures 6.11 through 6.13.

A typical shear force time history for each supplemental case is presented in Figures 6.14 and 6.15. A typical control rod impact velocity time history for each case is presented in Figures 6.16 and 6.17.

\subsection{EFFECTS OF GAP DISTRIBUTION ON COLUMN RESPONSE}

The effect of gap distribution on column response has been assessed by comparing the peak responses for the rod withdrawn case reported in Chapter 5 with the responses resulting from the analysis in which the modified gap distribution was used.

As shown in Figure 6.1, the change in gap distribution resulted in a considerable change in the shear force distribution in the column. For the rod withdrawn case reported in Chapter 5, the largest shear forces were found to occur at the top, middle, and bottom of the column, with the peak shear of 4,800 pounds occurring near the column midheight. For 
the modified gap distribution, the shear increased at the top of the column and decreased in the middle of the column. The peak shear with the modified gap is 6,100 pounds and occurs just below the plenum element. For the gap distribution used in Chapter 5, the peak shear below the top element was 2,900 pounds. The increased shear at the top of the column is caused by the decrease in gap in the top element which in turn restrains motion of the top of the column. This decrease in gap effectively stiffen the upper portion of the column, resulting in more shear load being transferred through the top element. The decrease in shear load at the center of the column indicates that with larger more evenly distributed gaps, the shear forces resulting from impacts become less significant when compared with those resulting from the simple beam bending mode of response. As noted in Chapter 5, simple beam behavior results in high shears at the top and bottom of the column and lower shears in the center of the column. The high shears in the center of the column reported in Chapter 5 are the result of impacts of the column with the left boundary. By increasing the left boundary gap, these impact shears have been significantly reduced while the shears at the top of the column caused by beam behavior have been increased.

The peak column velocities were found to be only slightly affected by the change in gap distribution. The peak velocities in both rod withdrawn cases occur near the center of column and decrease at the top and bottom which is indicative of simple beam behavior. The peak velocity for the modified gap distribution is 140 inches/sec. as compared with a peak velocity of 124 inches/sec. for the basic gap distribution. Thus the increased gap has caused about a 15 percent increase in the peak velocity. It is expected that a corresponding increase would occur in the peak impact force in the column elements. 
The peak relative angles were found also to be affected by gap distribution. In general larger angles occurred throughout the column for the modified gap distribution especially near the top of the column where the peak angle reached 8.0 degrees. The peak angle for the basic gap distribution was only 5.9 degrees, thus the modified gap distribution resulted in a 35 percent increase in the relative rotations. This increase in response is reasonable since larger gaps permit larger relative rotations of the blocks. It should be noted that in both cases, the peak relative angles occurred during periods of vertical separations when there is essentially no rotational stiffness between blocks. During other periods, peak rotations do not exceed 3.5 degrees.

\subsection{EFFECT OF MODIFIED CONTROL ROD ON COLUMN RESPONSE}

The effect of control rods which have been stiffened to conservatively simulate the effect of cannister bindup on column response has been assessed in two ways. First, the column response from the modified rod fully inserted analysis has been compared with response from the modified rod withdrawn analysis. Secondly, the results of the modified control rod fully inserted analysis are compared with the results of the basic control rod fully inserted analysis presented in Chapter 5.

The effect of insertion of the modified control rod on the lateral column response was similar to those reported for the basic control rod model in Chapter 5. During the first 0.7 seconds, the modified rod has apparently no effect on response since both the lateral column displacement and velocity time histories match closely (see Figures 6.5 through 6.10). Deviations in responses begin to occur between 0.7 and 1.2 seconds. As discussed in Chapter 5 , during this period significant vertical separations between elements a re found to occur throughout the column. Since the rotational stiffnes between blocks is negligible during such periods, the individual fuel elements become very sensitive to the 
lateral impact and stiffness of the control rods. Once the blocks fall back onto one another, they are no longer sensitive and the responses again match closely.

Peak column impact velocities for both the modified rod inserted and rod withdrawn cases are shown in Figure 6.2. In the upper portion of the column into which the rod has been inserted, the impact velocities are between 15 to 25 percent less than those predicted to occur in a column in which the rods have been withdrawn. At levels below the bottom of the control rod, the responses for the two cases are nearly identical. The peak velocity with the rod inserted in 124 inches/sec., while with the rod withdrawn, the peak velocity is 140 inches/sec. Peak column velocities for the modified rod inserted case were also found to be slightly less than those computed for the rod inserted case described in Chapter 5 even though the gaps are larger. Thus it can be concluded that the increased rotational stiffness between blocks associated with control rod cannisters bindup would reduce the lateral column velocity slightly (about 15 percent).

The peak relative angles between blocks were greatly affected by the increased rod stiffness. As seen in Figure 6.3, in the zone of rod insertion, the peak rotations were reduced from a maximum of 6.5 degrees with the rod withdrawn to less than 2.1 degrees with the rod inserted. Note that the modified rod stiffness also results in a reduction from the relative angles reported in the principal analyses. Using the equivalent pendulum stiffness used in the Chapter 5 analyses, the peak angles in the portion of the column in which the rod is contained is 3. 7 degrees. Below the bottom tip of the rod, relative angles increase and are nearly equal to those predicted to occur with the rod withdrawn. An examination of the relative angle time histories reveal that all larger angles occur at times when vertical separations occur between the blocks. At all other times, the angeles for both cases are less than 3.5 degrees with the control rod inserted response 
in general slightly less than the rod withdrawn response. Thus, the increase in control rod stiffness greatly reduces and limits rotations between blocks during periods of separation and also tends to slightly reduce rotations during other periods.

The insertion of the modified control rod was found to effect the horizontal shears significantly at only one location. At the top of the column, the horizontal shear force is 6,100 pounds with the rod withdrawn and 3,800 pounds with rod inserted. However, throughout the remainder of the column, the peak shears match closely with the peaks shears not exceeding 4,000 pounds. Comparing the shear time histories at the column midheight (Figures 6.13 and 6.14), one finds that with the control rod inserted, large shear spikes are generally reduced. Therefore, while no trends in the shear distribution related to control rod insertion depth are apparent, the insertion of control rods appears to reduce shear forces at local regions in the column.

\subsection{CONTROL ROD RESPONSE}

The response of the modified control rod was found to match closely the response of the column. As shown in Figure 6.4, the peak relative velocity between the control rod and column with the rod fully inserted occurs at the midheight of the column at the same point as the peak column impact velocity with the boundary. The peak control rod impact velocity is 127 inches/sec. as compared to a peak column velocity of $124 \mathrm{inches} / \mathrm{sec}$. The increased stiffness of the modified control rod has two apparent effects. First it reduces the column velocity response slightly and second it causes the control rod to more closely follow the column motion. These effects result in an overall 25 percent reduction in the peak control rod velocity from that predicted to occur in the principal analyses presented in Chapter 5. 
Time histories of the control rod relative velocities are plotted for each case in Figures 6.16 and 6.17. The responses are similar to those presented in Chapter 5, with impacts tending to occur at a frequency of four per second and with the peak impact velocity coinciding with the time of occurrence of the peak column velocity $(0.49$ seconds $)$.

\subsection{SUMMARY OF RESULTS OF SUPPLEMENTAL ANALYSES}

In the first analysis, the lateral gap distribution was modified for the purpose of investigating the influence of gaps on column response. In the second analysis, the control rods were treated as continuous tubes for the purpose of assessing the effects cannister bindup would have on column response. Highlights of the results are presented below.

1. The lateral boundary gap distribution was found to be a significant factor in core column response. It was found that a highly skewed gap distribution (as used in the analyses reported in Chapter 5) resulted in large shears at top, middle, and bottom of the column. A gap distribution with larger more evenly distributed gaps at the midheight and smaller gaps in the top element resulted in an increase in the shears at top of the column and a decrease in shears in the center of the column. The larger midheight gaps also resulted in slight increases (about 15 percent) in the column lateral velocity and significant increases in the peak rotations between blocks (about:35 percent).

2. Inserted control rods stiffened to simulate the effects of cannister bindup we re found to significantly effect column response only during periods when vertical separations occurred between blocks. 
3. During periods of separation, the stiffened control rods have a significant effect on the relative rotation response of column. Stiffened fully inserted rods reduce rotations from 6.5 degrees to 2.1 degrees in the portions of the column in which they are located. Below the bottom tip of the control rod, column rotations were relatively unaffected.

4. Stiffened fully inserted rods were also found to reduce the lateral velocity response of the column slightly (15 percent) in the region of the column in which the rod is inserted.

5. In general, peak shear forces were generally unaffected by the stiffened rods although high peak shear spikes in some local areas were reduced with the rods inserted.

6. With the control rod stiffened, control rod impact velocities were reduced by approximately 25 percent from those reported in Chapter 5. This reduction occurs because the stiffened control rods tend to reduce column velocity and because the bending continuity of the control rod causes the rods to mare closely follow the column response. 
Column Shears
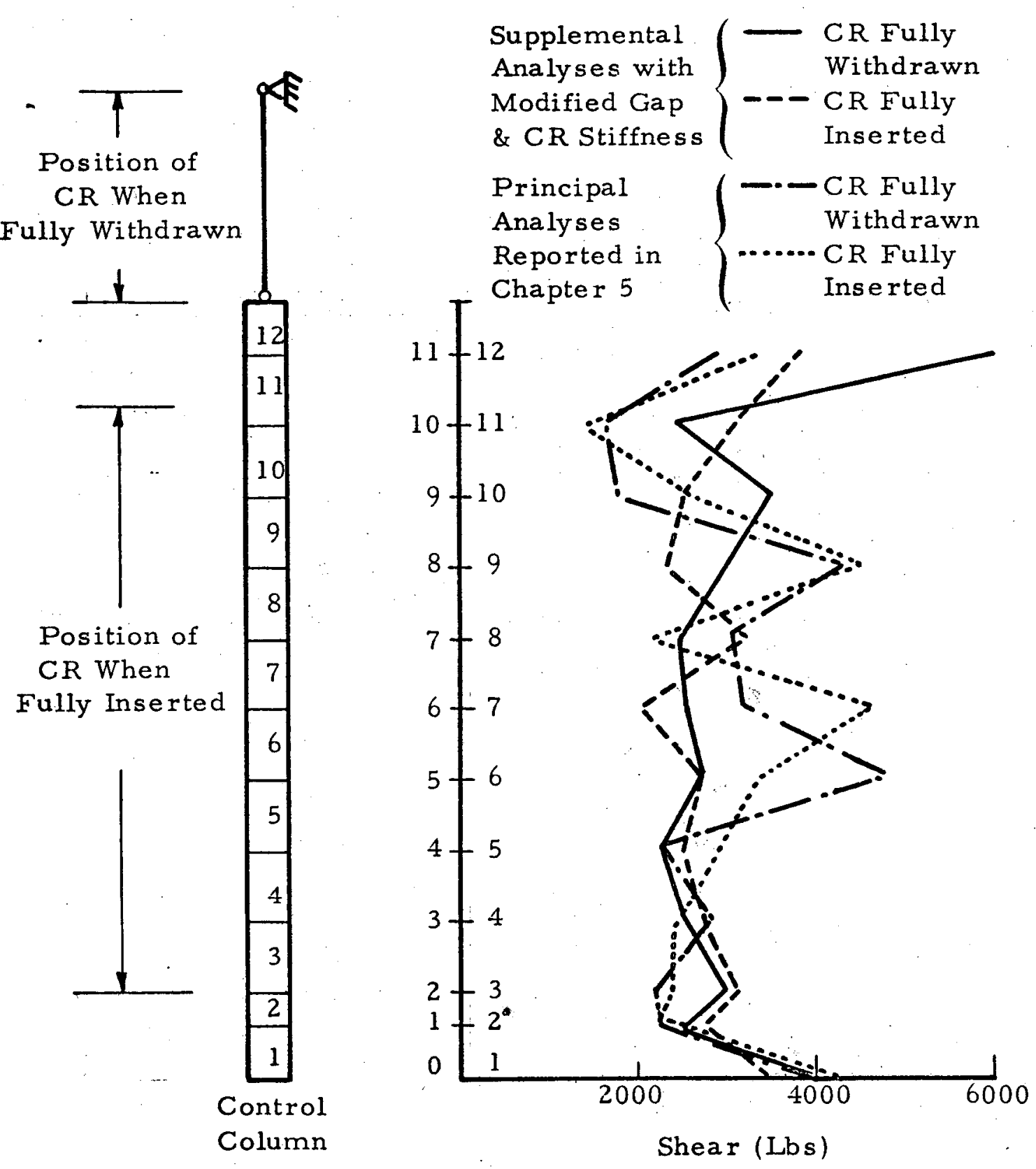

FIGURE 6.1 COMPARISON OF PEAK COLUMN RESPONSE FOR CONTROL ROD WITHDRAWN AND INSERTED PRINCIPAL AND SUPPLEMENTAL ANALYSES HORIZONTAL SHEARS BETWEEN BLOCKS 
Column

Lateral Velocity
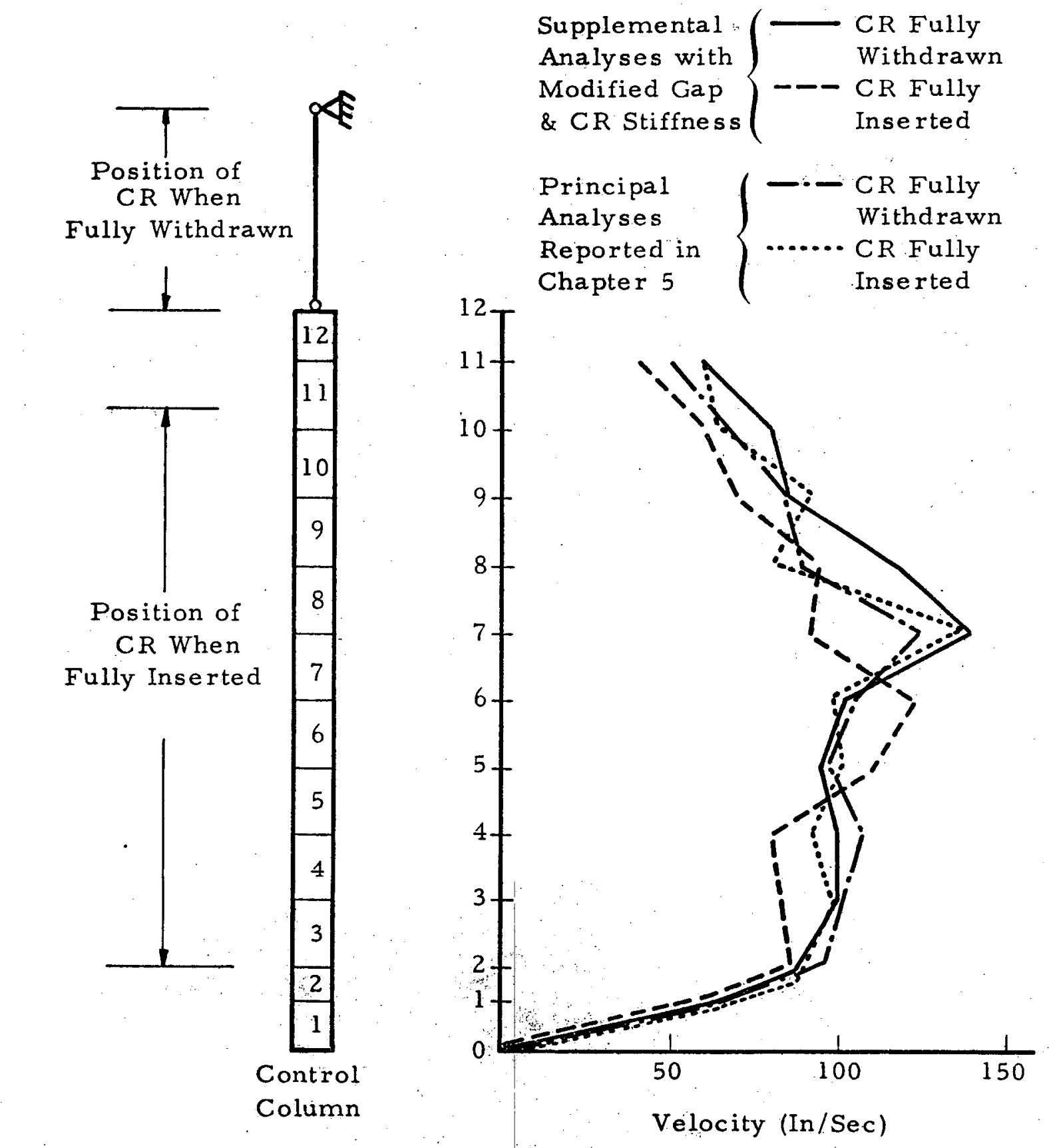

FIGURE 6.2 COMPARISON OF PEAK COLUMN RESPONSE FOR CONTROL ROD WITHDRAWN AND INSERTED

PRINCIPAL AND SUPPLEMENTAL ANALYSES

HORIZONTAL RELATIVE VELOCITY BETWEEN

COLUMN AND BOUNDARY

$$
6-11
$$




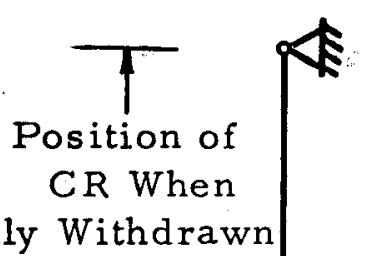

Fully Withdrawn

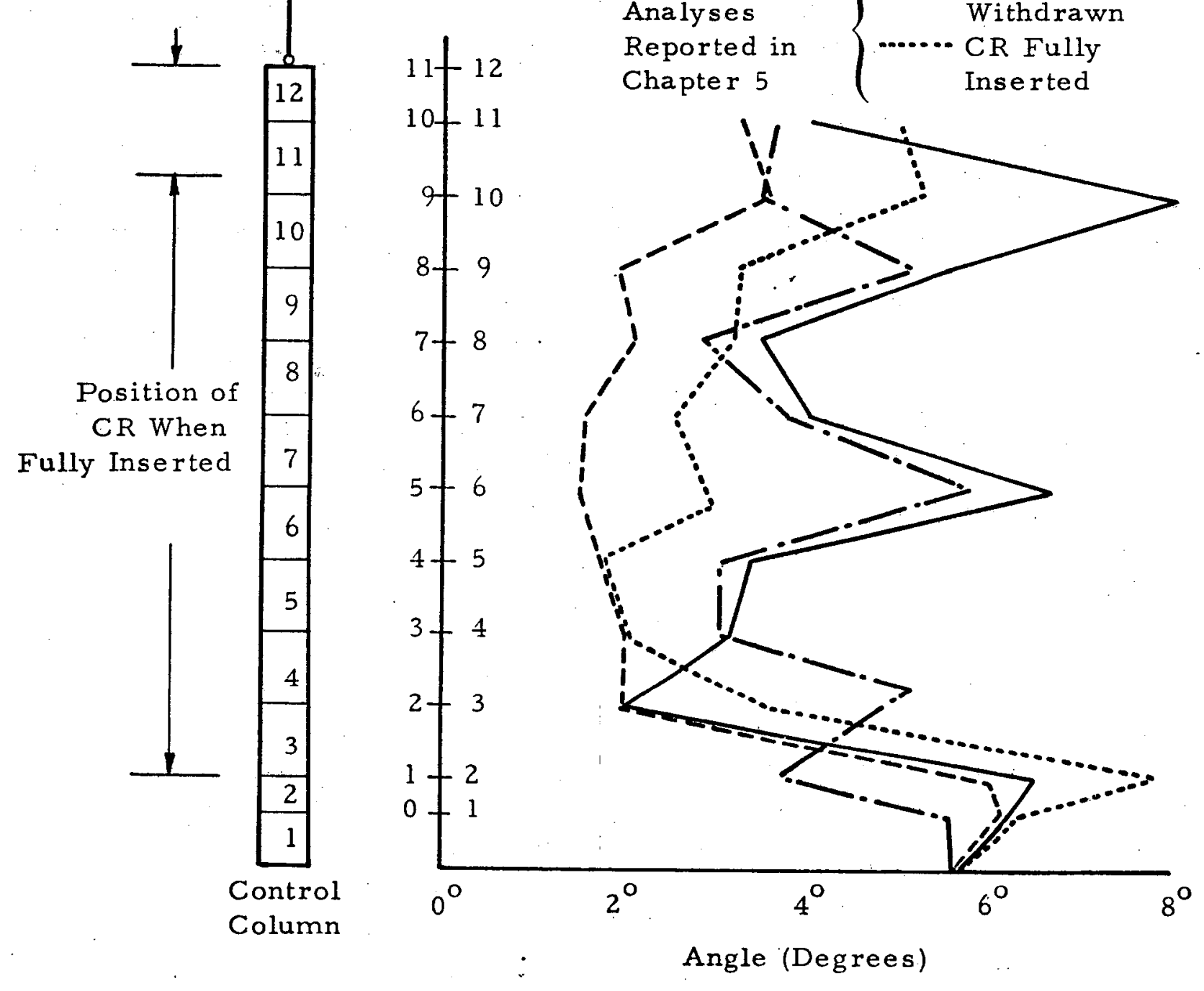

Relative Angle

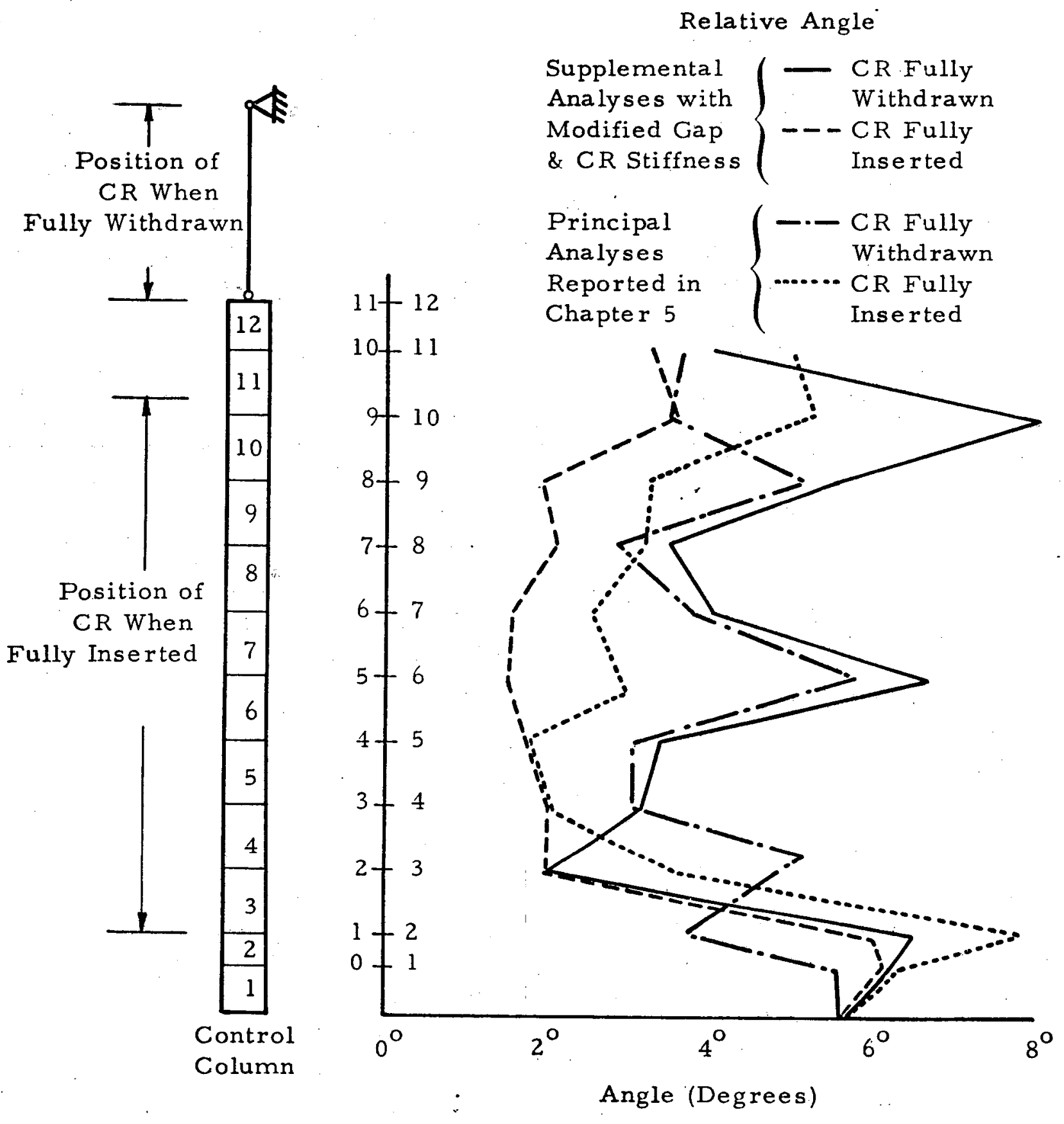

FIGURE 6. 3 COMPARISON OF PEAK COLUMN RESPONSE FOR CONTROL ROD WITHDRAWN AND INSERTED PRINCIPAL AND SUPPLEMENTAL ANALYSES RELATIVE ANGLE BETWEEN BLOCKS 


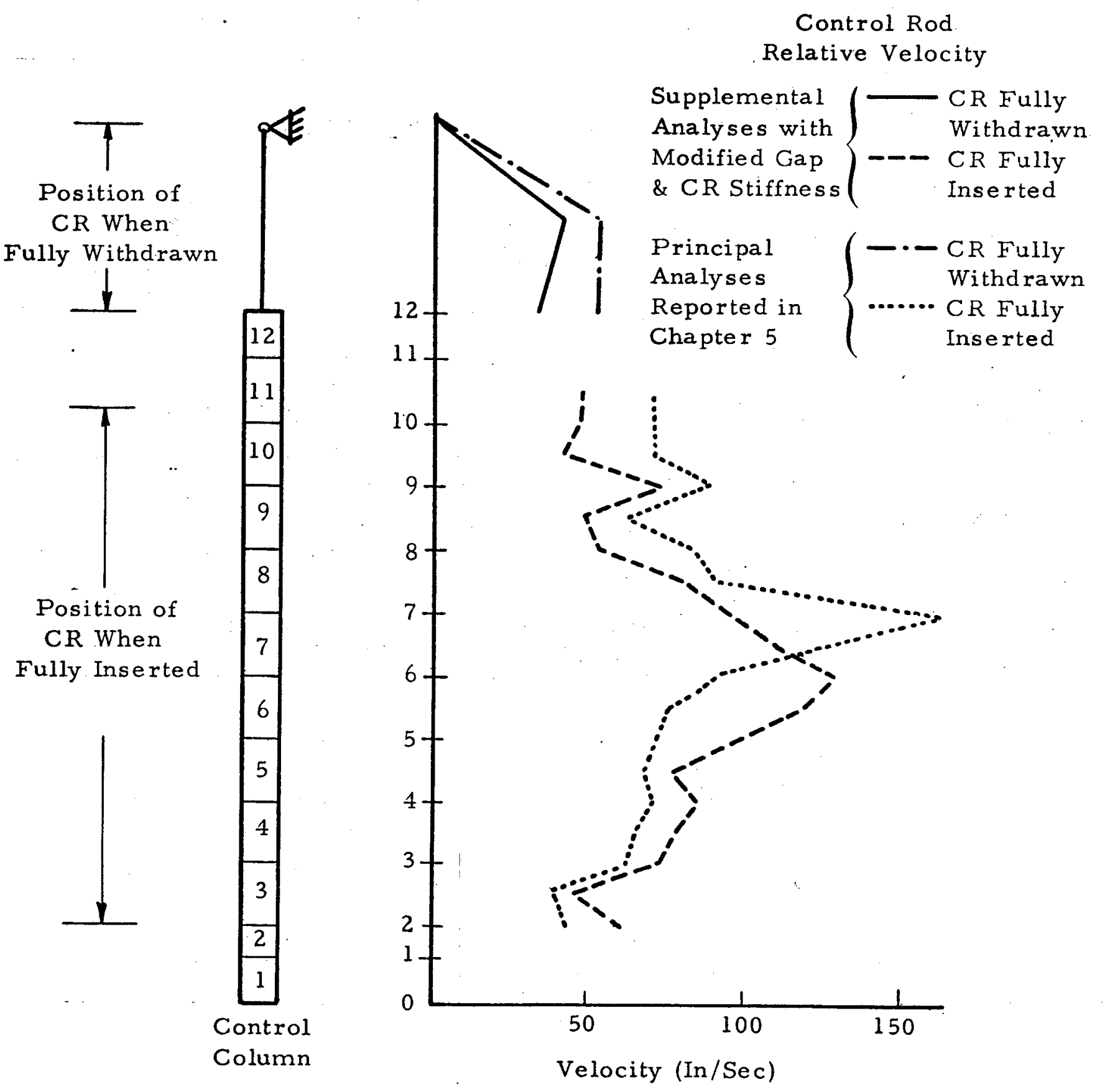

FIGURE 6. 4 COMPARISON OF PEAK CONTROL ROD RESPONSE FOR CONTROL ROD WITHDRAWN AND INSERTED

PRINCIPAL AND SUPPLEMENTAL ANALYSES

HORIZONTAL RELATIVE VELOCITY BETWEEN CONTROL

ROD AND CONTROL ROD CHANNEL 


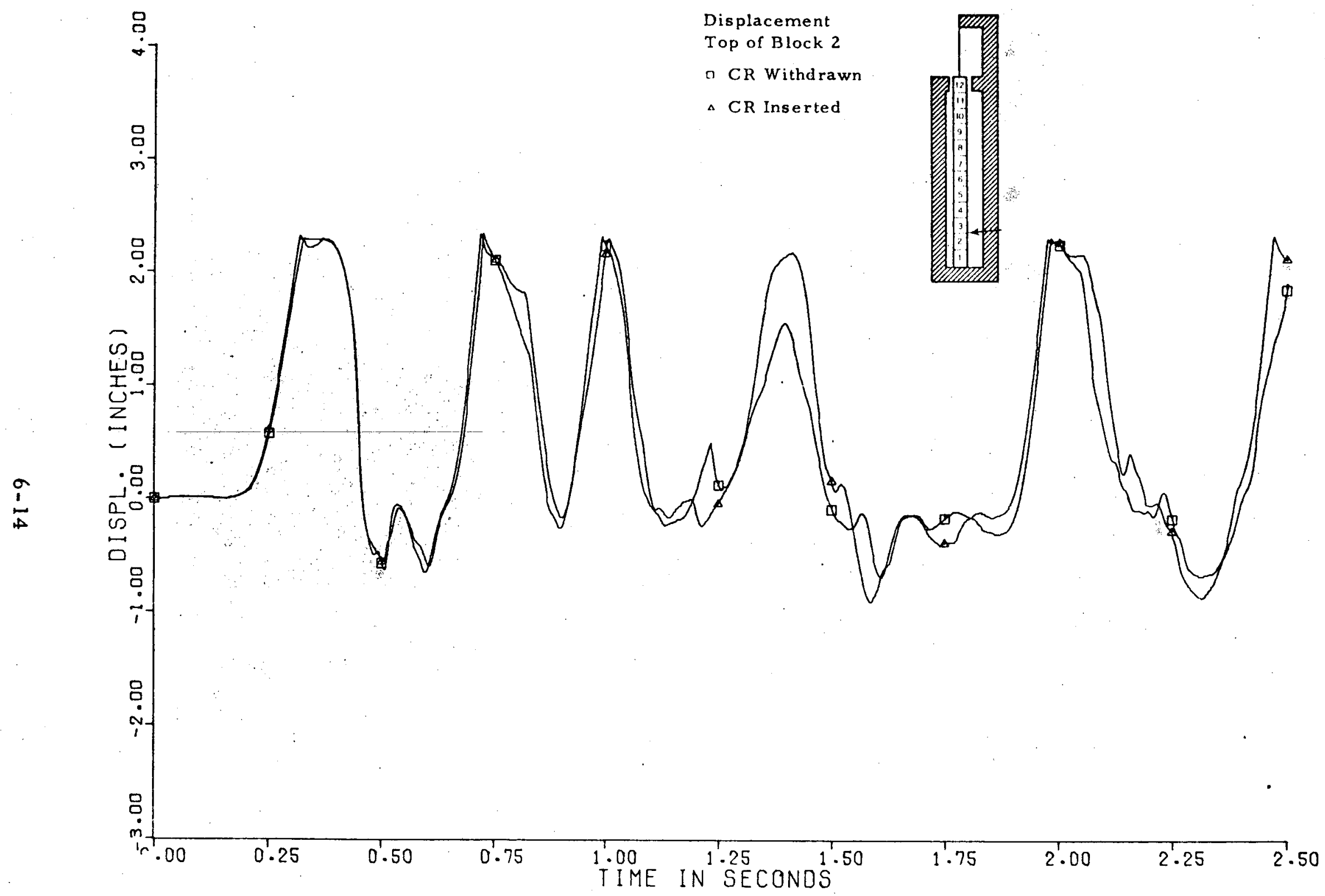

FIGURE 6.5 COMPARISON OF COLUMN RESPONSE FOR CONTROL RODS WITHDRAWN AND INSERTED

SUPPLEMENTAL ANALYSES WITH MODIFIED GAP AND CONTROL ROD STIFFNESS RELATIVE HORIZONTAL DISPLACEMENT BETVEEN TOP OF BLOCK 2 AND BOUNDARY 


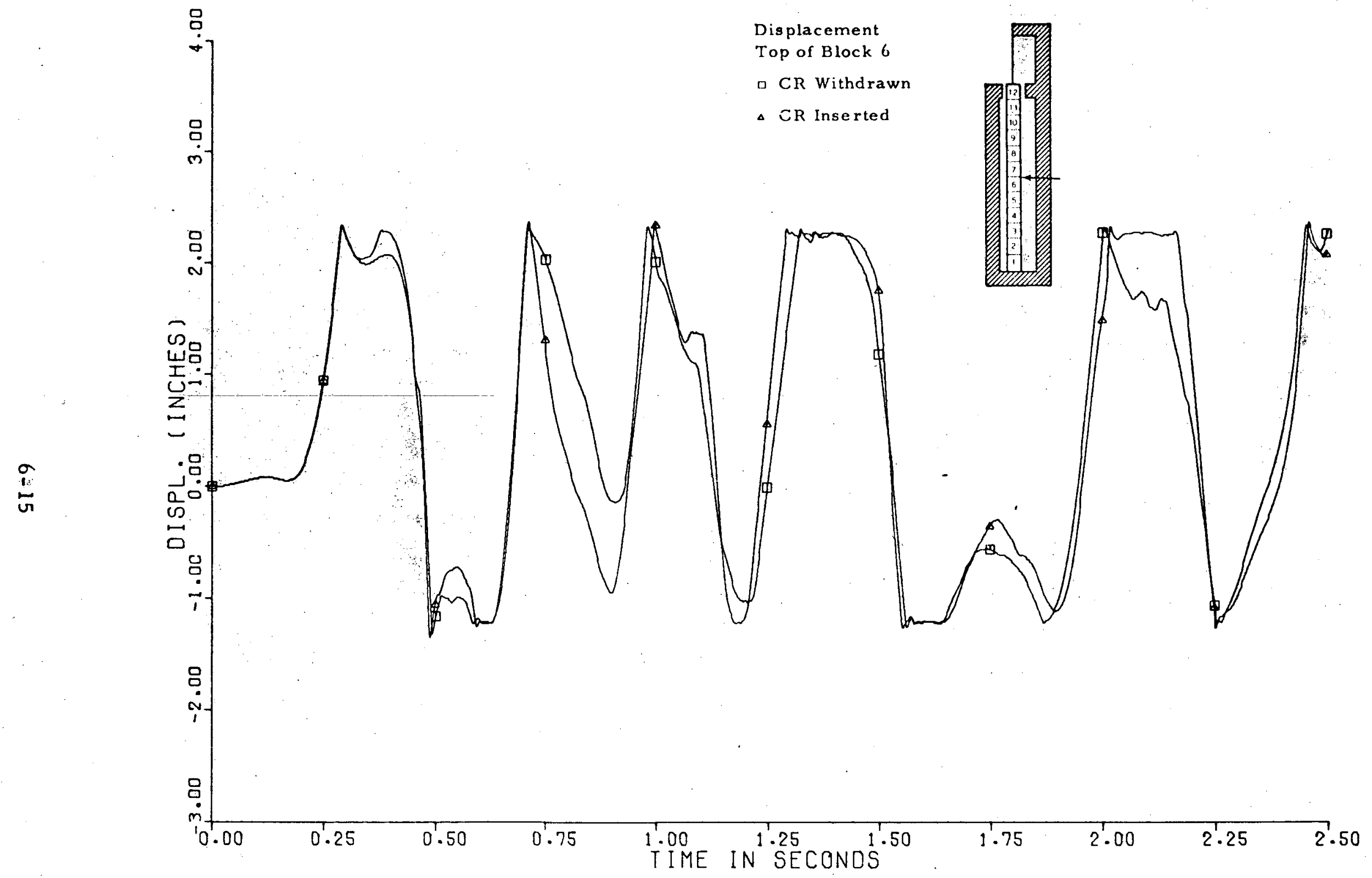

FIGURE 6. 6 COMPARISON OF COLUMN RESPONSE FOR CONTROL RODS WITHDRAWN AND INSERTED

SUPPLEMENTAL ANALYSES WITH MODIFIED GAP AND CONTROL ROD STIFFNESS RELATIVE HORIZONTAL DISPLACEMENT BETWEEN TOP OF BLOCK 6 AND BOUNDARY 


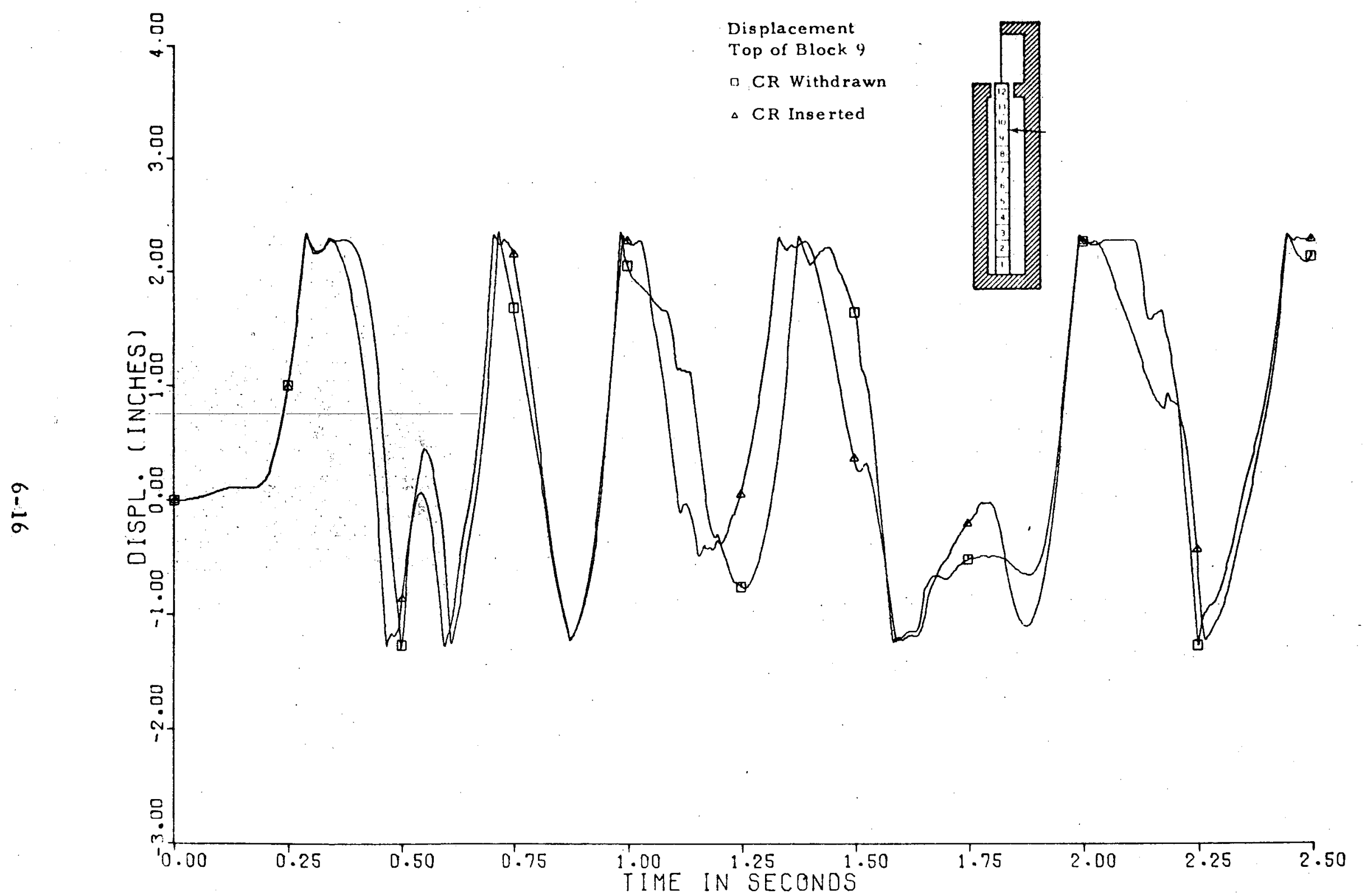

FIGURE 6. 7 COMPARISON OF COLUMN RESPONSE FOR CONTROL RODS WITHDRAWN AND INSERTED

SUPPLEMENTAL ANALYSES WITH MODIFIED GAP AND CONTROL ROD STIFFNESS

RELATIVE HORIZONTAL DISPLACEMENT BETWEEN TOP OF BLOCK 9 AND BOUNDARY 


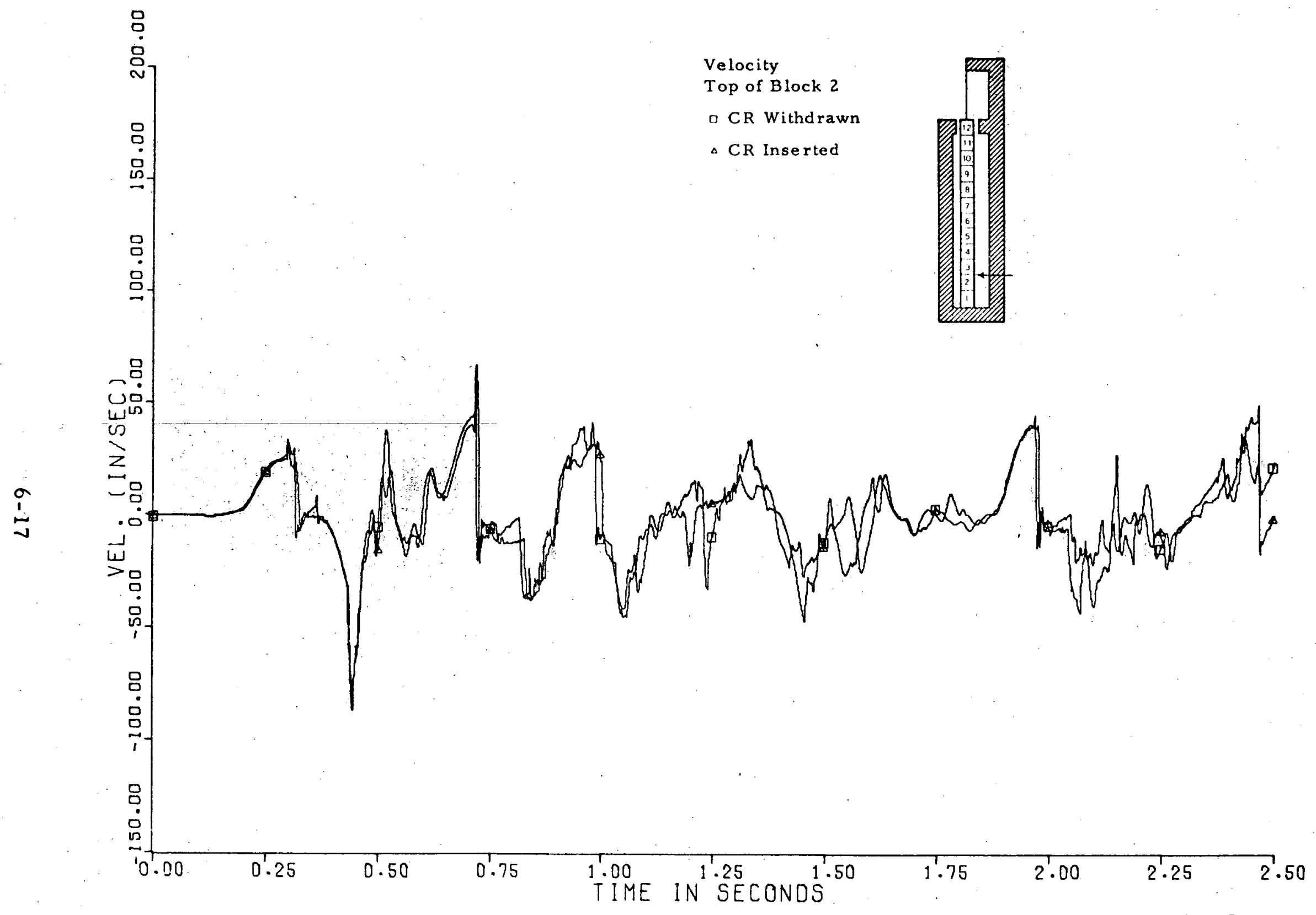

FIGURE 6. 8 COMPARISON OF COLUMN RESPONSE FOR CONTROL RODS WITHDRAWN AND INSERTED

SUPPLEMENTAL ANALYSES WITH MODIFIED GAP AND CONTROL ROD STIFFNESS RELATIVE HORIZONTAL VELOCITY BETWEEN TOP OF BLOCK 2 AND BOUNDARY 


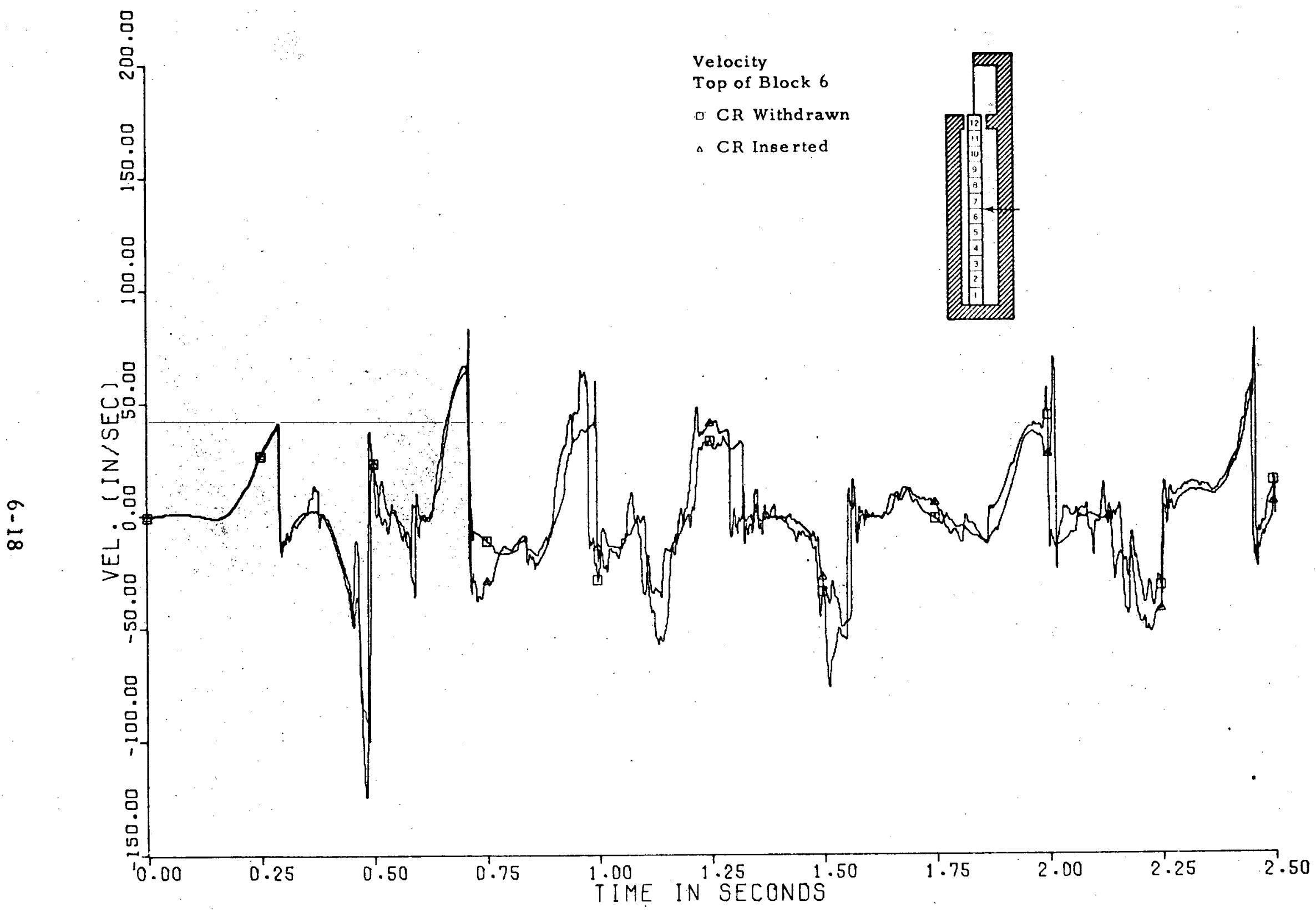

FIGURE 6. 9 COMPARISON OF COLUMN RESPONSE FOR CONTROL RODS WITHDRAWN AND INSERTED

SUPPLEMENTAL ANALYSES WITH MODIFIED GAP AND CONTROL ROD STIFFNESS RELATIVE HORIZONTAL VELOCITY BETWEEN TOP OF BLOCK 6 AND BOUNDARY 


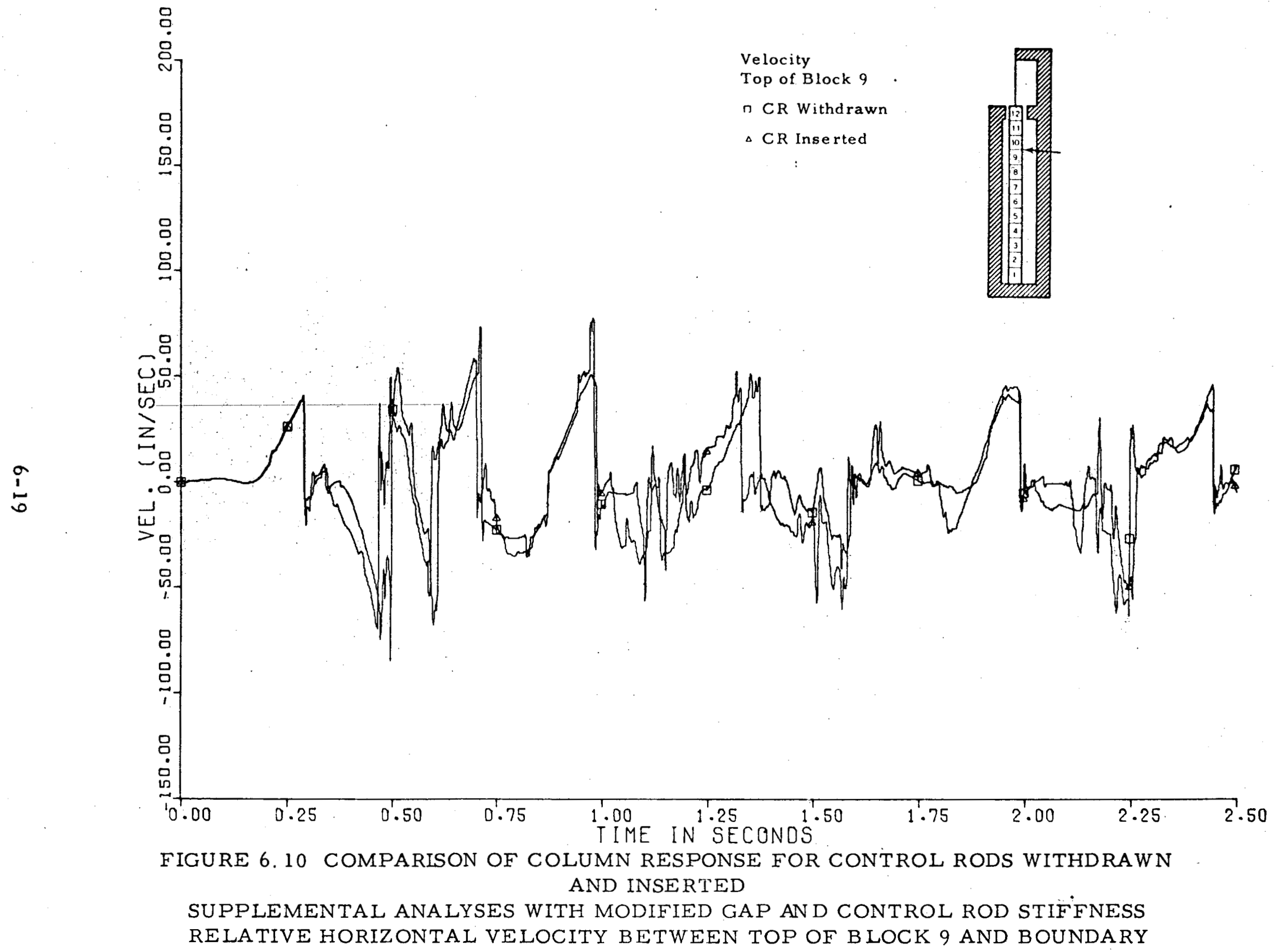




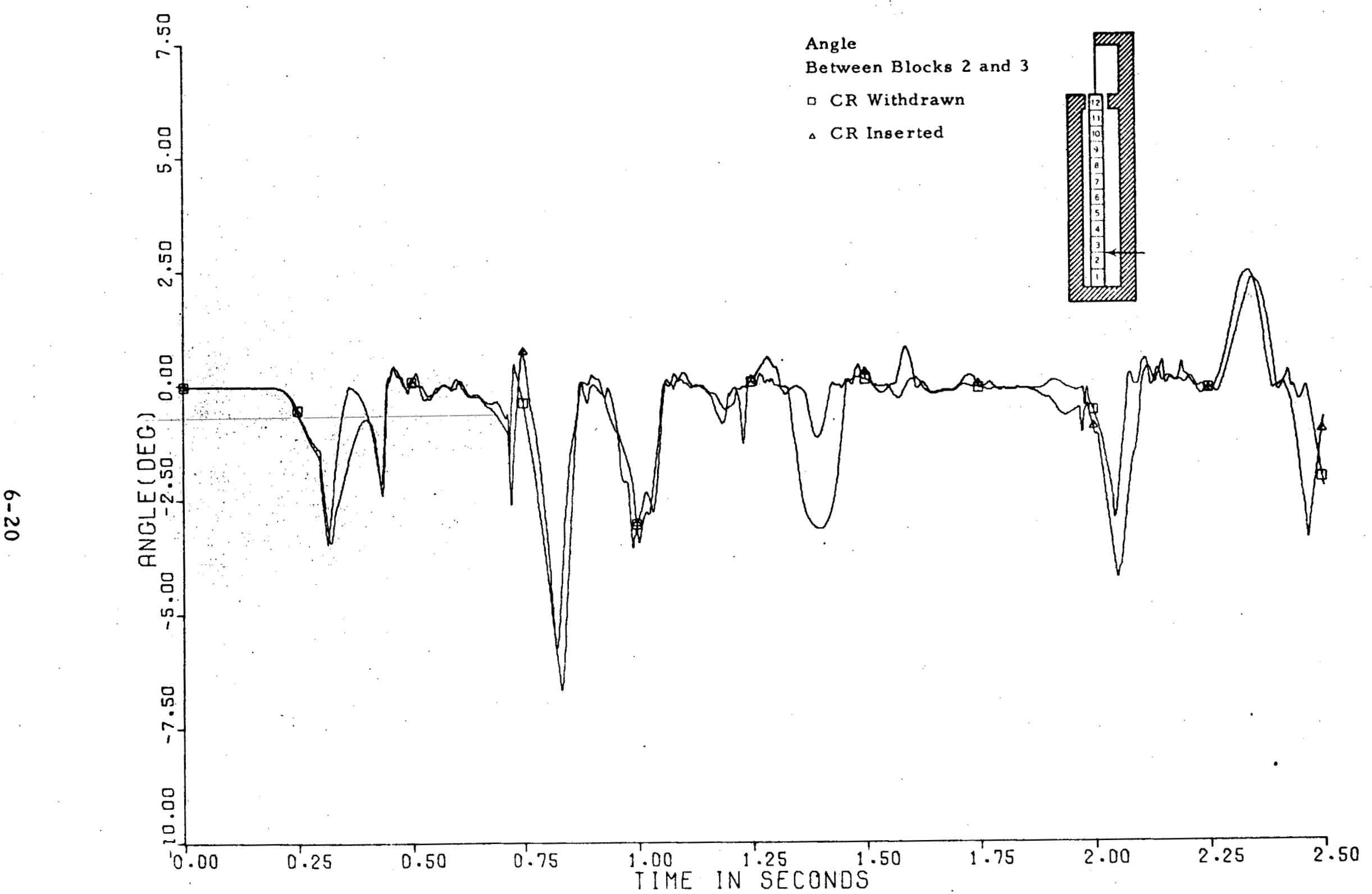

FIGURE 6.11 COMPARISON OF COLUMN RESPONSE FOR CONTROL RODS WITHDRAWN AND INSERTED

SUPPLEMENTAL ANALYSES WITH MODIFIED GAP AND CONTROL ROD STIFFNESS RELATIVE ANGLE BETWEEN BLOCKS 2 AND 3 


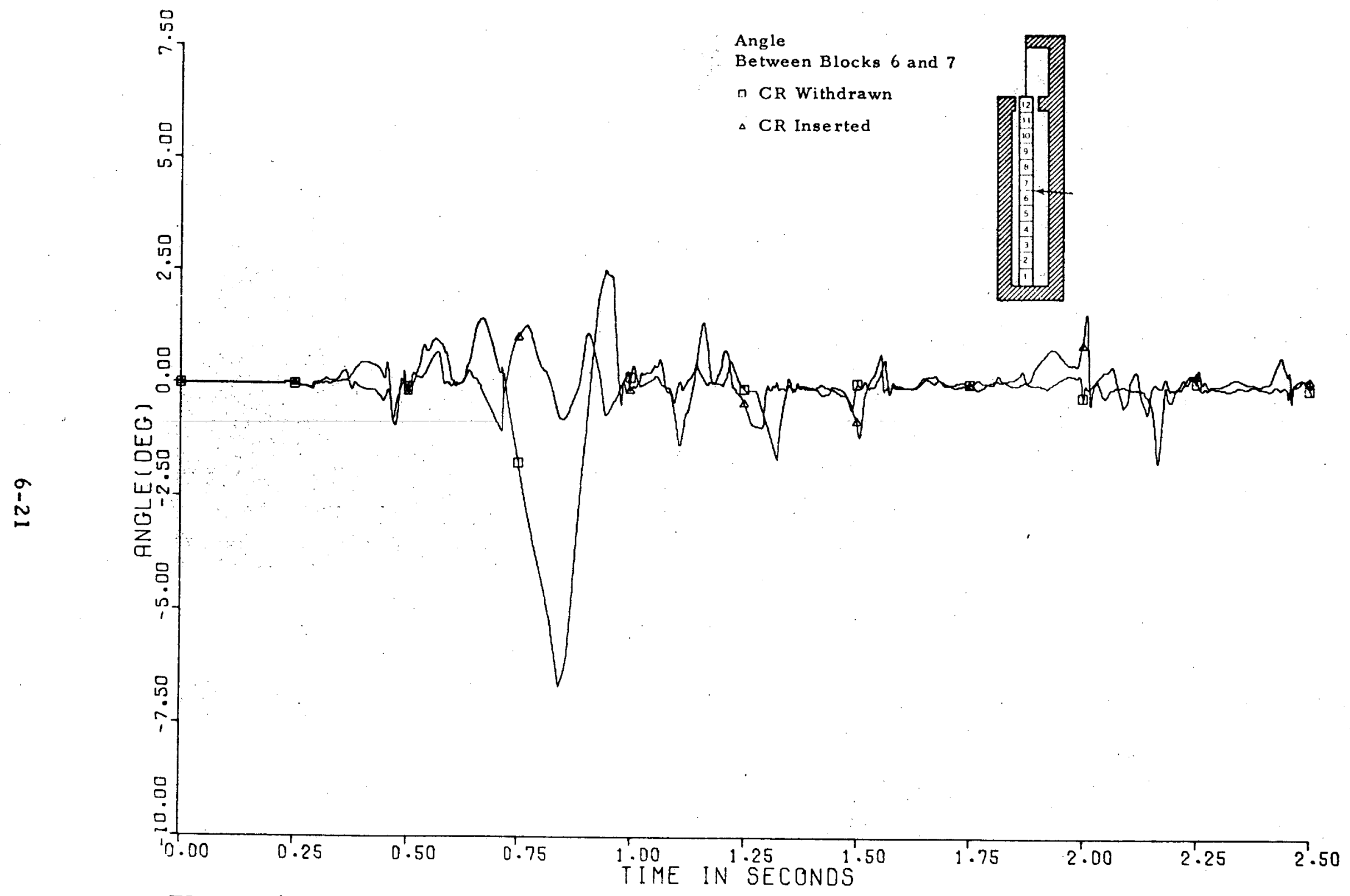

FIGURE 6.12 COMPARISON OF COLUMN RESPONSE FOR CONTROL RODS WITHDRAWN AND INSERTED

FOR SUPPLEMENTAL ANALYSES WITH MODIFIED GAP AND CONTROL ROD STIFFNESS RELATIVE ANGLE BETWEEN BLOCKS 6 AND 7 


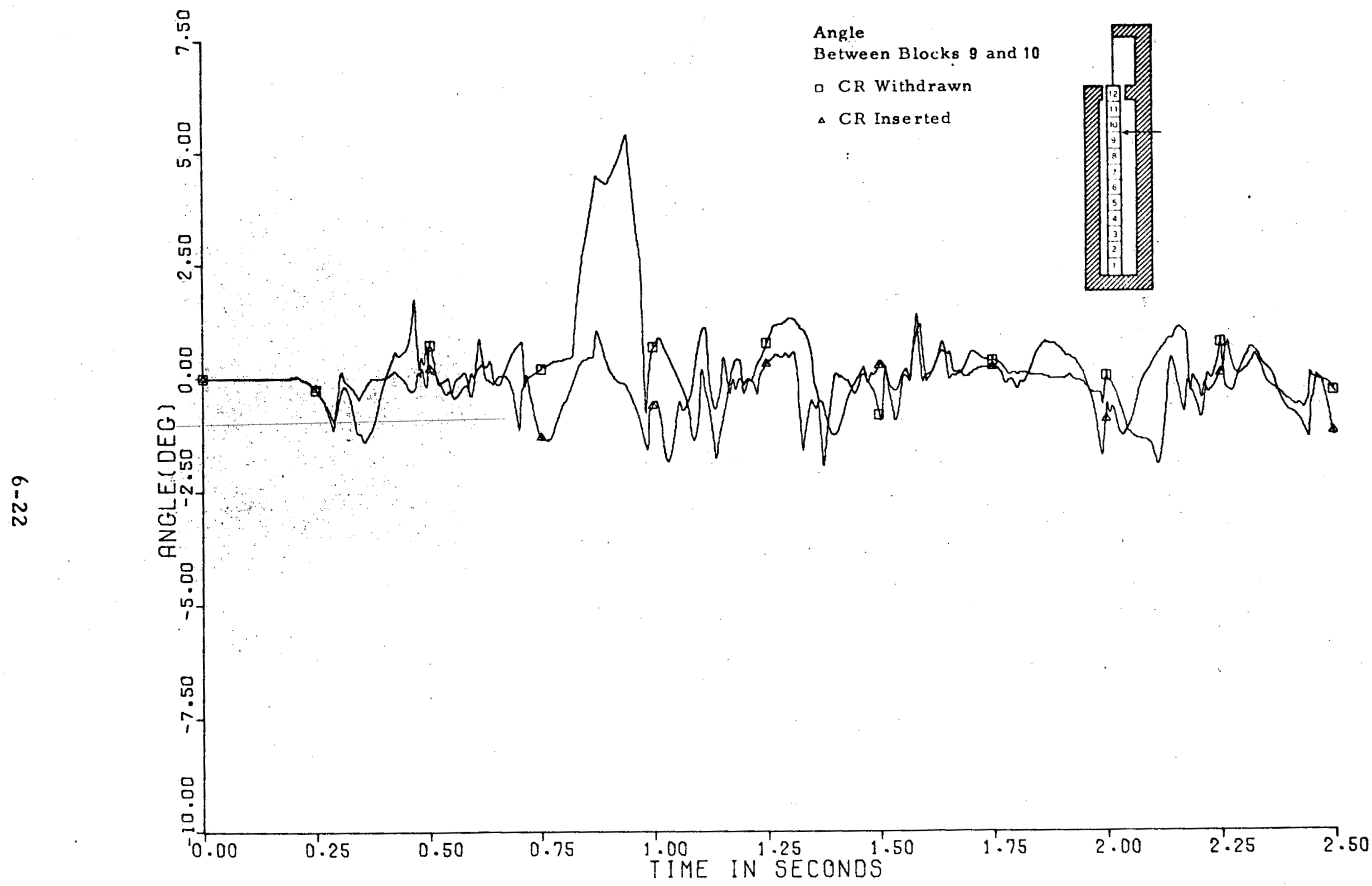

FIGURE 6.13 COMPARISON OF COLUMN RESPONSE FOR CONTROL RODS WITHDRAWN AND INSERTED

SUPPLEMENTAL ANALYSES WITH MODIFIED GAP AND CONTROL ROD STIFENESS RELATIVE ANGLE BETWEEN BLOCKS 9 AND 10 


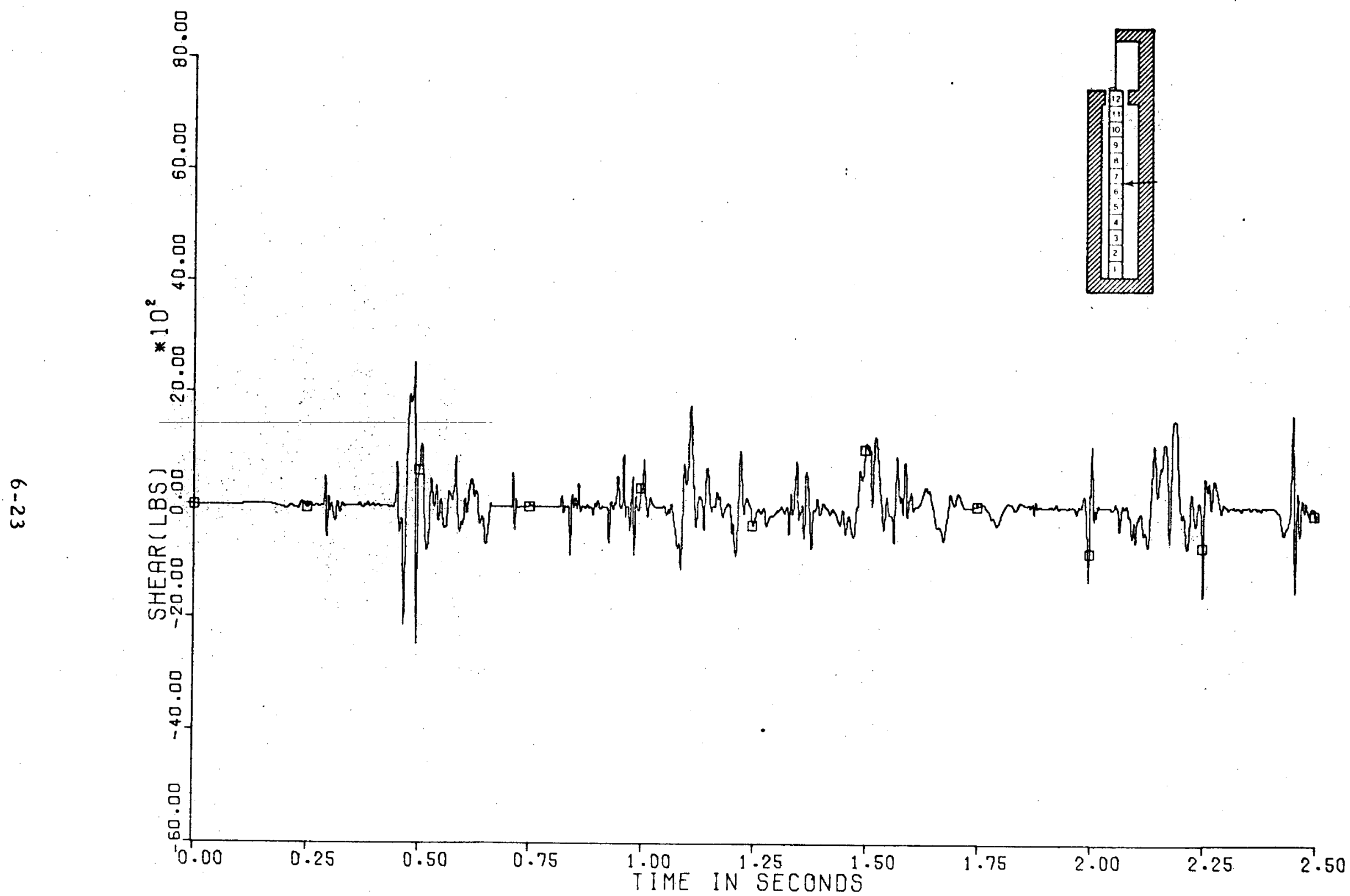

FIGURE 6. 14 HORIZONTAL SHEAR FORCE TIME HISTORY BETWEEN BLOCKS 6 AND 7 CONTROL ROD WITHDRAWN

SUPPLEMENTAL ANALYSES WITH MODIFIED GAP 


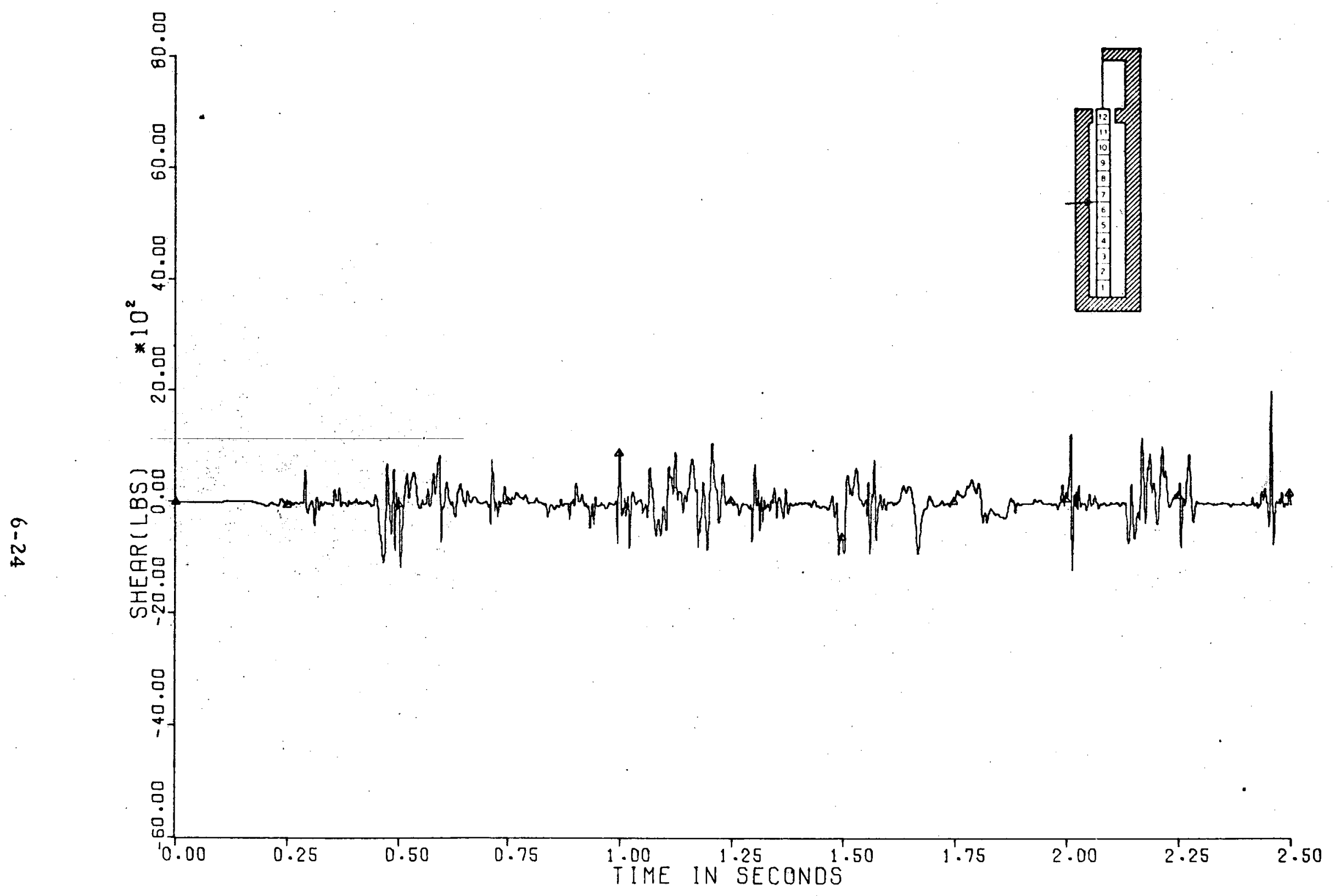

FIGURE 6. 15 HORIZONTAL SHEAR FORCE TIME HISTORY BETWEEN BLOCKS 6 AND 7 CONTROL ROD INSERTED

SUPPLEMENTAL ANALYSES WITH MODIFIED GAP AND

CONTROL ROD STIFFNESS 


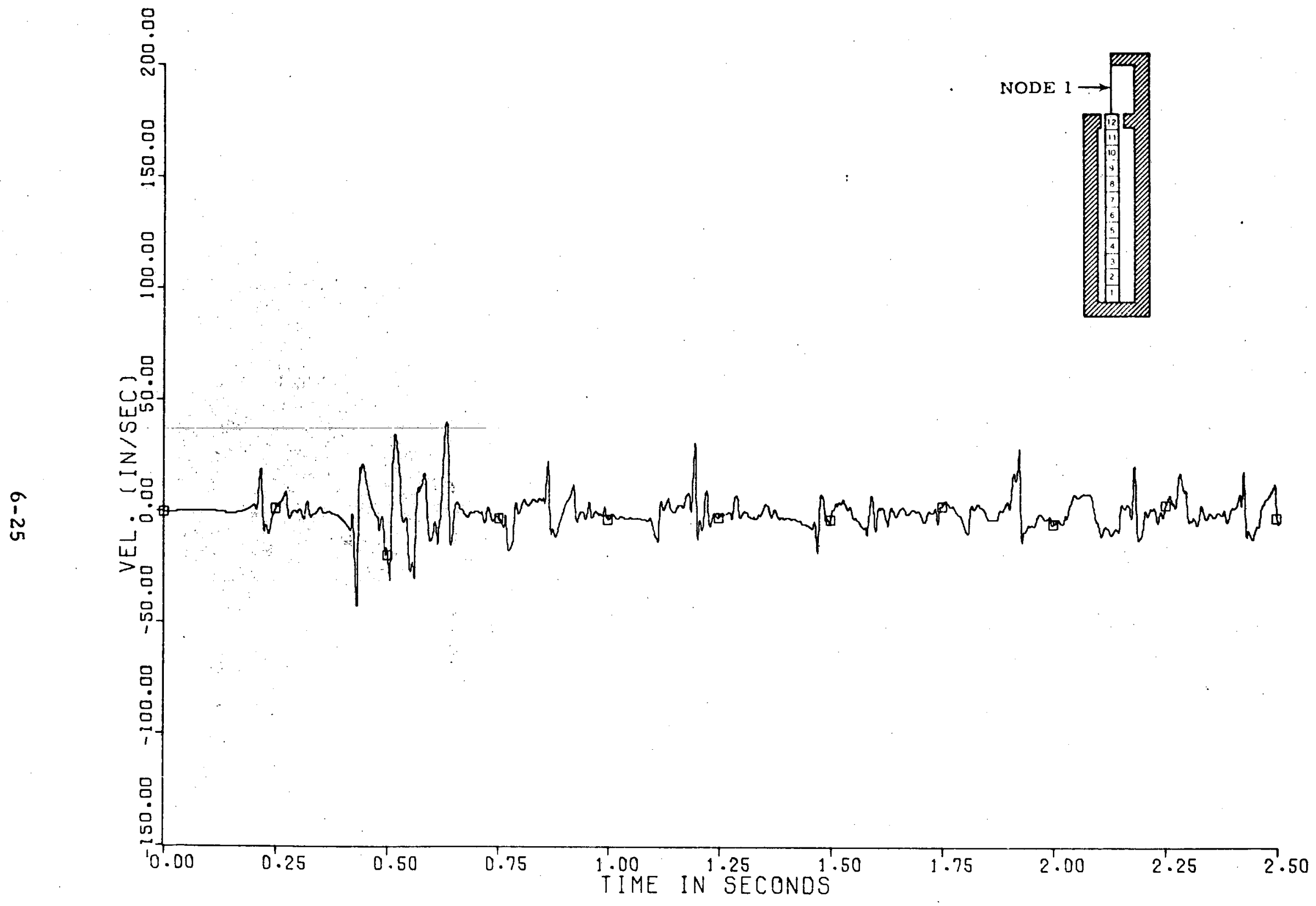

FIGURE 6.16 HORIZONTAL RELATIVE VELOCITY BETWEEN CONTROL ROD AND GUIDE TUBE AT NODE 1 - CONTROL ROD WITHDRAWN SUPPLEMENTAL ANALYSES WITH MODIFIED GAP 


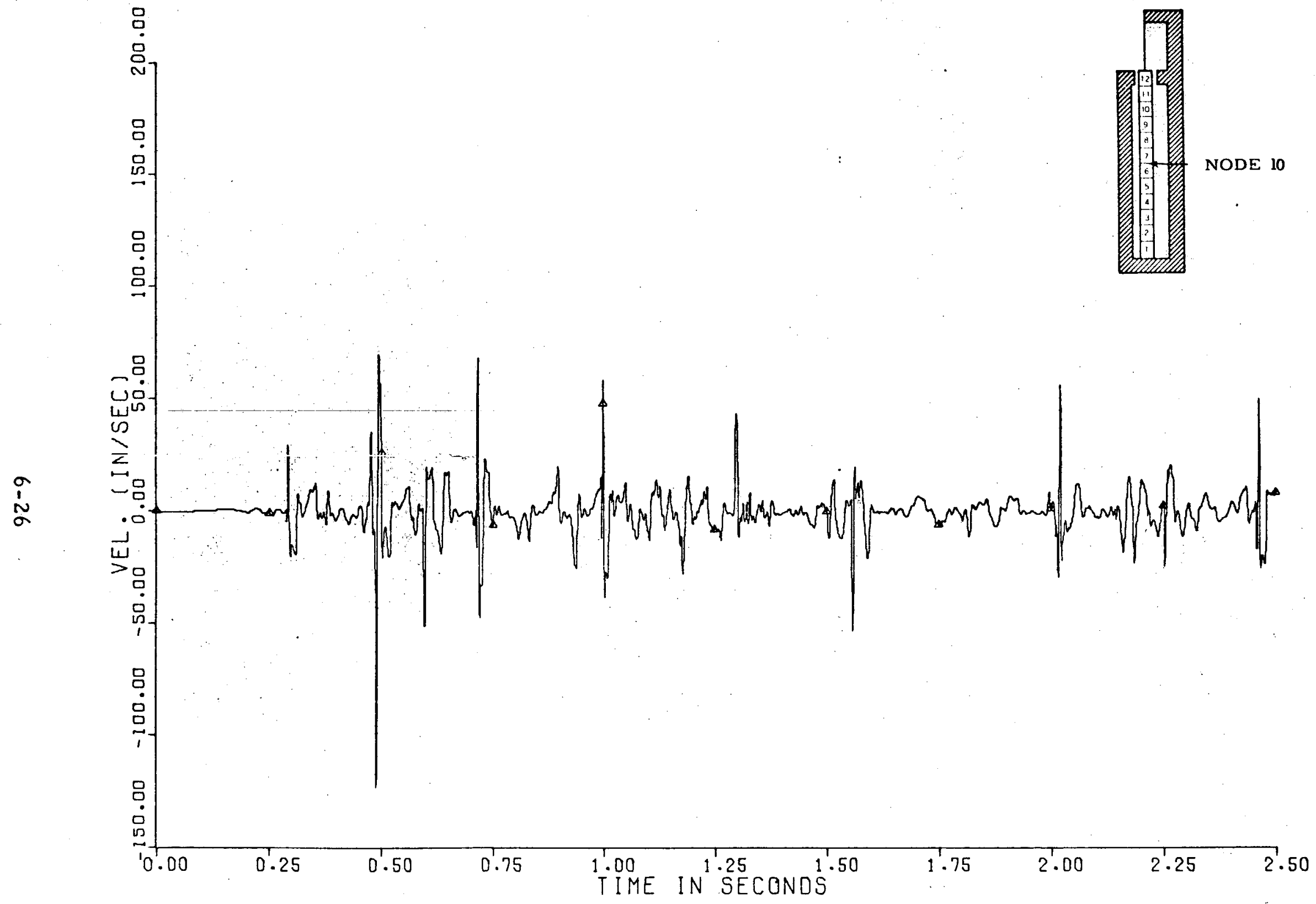

FIGURE 6.17 HORIZONTAL RELATIVE VELOCITY BETWEEN CONTROL ROD AND CHANNEL A T NODE 10 - CONTROL ROD INSERTED

SUPPLEMENTAL ANALYSES WITH MODIFIED GAP AND CONTROL ROD STIFFNESS 


\subsection{REFERENCES}

1. GA Memo, D. W. Doll, "3000/2000 Mw(t) - Column Arrägements," CD:019:DWD:73, March 20, 1973. Revised by Personal Communication $8 / 7 / 74$.

2. General Atomic Company Preliminary Drawings "017201 Guide Tube Lower" and "013973 Orifice Va.Ive Assembly"

3. Wagner, P., A. R. Driesner, and E. A. Kinetko, "Some Mechanical Properties of Graphite in the Temperature Range 20-3000 C," Proceedings in the Second UN Conference, Geneva 1958, Page 7.

4. Nightingale, R. E., "Nuclear Graphite"' Academic Press, New York, 1962.

5. GA Memo, S. J. Brown and R. E. Bachman to H. Jones $" 2000 \mathrm{Mw}(\mathrm{t})$ Plant Core, Core Support, and Reflector Gaps," RIC:113:74, November 27, 1974.

6. Stenger, R., "2000/3000 Mw(t) Hexagonal Element Dowel/Socket Strength Test Report," GA-01289, General Atomic Company, La Jolla, California, Decembej: 1973.

7. "Fuel Element Basic Rocking Test," Test Procedure 5430-5845, General Atomic Company, January 20, 1975.

8. "Full Scale Reactor Element Collison Behavior," Approved Engineering Test Laboratory, June 20, 1975.

9. Wonacott, G. D., and R. E. Be.chman, "Preliminary Investigation of the Influence of Control Rods on the Core Seismic Response and Seismically Induced Core Motion on the Control Rod Scram Time," GAA-13240, June 1975. 
10. "Design Resporise Spectra for Seismic Design of Nuclear Power Plants," Regulatory Guide 1.60, Directorate of Regulatory Standards, United States Atomic Energy Commission, October 1973.

11. "DC 4-4, Issue G, Seismic Design Criteria," General Atomic Company, Document No. 901143 , April 30, 1975.

12. Johnson, D. D., and D. M. Trujillo, "STUF Users Guide," Holmes \& Narver, Inc., Anaheim, California, February 1975.

13. Kanaan, A. E. and Powell, G. H., "DRAIN-2D A General Purpose Computer Program for Dynamic Analysis of Inelastic Plane Structures, "University of California, Berkeley, California, September 1973.

14. DeSalvo, G. J. and Swanson, J. A. ANSYS User's Manual, Swanson Analysis Systems, Inc., Elizabeth, Pennsylvania, 1972. 


\section{APPENDIX A}

\section{THE EFFECT OF THE INTE:GRATION TIME INTERVAL}

SIZE ON STRUCTURAL RESPONSE

In order to evaluate the accuracy of a time interval of 0.0003 seconds, analyses were also performed at time steps of 0.0002 and 0.0004 seconds. The analyses were performed on the rod withdrawn model described in Chapter 6.

The peak column response obtained from the three different time steps are compared in Figures $\mathrm{A}-1$ and $\mathrm{A}-2$. The column shears and lateral column velocities are compared in these figures. Time history plots of response at three points in the column are presented in Figures A-3 through A-10. Time history responses compared for the different time steps are the column lateral displacement and velocities and relative angles between blocks.

The peak shears and lateral velocities compare very closely for all time step sizes. However, variation was found in the relative angles between blocks. A comparison of time history responses shows that through the first 0.7 seconds, the displacements, velocities, and relative angles between blocks are essentially identical for all time step sizes. Between 0.7 and 1.3 seconds, the displacement and velocity time history responses continue to compare reasonably accurately for each time step size. However, relative rocking angle responses deviate during this period. After 1.3 seconds, all the responses again match closely. In Chapter 5 , it is noted that during 0.7 and 1.3 seconds significant separations are predicted to occur in the column. It is apparent that the relative block rotations are very sensitive to phasing of block side wall impacts during this time period and some numerical error is introduced in the relative rotational response by not having a sufficiently short time step. 
Because the peak velocity and horizontal shear with an integration time interval of 0.0003 seconds was found to agree so closely to corresponding results with an integration time step to 0.0002 seconds, it can be concluded that for the purposes of this study, a sufficiently accurate solution for these quantities has been obtained with an integration time interval of 0.0003 seconds. However, it is recognized that the relative angle is still numerically sensitive to time steps of this size during periods of block separations and that, therefore, this response quantity cannot be predicted with nearly the same accuracy as can the shear or velocity during vertical separation. 


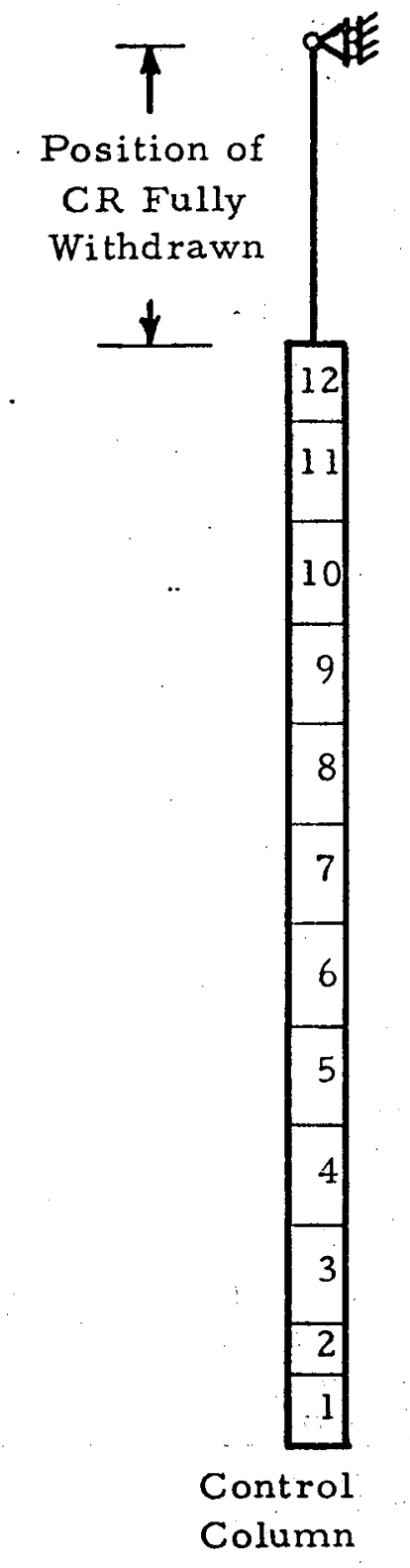

$$
\begin{aligned}
& \text { Column Shears } \\
& -\Delta t=.0004 \\
& --\Delta t=.0003 \\
& -\Delta t=.0002
\end{aligned}
$$

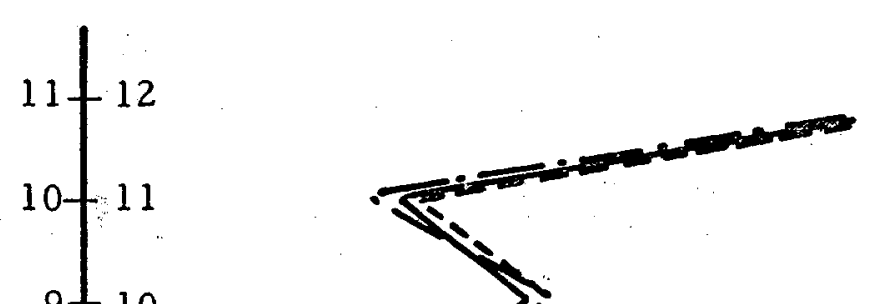

FIGURE A-1 COMPARISONOF RESPONSE FOR ROD WITHDRAWN ANALYSES IN WHICH DIFFERENT INTEGRATION TIME STEPS ARE USED

COLUMN SHEARS

$$
\text { A - } 3
$$




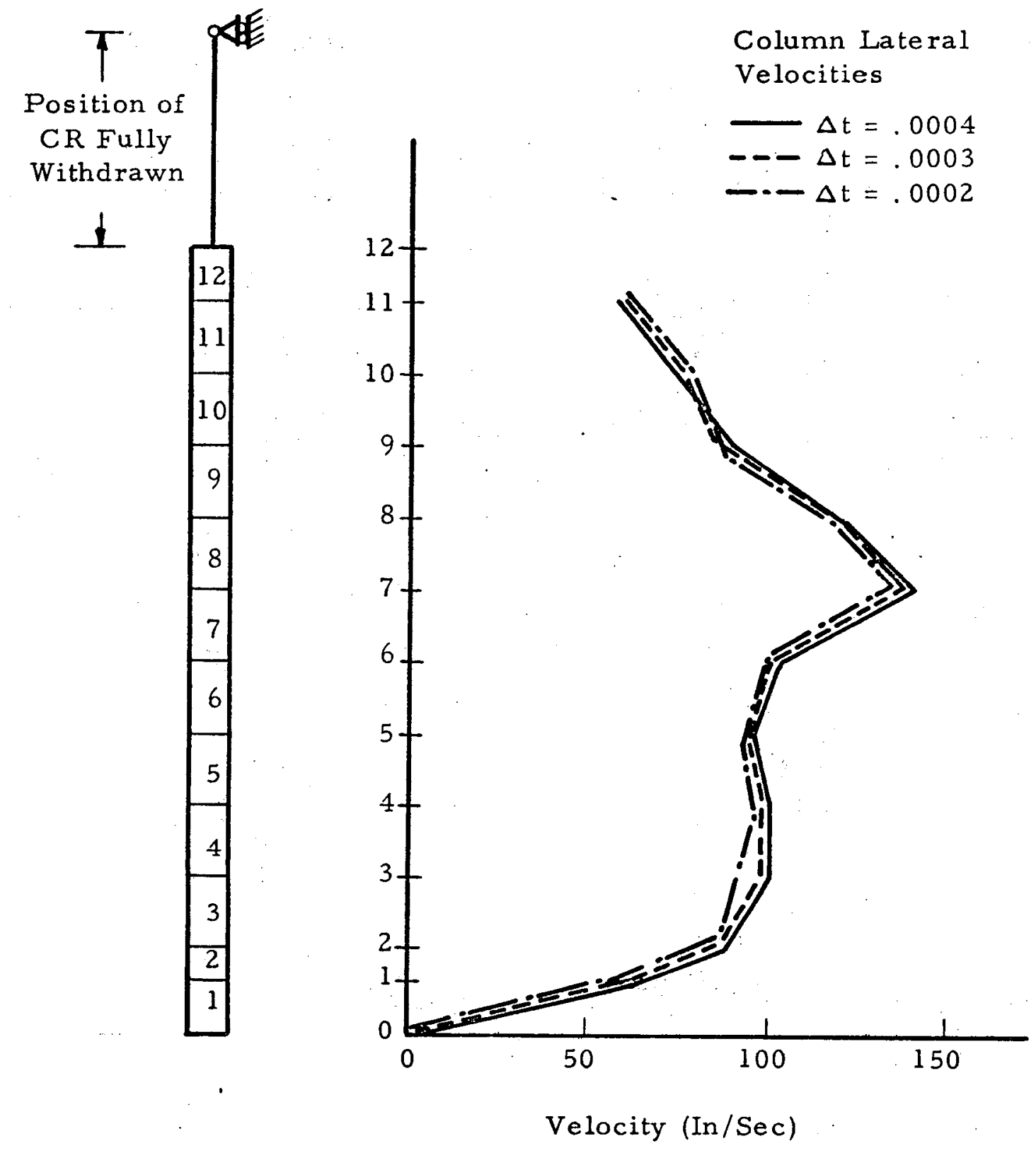

FIGURE A-2 COMPARISON OF RESPONSE FOR ROD WITHDRAWN ANALYSES IN WHICH DIFFERENT INTEGRATION TIME STEPS ARE USED

COLUMN LATERAL VELOCITY RELATIVE TO BOUNDARY

$$
\text { A }-4
$$




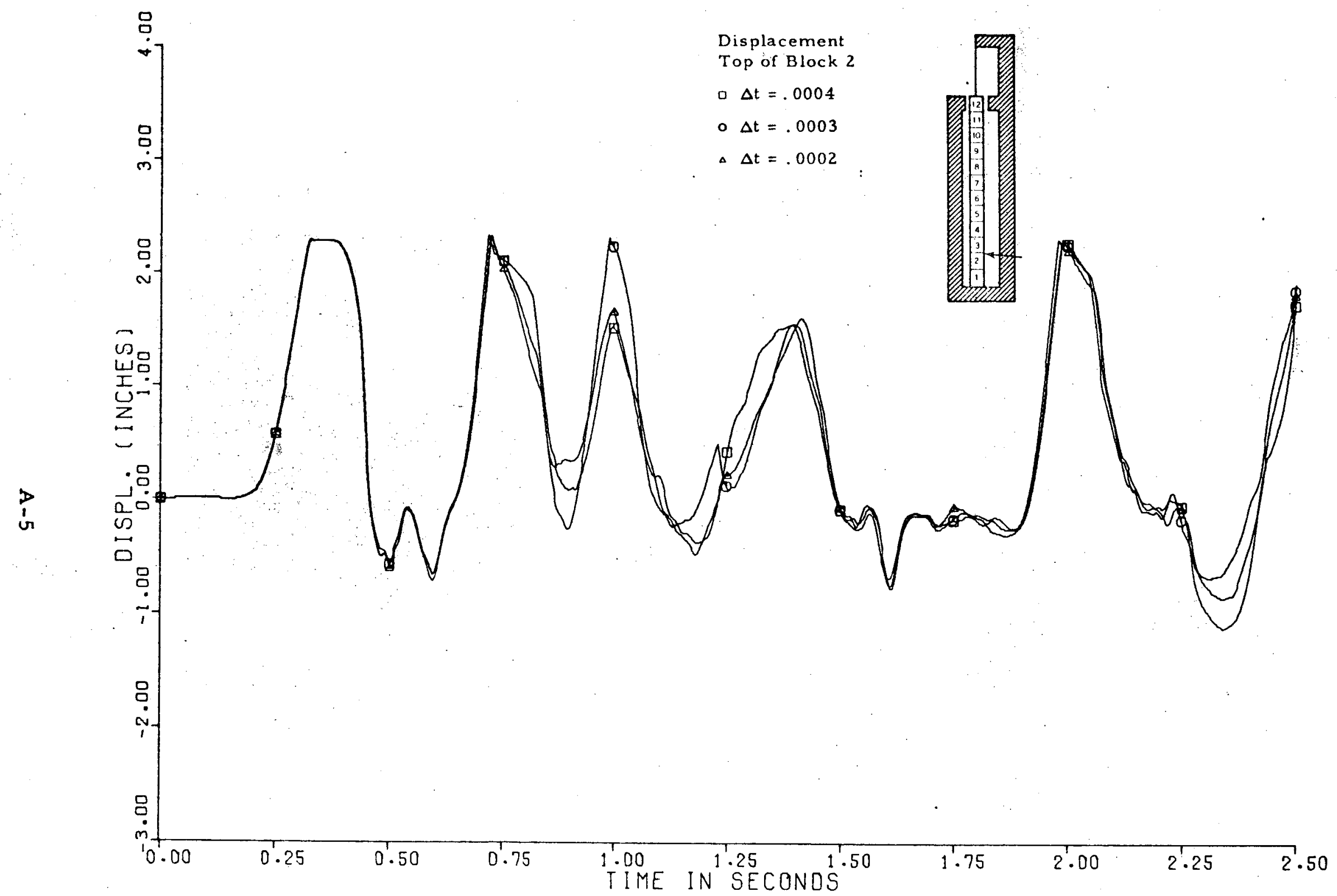

FIGURE A-3 COMPARISON OF COLUMN RESPONSE FOR MODIFIED ROD WITHDRAWN ANALYSES IN WHICH DIFFERENT INTEGRATION TIME STEPS ARE USED.

HORIZONTAL RELATIVE DISPLACEMENT BETWEEN TOP OF

BLOCK 2 AND BOUNDARY 


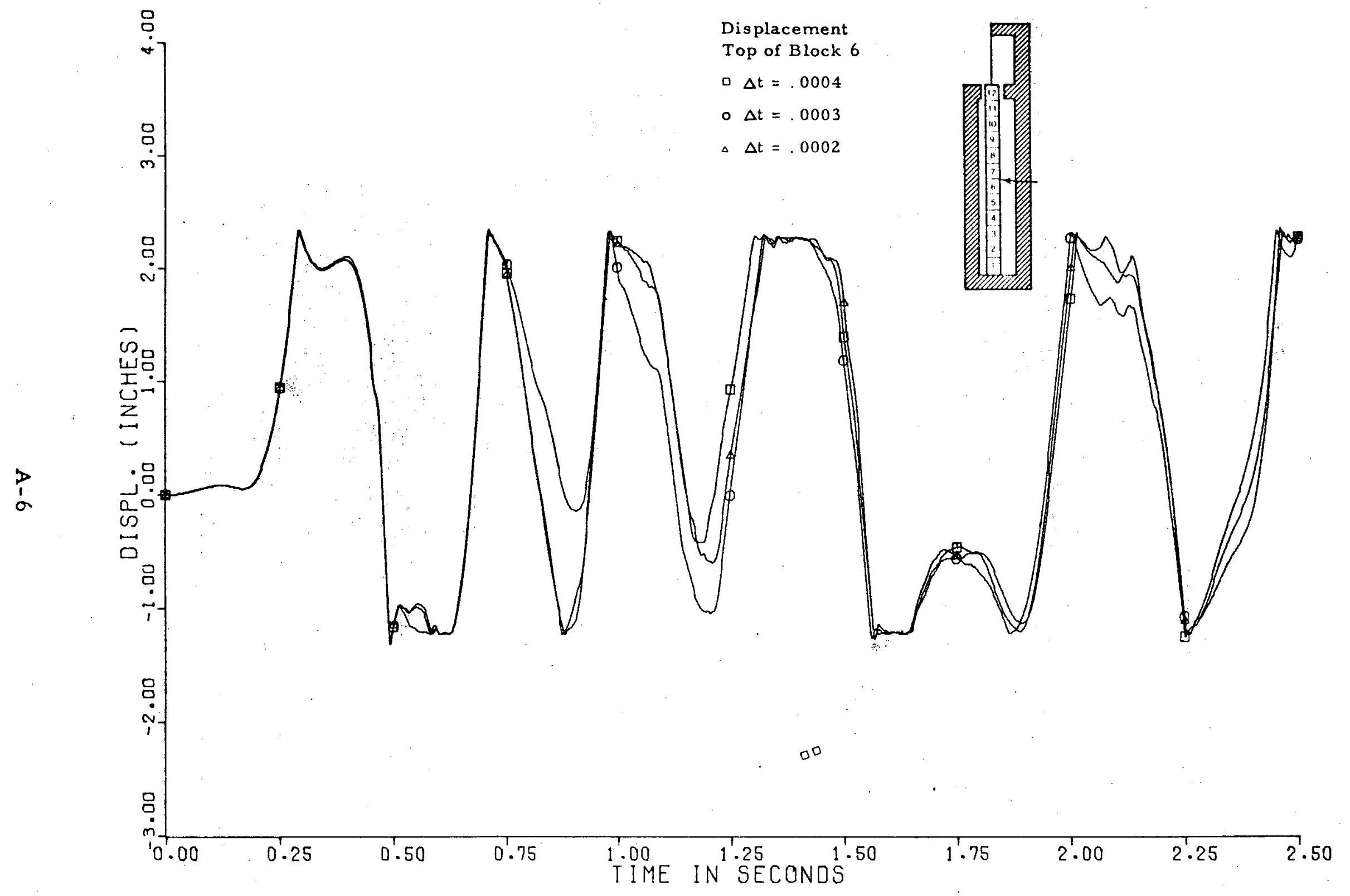

FIGURE A-4 COMPARISON OF COLUMN RESPONSE FOR MODIFIED ROD WITHDRAWN ANALYSES IN WHICH DIFFERENT INTEGRATION TIME STEPS ARE USED. HORIZONTAL RELATIVE DISPLACEMENT BETWEEN TOP OF BLOCK 6 AND BOUNDARY 


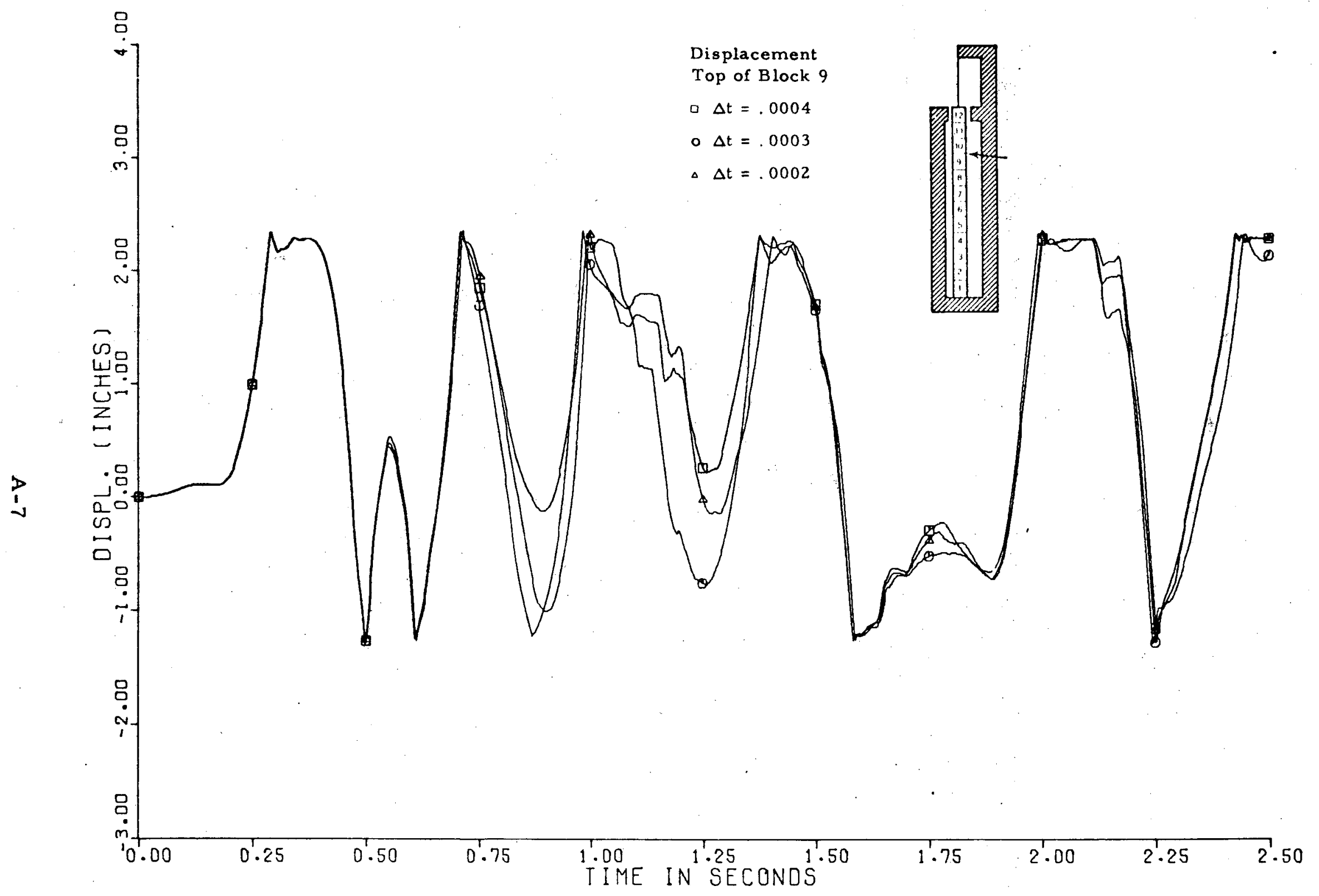

FIGURE A-5 COMPARISON OF COLUMN RESPONSE FOR MODIFIED ROD WITHDRAWN ANALYSES IN WHICH DIFFERENT INTEGRATION TIME STEPS ARE USED HORIZONTAL RELATIVE DISPLACEMENT BETWEEN TOP OF BLOCK 9 AND BOUNDARY 


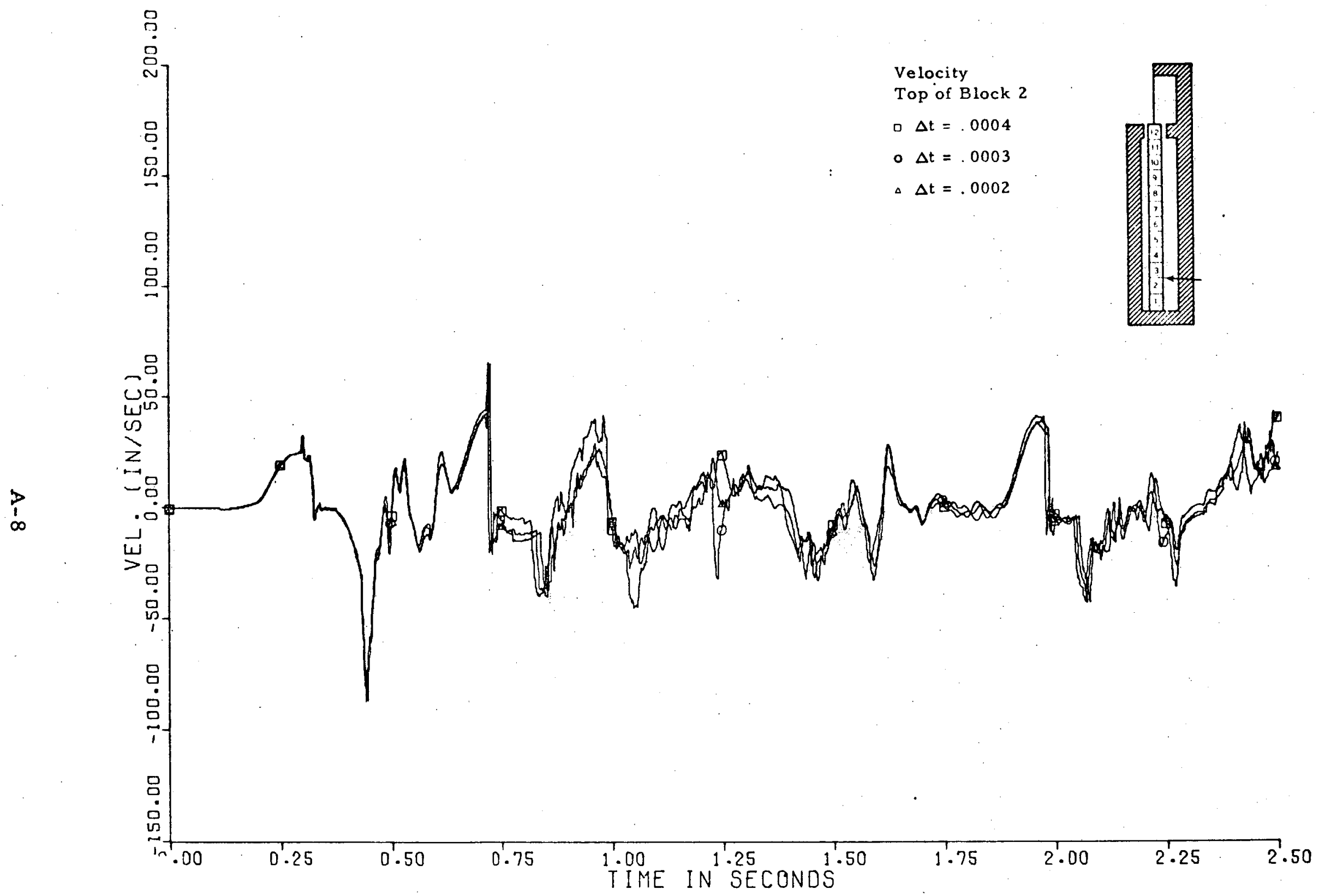

FIGURE A-6 COMPARISON OF COLUMN RESPONSE FOR MODIFIED ROD WITHDRAWN ANA LYSES IN WHICH DIFFERENT INTEGRATION TIME STEPS ARE USED HORIZONTAL RELATIVE VELOCITY BETWEEN TOP OF BLOCK 2 AND BOUNDARY 


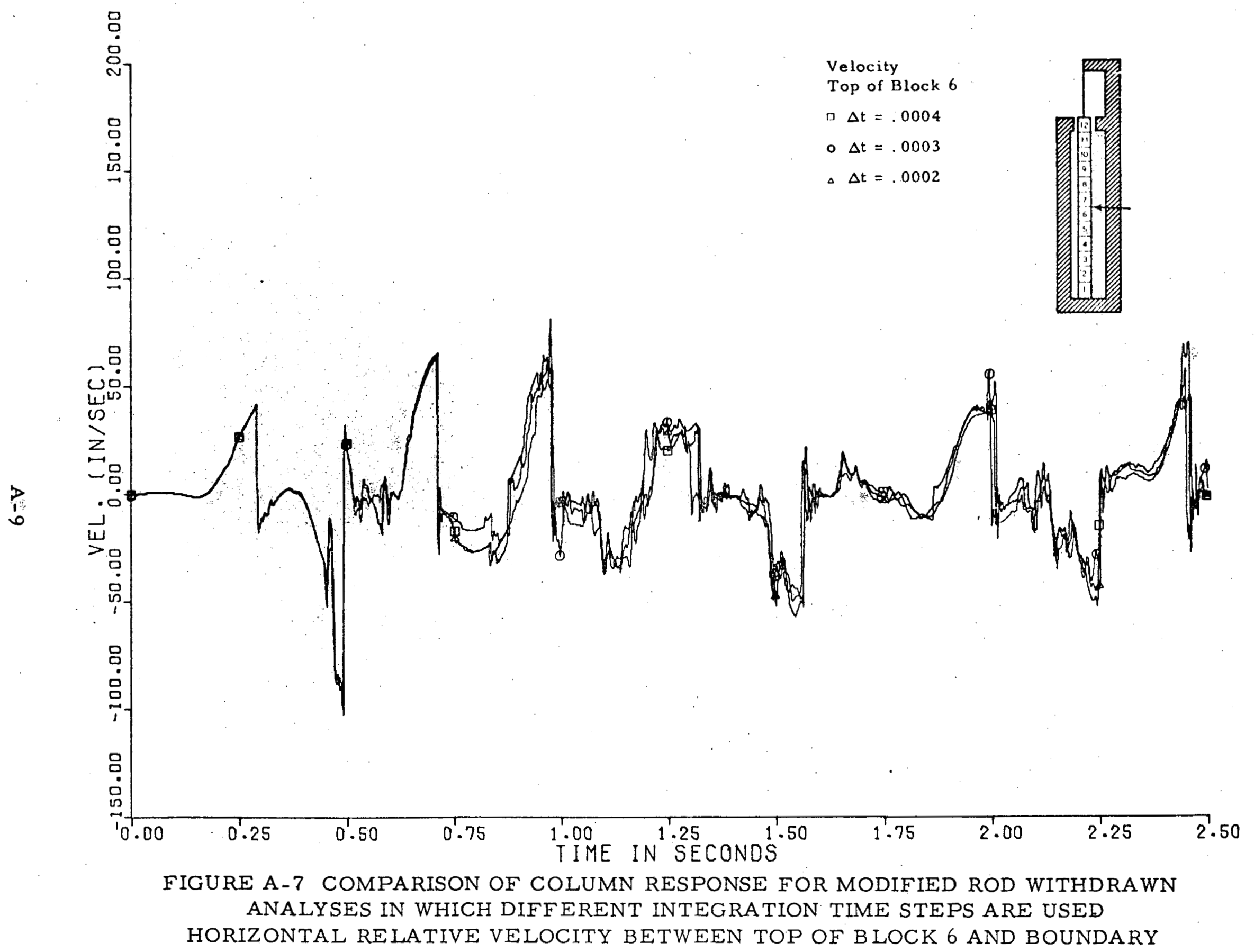




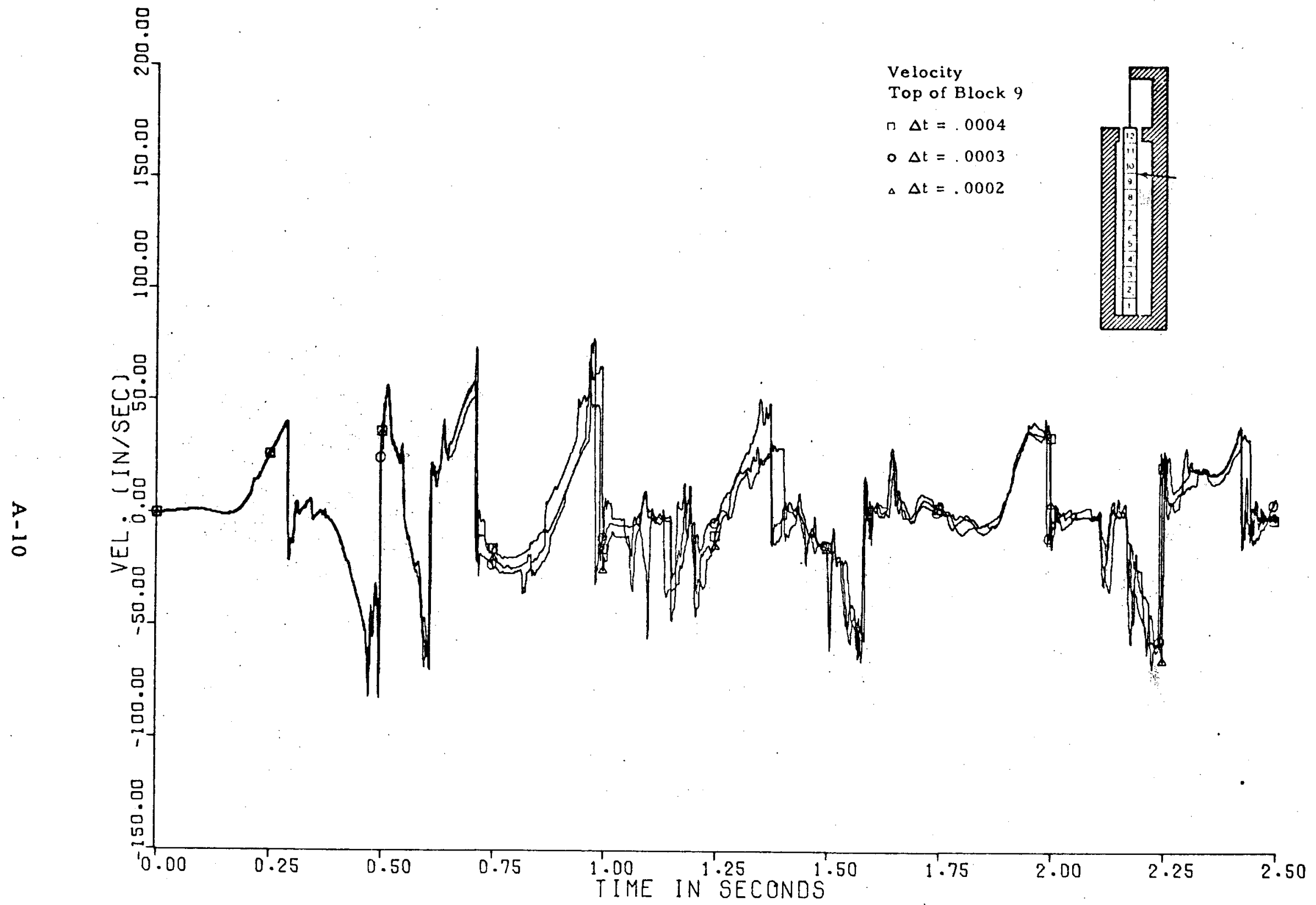

FIGURE A-8 COMPARISON OF COLUMN RESPONSE FOR MODIFIED ROD WITHDRAWN ANALYSES IN WHICH DIFFERENT INTEGRATION TIME STEPS ARE USED HORIZONTAL RELATIVE VELOCITY BETWEEN TOP OF BLOCK 9 AND BOUNDARY 


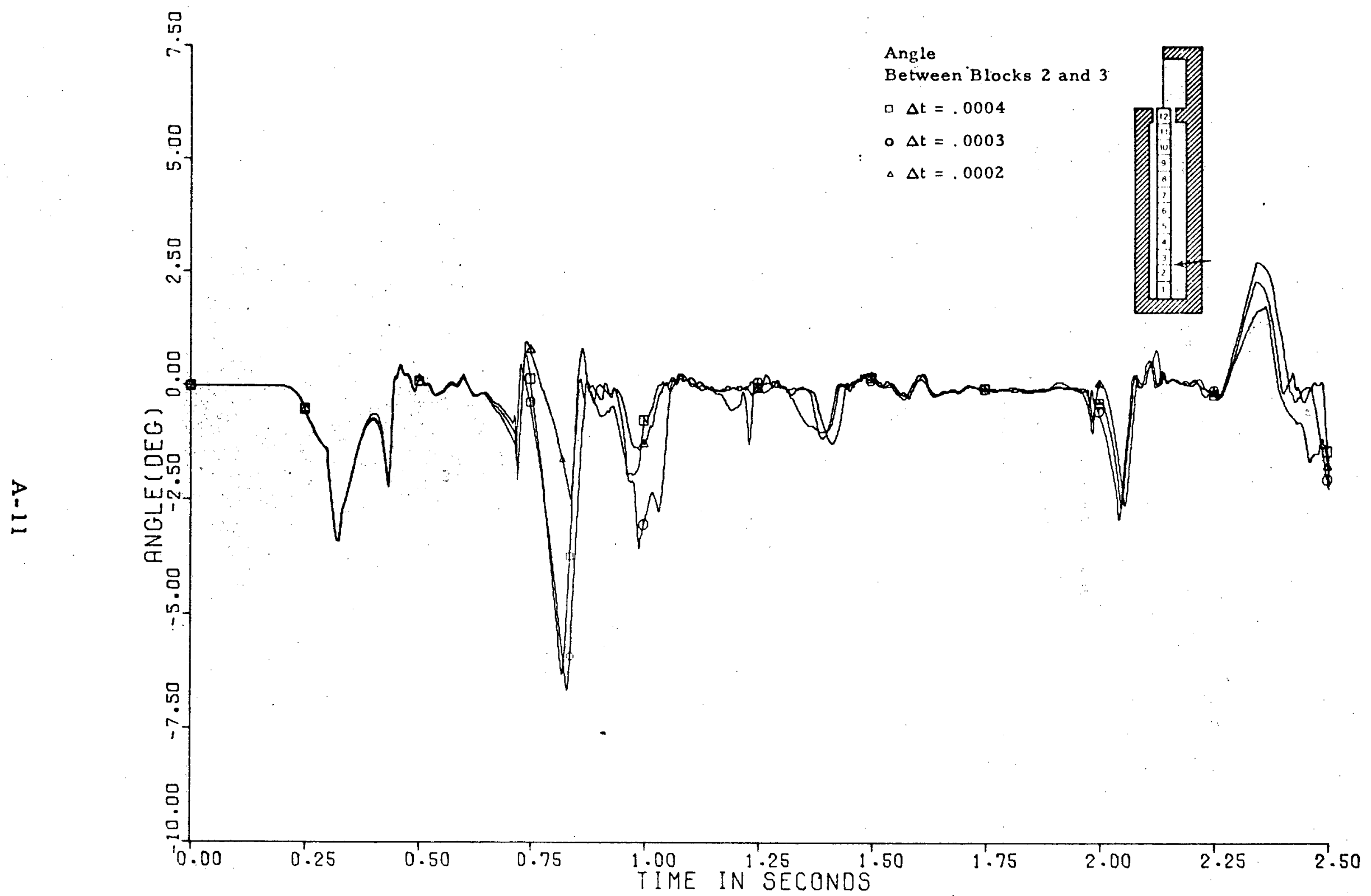

FIGURE A-9 COMPARISON OF COLUMN RESPONSE FOR MODIFIED ROD WITHDRAWN ANALYSES IN WHICH DIFFERENT INTEGRATION TIME STEPS ARE USED.

RELATIVE ANGLE BETWEEN BLOCKS 2 AND 3 


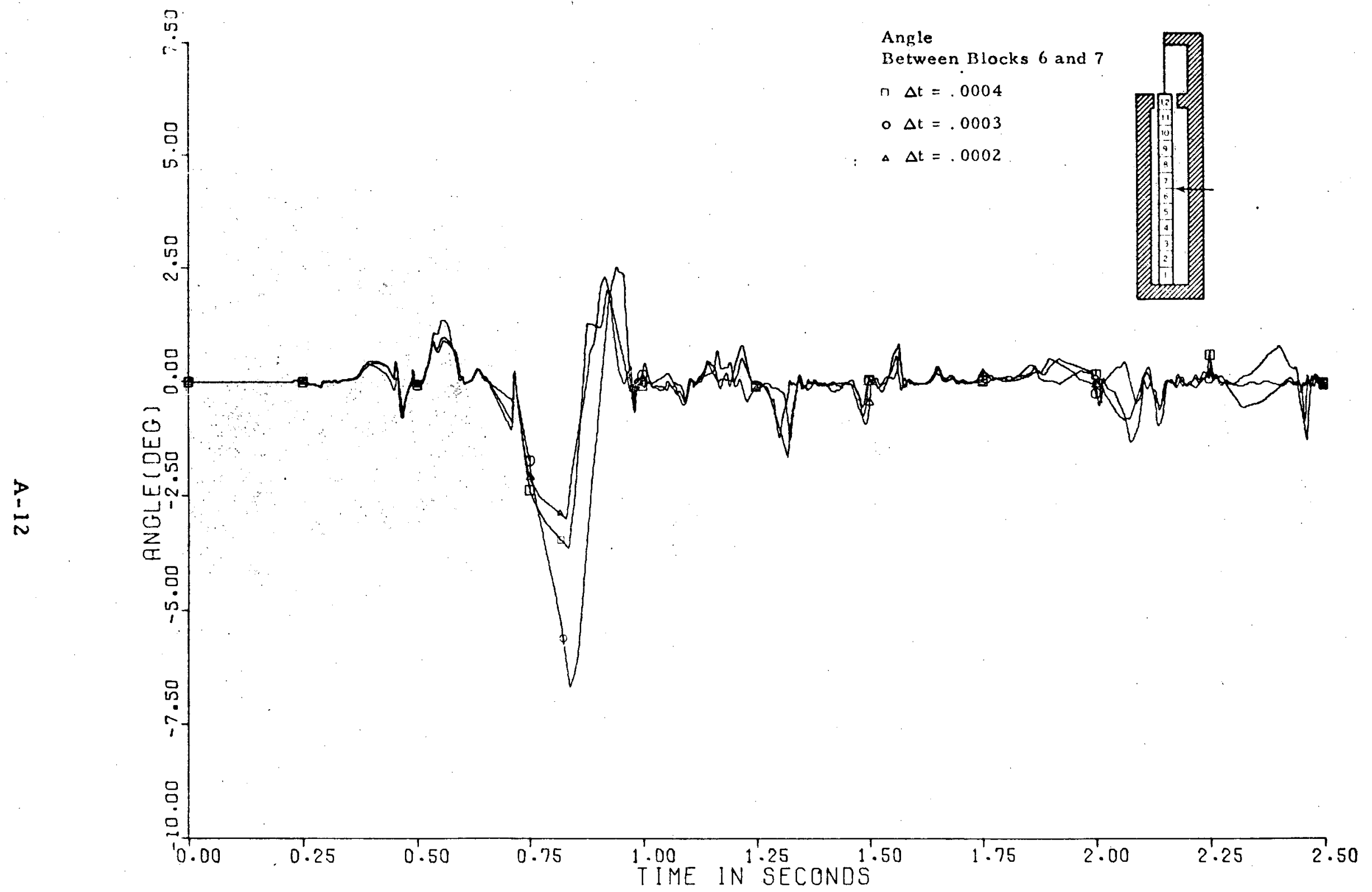

FIGURE A-10 COMPARISON OF COLUMN RESPONSE FOR MODIFIED ROD WITHDRAWN ANALYSES IN WHICH DIFFERENT INTEGRATION TIME STEPS ARE USED. RELATIVE ANGLE BETWEEN BLOCKS 6 AND 7 


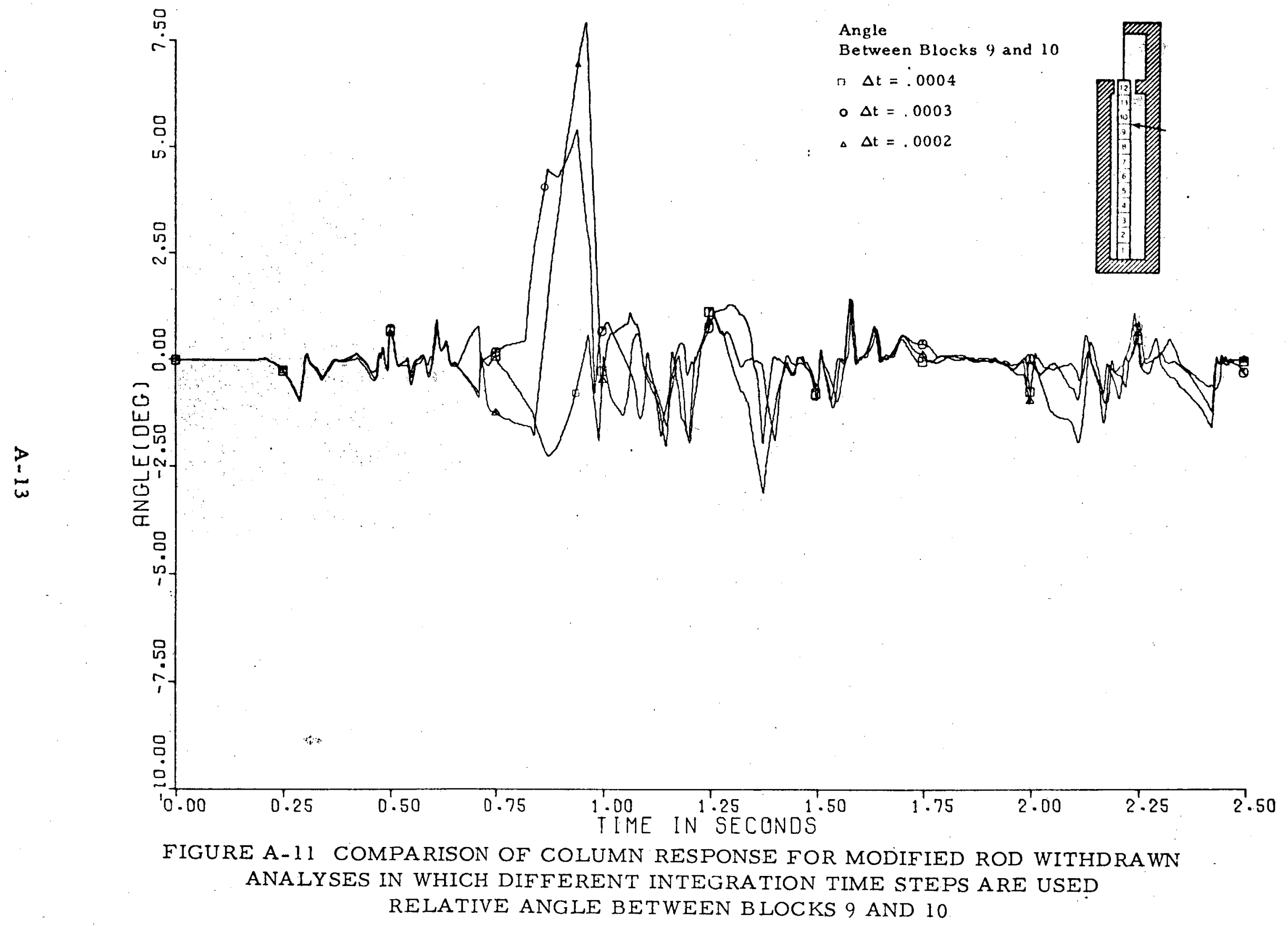

